\title{
Native born but not yet citizen
}

Citation for published version (APA):

Labussière, M. (2021). Native born but not yet citizen: citizenship and education outcomes of the children of immigrants in the Netherlands. [Doctoral Thesis, Maastricht University]. Maastricht University. https://doi.org/10.26481/dis.20211103ml

Document status and date:

Published: 01/01/2021

DOI:

10.26481/dis.20211103ml

Document Version:

Publisher's PDF, also known as Version of record

\section{Please check the document version of this publication:}

- A submitted manuscript is the version of the article upon submission and before peer-review. There can be important differences between the submitted version and the official published version of record.

People interested in the research are advised to contact the author for the final version of the publication, or visit the DOI to the publisher's website.

- The final author version and the galley proof are versions of the publication after peer review.

- The final published version features the final layout of the paper including the volume, issue and page numbers.

Link to publication

\footnotetext{
General rights rights.

- You may freely distribute the URL identifying the publication in the public portal. please follow below link for the End User Agreement:

www.umlib.nl/taverne-license

Take down policy

If you believe that this document breaches copyright please contact us at:

repository@maastrichtuniversity.nl

providing details and we will investigate your claim.
}

Copyright and moral rights for the publications made accessible in the public portal are retained by the authors and/or other copyright owners and it is a condition of accessing publications that users recognise and abide by the legal requirements associated with these

- Users may download and print one copy of any publication from the public portal for the purpose of private study or research.

- You may not further distribute the material or use it for any profit-making activity or commercial gain

If the publication is distributed under the terms of Article $25 \mathrm{fa}$ of the Dutch Copyright Act, indicated by the "Taverne" license above, 


\section{Native born but not yet citizen Citizenship and educational outcomes of the children of immigrants in the Netherlands}

Marie Labussière 
(c) Marie Labussière, Maastricht 2021.

All rights reserved. No part of this publication may be reproduced, stored in a retrieval system or transmitted in any form or by any means, electronic, mechanical, photocopying, recording or otherwise, without prior written permission of the author.

Typesetting This book was typeset in LTEX by Marie Labussière based on the mtt template developed by Robbert Harms.

Cover design Claudia Flandoli| https://www.draw.science/home

Production ProefschriftMaken|https://www.proefschriftmaken.nI ISBN 978-94-6423-485-5 


\title{
Native born but not yet citizen Citizenship and educational outcomes of the children of immigrants in the Netherlands
}

\begin{abstract}
Dissertation
To obtain the degree of Doctor at Maastricht University, on the authority of the Rector Magnificus, Prof. Dr. R.M. Letschert, in accordance with the decision of the Board of Deans, to be defended in public on Wednesday 3 November, at 10:00 hours
\end{abstract}

by

Marie Labussière 


\section{Promotores}

Prof. Dr. M. Vink

Prof. Dr. M. Levels

Maastricht University / EUI

Maastricht University

\section{Assessment Committee}

Prof. Dr. V. Mazzucato (Chair) Maastricht University

Prof. Dr. T. Soehl

McGill University

Prof. Dr. F. van Tubergen

Utrecht University

Dr. M. Vanore

Maastricht University

Prof. Dr. I. de Wolf

Maastricht University

This research has received funding from the European Research Council (ERC) under the European Union's Horizon 2020 research and innovation programme (project "Migrant Life Course and Legal Status Transition", grant number 682626). 
À Jean, Jacqueline et Elisabeth 


\section{Contents}

$\begin{array}{ll}\text { List of Figures } & \text { ix }\end{array}$

List of Tables $\quad$ xiii

1 Introduction 1

Introduction ............................................. 2

The relevance of host country citizenship for the second generation . . 9

A life course perspective on the citizenship of children ............ 11

The Dutch context ................................................. 14

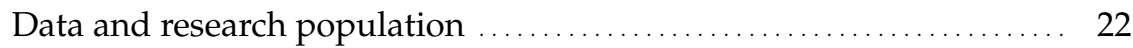

Empirical strategy ........................................ 30

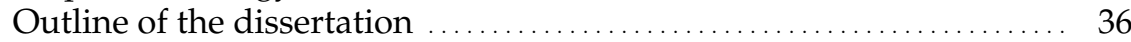

2 Citizenship and educational attainment: a life course perspective $\quad 39$

Introduction ............................................. 40

The sociological life course approach ......................... 41

Law in the lives of immigrant families ........................ 48

Legal status and educational outcomes of the second generation..... 55

Timing and effect heterogeneity: effects over the life course ........ 73

Conclusion .............................................. 81

3 The intergenerational impact of naturalisation reforms: the citizenship status of the children of immigrants in the Netherlands, 1995-2016 85

Introduction ................................................. 86

Becoming a Dutch citizen ................................... 88

Analytical framework ...................................... 91

Data and Methodology ....................................... 95

Analysis ..................................................... 103

Conclusion ............................................... 110 
4 Citizenship and education trajectories of the children of immigrants in secondary school: an exploratory analysis $\mathbf{1 1 3}$

Introduction ................................................. 114

Conceptualising the effect of citizenship within the life course ....... 116

The Dutch context and our hypotheses .......................... 120

Empirical strategy: a transition-oriented sequence analysis ......... 124

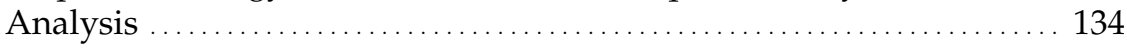

Conclusion .............................................. 144

5 Timing of citizenship acquisition and immigrants' children educa$\begin{array}{ll}\text { tional performance: towards causal inference } & 147\end{array}$

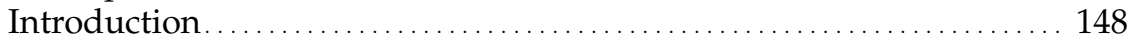

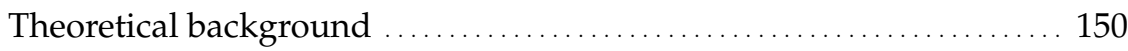

Research strategy ............................................. 154

Data and operationalisation ................................. 158

Analyses ..................................................... 162

Discussion ............................................ 172

6 Conclusions 175

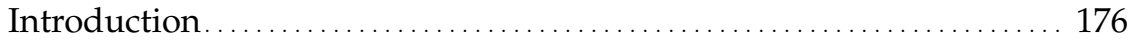

Main contributions to the literature ......................... 178

Limitations and avenues for further research ..................... 189

$\begin{array}{ll}\text { Bibliography } & 203\end{array}$

Appendix A Supplementary Materials Chapter 3 225

$\begin{array}{lll}\text { Appendix B Supplementary Materials Chapter 4 } & 247\end{array}$

$\begin{array}{lll}\text { Appendix C Supplementary Materials Chapter } 5 & 279\end{array}$

$\begin{array}{ll}\text { Impact Paragraph } & 307\end{array}$

Nederlandse samenvatting (Dutch summary) 311

$\begin{array}{ll}\text { Acknowledgments } & 319\end{array}$

$\begin{array}{ll}\text { About the author } & 325\end{array}$ 



\section{List of Figures}

1.1 Distribution of the birth cohorts included as research populations in the empirical Chapters 3, 4 and 5.

2.1 Diagram for the direct and indirect effects of host country citizenship on educational outcomes.

2.2 Diagram for selection effects between host country citizenship and educational outcomes.

3.1 Main procedures for the acquisition of Dutch citizenship by immigrants' children born in the Netherlands.

3.2 Dutch citizenship acquisition by immigrants' children born in the Netherlands, by year of birth.

3.3 Family patterns of naturalisations before the age of majority among immigrants' children born in the Netherlands, by year of naturalisation.

3.4 Acquisition of Dutch citizenship after birth by immigrants' children born in the Netherlands: Kaplan-Meier failure functions, by cohort of eligibility.

3.5 Acquisition of Dutch citizenship after birth by immigrants' children born in the Netherlands: odds-ratio associated with eligibility cohort categories, by years after eligibility.

3.6 Acquisition of Dutch citizenship after birth by immigrants' children born in the Netherlands: coefficient plot for cause-specific hazards models.

3.7 Acquisition of Dutch citizenship with both parents and with only one parent among immigrants' children born in the Netherlands: odds ratio associated with eligibility cohort categories, by years after eligibility. .

4.1 Simplified diagram of the Dutch educational system. 
4.2 Index-plot based on transition elements for the full sample. .... 137

4.3 Plot of the odds of experiencing different trajectories in secondary and tertiary education, by citizenship status.

4.4 Plot of the average marginal effects of Dutch citizenship predicting trajectory in secondary and tertiary education.

5.1 Average standardised Cito test scores for the children of immigrants born in the Netherlands, by age at naturalisation groups. 163

5.2 Predicted average standardised test score obtained at the end of primary school by children of immigrants born in the Netherlands, conditionally on citizenship status and parents' highest education level and homeownership status.

A1 Test of the proportionality assumption for the Cox proportionalhazard model: Schoenfeld residuals of the eligibility period 1998-2002.

A2 Test of the proportionality assumption for the Cox proportionalhazard model: Schoenfeld residuals of the eligibility period 2003 and after.

A3 Acquisition of Dutch citizenship after birth by immigrants' children born in the Netherlands: Kaplan-Meier failure function. .. 237

A4 Acquisition of Dutch citizenship after birth by immigrants' children born in the Netherlands: coefficient plot based on Cox regression models $\mathrm{A}$ to $\mathrm{D}$.

A5 Acquisition of Dutch citizenship after birth by immigrants' children born in the Netherlands: coefficient plot for the causespecific hazards models A to D.

B1 Distribution of naturalisation date among the children born as foreign citizens.

B2 Comparison of the Average silhouette width between three different clustering algorithms.

B3 Average silhouette width for the ten first cluster solutions from the Partition around Medoids algorithm...................... 264

B4 Average silhouette width for the six-cluster solution from the Partition around Medoids algorithm. ....................... 264

B5 Index-plot based on states elements for the full sample......... 265

B6 Plot of the average marginal effects of Dutch citizenship predicting trajectories through secondary and tertiary education. . 278 
C1 Age difference between siblings in the full sample.

C2 Age difference between siblings in the sample of exposurediscordant families.

C3 Average standardised Cito test scores for the children of immigrants born in the Netherlands, by age at naturalisation.

C4 Difference in age at naturalisation between siblings in the sample of exposure-discordant families.

C5 Predicted average standardised test score obtained at the end of primary school by children of immigrants born in the Netherlands, conditionally on age at naturalisation and parents' highest education level.

C6 Predicted average standardised test score obtained at the end of primary school by children of immigrants born in the Netherlands, conditionally on age at naturalisation and parents' homeownership status. 



\section{List of Tables}

1.1 Overview of the main characteristics of the three empirical Chapters 3,4 and 5 .

3.1 Cox proportional-hazard model for the risk of naturalisation among immigrants' children born in the Netherlands.

4.1 Examples of artificial sequences built on states and sequences... 126

4.2 Examples of substitution costs matrices based on states and sequences.

4.3 State elements........................................... 131

4.4 Transition elements. ................................... 131

4.5 Cluster description and medoids sequences of the six-cluster solution.

4.6 Cluster descriptives: occurrence of state elements within each cluster and in the full sample.

5.1 Distribution of age at naturalisation groups among children of immigrants born in the Netherlands.

5.2 Random-effects and between-within models for the standardised test scores obtained at the end of primary school by children of immigrants born in the Netherlands, by age at naturalisation.

5.3 Random-effects model for the standardised test scores obtained at the end of primary school by children of immigrants born in the Netherlands.

5.4 Bounding the effect of naturalisation on standardised test scores obtained at the end of primary education by children of immigrants born in the Netherlands.

A1 Socio-demographic characteristics of the whole sample. 
A2 Eligibility, citizenship and naturalisation characteristics of restricted samples. ........................................ 228

A3 Dutch citizenship status by mother's country of origin. ........ 229

A4 Cox proportional-hazard model for the risk of naturalisation by immigrants' children born in the Netherlands - with twoyear clusters of eligibility cohorts.

A5 Cox proportional-hazard model for the risk of naturalisation by immigrants' children born in the Netherlands - with year of eligibility.

A6 Cox proportional-hazard model for the risk of naturalisation by immigrants' children born in the Netherlands - main model with father's country of origin.

A7 Cause-specific hazards model for the risk of naturalisation by immigrants' children born in the Netherlands - naturalisation with both parents.

A8 Cause-specific hazards model for the risk of naturalisation by immigrants' children born in the Netherlands - naturalisation with only one parent.

A9 Evolution of administrative fees between 2001 and 2020, by type of citizenship acquisition procedure.

B1 Overview of the sample with sociodemographic characteristics measured at the start of the observation period.

B2 Overview of the sample with numerical characteristics measured at the start of the observation period.

B3 Legal status of the child measured at the start and the end of the observation period.

B4 States-to-transitions matrix for the transition-oriented Optimal Matching.

B5 Substitution Costs Matrix for the transition-oriented Optimal Matching. .............................................. 257

B6 Indel Costs vector for the transition-oriented Optimal Matching. 257

B7 Detailed overview of the covariates for the main regression model. .................................................... 263

B8 Type of transition experienced in secondary education by cluster membership........................................... 266

B9 Citizenship status by cluster membership. ................. 266

B10 Multinomial logistic regression of the odds of experiencing different trajectories through secondary and tertiary education. 
B11 Step-wise multinomial logistic regressions of the odds of experiencing different trajectories through secondary and tertiary education, by citizenship status.

B12 Average marginal effects (AME) of citizenship status predicting pathways into secondary and tertiary education.

B13 Average marginal effects (AME) of parental education predicting pathways into secondary and tertiary education.

B14 Average marginal effects (AME) of citizenship at representative values of language spoken at home, predicting pathways into secondary and tertiary education.

B15 Average marginal effects (AME) of citizenship at representative values of parental education, predicting pathways into secondary and tertiary education.

B16 Average marginal effects (AME) of citizenship at representative values of mother's years since migration (YSM), predicting pathways into secondary and tertiary education.

C1 Distribution of age at the time of the test in the full sample of children of immigrants born in the Netherlands taking the Cito test between 2008 and 2015.

C2 Information about the coding of all variables................. 283

C3 Descriptive statistics for covariates ........................ 286

C4 Distribution of age at naturalisation in the full sample......... 288

C5 Between-within model for the standardised test scores obtained at the end of primary school by children of immigrants born in the Netherlands.

C6 OLS, random-effects and between-within models for the standardised test scores obtained at the end of primary school by children of immigrants born in the Netherlands, by age at naturalisation groups.

C7 Random-effects model for the standardised test scores obtained at the end of primary school by children of immigrants born in the Netherlands, with interactions between naturalisation dummy and parental education.

C8 Random-effects model for the standardised test scores obtained at the end of primary school by children of immigrants born in the Netherlands, with interactions between age at naturalisation and parental education. 
C9 Random-effects model for the standardised test scores obtained at the end of primary school by children of immigrants born in the Netherlands, with interactions between naturalisation dummy and parental education and homeownership status.

C10 Random-effects model for the standardised test scores obtained at the end of primary school by children of immigrants born in the Netherlands, with interactions between age at naturalisation and parental education and homeownership status.

C11 OLS, random-effects and between-within models for the standardised test scores obtained at the end of primary school by children of immigrants born in the Netherlands, by naturalisation dummy.

C12 Bounding the effect of naturalisation on standardised test scores obtained at the end of primary education by children of immigrants born in the Netherlands.

C13 Random-effects and between-within models for the standardised test scores obtained at the end of primary school by children of immigrants born in the Netherlands, by age at naturalisation.

C14 Random-effects and between-within models for the standardised test scores obtained at the end of primary school by children of immigrants born in the Netherlands, by age at naturalisation censored at age 10 .

C15 Random-effects and between-within models for the standardised test scores obtained at the end of primary school by children of immigrants born in the Netherlands, by age at naturalisation (age dummies).

C16 Random-effects and between-within models for the standardised test scores obtained at the end of primary school by children of immigrants born in the Netherlands, by age at naturalisation (6 instead of 7 clusters). 


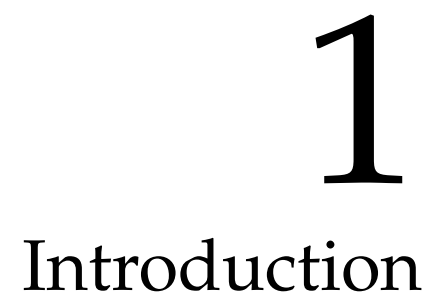




\section{Introduction}

Native-born children with two foreign-born parents represent a growing and sizeable proportion of the European student population. According to the OECD (2017a), this so-called second generation ${ }^{1}$ accounts for $11 \%$ of all children below the age of 15 in the European Union. The educational outcomes of second-generation children have been widely studied in recent decades (see, e.g., Heath et al., 2008; Crul et al., 2012; Alba and Holdaway, 2013), as a key indicator of the barriers and opportunities those children face in host societies $^{2}$.

On the one hand, native-born children of immigrant descent may face fewer obstacles in school than those born abroad. Contrary to their parents, the second generation goes through the same education system as the children of native-born parents. They have therefore more opportunities to acquire proficiency in the host country language and to develop context-specific skills (Esser, 2006; Heath et al., 2008, p.222). Through school, second-generation children are also intensively exposed to the host society culture and norms from an early age. Moreover, although the process of family settlement and

\footnotetext{
${ }^{1}$ The term "second generation" identifies the children of immigrants that are born in the country to which their parents migrated. It is part of a broader typology that distinguishes immigrants and their descendants based on where they are born and whether they have migrated themselves (see Rumbaut, 2004). This typology is used in this dissertation for two main reasons. First, I argue that the differentiation between generations is important for conceptual clarity, as individuals face very different socialisation conditions depending on whether and when they have migrated (Frauenfelder, 2007, pp.46-47; Crul and Schneider, 2010, p.1251). This has implications for the barriers and opportunities they face in their country of residence in general and in its education system in particular. Second, I prefer the term "second generation" to broader categories such as "migrant children" or "migrant youth", which foster a language of exclusion when they include native-born children of immigrants. Indeed, such children can be considered as natives given the locality of their birth (Lessard-Phillips et al., 2017, p.40) and may have never migrated from their country of birth. By contrast, the term "second generation" emphasises the legacy left by international migration in the lives of children of immigrants, without making them perpetuate foreigners in their country of birth. However, this term has the disadvantage to identify children only in terms of their parents' migration move to the destination country, thereby obscuring possible complex patterns of international and transnational mobility (van Geel, 2019, p.46; Gardner, 2012, p.900). While this dissertation focuses primarily on descendants of immigrants who remain in the destination country, it recognises that migration is not always exceptional in the lives of individuals, nor is it necessarily permanent (Della Puppa and Sredanovic, 2017, p.368).

${ }^{2}$ In this dissertation, "host society", " receiving society", "host country" and "destination country" are used interchangeably to refer to the country of residence of second-generation children. The term "origin country" refers to the country of birth of their parents - I use the singular for the sake of simplicity, but it is important to bear in mind that immigrant parents are not necessarily born in the same country.
} 
adaptation may continue long after their birth, native-born children have not migrated themselves, which is often a disorienting and stressful experience (Suárez-Orozco and Suárez-Orozco, 2002, pp.69-72).

On the other hand, second-generation children are not just like children of native-born parents. The migration experience of their parents and their family's adaptation to a new context create an "essential background difference" (Luthra et al., 2018b, p.27), which shapes their lives in specific ways. While second-generation children have been socialised in the host society, they may maintain strong emotional and physical ties with their parents' country of origin and develop transnational forms of belonging (Levitt and Waters, 2002; Wessendorf, 2007; Levitt, 2009). This transnational experience may affect the way children of immigrants ${ }^{3}$ orient themselves toward the host society and how they frame and construct their life trajectories between here and there (e.g., Keskiner and Crul, 2017; Shahrokni, 2019; Orupabo et al., 2020).

Furthermore, although born in the host country, the second generation does not face the same opportunities as children born to natives. First, there is evidence that, depending on their ethnic background, children of immigrants may be treated differently by their teachers, peers, and potential employers (Heath et al., 2008, pp.225-227), which can lead to experiences of racism and discrimination. Second, immigrant parents may face specific barriers to supporting their children's educational progress. Due to their disadvantaged position in the labour market, immigrants often experience downward mobility in the host society (Engzell and Ichou, 2020) and tend to occupy low-skilled and low-paid jobs (e.g., Alba and Foner, 2015). This loss of status affects their socioeconomic position and the resources they mobilise for their children. Immigrant parents may also find it difficult to transfer their own educational experience and knowledge to a new context, especially if they are not proficient in the host country language and/or have limited access to information (van De Werfhorst and Van Tubergen, 2007; Kristen, 2008). As a result, there are reasons to think that the children of immigrants face specific challenges when navigating the host society in general and its education system in particular.

In most countries, there is another important characteristic that separates chil-

\footnotetext{
${ }^{3}$ This dissertation focuses only on children who were born in the host country and leaves aside the so-called " 1.5 generation", i.e., children who were born in a foreign country before migrating at a young age (see p.29 for more details). The term "children of immigrants" thus exclusively refers to the second generation. Note that the term identifies individuals in their capacity as offspring of immigrants rather than as minors.
} 


\section{Chapter 1}

dren of immigrants from their peers born to native parents: their citizenship status. ${ }^{4}$ While some classic immigration countries, such as the United States, grant citizenship automatically and unconditionally on the basis of birth on the national territory (ius soli), two out of three countries in the world do not offer such provisions to second-generation children (Honohan and Rougier, 2018). Instead, the children of immigrants acquire citizenship by descent (ius sanguinis) and thus become citizens of their parents' country - or countries of origin. This is particularly true in Europe, where pure ius soli regimes no longer exist ${ }^{5}$ and only a few countries provide for conditional forms of ius soli $^{6}$ (Honohan and Rougier, 2018, p.350). Second-generation children therefore mainly rely on their parents' ability and desire to naturalise if they are to acquire the citizenship of their country of birth and residence.

In recent decades, immigrants' access to host country citizenship has been increasingly restricted in Western Europe (Vink and de Groot, 2010). A number of countries have raised the level of requirements for naturalisation, restricting eligibility criteria and introducing compulsory language and countryspecific tests (Goodman, 2010; van Oers, 2013). The length and conditions of the legal residence requirements have generally been tightened (Vink and de Groot, 2010, pp.725-726), while candidates are increasingly required to provide evidence of integration, including proof of self-support, absence of criminal records, and oaths of loyalty. This trend has been accompanied by a change in the conception of naturalisation, from a right or means for integration to a reward marking the end of immigrants' integration process (van Houdt et al., 2011). The increasing emphasis of states on immigrants' own responsibility for their integration has introduced new barriers to naturalisation, with possible exclusionary effects. Research indicates that stricter natu-

\footnotetext{
${ }^{4}$ In this dissertation, I define citizenship as the legal (i.e., de jure) status involving rights, privileges and duties associated with nation state membership (see Bauböck, 2006, Chapter 1). I therefore focus exclusively on formal citizenship, as opposed to normative or substantive citizenship, which refers to the practices and attitudes through which individuals negotiate their membership to the political and social community (see, e.g., Smith et al., 2005; Lange et al., 2007, p.33). While citizenship is often called nationality in international law, I use the term citizenship to emphasise the relationship between an individual and a sovereign state within its borders (see Bauböck, 2006, p.17, for a discussion of this point)

${ }^{5}$ As an exception, Moldova offers unconditional ius soli since 2003 (de Groot and Vonk, 2018, p.331) but does not grant Moldova citizenship automatically: parents need to complete a registration procedure on the behalf of their children.

${ }^{6}$ According to Honohan and Rougier (2018), eight European countries do provide restricted forms of ius soli. These include conditional or after birth ius soli provisions, whereby children born in the country (or their parents, on their behalf) can claim citizenship provided that they fulfil a number of requirements, most often related to their length of legal residence (see p.350).
} 
ralisation requirements affect not only immigrants' naturalisation propensity (e.g., Vink et al., 2021; Peters et al., 2016; Vink et al., 2013; van Oers, 2013) but also their very ability to apply for naturalisation (Jensen et al., 2019).

A less explored aspect are the potential effects of naturalisation requirements on access to host country citizenship for the children of immigrants. In ius sanguinis citizenship regimes, second-generation children may grow up as foreign citizens in their country of birth, not by choice but because the overall costs of naturalisation are too high for their parents. Without host country citizenship, children of immigrants are typically not entitled to vote in national elections, nor to access certain positions in the public sector ${ }^{7}$. They may also experience legal precariousness, especially if their family has not secured permanent legal residency. In addition, those holding non-EU passports may face various mobility restrictions when crossing international borders. Children of immigrants may thus face additional obstacles because of their foreign citizenship, with possible consequences on their educational and later-life outcomes.

Surprisingly, the potential consequences of host country citizenship - or lack thereof - on the life trajectories of second-generation children have remained largely unexplored. What is the share of the second-generation growing up as foreign citizens in ius sanguinis citizenship regimes? And what are the patterns of citizenship acquisition among the children of immigrants? Figures concerning access to host country citizenship for the second generation are typically not available in official statistics. For example, the OECD Database on Immigrants in OECD Countries (DIOC) does not contain comprehensive information on immigrant populations by country of birth and citizenship status. ${ }^{8}$ This blind spot in official statistics makes it difficult to assess the prevalence and modalities of host country citizenship acquisition among secondgeneration children.

Furthermore, little is known about the potential effects of host country citizenship on the life opportunities of children of immigrants. Does naturalisation affect their well-being, their sense of security and their orientation towards the host society? Does it help them to mitigate some of the potential

\footnotetext{
${ }^{7}$ In the Netherlands, the case studied in this thesis, certain public functions are only open to Dutch citizens, such as police officers, soldiers or professions in the judiciary.

${ }^{8}$ The OECD DIOC statistics on Immigrants by citizenship and country of birth are available at the following link: https://stats.oecd.org/Index.aspx?DataSetCode=DIOC_ CITIZEN_AGE [accessed July 19, 2021].
} 


\section{Chapter 1}

disadvantages they face in education? These questions are at the intersection of different bodies of literature, which have so far developed largely in isolation.

On the one hand, there is an extensive literature on the educational outcomes of the second generation, studying how children of immigrants fare in education relative to their peers of native descent (e.g., Heath et al., 2008; Crul et al., 2012; Alba and Holdaway, 2013). This literature has paid increasing attention to the diversity of educational pathways within the second-generation and to the role of parental characteristics associated with migration (e.g., Louie, 2012; Crul et al., 2017; Luthra et al., 2018b; Engzell and Ichou, 2020). However, despite the predominance of ius sanguinis citizenship provisions in Europe, very few studies carried out in the European context consider the citizenship status of second-generation children (see Dronkers and Fleischmann, 2010, for an exception). This is problematic because access to host country citizenship may be an unobserved factor of heterogeneity, contributing to the wide variations in educational outcomes observed among the second generation.

On the other hand, an important field of research in citizenship studies analyses the relevance of naturalisation for immigrants (e.g., Peters, 2018; Hainmueller et al., 2017; Gathmann and Keller, 2018; Helgertz and Bevelander, 2017). Yet, due to the individual- and adult-centred perspective prevailing in citizenship studies (Cohen, 2005; Street, 2014; Soehl et al., 2018), existing research tends to invisibilise the place and role of children in the naturalisation process. As a result, the ways in which children engage with and are affected by host country citizenship have remained mostly unexplored.

Connecting these two separate strands of literature is at the core of this dissertation. It aims to better contextualise and conceptualise citizenship acquisition among the children of immigrants, and to assess its effects on their educational outcomes. It addresses the following research question:

To what extent does citizenship status affect the educational outcomes of native-born children of immigrants?

To answer this question, I focus on the Netherlands, a country representative for the ius sanguinis citizenship tradition in Europe (Honohan and Rougier, 2018; Vink and de Groot, 2010). In the Dutch context, the children of immigrants depend on their parents to naturalise in order to acquire Dutch citizenship while minors, regardless of whether or not they were born in the 
country. ${ }^{9}$ This makes it a suitable case to analyse the patterns and effects of citizenship acquisition among the second generation, in the absence of automatic and unconditional ius soli provisions. Another advantage of the Netherlands is that its naturalisation policy occupies an intermediate position in the European landscape (Vink and de Groot, 2010, p.727). According to the Migrant Integration Policy Index 2019, Dutch law can be considered as "halfway favourable" in terms of access to nationality, with a score of 55 out of $100 .^{10}$ This middle position facilitates the generalisation of the results, as a number of other citizenship regimes are similar to the Dutch case. Furthermore, as elsewhere in Europe, Dutch naturalisation laws have undergone important reforms since the 1990s, in line with the "civic integration turn" (Goodman, 2019; van Oers, 2013). This variation in naturalisation policies allows me to assess whether the introduction of stricter naturalisation requirements have spillover effects on the acquisition of Dutch citizenship among immigrants' children.

I analyse the citizenship of the Dutch second generation using individuallevel register data from Statistics Netherlands (CBS). Register data offer the opportunity to analyse complete birth cohorts of children of immigrants born in the Netherlands and to follow their trajectories over time. This has two important advantages: a comprehensive coverage of the Dutch second generation provides reliable estimates of the prevalence of acquiring host country citizenship in this population, while a wide observation window allows capturing potential long-term naturalisation patterns and effects. In addition, the use of large-scale data offers opportunities to address the issue of parents' self-selection into naturalisation, which is a key methodological concern when analysing the relationship between citizenship and education.

Quantifying and measuring the potential effects of citizenship is not only relevant from an academic perspective, but also from a societal and policy perspective. There is evidence that children of immigrants generally experience disadvantages in various life domains with respect to their peers of native descent in Europe (see Heath and Brinbaum, 2007; Dustmann et al.,

${ }^{9}$ Note that since 1985 the Netherlands has had conditional ius soli provisions for the children of immigrants, once they have reached the age of majority and provided that they have been resident in the Netherlands since birth. This procedure, known as the option application, is further detailed on p.18.

${ }^{10}$ MIPEX takes into account several dimensions to determine its Access to Nationality Index, including eligibility criteria, naturalisation requirements, attitude towards dual citizenship and birthright citizenship provisions for the second generation. See https://mipex.eu/ access-nationality [accessed July 19, 2021] for more information. 


\section{Chapter 1}

2012; Drouhot and Nee, 2019). This is especially true for children whose parents originate from non-EU countries and have low levels of education and socio-economic resources (ibid.). Yet, the argument that facilitating citizenship acquisition may be an effective policy lever for improving the position of these disadvantaged groups has so far received limited public attention, especially in the Netherlands. ${ }^{11}$ This dissertation therefore aims to shed light on an often neglected dimension of the lives of the children of immigrants, which may have far-reaching consequences for the way they navigate the host society. By analysing not only whether citizenship matters, but also when and under which conditions, I aim to enhance scholarly understanding of the relevance of host country citizenship for native-born children of immigrants, which can also inform policy debates on the rights and outcomes of the second generation.

The research question guiding this dissertation is broken down in a number of sub-questions, which are addressed in the three empirical chapters (Chapters 3-5):

1. Who acquires host country citizenship among second-generation children in the Netherlands, when and under which conditions? To what extent is children's access to host country citizenship affected by the implementation of restrictive naturalisation laws? (Chapter 3)

2. How do the children of immigrants navigate the Dutch secondary school system, and is host country citizenship associated with specific educational trajectories? (Chapter 4)

3. To what extent are the effects of citizenship on education driven by parental selection into naturalisation? Does the effects of citizenship vary over time and across individuals? (Chapter 5)

The following sections elaborate on these sub-questions and highlight the academic relevance of this dissertation.

\footnotetext{
${ }^{11}$ In comparison, the citizenship status of the second generation has received relatively more attention in Switzerland, where two referenda to facilitate access to Swiss citizenship for the second and third generation were rejected in September 2004; and in Italy, where the political collective "Italiani senza Cittadinanza" (Italians without Citizenship) campaigns for the introduction of conditional ius soli for the second generation.
} 


\section{The relevance of host country citizenship for the second generation}

To date, only a limited number of studies have analysed the relevance of host country citizenship for the second generation, either quantitatively (Fibbi et al., 2007; Kilpi-Jakonen, 2014; Cygan-Rehm, 2018; Felfe et al., 2020) or qualitatively (Frauenfelder, 2007; Ribert, 2000; Colombo et al., 2011). These studies have been carried out in various national settings marked by ius sanguinis provisions, such as Switzerland (Fibbi et al., 2007; Frauenfelder, 2007), Italy (Colombo et al., 2011) and Germany before 2000 (Felfe et al., 2020; CyganRehm, 2018). Despite using different data, methods and measures, these studies provide a fairly coherent picture: citizenship matters for second-generation youth (Frauenfelder, 2007; Ribert, 2000; Colombo et al., 2011), and has positive effects on a wide range of educational outcomes, from grades and school track placement (Kilpi-Jakonen, 2014; Felfe et al., 2020; Cygan-Rehm, 2018) to continuation in higher education (Fibbi et al., 2007).

Two broad sets of explanation are usually advanced to explain the relevance of host country citizenship for the second generation. On the one hand, qualitative studies highlight that children of immigrants value citizenship for both its practical and formal dimensions: they perceive it as a protection from legal precariousness, as well as a condition for full and effective participation in the host society (Colombo et al., 2011; Colombo, 2015; Ribert, 2000). While citizenship is certainly not experienced as a form of allegiance to the host country, it is seen as an important resource for shaping one's future and being involved in collective decisions (Colombo, 2015). By contrast, those who cannot acquire host country citizenship may experience various forms of exclusion, from not being able to go on a school trip due to a lack of passport to not being able to apply for certain internships or jobs (Frauenfelder, 2007; Colombo et al., 2011; Colombo, 2015).

On the other hand, quantitative studies typically conceptualise citizenship within human capital theory (Becker, 1993). The acquisition of host country citizenship is modelled as a positive shock to the long-term rate of return to education, triggering early parental investments in their children's educational trajectories (Felfe et al., 2020; Cygan-Rehm, 2018; von Haaren, 2016). This set of explanations focuses on the expected benefits of host country citizenship in the labor market: because citizens have unrestricted access to the labor market, they can derive greater benefits from their educational investments. Increased opportunities in the host society are expected to incentivise 


\section{Chapter 1}

children and their families to invest in their human capital and embark on longer and/or more prestigious educational careers (Kilpi-Jakonen, 2014).

These studies have laid the foundations for a better understanding of the relationship between citizenship and education. Yet, this emerging body of work is also marked by a number of limitations. First, the effects of citizenship are not embedded in a comprehensive theoretical framework. While previous studies advance some mechanisms for an independent effect of citizenship on education, they do not incorporate insights from other relevant bodies of literature. Two areas of research have been particularly neglected: the literature on the educational outcomes of the second generation, which highlights the specific obstacles that immigrant families face when navigating a foreign education system (e.g., Heath et al., 2008; Crul et al., 2012; Alba and Holdaway, 2013); and the literature on the relevance of citizenship of first-generation immigrants (e.g., Peters, 2018; Hainmueller et al., 2017; Gathmann and Keller, 2018). This dissertation connects these two areas of research to show that citizenship may not only increase the educational aspirations of immigrant families, but also provide them with additional resources to achieve those aspirations. By doing so, I contribute to a more comprehensive conceptualisation of the effects of citizenship, which is key to derive well-grounded theoretical expectations.

Second, previous studies tend to model citizenship acquisition as a one-off treatment effect on children's outcomes (e.g., Felfe et al., 2020). Such a view is reductive in light of recent work on immigrant naturalisation (Peters et al., $2017,2016)$, showing that naturalisation is a process that starts long before citizenship is officially granted to the naturalisation candidate. While immigrant families can only enjoy the rights and benefits of host country citizenship once they have acquired it, their mere engagement in the naturalisation process can increase their orientation towards the host country and produce anticipated effects (Peters et al., 2017). The narrow conceptualisation of citizenship acquisition that prevails in previous studies is also reflected in the outcomes used to measure children's educational success. Previous studies typically assess the effects of citizenship on isolated educational transitions or outcomes, whereas one could expect citizenship to have long-term and cumulative effects on children's life trajectories. To better capture such potential effects, I analyse the educational trajectories of second-generation children in the Dutch school system. This longitudinal approach provides a more comprehensive picture of how children of immigrants navigate education, depending on whether and when they acquire Dutch citizenship. 
Lastly, due to different data and identification strategies, previous studies also focus on specific modes of citizenship acquisition - or analyse them indiscriminately. Some studies that measure students' citizenship status at one point in time (Fibbi et al., 2007; Kilpi-Jakonen, 2014) do not distinguish between those who acquired citizenship at birth and those who acquired citizenship through naturalisation during their childhood or youth. Other studies exclusively focus on citizenship acquisition at birth due to the policy context under study (Felfe et al., 2020; Cygan-Rehm, 2018 but see von Haaren, 2016). Yet, a substantial share of second-generation children in Europe may only acquire citizenship after birth, especially if they are born before their parents complete the minimum period of residence required for naturalisation. Overall, previous literature pays limited attention to when citizenship is acquired, thereby obscuring the potential effects of the timing of citizenship acquisition.

In the same vein, the effect of citizenship is often assumed to be uniform across individuals (see Dronkers and Fleischmann, 2010; Cygan-Rehm, 2018, for exceptions). Yet, children of immigrants form a very heterogeneous group: while the lack of host country citizenship may be very detrimental to some, becoming a citizen may have little value for others. For example, those from privileged backgrounds or who already enjoy the rights and benefits attached to EU citizenship may have little interest in becoming citizens. To date, it remains unclear, both conceptually and empirically, whether and how host country citizenship interacts with other characteristics of immigrants' children. In this dissertation, I draw on the literature on immigrant naturalisation to add new layers of complexity in the analysis of citizenship and education of children, highlighting potential timing and interaction effects.

\section{A life course perspective on the citizenship of children}

This dissertation draws on the life course approach to embed the patterns and effects of citizenship acquisition within a more comprehensive theoretical framework. The life course approach originates from the sociological life course paradigm, which was initially developed by Elder (1974) to better understand and conceptualise individual lives in the context of changing societies. This paradigm has been increasingly used in migration studies (see Wingens et al., 2011b, for an overview) and, more recently, in citizenship 


\section{Chapter 1}

studies (Peters, 2018). Life course research posits that the life courses of individuals interact with the historical, institutional and societal environment in which they live (Elder, 1994): social contexts shape the contours of human biographies, while being influenced in turn by the actions and personal characteristics of individuals. The life course approach aims to open "the black box of the missing links between individual lives and macro-social contexts" (Mayer, 2004, p.179), using a multilevel and longitudinal approach that captures the dynamics and interdependence of human life courses.

Such a perspective is particularly fruitful for analysing how the lives of individuals change as a result of migration (Wingens et al., 2011a). A life course approach draws attention to the specific constraints faced by immigrants in host societies, which are marked not only by the institutions and norms of the country of destination but also by those of their country of origin (ibid.). At the same time, it sheds light on the different resources immigrants develop and use here and there to construct their life courses in the face of new and changing institutional conditions (see de Hart et al., 2013). Naturalisation and citizenship laws are part of these institutional conditions: the lack of citizenship status can hinder individuals' plans and actions (e.g., Gilbertson and Singer, 2003; Stewart and Mulvey, 2014; Della Puppa and Sredanovic, 2017). Conversely, becoming a citizen of the host country may help immigrants to take agency over their lives, by increasing their opportunities and ability to adapt (e.g., Finotelli et al., 2017; Della Puppa and Sredanovic, 2017; Sredanovic, 2020).

While a life course approach to immigrant naturalisation has proven particularly insightful to understand its patterns and effects (Peters, 2018), the citizenship of the second generation has not yet been conceptualised within a life course perspective. However, some of the guiding principles of the life course approach are essential to conceptualise children's citizenship status comprehensively. First, because children of immigrants mainly rely on their parents to become citizens, their access to citizenship needs to be modelled at the family level. As Bonjour and de Hart (2021) note, immigrant parents do not experience citizenship "(...) as isolated individual[s], but as member[s] of a web of significant relationships, most notably family relationships" (p.7). Parents may therefore naturalise not only for themselves, but also or mainly for the sake of their children (Street, 2014; Della Puppa and Sredanovic, 2017; Sredanovic, 2020). Similarly, the positive effects of naturalisation on parents' integration outcomes (e.g., Peters, 2018; Hainmueller et al., 2017) may have spillover effects on their children's educational and later-life outcomes, due to interaction processes between parents and children (see, e.g., Elder, 1974, 
p.12). This intergenerational dependence within the family has been extensively studied in life course research, based on the principle of linked lives (see Wingens et al., 2011a, p.12). This dissertation, particularly in Chapter 3, draws on this principle to highlight the intra-family dynamics at play in the naturalisation process, building on recent developments in citizenship studies (Street, 2014; Soehl et al., 2018).

Second, a life course approach allows for a better understanding of the structure of opportunities and constraints faced by the second generation in host societies. While children of immigrants are often compared with children of native descent (Lessard-Phillips et al., 2017), the trajectories of the former are singularly shaped by the migration experience of their parents (Luthra et al., $2018 b, p .28)$. Contrary to natives, immigrant parents need to navigate a new and changing institutional context, whilst having varying levels of language proficiency and access to information. This includes immigration and citizenship laws, which determine their rights and obligations in the host country (de Hart et al., 2013), but also the education system, which may be widely different from the one they experienced as students. At the same time, immigrant families actively plan and structure their lives; they elaborate strategies and tactics within those constraints (Sredanovic, 2020). This interplay between context and agency is another key principle of the life course perspective (see Wingens et al., 2011a, p.6), which I use to model citizenship in the context of changing institutional constraints. On the one hand, I analyse the effects of naturalisation reforms on the propensity of second-generation children to acquire Dutch citizenship, as stricter naturalisation requirements may impose additional constraints on the decision-making process of immigrant families (Chapter 3). On the other hand, I conceptualise citizenship as a potential resource increasing their level of agency and ability to navigate complex institutions such as the Dutch school system (Chapter 4).

Finally, the life course approach helps to conceptualise the effects of citizenship over the life course (Peters and Vink, 2016). While previous research analysing the relationship between citizenship and education tends to model citizenship acquisition as a dichotomous and one-off event, I argue that it should be seen as a multi-faceted process whose effects unfold over time. Such a process is not expected to affect educational outcomes overnight, but rather to gradually steer naturalised children into distinct educational paths. The life course concept of trajectory (see Wingens et al., 2011a, p.13) is particularly relevant to capture those potential long-term and cumulative effects, by shifting the focus from isolated educational outcomes to longer sequences of school events and transitions. Educational trajectories are central to Chap- 


\section{Chapter 1}

ter 4, where I observe the pathways of the second generation into the Dutch secondary school system and analyse whether the acquisition of Dutch citizenship is associated with specific school mobility or dropout patterns.

Furthermore, a life course approach draws attention to the conditions under which host country citizenship is acquired: naturalisation does not occur in a vacuum, but interacts with the personal characteristics and resources of children. While in previous research the effects of citizenship are generally assumed to be uniform over time and across individuals, I analyse not only whether citizenship matters but also when and for whom in Chapter 5. By doing so, I contribute to a more contextualised understanding of the citizenship of second-generation children, following recent work by Peters et al. (2016) on the ecology of immigrant naturalisation.

A life course approach offers valuable analytical tools to address key gaps identified in the previous literature on the citizenship and educational outcomes of the second generation. In Chapter 2, I discuss the research to date in more detail and draw on the life course principles to develop the theoretical underpinnings of this thesis.

\section{The Dutch context}

The life course perspective highlights the need to embed individuals' lives in the historical time and places they experience (Wingens et al., 2011a). In this dissertation, I focus on children of immigrants living in the Netherlands, a country with specific institutional conditions regarding immigration, naturalisation and education. This section details the Dutch context with respect to these three dimensions to highlight the constraints and opportunities faced by the Dutch second generation and their parents.

\section{Immigration to the Netherlands since 1945}

On January 1, 2020, the Netherlands recorded 17.4 million registered residents, of which 4.2 million had a migration background, either as immigrants (2.2 million) or as children of immigrants ( 2 million). ${ }^{12}$ This is the result of

\footnotetext{
${ }^{12}$ The figures used in this section have been retrieved from Statistics Netherlands (https: //opendata.cbs.nl/statline [accessed July 19, 2021]). Note that the definition of the second generation used by Statistics Netherlands differs from the one used in this thesis: Statistics Netherlands defines the Dutch second generation as children born in the Nether-
} 
several waves of immigration since the 1960s, during which the share of immigrants and their descendants has not only increased in volume but also in diversity (see van Meeteren et al., 2013).

While the Netherlands has long been a country of emigration, a long period of net migration into the country started after the Second World War. First, following Indonesia's independence in 1949, the Netherlands experienced a large influx of repatriates from their former colony. New migration flows then emerged in the early 1960s with the introduction of official guest worker programmes in response to severe labour shortages. Guest workers initially came from Southern Europe, before being recruited from Turkey and Morocco. Although the oil crisis put an end to the guest workers programs in 1973, migration continued from Turkey and Morocco, notably through family reunification (see Vink, 2007, p.116, for details). At the same time, the Netherlands experienced new waves of post-colonial migration, with a peak following the independence of Suriname in 1975.

These early migration flows had a lasting impact on the composition of the Dutch migrant population: in 2020, Turkey, Suriname and Morocco were still the three most represented countries of origin among "non-Western" 13 immigrants living in the Netherlands, including 197, 177 and 172 thousands individuals respectively. These are also the three most represented origin countries among the "non-Western" second generation, although in different proportions: there were 237 thousands native-born children of Moroccan descent in 2020, compared to 219 thousands children of Turkish descent and 179 thousands of Surinamese descent.

Immigrants arriving through guest worker programs and family reunification generally had secure residence statuses. Similarly, immigrants from the former colonies were either Dutch citizens - for those from the former Netherlands Antilles - or had privileged access to Dutch territory and citizenship (Engbersen et al., 2007, p.399). In contrast, from the early 1990s onwards, the

lands to at least one foreign-born parent, while I only include children born in the Netherlands to two foreign-born parents. I discuss this point in more detail in the next section of this chapter when presenting the research population on p.29.

${ }^{13}$ Until very recently, Statistics Netherlands divided immigrants into those from "Western" countries, including Europe (except Turkey), North America, Oceania, Japan and Indonesia; and those from "non-Western" countries, including Turkey, Africa, Latin America and Asia. Statistics Netherlands has announced in 2021 that it will abolish this distinction; however, it is still used in current official statistics. For a critical perspective on the Western/non-Western distinction, see Yanow and van der Haar (2013, pp.240-243). 


\section{Chapter 1}

Netherlands experienced a large influx of immigrants with more precarious residence statuses.

The number of asylum seekers rose sharply following the wars in former Yugoslavia, and was subsequently fuelled by immigrants from various countries, including the post-Soviet states, Turkey, Afghanistan, Iraq, Iran, Sri Lanka, Angola, Somalia and Sierra Leone (see Engbersen et al., 2007, pp.402403). While the approval rate of asylum requests was relatively favourable in the early 1990s, it decreased significantly at the end of the decade, contributing to an increase in irregular stays on Dutch territory (van Meeteren et al., 2013, p.116).

In parallel, there was an increase in the number of temporary labor immigrants, mostly from Western Europe and more particularly from eastern European countries. The EU enlargements of 2004 and 2007 stimulated immigration from new EU member states to the Netherlands, especially from Poland, followed at a large distance by Romania and Bulgaria (Engbersen et al., 2007, p.405). This contributed to a sharp increase in the share of immigrants from other-EU countries, which had been growing steadily over the past decades.

The 1990s and 2000s were therefore characterised by new patterns of migration: immigrants from the traditional sending countries - Turkey, Morocco and Suriname - were gradually supplemented with new categories of immigrants from more diverse parts of the world, and whose settlement conditions were generally more insecure or temporary. The children of immigrants born in the Netherlands between 1995 and 2010, who are the focus of this dissertation, reflect this growing plurality in the composition of the Dutch population.

\section{Citizenship laws and integration policies}

Successive migration waves to the Netherlands since the Second World War have been accompanied by various changes in Dutch immigration and integration policies, which have shaped the context of settlement for immigrants and their families. In what follows, I pay particular attention to the different conditions under which the first and second generations could become Dutch citizens over time, either through the naturalisation of (one of) the parents or through the acquisition of Dutch citizenship after birth, by the children themselves. 
Until 1892, children could acquire Dutch citizenship through descent from a parent or through birth on the territory. The Netherlands had a pure ius soli regime: children born on the Dutch soil acquired Dutch citizenship automatically, irrespective of the citizenship of their parents. However, in 1892, the Dutch Nationality Act replaced the ius soli principle by a gender-specific ius sanguinis transmission, through descent from the father. This change was based on the consideration that "the 'sole' fact of birth on Dutch territory was perceived as a coincidental event which did not necessarily create a bound with the Netherlands, while descent from a Dutch father did." (de Hart, 2010, p.99). From that date, children of immigrants born in the Netherlands to two foreign-born parents could only become Dutch if their fathers had become Dutch before their birth, or through their own naturalisation after the age of majority.

However, in the 20th century, some reforms facilitated access to Dutch citizenship for the descendants of immigrants. First, in 1958, a form of ius soli was adopted for the third generation, i.e., the children born in the Netherlands from second-generation parents. Second, in 1976, a partial Amendment of the 1892 Nationality Act gave certain categories of applicants, including the second generation, the possibility of acquiring Dutch citizenship through a simplified and shorter procedure as adults. Citizenship could be acquired upon a simple decision by the Minister of Justice, in contrast to the standard naturalisation procedure, which had to be approved by both houses of Parliament (van Oers et al., 2009, p.6).

Despite the large influx of guest-workers from the Mediterranean in the 1960s, the Netherlands did not develop a comprehensive policy to address the legal status and integration of these newcomers until the early 1980s. Guest workers were expected to eventually return to their home countries, leading to a pragmatic strategy to foster immigrants' integration while preserving their cultural identity (Vink, 2007, p.345). However, at the end of the 1970s, it was increasingly recognised that most guest workers would remain in the Netherlands, and that the government should therefore ensure their equal participation in Dutch society. (WWR, 1979; AOCM, 1979). The so-called "minorities' policy" (Minderhedenbeleid) was introduced in 1983 to ensure equal opportunities for all residents in the Netherlands (Dutch Government, 1983).

A central element of this minorities' policy was to strengthen the legal position of immigrants in the Netherlands. This led to the adoption of the Dutch Nationality Act in 1985, which simplified the acquisition of Dutch citizenship through naturalisation and allowed candidates to appeal negative decisions. 


\section{Chapter 1}

With the new Act, "naturalisation became a right rather than a favour" (van Oers et al., 2009, p.13). Immigrants had to meet the following requirements to naturalise:

- "being at least 18 year of age,

- having been granted a residence permit for a purpose not limited in time,

- having been residing in the Netherlands for at least five consecutive years prior to the application

- having made an effort to renounce one's foreign nationality, unless renunciation could not reasonably be demanded,

- not constituting a danger to public order,

- having reasonable knowledge of the Dutch language and being accepted into Dutch society." (van Oers, 2013, p.43)

Fulfilment of the last requirement - commonly known as the "integration requirement" - was tested by a municipal official in a short interview, free of charge, which allowed for a more lenient treatment of some categories of immigrants (van Oers, 2013, Chapter 3). In addition to facilitating the naturalisation of immigrants, the new Act improved access to Dutch citizenship for the second generation. Native-born children of immigrants were indeed given the possibility to acquire Dutch citizenship by lodging a unilateral declaration between the ages of 18 and 25. This declaration, known as the option procedure, did not require the renunciation of the applicant's existing nationality as did naturalisation (van Oers et al., 2009, p.13).

The number of naturalisations rose significantly after 1985. In particular, there was a considerable increase between 1992 and 1997, when dual nationality was temporarily tolerated following a compromise between the government parties. Yet, this liberalisation appears to be an exception to the other developments of the decade (Vink, 2007, p.346). In the 1990s, the idea that newcomers should take responsibility for their integration, rather than being treated as "care categories", gained increasing support at the institutional level (WWR, 1989; Dutch Government, 1994) and in Dutch society (van Oers, 2013, p.48). In this context, the acquisition of Dutch citizenship came to be seen more as a reward or trophy than as an instrument for integration (see de Waal, 2017; van Oers, 2013, pp47-51). The introduction of stricter language and integration requirements for naturalisation was increasingly discussed in Parliament, and finally came into force in 2003 with the Naturalisation Test 
Decree. The Decree introduced a formalised language and knowledge of the Dutch society test, which had to be paid for by applicants (€260). The level of language skills required to pass the naturalisation test was much more demanding than the previous integration interview; it was set at level A2 of the Common European Framework of Reference (CEFR). Overall, the introduction of the naturalisation test made it significantly more difficult and costly for applicants to meet the integration requirement, and was associated with a decline in naturalisations by almost $50 \%$ (van Oers, 2013, Chapter 7).

The Naturalisation Test decree came into force with the revised Dutch Nationality Act, which changed the right of option for the second generation. While the maximum age of 25 for lodging a declaration of option was cancelled, the procedure could now be interrupted by the mayor on discretionary grounds (van Oers et al., 2009, p.21). In addition, the new procedure included a requirement of lawful residence in the Netherlands, and was no longer free of charge. According to van Oers et al. (2009), this changed the very nature of the option procedure: "[since 2003] the right of option no longer constitutes a middle course between ex lege acquisition and naturalisation. It can be seen as a simplified form of naturalisation." (p.22).

The emphasis on the need to earn or deserve one's citizenship only became stronger in the 2000s, following a wider trend in Europe (van Houdt et al., 2011; van Oers, 2013). The Dutch political and social climate was highly conducive to the politicisation of immigration and integration issues, and led to the rise of political parties with explicit anti-immigration agendas (see Entzinger, 2014; van Oers, 2013, pp.51-53). Immigration policies became more selective, while integration policies were increasingly centred on the acceptance of so-called "Dutch" values and norms by immigrants (see Schinkel and Van Houdt, 2010). This led to the introduction of a naturalisation ceremony in 2006, and to the entry into force of the Integration Act in 2008, which imposed a "civic integration duty" (inburgeringsplicht) to all non-Dutch/EU residents between the ages of 16 and 65 - unless they had participated sufficiently in the Dutch education system or passed their naturalisation exam (see Vink, 2007, p.347).

The 2008 Integration Act replaced the naturalisation test by the "integration examination", which further increased the overall cost of the naturalisation procedure for applicants (van Oers, 2013, p.54). Candidates now had to pay for both the examination and the integration course themselves, with limited opportunities for financial support ${ }^{14}$. Compared to the naturalisation test, the

\footnotetext{
${ }^{14}$ The costs of the integration course rose dramatically after 2008 because the government trans-
} 


\section{Chapter 1}

content of the integration test was expanded, while maintaining the required level of language skills at A2 of the CEFR (see van Oers, 2013, p.63).

These subsequent changes in Dutch integration policies at the turn of the 20th century reflect broader transformations in the very conception of citizenship: its formal or juridical definition has progressively given way to normative views of what a "good" or "active citizen" should be (Schinkel and Van Houdt, 2010). This growing emphasis on the moral dimension of citizenship had important implications for the legal status of immigrant families. On the one hand, immigrant parents have been faced with increasingly stringent and costly naturalisation requirements, which may prevent or postpone their acquisition of Dutch citizenship and, indirectly, that of their children. On the other hand, the introduction of the option procedure in 1985 provided a specific legal route to Dutch citizenship for the native-born children of immigrants. Yet, access to this procedure was also restricted, so as to become a simplified form naturalisation. Furthermore, this procedure is only available from the age of majority, which means that second-generation children are exclusively dependent on the naturalisation of (one of) their parents if they are to become Dutch citizens when they are minors.

\section{The Dutch education system}

Previous studies analysing the relationship between citizenship and education of the second generation have been conducted in different national settings, marked by specific educational arrangements. While some education systems steer students into hierarchical tracks at an early age (e.g., Germany, Switzerland), others postpone selection and have low levels of stratification (e.g., Sweden) - or fall somewhere in between (e.g., Italy). The Netherlands, with its full-curriculum tracking system in secondary education, belongs to the first category (see Nuffic, 2019, for a detailed overview). Students are assigned to a specific track for all subjects right after the end of primary school, around age 12, on the basis of a binding school advice they receive. The school advice is based on teachers' recommendation and, in most schools, on students' performance at a standardised test taken in the last year of primary school to measure cognitive abilities.

ferred the responsibility for the provision of the courses to the market. The average costs were estimated to be around $€ 4,300$, not including the costs of the examination itself (van Oers, 2013, p.54). The "Deltaplan integration" temporarily allowed municipalities to pay for the integration courses of those having a civic integration duty under the Integration Act. However, this was replaced by a system of loans in 2013 (see van Oers, 2013, pp.63-64). 
The track in which students enter secondary education has important consequences for their subsequent trajectories, as tracks offer unequal opportunities to access higher education and move upward through the system. On the one hand, the pre-university (VWO) and general (HAVO) tracks provide direct routes to research universities (WO) and universities of applied science (HBO) respectively. On the other hand, students enrolled in the vocational track (VMBO) can only gain access to higher general education if they have been enrolled in the right sub-tracks, and at the cost of additional years of study. Moreover, students are generally grouped in different schools depending on their initial track, which places the Netherlands on the side of the between-school tracking systems (see LeTendre et al., 2003, p.51).

Despite its high level of stratification, Dutch secondary education is relatively flexible: students are able to correct a possible misplacement by moving upward or downward between tracks. However, students are not equally equipped to make use of this flexibility. Families need quality information to navigate this complex system and choose (sub-)tracks and schools with good upstream possibilities (Pfeffer, 2008; Forster and van de Werfhorst, 2019). Without a good knowledge of the available pathways and back doors, parents may inadvertently limit their children's options. Immigrant families may face specific obstacles in that respect (Crul, 2015, 2018). Because of their school experience in a foreign education system, immigrant parents are more likely than native-born parents to lack the necessary content and strategic knowledge (Pfeffer, 2008) to effectively guide their children through the system (van De Werfhorst and Van Tubergen, 2007). Parents' lack of proficiency in Dutch can also complicate their participation in school decisions, and limit their involvement at key stages of their children's school careers.

Parental resources have been shown to be particularly crucial in the Dutch education system (see Stevens et al., 2011, pp23-28, for an overview). At the end of primary school, children of highly-educated parents tend to get higher track recommendations from teachers and are more likely to be enrolled in a track above the one corresponding to their test scores (Inspectie van het Onderwijs, 2016; Timmermans et al., 2018). This suggests that parents from privileged backgrounds negotiate with teachers to secure a higher track than initially advised. There is also evidence that students whose parents have a high level of education and cultural capital are more likely to be mobile between tracks (Forster and van de Werfhorst, 2019), which is consistent with the idea that these intra-secondary transitions require significant parental involvement. 


\section{Chapter 1}

Comparative studies confirm the determining influence of parental resources in this type of education system (e.g., Pfeffer, 2008; van de Werfhorst and Mijs, 2010; van de Werfhorst, 2019). Early-tracking education systems such as the Dutch one are generally found to increase the level of social inequalities at school, including disparities by parental socioeconomic and migration background (van de Werfhorst, 2019, p.69). Conversely, students from underprivileged families are less disadvantaged when they are in comprehensive unstratified systems, because they are less dependent on the resources and involvement of their parents.

In other words, the institutional characteristics of the school system shape the learning opportunities of students, and moderate the influence of their social background. In the Netherlands, unequal access to parental resources are expected to be a key factor in the heterogeneity of educational outcomes among children of immigrants (van De Werfhorst and Van Tubergen, 2007). If citizenship fosters the access of immigrant families to relevant country-specific resources and increases their level of agency, its effects on education may be more important in the Netherlands than in unstratified education systems. In that sense, the acquisition of host country citizenship is expected to be particularly relevant in the Dutch education context. In empirical Chapter 4, I explain in more detail how these specific educational arrangements may moderate the relationship between citizenship and education.

\section{Data and research population}

To analyse the relationship between host country citizenship and education of the Dutch second generation, I make use of register data from Statistics Netherlands. In the following, I describe the main characteristics of this administrative data and the conditions in which they were used. In a second step, I describe the research population that is at the focus of this thesis.

\section{The Dutch administrative registers}

Information on individuals and households is traditionally collected through surveys. However, the steady rise in survey nonresponse over the last decades has raised a number of difficulties (Singer, 2006). From a methodological point of view, non-random nonresponse violates one of the key assumptions of probability sampling, which may severely bias the inferential process. Besides casting doubts on the reliability of survey estimates, rising nonresponse 
rates have substantially increased the costs of implementing surveys. In this context, administrative data have received growing attention from statistical offices, leading to the development and use of population registers in several countries (Bakker et al., 2014a).

In the Netherlands, Statistics Netherlands started to develop the System of Social Statistical Datasets (SSD) in the second half of the 1990s. The SSD refers to a system of linked administrative registers and surveys that can be combined efficiently using standardised linkage keys (see Bakker et al., 2014a, for a technical overview). This combination makes it possible to cover various life domains, from education and labour force participation to health and housing. A key part of this system is the Municipal Basis Registration for population data (Gemeentelijke Basis Administratie persoonsgegevens, GBA), a computerised and decentralised register at the municipality level which provides longitudinal data on all individuals residing in the Netherlands ${ }^{15}$.

In principle, everyone legally residing in the Netherlands is recorded in the register of the municipality where he or she usually lives, regardless of their citizenship status. Foreign-born individuals who are planning to stay in the Netherlands for at least two third of the forthcoming six months are considered as immigrants, and must register at their municipality using a residence permit (van der Erf et al., 2006). Conversely, individuals who leave the Netherlands for at least eight months in the coming year must notify their municipality in order to be deregistered. If they do not declare their departure, they may be removed from the registers when it becomes apparent that they no longer live at the registered address and/or have no contact with the Dutch administration (see van der Erf et al., 2006, p.555). In this way, the GBA ensures extensive and up-to-date coverage of the population of the Netherlands. Municipal population registers provide basic information on the sociodemographic characteristics of individuals, which can be linked to other administrative data using unique and anonymised personal identifiers.

\footnotetext{
${ }^{15}$ Since 2015, the GBA has been merged with the Registration of Non-Residents (RNI) to form the Basic Registration of Persons (Basisregistratie Personen, BRP), comprising personal data of both residents and non-residents who have had a relationship with the Netherlands. As the BRP was not available for most of the observation period considered in this thesis (1995-2016), I used only the GBA.
} 


\section{Chapter 1}

\section{Advantages of administrative register data}

Using register data presents important advantages in the context of this dissertation. First, register data are especially relevant when studying small populations or low-incidence phenomena that cannot be captured in surveys. This is notably the case for immigrants and their descendants, who are typically underrepresented in surveys due to specific sampling and coverage difficulties (see Kappelhof, 2015, pp.18-23). As this dissertation exclusively focuses on the Dutch second generation, an adequate coverage of this population is crucial to obtain reliable estimates. Although some surveys are designed to over-sample the children of immigrants (e.g., Dollmann and Jacob, 2014; Groenewold and Lessard-Phillips, 2012), they generally do not provide detailed information on respondents' changes in nationality. By contrast, data on acquisitions and losses of Dutch citizenship are available in the administrative registers of the Immigration and Naturalisation Service (IND) (van der Erf et al., 2006, p.563), which provides information on change of citizenship on a yearly basis and decreases the risk of inaccuracies compared to self-reported data.

Second, by design, population registers provide panel data where individuals are continuously followed over time, without generating attrition. This micro-level longitudinal aspect is crucial for analysing the relationship between citizenship and education from a life course perspective (Wingens et al. 2011a). In the empirical Chapter 3, panel data make it possible to assess the relevance of the policy context, by analysing the naturalisation propensity of immigrant families under changing institutional conditions. A longitudinal perspective is also pivotal in the empirical Chapter 4 , where educational registers allow me to trace students' school careers on an annual basis, from entry into secondary education to early adulthood.

Finally, population registers offer the opportunity to match individuals with their partners, parents and children. This feature is important when analysing the citizenship of the second generation in the Netherlands, as children are dependent on their parents to acquire Dutch citizenship when they are minors. The matching of parents and children enables me to analyse naturalisation patterns at the family level in Chapter 3, highlighting the social dimension of the acquisition of citizenship by children. The possibility to match family members is also crucial in Chapter 5, where I identify siblings to estimate within-family effects of age at naturalisation on educational achievement. This empirical strategy is also made possible by the use of the total popula- 
tion of Dutch second-generation children, which ensures sufficient statistical power to analyse variations between siblings.

\section{Limitations and drawbacks of administrative register data}

The use of administrative register data also comes with limitations. First, it is important to note that, despite its inclusive coverage of the population, registers only include people who are legally resident in the Netherlands. This notably excludes undocumented populations who are living in the Netherlands without a valid residence permit. In addition, some immigrant populations are likely to be underrepresented in the registers. For instance, asylum seekers are only registered after they have been granted a residence permit, or can register on their own initiative if the decision has been pending for more than six months. In practice, this leads to under-coverage and delays in the administrative registration of this population (van der Erf et al., 2006, p.553). The population statistics therefore "reflect the de jure population of the Netherlands and not the de facto population" (van der Erf et al., 2006, p.561). However, this should not introduce a significant selection bias in the analysis of the citizenship of children. Children of undocumented immigrants and pending asylum seekers are indeed not included in the target population, since a valid residence permit is a formal requirement for naturalisation. Nevertheless, the use of register data implies that the findings of this dissertation are only relevant for the population of children who are legal residents in the Netherlands.

Other limitations relate to the quality and availability of register data. Notably, there is evidence that register data contain considerable measurement error (Oberski et al., 2017, p.1477). Although existing studies suggest that the bias is not higher than the bias found in surveys (e.g., Bakker, 2012; Pavlopoulos and Vermunt, 2015; Oberski et al., 2017), it is essential to critically assess the plausibility of the data. In the face of data inconsistencies, I paid particular attention to comparing information from several registers for crossvalidation. Some self-constructed variables, such as immigrants' date of eligibility for naturalisation (Chapter 3), were created in several ways using different data sources to assess the risk of measurement error. I also systematically identified cases with missing or atypical information to assess the sensitivity of the results to the inclusion of such cases.

At the same time, register data impose important constraints in terms of data availability. Because the registers have only been computerised from 1994 on- 


\section{Chapter 1}

wards, it is not possible to trace the trajectories of individuals before that date. This is especially problematic for reconstructing the migration pathways of the parents included in the study, the majority of which arrived before 1994 in the Netherlands. The variables related to parents' migration background, such as their number of years since migration (Chapter 4 ), should therefore be interpreted with particular caution, as the risk of measurement error is not negligible. Furthermore, the registers have developed over time to cover an increasing range of themes and characteristics. This implies that some variables have only become available - and reliable - over time, which imposes additional constraints when analysing the data longitudinally. This was notably the case with the educational variables used in Chapters 4 and 5: educational registers were only added to the SSD in the early 2000s, and information on students' school outcomes became reliable at the end of the decade.

Finally, although the scope of register data has significantly improved over time, it is inherently limited by its administrative nature. Contrary to surveys, register data do not provide information on individuals' aspirations, motivations or experiences. This makes it difficult to explain the observed patterns, as the decision-making processes involved are not observable. Therefore, while this dissertation aims to investigate the mechanisms by which citizenship affects educational outcomes (see Chapter 2), it can only use empirical proxies to test these hypothesised mechanisms, due to the lack of appropriate data. Administrative registers nevertheless provide the basic information needed for the aggregate approach followed in this thesis, leaving aside the way individuals perceive and experience citizenship. In the conclusion, I will further reflect on the implications of the data limitations described in this section.

\section{Access to register data and data confidentiality}

The datasets provided by Statistic Netherlands contain strictly confidential personal information that must be treated with great care. To ensure a sufficient level of data security, Statistics Netherlands has taken a number of measures (see Bakker, 2012, p.419). First, personal identifiers are removed from the statistical data and are replaced by anonymous linkage keys that preclude direct identification. Second, the data are stored on a network with strictly regulated access rights. To access the network, a global plan for the analysis including a detailed description of the required data must be submitted to Statistics Netherlands. After approval, access is granted only for 
the required data. In addition, the data are exclusively accessible via computers at the central offices of Statistics Netherlands, or via personal and secure remote access. When working on the data, access to email facilities is limited and any do-file or output is checked for compliance with Statistics Netherlands guidelines before being exported. Altogether, these measures ensure a high level of data protection and limit the risk of breach of confidentiality.

\section{The research population}

This dissertation focuses on the children of immigrants born in the Netherlands between 1995 and 2010. This choice is the result of several considerations. On the one hand, the naturalisation trajectories of those born before 1995 are difficult to trace due to the absence of computerised registers before that date. On the other hand, the data provided for this thesis go up to 2016, which prevented the inclusion of the youngest birth cohorts that could only be observed in their first years of life. This broad research population is used in the empirical Chapter 3 to get an overview of patterns of citizenship acquisition among the Dutch second generation from the mid-1990s to the mid-2010s. In the empirical Chapters 4 and 5, more restricted research populations were selected depending on the data constraints and research needs (see Figure 1.1 and Table 1.1).

In Chapter 4, I follow the cohort of second-generation students who were first enrolled in secondary education in 2008, which mainly corresponds to children born in 1995 and $1996 .{ }^{16}$ This narrow focus allows me to cover the entirety of these students' secondary schooling, while ensuring sufficient quality for the educational data. In Chapter 5 , I focus on the cohorts of secondgeneration students who were first enrolled in secondary education between 2008 and 2015, the large part of which were born between 1996 and 2002. The selection of several student cohorts is important for the empirical strategy of this chapter, which is based on the comparison of the standardised test scores obtained at the end of primary school by students from the same sibling. It is important to note that no major structural reforms took place in the Dutch education system during the observation period (see Garrouste-Norelius et al., 2010, p.68), which facilitates the comparison of students from different school cohorts.

\footnotetext{
${ }^{16}$ As Figure 1.1 shows, a small share of students are born before 1995 in Chapter $4(6.4 \%)$ and Chapter $5(0.6 \%)$. This is due to the selection criteria used in these Chapters, which are both based on student cohorts. Individuals born before 1995 correspond to students who have repeated one or more grades before entering secondary education.
} 


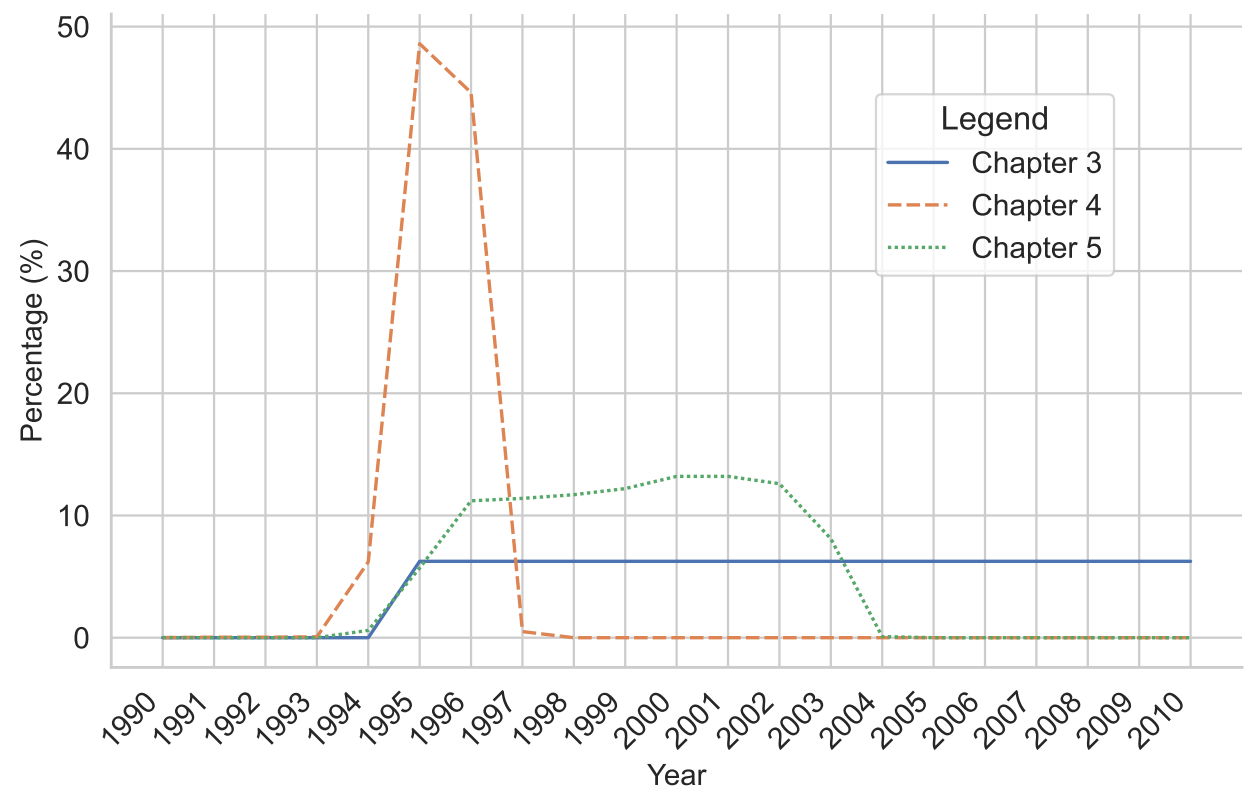

Figure 1.1: Distribution of the birth cohorts included as research populations in the empirical Chapters 3, 4 and 5.

\begin{tabular}{cccc}
\hline & Chapter 3 & Chapter 4 & Chapter 5 \\
\hline Population & SG*orn in $^{*}$ SG first enrolled & SG first enrolled \\
Sample size & $1995-2010$ & in SE** in 2008 & in SE in 2008-2015 \\
Observation period & 287,250 & 12,505 & 122,356 \\
Method & $1995-2016$ & $2008-2016$ & $2008-2015$ \\
& Event history & Sequence & Family \\
& analysis & analysis & fixed-effects \\
\hline
\end{tabular}

Table 1.1: Overview of the main characteristics of the three empirical Chapters 3, 4 and 5.

*SG: Second generation; **SE: Secondary education. 


\section{Definition of the second generation}

In all three empirical Chapters, I define second-generation children as those born in the Netherlands to two foreign-born parents, who themselves are born to at least one foreign-born parent. This is a stricter definition than the one used by Statistics Netherlands, which includes children with only one foreign-born parent. While some studies use the same criterion as Statistics Netherlands when analysing the relationship between citizenship and education (Kilpi-Jakonen, 2014; Cygan-Rehm, 2018), I argue that the children of mixed descent are a distinct group that should be analysed separately. Having one native parent, children of mixed descent are indeed likely to have facilitated access to host country-specific resources, as previous studies suggest (see, e.g., van Ours and Veenman, 2010; Emonds and van Tubergen, 2015). Second, and perhaps more importantly, the children of mixed descent ought to obtain Dutch citizenship at birth by descent through their native parent. This group is therefore expected to have privileged access to Dutch citizenship, compared to those whose parents are both immigrants. Although children of mixed descent may still benefit from the naturalisation of their nonnative parent, the mechanisms involved are likely to be specific to this group and would therefore warrant a separate analysis. ${ }^{17}$

My definition of the second generation also excludes the so-called 1.5 generation, i.e., the children who migrated to the Netherlands at a young age. While some studies do combine the 1.5 and second generations (Fibbi et al., 2007; Bean et al., 2011; Patler, 2017), these two groups often differ in their access to host country citizenship. ${ }^{18}$. Furthermore, one can expect the 1.5 generation to face specific obstacles at school, due to their previous socialisation in another national context (see Suárez-Orozco and Suárez-Orozco, 2002, Chapter $3)$. As including this group would add substantial heterogeneity to an already widely diverse population, I have chosen to focus only on the second generation. Nevertheless, the importance of host country citizenship for the 1.5 generation should not be underestimated (Luthra et al., 2018b; Cebulko, 2014; Gonzales, 2011), and undeniably deserves further research in Europe (Homuth et al., 2020).

\footnotetext{
${ }^{17}$ Note that for similar reasons, children born in the Netherlands from second-generation parents - the third generation - are not included either, since they acquire Dutch citizenship automatically.

${ }^{18}$ For instance, children of immigrants who are born abroad can obtain Dutch citizenship by option, provided that they have been resident in the Netherlands since the age of 4 . This is the so-called socialisation based acquisition.
} 


\section{Chapter 1}

Finally, I excluded children from specific origin groups in all three empirical Chapters. I first omitted the children originating from the Caribbean territories of the Kingdom of the Netherlands (the former Netherlands Antilles), who are Dutch citizens by law. Second, I excluded children whose parents came from the former Dutch colonies, namely Suriname, Indonesia and Netherlands New Guinea. The reason is that the immigrants or so-called "repatriates" from the former colonies had privileged access to Dutch territory and citizenship (see van Meeteren et al., 2013, pp.115-116). ${ }^{19}$ Moreover, because of the historical ties of the Netherlands with its former colonies, those who came from these countries in the 1970s-1980s were likely to be proficient in Dutch and familiar with Dutch institutions, which shaped the settlement process - for them and their children - in specific ways. As a result, my research population only includes children whose parents were born outside the former Dutch empire.

\section{Empirical strategy}

From a methodological point of view, analysing the relationship between citizenship and education raises a number of questions. First, while the literature on the second generation typically compares the outcomes of children of immigrants with those of native-born, the focus on citizenship status highlights the heterogeneity within the second generation, calling for an alternative empirical strategy. Second, analysing the patterns and effects of naturalisation from a life course perspective requires appropriate methodological tools that capture the temporal dynamics involved. Finally, an important challenge when analysing the effects of citizenship is selection bias: because naturalisation is a costly and selective process, the observed relationship between citizenship and education may be confounded by unobserved parental characteristics that affect both the propensity to naturalise and the educational performance of children. Unobserved heterogeneity at the family level therefore needs to be taken into account in order to identify a potential causal effect of citizenship on education. In what follows, I further detail the empirical strategy of this thesis with regard to these three dimensions.

\footnotetext{
${ }^{19}$ According to van der Erf et al. (2006, p.561), this is one of the reasons why Statistics Netherlands used the concept of allochtoon - instead of citizenship status - to identify individuals who do not originate from the Netherlands stricto sensu. For a critical discussion of the notions of allochtoon and autochtoon in the Dutch context, see Yanow and van der Haar (2013).
} 


\section{Exploring the heterogeneity within the second generation}

Studies analysing the educational outcomes of second-generation children have so far largely focused on comparing children of immigrants with those of natives (see Fernández-Reino, 2016; Hadjar and Scharf, 2019; Dollmann and Weißmann, 2019; van de Werfhorst and Heath, 2019, for recent examples). This approach, sometimes referred to as the "majority/minority dichotomy" (Lessard-Phillips et al., 2017, p.40), has proved analytically useful in explaining gaps in educational outcomes between children of immigrants and their peers with native-born parents. However, the majority/minority dichotomy comes with limitations.

A main limitation is that the systematic comparison of immigrant and native families tends to treat both groups as homogeneous populations (Wimmer and Schiller, 2003, p.588). On the one hand, children of native-born parents are often grouped together in the same category despite significant heterogeneity in terms of social and ethnic origin within this group (Lessard-Phillips et al., 2017, p.40). On the other hand, comparing the children of immigrants against this unspecific benchmark tends to obscure the diversity of educational trajectories within the second generation. Although the literature has paid growing attention to the heterogeneity of educational outcomes of children of immigrants (e.g., Portes and Fernández-Kelly, 2008; Louie, 2012; Crul et al., 2017), the underlying factors have received limited focus so far (see, e.g., Ichou, 2014; Engzell and Ichou, 2020).

This is particularly the case for factors relating to the migration and settlement experience of immigrant families. The context of reception is often proxied by the country of origin or nationality of immigrant parents (Luthra et al., 2018a), despite significant heterogeneity among immigrants from the same country of origin. As van Meeteren et al. (2013) note for the Dutch case, “(...) there are substantial differences between migrants from specific countries in terms of generation, migration motives, religious background and education" (p.115). Using multilevel modeling, Dronkers and Fleischmann (2010) show that the vast majority of the variance in the educational achievement of second-generation students in EU countries is at the individual level (above $80 \%$ for males and nearly $90 \%$ for female), "while the rest of the variance is mostly at the country of destination level and hardly at the country of origin level" (p.188; p.197). While this does not mean that the characteristics of the origin country are irrelevant, it does suggest that the country of origin alone does not adequately capture the diversity of migration and settlement patterns at the family level. 


\section{Chapter 1}

Parents' conditions of arrival in the destination country and access to host country citizenship may contribute to the variance in the educational outcomes of the second generation. Yet, analysing the effects of these specific characteristics of immigrant families requires restricting the analysis to children of immigrants. Otherwise, as Dronkers and Fleischmann (2010) explain, "[the] estimation [of such characteristics] would be dominated by the much larger group of natives for whom they are not applicable." (p.187).

In this thesis, I therefore focus solely on the children of immigrants to analyse the effects of citizenship on education. By doing so, I shift attention to the hitherto under-explored heterogeneity of the second generation, and contribute to a better understanding of the factors that may explain the variation in their educational outcomes, both between and within groups of different national origin. This empirical strategy also allows me to assess how naturalisation and citizenship laws contribute to such variation, highlighting "the way in which different ethnic or national groups negotiate in similar societal structures and institutional constraints that might not be relevant for the non-immigrant populations" (Lessard-Phillips et al., 2017, p.43).

\section{Uncovering temporal dynamics}

To analyse the patterns and effects of citizenship acquisition, I draw on two main sets of methods that bring temporal dynamics to the fore: event history analysis and sequence analysis. These methods help to model citizenship in a life course perspective in two ways. First, event history analysis provides adequate methodological tools to model the propensity of second-generation children to become Dutch citizens, in the context of changing institutional conditions (Chapter 3). Second, sequence analysis allows the construction of educational trajectories - as opposed to one-off school transitions or outcomes - in order to capture potential long-term and cumulative effects of citizenship on education (Chapter 4).

Previous research analysing the naturalisation propensity of immigrants typically relies on aggregated data (e.g., van Oers, 2013; Perchinig, 2010; Green, 2012), due to the absence of individual-level data to identify and date the acquisition of host country citizenship by foreign nationals. Although informative, the use of aggregated data has important limitations when analysing the effect of naturalisation reforms on individuals' decision and ability to naturalise. Indeed, aggregated data make it difficult to analyse how such reforms translate at the individual level, and to isolate potential reform effect from 
other temporal dynamics, such as changes in the composition of the immigrant population. The use of longitudinal individual-level data, combined with event history methods, provide opportunities to overcome these limitations.

Event history methods are well suited to analyse the timing and occurrence of events in the life course of individuals (Mayer and Tuma, 1990). Although rarely used in citizenship studies, such methods have proven useful in modeling immigrant naturalisation in the context of institutional conditions (Peters et al., 2016; Vink et al., 2021). This is particularly true of the Cox proportional hazard model, which allows for the inclusion of both time-invariant and time-varying covariates when estimating individuals' rate of naturalisation at a given time (Cox, 1972). In Chapter 3, I use the Cox model to analyse the patterns of citizenship acquisition among the Dutch second generation between 1995 and 2016, according to the conditions under which immigrant families were eligible for naturalisation. I contribute to previous work on immigrant naturalisation by adding specific time-by-covariates interactions to explicitly model time dependency in the Cox model (Box-Steffensmeier et al., 2003).

Next to event history methods, I use sequence analysis to model the relation between citizenship and education in a life course perspective. While existing studies tend to conceptualise and operationalise naturalisation as a one-off transition from non-citizen to citizen, I adopt a more holistic perspective by analysing whether citizenship is associated with specific education trajectories within the Dutch school system. The benefit of this approach is twofold. First, trajectories better capture the internal dynamics of students' educational pathways than single educational transitions (Boylan, 2020, p.3), especially in school systems such as the Netherlands where students can move from one track to another. Second, by focusing on educational trajectories, it is possible to model the complex relation between citizenship and education in a more comprehensive way, beyond a one-off treatment effect. Because trajectories take into account the interdependence of events within the life course (Wingens et al., 2011a, p.13), they make it possible to capture potential long-term and cumulative effects of citizenship acquisition on education.

In Chapter 4, I use sequence analysis to map the educational trajectories of the children of immigrants in the Dutch secondary school system. This set of methods, originally developed within biology to compare DNA sequences, is now widely used in the social sciences (Ritschard and Studer, 2018). In particular, I draw on recent studies that have analysed educational careers 


\section{Chapter 1}

in various education systems using optimal matching methods (Baysu and de Valk, 2012; Gomensoro and Bolzman, 2016; Boylan, 2020). However, unlike previous modelling of educational trajectories, I use a variant of optimal matching based on students' transitions within the school system (Biemann, 2011). This transition-oriented approach better captures non-standard trajectories that make use of the flexibility and back doors of the system. Such mobility patterns are important when analysing the effect of citizenship: they reflect not only how students navigate secondary education, but also how they adapt to the constraints and opportunities of the education system.

\section{Dealing with self-selection into naturalisation}

Analysing the effects of citizenship acquisition on the educational outcomes of the second generation is an important methodological challenge, due to potential endogeneity in the relationship between citizenship and education. A major source of endogeneity is common-cause confounding bias (Elwert and Winship, 2014): the parents that secure host country citizenship for their children may be better equipped to support their school achievement, already prior to becoming Dutch.

Common-cause confounding bias may arise from a dual mechanism. On the one hand, naturalisation is a selective process involving a broad range of financial and non-financial costs, which not all immigrants can afford or bear. While high application fees are a significant barrier for low-income households (Hainmueller et al., 2017), language and integration requirements have been shown to hinder the naturalisation of less educated applicants (Jensen et al., 2019; Vink et al., 2021). Moreover, in the absence of dual citizenship toleration, renouncing existing citizenship has greater emotional and practical implications for some immigrants than for others (Mazzolari, 2009; Vink et al., 2021, pp.4-5). Finally, the bureaucratic nature of the naturalisation process often requires candidates to deal with administrations, which favours immigrants who are are familiar with the host country context and able to navigate its institutions. Immigrants who naturalise are therefore not a random sample of the immigrant population: they are expected to be positively selected for income, level of education, and a number of host country-specific skills.

On the other hand, the parental resources involved in naturalisation propensity are likely to be associated with their children's educational outcomes. There is indeed well-established evidence that parents' education, occupation 
and resources are important factors for educational success, including among children of immigrants (Heath and Brinbaum, 2007; van De Werfhorst and Van Tubergen, 2007). Familiarity with the language and institutions of the host country may also facilitate the involvement of parents in school decisions (Esser, 2006; van De Werfhorst and Van Tubergen, 2007; Kristen, 2008). What is more, parents seeking host country citizenship despite its substantial cost may have higher aspirations for their children and be more oriented towards the host society regardless of whether or not they naturalise. As a result, (part of) the positive relationship observed between citizenship and education may not be due to an effect of citizenship, but rather to parental characteristics that influence both citizenship acquisition and children's educational outcomes.

It is difficult to eliminate this possible spurious association between citizenship and education, as some of the parental characteristics involved are generally unobserved or unobservable in quantitative data. This is especially true when using administrative register data, which do not provide information on individuals' knowledge, aspirations and non-certified skills. In the presence of omitted variable bias, the standard strategy of conditioning on the common causes of the two variables of interest is not appropriate (Elwert and Winship, 2014, p.36). Some studies that are only able to include a limited number of parental characteristics are hence likely to measure spurious correlations between citizenship and education (e.g., Fibbi et al., 2007; Kilpi-Jakonen, 2014).

To avoid the risk of omitted variable bias, a series of studies use recent changes in German citizenship law as a natural experiment (Felfe et al., 2020; CyganRehm, 2018; Avitabile et al., 2014; von Haaren, 2016). These studies focus on the introduction of a conditional right to German citizenship at birth in 2000, which offers a unique opportunity to measure the effect of birthright citizenship net of parents' self-selection into naturalisation. Overall, these causal approaches provide further evidence for an independent effect of citizenship on education. Yet, the empirical strategy used in these studies is not easily replicable in other national contexts, as birthright citizenship laws have remained relatively stable over the past decades (de Groot and Vonk, 2018).

Another strategy to deal with omitted variable bias is to employ an instrumental variable, i.e., a variable that is correlated with citizenship acquisition but uncorrelated with children's educational outcomes. For example, Bean et al. (2011) create an instrumental variable using the 1986 Immigration and Reform Act in the US. This reform, which introduced a legalisation program 


\section{Chapter 1}

to all immigrants residing in the country since January 1, 1982, provides an exogenous variation in the legal status of immigrants, which does not depend on the ability of parents to change their legal status. This strategy confirms the authors' result of a net positive impact of mothers' naturalisation on their children's years of schooling. However, with the exception of a few specific citizenship contexts (e.g., Hainmueller et al., 2017), it is difficult to find suitable instrumental variables for citizenship acquisition.

Unfortunately, the Dutch context does not provide the possibility of using natural experiments or instrumental variables to measure a causal effect of citizenship on education during the observation period. For this reason, I developed an alternative empirical strategy in Chapter 5, based on the variation in age at naturalisation between siblings. This strategy is based on the idea that siblings share many of the parental characteristics that are expected to confound the relationship between citizenship and education. For instance, parents' context of migration, level of education and orientation towards the host country are constant or relatively stable over time, making siblings comparable in this respect. This strategy has already been used in the literature to account for unobserved heterogeneity at the family level (Nielsen and Rangvid, 2012; Böhlmark, 2008; Sigle-Rushton et al., 2014), but, to my knowledge, it has never been applied to assess the strength of parental self-selection into naturalisation. Unlike previous approaches, I use the between-within model to explicitly model unobserved heterogeneity at the family level (Bell and Jones, 2015). This empirical strategy is complemented by a novel bounding technique developed by Oster (2019), which takes into account both timeconstant and time-varying unobserved characteristics.

\section{Outline of the dissertation}

This thesis is structured along four substantive chapters: a conceptual chapter (Chapter 2) and three empirical chapters (Chapters 3-5). The empirical chapters are all independent papers that have been published in or submitted to peer-reviewed journals (see the footnotes at the beginning of each empirical chapter). Only minor changes have been made to the empirical chapters for stylistic purposes. For ease of reading, all references and the supplementary materials have been placed at the end of the thesis.

The three empirical chapters are preceded by Chapter 2, which presents the theoretical underpinnings of this dissertation. In this chapter, I bring together 
different bodies of literature relevant for the analysis of citizenship and education, which have so far mostly developed in isolation. Drawing on the life course perspective, I show how the literature on the second generation and citizenship studies can be connected to enhance our understanding of the relationship between citizenship and education. I identify the need for a more comprehensive theoretical framework, which takes into account the contextual and family dynamics involved in naturalisation and integration processes. This chapter lays the foundation for such a framework, and formulates well-grounded hypotheses for the empirical analysis. These hypotheses are then tested in the subsequent chapters using Dutch administrative register data from Statistics Netherlands.

In Chapter 3, I analyse the propensity to acquire Dutch citizenship among the children of immigrants in the Netherlands, with particular attention to how immigrant families adapt to changing institutional constraints. The descriptive results indicate that the vast majority of children who become Dutch citizens do so by co-naturalising with (one of) their parents before the age of majority. The dependence of children on their parents for the acquisition of Dutch citizenship is further confirmed in the analysis by the evidence of an intergenerational impact of naturalisation reforms: children have less or delayed access to Dutch citizenship when their parents become eligible under stricter requirements. The analyses also highlight changes in naturalisation patterns at the family level, which suggests that naturalisation reforms not only affect whether and when the children of immigrants acquire Dutch citizenship, but also with whom.

Chapter 3 indicates that immigrant families faced increasing barriers to naturalisation since the end of the 1990s. Chapters 4 and 5 then assess the consequences of these delayed or abandoned naturalisation projects for their children's educational opportunities. Chapter 4 takes an exploratory approach to analysing the relationship between citizenship and education, by investigating whether the acquisition of Dutch citizenship is associated with specific pathways in secondary education. I use sequence analysis to map the educational trajectories of a full cohort of second-generation students, providing an overview of how they negotiate their way through a complex stratified system. Results show that the acquisition of Dutch citizenship at birth or before entry into secondary education decreases the likelihood of following a dropout trajectory, while it increases students' chances of moving upward after their initial track placement. This chapter thus provides suggestive evidence that naturalised families are better equipped to navigate the Dutch 


\section{Chapter 1}

school system and take advantage of its flexibility, compared to those who have not (yet) become Dutch.

Chapter 5 complements Chapter 4 with a stricter approach to causal inference: while Chapter 4 measures associations between citizenship and education, Chapter 5 aims to assess the extent to which such associations are confounded by unobserved heterogeneity at the family level. Using a family fixed-effects approach, I show that second-generation students who acquired Dutch citizenship in early childhood have a substantial advantage over their peers of foreign nationality in the standardised test they take at the end of primary school. Importantly, I do not find evidence that these results are significantly biased by parents' self-selection into naturalisation. Empirical findings further highlight that the effect of citizenship is not uniform over time and across individuals. The advantage of naturalised students indeed decreases when they naturalise after the age of 6 , and becomes negligible when Dutch citizenship is acquired at the end of primary school. Furthermore, the positive effects of Dutch citizenship are concentrated among children whose parents are at a disadvantage in the labour market and housing market, which sheds light on hitherto under-explored effect heterogeneity.

This dissertation ends with the conclusions (Chapter 6), which summarise the main research findings and discuss the main conceptual, empirical and methodological contributions of the dissertation. In this chapter, I also discuss the limitations of the thesis and provide suggestions for future research on the citizenship of children of immigrants. 


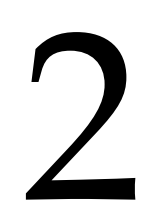

\section{Citizenship and educational attainment: a life course perspective}




\section{Chapter 2}

\section{Introduction}

This chapter reviews and discusses the research conducted to date on the relationship between citizenship and education, with a particular focus on the theoretical channels through which citizenship status is likely to affect educational attainment. While a range of studies have identified positive effects of host country citizenship on various educational outcomes, the underlying mechanisms remain unclear, or are not embedded in a comprehensive theoretical framework. Why would naturalised children be more likely to perform well at school and follow the most prestigious tracks, compared to their fellow foreign citizens? Do immigrant parents behave differently depending on whether they or their children are citizens of their country of residence? And do children of immigrants care about host country citizenship, although they may not reap its benefits until the age of majority? These questions are at the intersection of different bodies of literature, which hitherto have largely remained unconnected.

On the one hand, there are important areas of research on children of immigrant descent and immigrant families (e.g., Suárez-Orozco and Suárez-Orozco, 2002; Alba and Holdaway, 2013; Menjívar et al., 2016). Such studies have shown that second generation life trajectories unfold in specific ways due to their parents' migration experience; however, little attention has been devoted to how these trajectories are shaped by law and legal institutions. In particular, few studies have examined whether immigrant offspring's access to host country citizenship matters for their prospects in life. On the other hand, citizenship studies bring the naturalisation process to the fore and highlight the relevance of host country citizenship for immigrants (e.g., Peters, 2018; Vink et al., 2013; Hainmueller et al., 2017). However, the bulk of research addresses naturalisation from an individual- and adult-centred perspective, overshadowing the role of family and children in the naturalisation process.

In the following sections, I explain how I bring together these different bodies of literature, drawing on the sociological life course approach (Elder, 1974). A life course approach to naturalisation is particularly useful for the purpose of this research, as it conceptualises individual trajectories as embedded in social structures and relationships. As I will show, such a perspective is key to understanding how legal contexts shape the realities not only of immigrants, but also of their children and families at large.

After presenting the life course perspective, I elaborate on some of its key 
principles to analyse how citizenship and migration laws shape immigrants' access to resources and mobility. Why do some immigrants seek citizenship in their country of residence, while others do not? Recent developments in the field of citizenship studies indicate that to fully grasp the decision-making process at play, naturalisation decision needs to be conceptualised within a broader family and institutional context.

I then proceed to examine different mechanisms through which citizenship may affect educational attainment. Based on the literature on immigrant youth's life experiences, I first review some direct effects highlighting the importance of host country citizenship to the sense of security, well-being and aspirations of the second generation. Second, I discuss potential indirect effects of citizenship, building upon citizenship studies and the sociology of education. To the best of my knowledge, no research has considered that immigrants' naturalisation may have spillover effects on their children's opportunities at school, despite growing evidence that naturalisation fosters the socioeconomic integration of immigrants. I therefore combine insights from various areas of research to offer a more comprehensive conceptualisation of the relationship between citizenship and educational attainment, including potential intergenerational dynamics from parents to children.

Finally, I conceptualise when and for whom citizenship matters. While previous work mainly considers whether host country citizenship is relevant for second-generation children, I argue that the effect of citizenship may vary over time and across the second generation, depending on the other resources available to children and their families.

\section{The sociological life course approach}

The sociological life course approach emerged in the 1960s following a landmark study by Elder (1974), who used a longitudinal and intergenerational perspective to analyse a cohort of Californian children who grew up during the Great Depression. One of the main concerns at that time was to better grasp "the pattern and content of life in changing societies" (Elder, 1994, p.10), with a theoretical perspective that would allow for the joint consideration of continuity and change in the life course.

The life course is conceived as a sequence of age-related events, social positions and roles through which individuals participate in society (Mayer, 2004, p.163). An important premise of the life course approach is that the life course 


\section{Chapter 2}

of individuals interacts with the historical and societal environment in which they live: life courses are embedded in societal structures and institutions, which are in turn affected by the way people construct their individual lives. Life courses are part and product of interdependent processes that develop at various levels: micro (individual), meso (institutional) and macro (historical) (Wingens et al., 2011a, p.10). The life course approach investigates those multilevel processes from a dynamic perspective, analysing in particular how the timing, pacing and sequencing of individual life events are associated with changes at the meso and macro levels (ibid., p.6).

Since Elder's (1974) seminal work, the life course has developed over several decades into an "emerging paradigm" (Elder, 1994, p.4) and has been applied to a wide range of research topics in the social sciences (see Mayer, 2004). Yet, as noted by Wingens et al. (2011a), migration research has long taken limited advantage of the analytical potential of the life course approach. This is surprising because this theoretical perspective seems particularly relevant to analyse migration and integration processes. Migration is arguably a disruptive experience in individuals' trajectories, which may affect their ability to plan their life and pursue their goals. This is particularly true for international migrants, who need to find their way in an often unfamiliar context, marked by the laws and institutions of the destination country.

In the wake of the collective work by Wingens et al. (2011b), recent developments in migration studies have shown the contribution of the life course approach to understanding the evolution of immigrants' trajectories in various life domains within and across borders (e.g., Kraus, 2019; Barbiano di Belgiojoso and Ortensi, 2019; Kleinepier et al., 2015). Although more moderate, attention has also been paid to the life courses of the children of immigrants, highlighting how their trajectories are shaped both by the destination context and by the migration experience of their family (e.g., Kleinepier and de Valk, 2016; Zorlu and Mulder, 2011). In this dissertation, I follow up on these studies and build on the life course approach to analyse the citizenship of children of immigrants.

Life course research has developed a number of guiding principles and concepts, some of which are particularly relevant for the purpose of this thesis (see Wingens et al., 2011a, pp.11-18 for a full overview of the life course approach). In what follows, I review three conceptual signposts of the life course approach and highlight their contribution to the conceptualisation of citizenship for the second generation: linked lives, trajectories, and the interplay between context and agency. 


\section{Linked lives}

One of the key principles of life course research is that of linked lives, which refers to the interdependence of individuals' life courses. Human lives are typically embedded in networks of social relationships that lie at the intersection of various social worlds, ranging from family and friends to work and wider communities (Elder, 1994, p.6). While individuals depend on such relationships, they also provide resources and opportunities. Elder (1994) places particular emphasis on the intergenerational interdependence within the family: children's trajectories depend heavily on the life decisions of their parents, while parents' life courses can be greatly influenced by those of their children. Such a perspective is crucial to contextualise the acquisition of host country citizenship by children of immigrants. Indeed, in most countries, the children of immigrants acquire citizenship by descent and legally depend on their parents to acquire the citizenship of their country of birth and residence while they are minors (Honohan and Rougier, 2018).

Children's access to host country citizenship does not only depend on parents' ability and desire to naturalise, but may also be conditioned by their migration trajectories. When countries provide conditional ius soli provisions for the second generation, these are often accompanied by conditions relating to the length of residence of parents or children (Honohan and Rougier, 2018). As a result, parents' migration decisions - for themselves or their family - may have long-term spillover effects on their children's ability to acquire the citizenship of their country of birth (Colombo et al., 2011, p.337). The interdependence of life courses at the family level may also be reflected in parents' naturalisation decisions, when host country citizenship is acquired for the sake of their children or the family as a whole (Street, 2014). The notion of linked lives therefore calls for a conceptualisation of children's citizenship acquisition at the family level, which I will elaborate in the next section of this chapter and in the empirical Chapter 3 of this dissertation.

The notion of linked lives is also relevant when analysing the potential effects of host country citizenship on the life opportunities of second-generation youth. The acquisition of host country citizenship by one family member may shape the trajectories of the others in specific ways, even if they themselves remain foreign citizens (Cook, 2020). On the one hand, children's access to host country citizenship may change the opportunity structure facing their family and affect parents' migration and settlement decisions. On the other hand, parents' own naturalisation may improve their socioeconomic position and their access to relevant information and resources, which, in turn, would 


\section{Chapter 2}

positively affect the educational trajectories of their children. As a consequence, while citizenship has undoubtedly a direct impact on the life course of its holder, a life course approach suggests possible indirect or "feedback" effects (Elder, 1994, p.12) due to interaction processes between children and parents. In the third section of this chapter, I develop in more detail these direct and indirect theoretical channels, arguing that such a distinction is a first analytical step towards a more comprehensive conceptualisation of citizenship effects.

\section{From one-off events to trajectories}

Transitions and trajectories are crucial concepts for translating the life course theoretical perspective into empirical research (Wingens et al., 2011a). While transitions refer to "changes in state that are more or less abrupt" (Elder, 1985), trajectories relate to longer sequences of life events and transitions, which may occur both within and between life domains. An important point is that life events and transitions should not be analysed in isolation: changes in state may have long-term spillover and cumulative effects on subsequent transitions, creating path-dependence in the life course (Wingens et al., 2011a, p.13). The life course approach thus invites to go beyond the investigation of one-off events and to take into account their temporal dynamics through the analysis of trajectories.

This longitudinal approach to life events is particularly relevant when conceptualising naturalisation and its potential effects on children's life opportunities. Although foreign citizens do not officially become citizens until the naturalisation procedure is completed, "citizenship acquisition is not an abrupt legal status transition, but rather a process that requires careful planning and preparation leading up to naturalisation." (Peters et al., 2017, p.6). Naturalisation candidates may need several months to collect the required documents and obtain the necessary certificates, and often face substantial administrative delays until they are informed of the decision. Those who are not yet eligible but will be able to apply in the future may also plan their lives differently from those who are unlikely or unwilling to meet the naturalisation requirements (e.g., Sredanovic, 2020; Della Puppa and Sredanovic, 2017). The naturalisation process may therefore start long before immigrants acquire host country citizenship, influencing their present behaviours and their expectations for the future. This draws attention to the potential anticipated effects of naturalisation (Peters et al., 2017), which I discuss in more detail in the third section of this Chapter. 
Understanding naturalisation as a process also invites us to conceptualise its potential effects in a dynamic perspective. While previous research on the second generation has measured the effects of host country citizenship on isolated educational outcomes or transitions (e.g., Felfe et al., 2020; KilpiJakonen, 2014; Fibbi et al., 2007), there are reasons to think that the acquisition of host country citizenship has long-term and cumulative effects on children's life course. Becoming citizen of the host country comes with a number of rights and benefits, which affect the opportunities and constraints of immigrant families and may increases their ability to plan and construct their lives. In that sense, the acquisition of host country citizenship by children is not expected to have a one-off effect, nor to uniformly affect subsequent events in children's lives. On the contrary, I hypothesise that naturalisation more generally influences the way children and their families navigate host country institutions and leaves a lasting imprint on their life courses. In the empirical Chapter 4, I therefore move away from static educational outcomes or single transitions to focus on the full education pathways of the children of immigrants in the Dutch secondary school system. This enables me to assess the effects of citizenship more comprehensively, by comparing whether host country citizens tend to follow specific trajectories in education compared to their non-citizen counterparts.

Finally, a longitudinal perspective on citizenship suggests that its effects may vary over children's life course. Children of immigrants may become citizens from birth or later, in childhood, adolescence or even adulthood. These periods correspond to distinct phases of development, during which citizenship may have a wide range of meanings and effects. In the last section of this chapter, I conceptualise further these potential timing effects of citizenship acquisition for the children of immigrants, before assessing them empirically in Chapter 5.

\section{The interplay between context and agency}

\section{Historical time and place}

The life course perspective highlights the need to embed individuals' decisions and actions in the historical times and places they experience (Wingens et al., 2011a). This is particularly relevant for immigrants, who are not only subject to a new national context but may also (still) be dependent on the institutions and norms of their country of origin (de Hart et al., 2013). 


\section{Chapter 2}

While research has long focused on the process of settlement of immigrants from the perspective of the host society alone, growing attention has been devoted to the characteristics of the origin country and its combinations with those of the destination country to explain the various integration outcomes of immigrants and their offspring (e.g., van Tubergen et al., 2004; Levels and Dronkers, 2008; Luthra et al., 2018a).

The importance of macro-level contextual factors should not be overlooked when analysing the citizenship of the second generation. First, the citizenship status of children of immigrants is jointly determined by the birthright citizenship laws of their country of birth and that of their parents (Honohan and Rougier, 2018; de Groot and Vonk, 2018). Second, the conditions under which immigrant parents and their children can acquire host country citizenship are defined by the naturalisation laws of the destination country, and, to some extent, by the attitude of the origin country towards dual nationality. Moreover, citizenship laws establish the rights and benefits of host country citizenship, which confronts immigrant families with a specific set of opportunities and constraints (Vink et al., 2013). This opportunity structure should be analysed over time, depending on the evolution of the legal context (Vink and de Groot, 2010). I give particular emphasis to this point in the next section and in the empirical Chapter 3, where I analyse the patterns of acquisition of Dutch citizenship among the children of immigrants in relation to two important legislative changes in the Netherlands.

Beyond the legal context, other macro-level factors are relevant for the purpose of this research. I analyse the potential effects of citizenship on the educational outcomes of the second generation, which are shaped by the characteristics of the school system. A significant number of comparative studies have highlighted how the institutional structure of the education system affects the level of social inequalities at school (see, e.g., Pfeffer, 2008; van de Werfhorst and Mijs, 2010; Bol et al., 2014; van de Werfhorst, 2019). In particular, there is consistent evidence that the timing and degree of stratification of the education system influences the relationship between parents' social and migration background and their children's achievement and attainment (Blossfeld et al., 2016; van de Werfhorst, 2019). School systems characterised by an early selection of students into different tracks, such as in the Netherlands, tend to magnify educational inequalities. By contrast, comprehensive unstratified systems are associated with a smaller socioeconomic gradient in educational outcomes (ibid.).

Although I do not adopt a cross-country comparison in this dissertation, the 
organisation of the education system needs to be taken into account when analysing the effect of citizenship. As I will detail in the empirical Chapter 4 , the Dutch education system is complex and requires relatively high levels of information and knowledge. Because parents' resources matter especially in this context, the family's access to host country citizenship may be more relevant in the Dutch system than in non-stratified or late tracking systems. I therefore use the life course approach to derive context-specific hypotheses for the effect of citizenship, based on the institutional arrangements of the school system.

\section{Agency in context}

While trajectories are embedded in the societal and institutional context in which individuals live, their life course is not merely the product of this context. Individuals construct their life courses as "self-monitored actors" (Wingens et al., 2011a, p.9) and interact with their environment through active and purposeful participation. The ability to master one's life, referred to as agency, is another key principle of the life course approach. It reflects the fact that individuals are planful and pursue their own goals within the constraints imposed by laws, institutions and social norms. This draws attention to immigrants' strategies and tactics in the face of legal constraints. Although international immigrants have fewer resources than non-immigrants to cope with such constraints (Wingens et al., 2011a), "even vulnerable groups of transnational families are within the law, as they learn about and learn to use various local, national and international laws" (de Hart et al., 2013, p.997).

In other words, the agency of immigrants should not be denied when assessing the effect of the legal context. Similarly, one should not overlook the resources that may enhance the agency of immigrant families in the host society, such as their access to host country citizenship. In the third section of this chapter, I detail how citizenship may increase the level of agency of immigrant families and their capacities to navigate complex institutions such as the Dutch school system.

In conclusion, a life course approach offers valuable analytical tools to analyse the effects of citizenship on the educational outcomes of children of immigrants. While this dissertation does not aim to offer a fully-fleshed theoretical framework, the principles described above serve as a conceptual glue to link its main theoretical contributions: modelling citizenship acquisition at the family level, in the context of changing institutional conditions (Chapter 


\section{Chapter 2}

3); focusing on long-term, multidimensional indicators of educational attainment, as opposed to isolated academic outcomes (Chapter 4); and conceptualising the timing of citizenship acquisition for the children of immigrants (Chapter 5).

In the next sections of this chapter, I draw on the life course approach to critically address previous conceptualisations of the drivers and effects of citizenship acquisition by immigrant families.

\section{Law in the lives of immigrant families}

In ius sanguinis citizenship regimes, the access of minor children to host country citizenship largely depends on their parents' initiative, whether through parents' naturalisation or through the administrative procedures parents carry on the behalf of their children. ${ }^{1}$ This suggests that the decision process leading to children's citizenship acquisition mostly takes place at the family level, with parents playing a leading role. However, few studies have analysed naturalisation from this perspective, obscuring either migrant families' citizenship status or the social dimension of the naturalisation process. In this section, I draw on two bodies of literature that provide complementary insights: the literature on migrant families, on the one hand, and citizenship studies, on the other.

\section{Immigrant families in the face of legal constraints}

The importance of the family has not always been recognised in migration studies. As observed by Kofman (2004), for various reasons, migration scholars have long used the individual as the primary unit of analysis and focused on males at the expense of migrant females and children (Zlotnik, 1995; Kofman et al., 2011). In response to this gap, a growing body of research has focused on migrant families since the late 1980s, analysing how family dynamics change in the process of migration and transnationalism (for an overview, see Kofman et al., 2011; Haagsman, 2015, pp.24-32). An important contribution of this field of research is to show that immigrants should not be considered as isolated individuals: they are embedded in dense networks of signif-

\footnotetext{
${ }^{1}$ In countries with conditional ius soli provisions, parents can claim citizenship for their children before they reach the age of majority provided that they fulfil a number of requirements most often relating to parents' length of residence (Honohan and Rougier, 2018, p.350).
} 
icant relationships - including family relationships - that affect their opportunities and constraints both in the countries of origin and destination.

Studies on migrant and transnational families have looked in depth at how family ties are preserved or transformed across national borders. Yet, although the role of law in such processes is often acknowledged, few studies analyse how migrant families navigate legal institutions and cope with legal constraints (exceptions include de Hart et al., 2013; Mazzucato and Schans, 2011, p.709). As a result, knowledge about how migration and citizenship policies affect the lives of immigrants families in practice is still relatively limited. There is valuable evidence that immigration and family reunification policies reshape family dynamics and impose important structural constraints on their agency and mobility (Menjívar, 2012; Poeze and Mazzucato, 2016). Research has highlighted the effects of such constraints on parenting, care-giving and family dynamics in general (e.g., Haagsman, 2015; Serra Mingot, 2018). Yet, less is known about the specific effects of citizenship laws, which define access to lawful residence and citizenship.

This lack of attention is puzzling, as legal status has a significant impact on the ability of family members to move freely across borders and to access education, employment and social protection in their country of residence. One reason for this gap is that most research has focused on immigrants with precarious or undocumented legal statuses, to the detriment of those undergoing legalisation (Cook, 2020, p.13). Furthermore, when citizenship status is considered, data do not always allow to differentiate legal residents from host country citizens (e.g., Díaz McConnell and Yellow Horse, 2020). This is problematic because legal residents and citizens have different access to rights and resources (Menjivar, 2012, 2006). Citizenship is the only status guaranteeing full formal membership and legal protection in one's country of residence. By contrast, non-citizen residents have to deal with tedious administrative procedures (e.g., Mazzucato, 2008) and face various restrictions on geographical mobility and access to employment (Della Puppa and Sredanovic, 2017).

The limited attention devoted to citizenship status has obscured important dynamics at the family level. According to Bonjour and de Hart (2021), previous studies on migrant families have overlooked the fact that "many families affected by migration policies consist not only of migrants, but also of citizens" (p.1). This is particularly true in countries recognising unconditional ius soli, such as the United Sates: those who are native-born automatically become citizens, regardless of their parents' legal status (Honohan and Rougier, 


\section{Chapter 2}

2018). However, research also highlights the growing complexity and restrictiveness of immigration laws, which make it increasingly difficult for families to share the same citizenship (Bonjour and de Hart, 2021; Cook, 2020).

Whether variation of legal statuses within the family is chosen or suffered (Cook, 2020), it can affect the opportunity structure of family members and shape their trajectories here and there. To better understand the specific relevance of citizenship for immigrants and their children, it is necessary to link research on migrant families with another area of research in the field of citizenship studies.

\section{Immigrant families as legal actors}

A large body of research in the field of citizenship studies has analysed immigrant naturalisation and the relevance of citizenship for immigrants' adaptation in the host society (see Peters and Vink, 2016). Traditionally, naturalisation has been interpreted as a moment that completes the settlement process of immigrants, and shows their full integration into the host society. This conception derives from the perspective of the modern nation-state (Wimmer and Glick-Schiller, 2002) that views citizenship as a status binding its holder to a particular state (Finotelli et al., 2017; Ip et al., 1997). The decision to change nationality is therefore understood as a deliberate choice through which immigrants establish allegiance to the state of which they become citizens.

In addition to this nation-state centred approach, traditional conceptions of naturalisation tend to be based on methodological individualism. This can be traced back to the seminal work of Yang (1994), who conceptualises naturalisation within the framework of the rational choice model. Yang models naturalisation as the result of an individual decision-making process, in which immigrants weight the costs and benefits of host country citizenship. This model is based on the idea that immigrants value the rights and privileges of citizenship differently depending on their background and preferences. Similarly, they are not equally able to manage the various costs and obligations attached to naturalisation. This approach has long been the dominant theoretical framework on citizenship acquisition, not only because the economic theory has been influential in this field of research (Street, 2014). This approach has also affinities with the epistemology of law and the way legal science conceives of the individual and human actions (see Frauenfelder, 2007, p.55). 
Following this perspective, scholars explain immigrants' propensity to naturalise by the socioeconomic factors that either increase the returns to naturalisation or make its costs more bearable. Previous research has shed light on important individual factors positively associated with naturalisation, such as income, level of education, and length of residence (see, e.g., Peters et al., 2016; Hainmueller et al., 2018; Street, 2014, p.270). Specific attention has also been paid to contextual factors, such as the acceptance of dual citizenship and the political or economic development of the country of origin (e.g., Dronkers and Vink, 2012; Chiswick and Miller, 2009), showing that migration background conditions the relative value and attractiveness of host country citizenship.

Such studies have been fruitful and undoubtedly contributed to an enhanced understanding of naturalisation propensity, both at the micro and macro level. However, they have also been criticised for their methodological individualism. This becomes apparent in the literature on immigrant naturalisation. As Street (2014) argues, "[the] critique (...) is not that scholars have settled on the wrong list of costs and benefits but rather that most have assumed that only individual interests figure in this decison" (p.271). For example, even when marital status or the presence of children are considered (e.g., Chiswick and Miller, 2009; Vink et al., 2013; Peters et al., 2016), the decision to naturalise tends to be conceptualised at the individual-level only. This is problematic from a life course perspective, since individuals are typically embedded in a web of social relationships that affect the way they experience their citizenship status (Bonjour and de Hart, 2021). The interdependence of life courses is particularly marked within the family, where children are legally dependent on their parents. Immigrants' decision to naturalise should therefore be conceptualised within a broader framework that takes into account potential family dynamics.

Towards a model of "embedded citizenship choice" (Soehl et al., 2018)

While migration studies have long since moved beyond the rational choice model (Nauck and Settles, 2001), this shift is still in its infancy in citizenship studies. Street (2014) has made an important contribution in that respect, highlighting the key role of the family in shaping the decision-making process leading to naturalisation. His study of the reform of German citizenship law in 2000 challenges traditional explanations of naturalisation propensity: Why was this reform followed by a drop in the number of naturalisations, even 


\section{Chapter 2}

though it simplified access to German citizenship? According to Street (2014), the partial introduction of ius soli for children born in the country removed an essential reason for the naturalisation of immigrant parents, namely to obtain German citizenship for the sake of their children.

The evidence of an intergenerational motive to naturalise shifts the focus to how family-level dynamics factor into the decision-making process. While it is now well established that the presence of children greatly influences their parents' migration decisions (for a critical overview, see Bushin, 2009), the role of children in parents' propensity to naturalise has remained largely unexplored. Yet, there is growing qualitative evidence that immigrant parents may seek to naturalise for the sake of their children, as to ensure them the best opportunities in the host society (Sredanovic, 2020; Della Puppa and Sredanovic, 2017; de Hart, 2010; Stewart and Mulvey, 2014). For instance, Della Puppa and Sredanovic (2017) note in their study of Ukrainian and Moroccan immigrants living in Italy that many parents acquired or wished to acquire Italian citizenship so that their children would have a chance to obtain public jobs - while few personally aspired to them (p.371).

As Street (2014) notes, naturalisation may also be a complementary good within the family, conferring higher utility if shared by all family members. This is particularly important when it comes to international mobility, as family members may only be able to reap the benefits of the host country passport if all family members possess a passport. This idea of complementarity is supported by a number of studies showing that the probability to naturalise is higher when other family members have naturalised in the same year or before (Street, 2013; Soehl et al., 2018; Helgertz and Bevelander, 2017). These family patterns lead Soehl et al. (2018) to call for an embedded model of citizenship choice, in which the social and family dynamics of the naturalisation process are fully integrated.

In the same way that "decisions to migrate are seldom the product of individual decision making, but are the result of collective efforts" (Nauck and Settles, 2001, p.462), decisions to naturalise are likely to be influenced by resources at the family level. Naturalisation is indeed a costly procedure, which can involve not only substantial fees but also significant administrative hurdles. As showed by Street (2013) in the Austrian case, family members support and assist each other in meeting naturalisation requirements. Moreover, the overall costs of naturalisation can be lower when family members initiate the procedure at the same time, especially in countries where applications 
with a spouse are financially advantageous. ${ }^{2}$

While naturalisation may be a collective endeavour, it may also reflect different interests within the family. As Cook (2020) observes in the United-States, "Legalisation decisions entail a process of negotiation, in the context of family relationships in which members often have widely different goals, desires, and motivations" (p.14). Families are not monolithic units: family members likely face different costs and returns to naturalisation and may even disagree over the value of host country citizenship (Frauenfelder, 2007). This is particularly the case for children and parents, who may develop different relationships with the countries of origin and destination. On the one hand, the acquisition of full and permanent membership may be particularly valuable for second-generation children who "grew up as de facto, but not de jure citizens" (Soehl et al., 2018, p.4). On the other hand, naturalisation may yield limited returns for parents who have maintained strong ties with their country of origin, especially when they have already secured permanent resident status.

In the empirical Chapter 3 of this dissertation, I analyse how these dynamics translate in different naturalisation patterns at the family level. To what extent do second-generation children have access to the citizenship of their country of birth and residence? Do children naturalise at the same time as (both of) their parents, or do they acquire citizenship independently from the age of majority? To answer these questions, a family approach to naturalisation is crucial; however, as the following paragraphs explain, it also needs to be embedded within the family's broader environment.

\section{The multiple uses of host country citizenship in changing contexts}

An important principle of the life course approach is that of historical time and place: individual lives are not evolving in a vacuum but are embedded in their respective "historical world" (Elder, 1994, p.5). Immigrants' naturalisation propensity should therefore be analysed within a given societal and institutional context, which is notably marked by the laws of the countries of origin and destination. Some studies have specifically focused on citizenship policies (Jensen et al., 2019; Dronkers and Vink, 2012; Mazzolari, 2009),

\footnotetext{
${ }^{2}$ As an example for the Netherlands, the administrative fees for naturalising together with a partner are far cheaper: in 2021 couples need to pay $€ 1,181$ (i.e., $€ 590$ each) to submit a joint application, against $€ 925$ to apply on their own.
} 


\section{Chapter 2}

analysing how "the legal framework set by the citizenship laws in the countries of origin and destination provides the opportunity structure with regard to access to citizenship." (Vink et al., 2013, p.3). Immigrants are generally found to have a lower naturalisation propensity when they face stricter naturalisation requirements, either because citizenship reforms restrict citizenship eligibility or increase candidates' obligations (Goodman, 2010; Jensen et al., 2019). Conversely, there is some evidence that naturalisation rates increase under favourable legal conditions, such as when dual citizenship is legalised in the origin country (Mazzolari, 2009).

In a context where naturalisation requirements have become increasingly strict (Vink and de Groot, 2010; Goodman, 2010), a growing attention has been devoted to the exclusionary effects of citizenship laws, shifting research focus from naturalisation propensity to naturalisation capacity (Jensen et al., 2019). Yet, these new barriers to citizenship acquisition should not overshadow immigrants' agency. As de Hart et al. (2013) argue, " there is no dichotomy but a continuum of opportunities and constraints" (p.997), even with restrictive migration and citizenship laws. First, the legal framework interacts with other contextual factors; the social and political context of reception, for instance, may also aid or impede naturalisation of immigrants (Bloemraad, 2002; van Hook et al., 2006). Second, immigrants' capacity to master their own life course should not be underestimated, as individuals interact with their environment and shape it in turn (de Hart et al., 2013; Elder, 1994).

In recent years, a growing body of literature has shed light on the tactics and strategies immigrants adopt in the face of changing circumstances, whether related to the economic, political or legal context (Della Puppa and Sredanovic, 2017; Finotelli et al., 2017; Sredanovic, 2020). This was encouraged by dissatisfaction with the predominant nation-state approach in citizenship studies (Finotelli et al., 2017), which tends to obscure the diversity of reasons for which immigrants naturalise. Traditional conceptions indeed assume that immigrants mainly naturalise for political and economic reasons, with the idea of settling permanently in the host society (Hoon et al., 2020; van Hook et al., 2006). By contrast, a transnational perspective sheds light on the multiple ties and interactions that link immigrants across national borders (Vertovec, 1999). For example, immigrants may seek the host country passport to carry out new migratory projects, maintain transnational ties or to pragmatically stabilise residence in times of crisis (Finotelli et al., 2017; Hoon et al., 2020; Della Puppa and Sredanovic, 2017; de Hart, 2010).

This recent body of literature highlights that citizenship may be acquired on a 
wide variety of grounds, and used in various ways: while some seek citizenship for affective and symbolic reasons, others use it for practical or instrumental purposes - or a combination thereof (Finotelli et al., 2017; Della Puppa and Sredanovic, 2017). Focus on practices redirects attention to how laws affect the decision-making process leading to naturalisation, and may prompt families to pursue different naturalisation tactics. In Chapter 3, I analyse how immigrant families cope with the tightening of naturalisation requirements in the Netherlands and how this translates into different family naturalisation patterns. In line with the concept of "embedded citizenship choice" advanced by Soehl et al. (2018), I contend that it is crucial to take into account the fundamentally social and contextual dimension of naturalisation when analysing citizenship acquisition among children of immigrants.

\section{Legal status and educational outcomes of the second generation}

The relative lack of attention to whether and how children of immigrants obtain host country citizenship is matched by limited knowledge of the potential effects of their citizenship status on their life chances. Does naturalisation affect the opportunities of second-generation children in host societies and, if so, how? In this section, I build upon different bodies of literature to examine the potential effects of citizenship on a key determinant of children's life chances: their education. Education is not only important in itself; it is also a crucial means of social advancement in post-industrial societies, which arguably matters especially for immigrant families (Levels and Dronkers, 2008, p.1405).

I start with the literature on the educational outcomes of the second generation, which has significantly enhanced our understanding of how children of immigrants fare in host societies. While the citizenship status of children is virtually absent from this literature, it provides important insights into the mechanisms by which children of immigrants can succeed in education. I then draw on a disparate body of research that has approached the citizenship of children of immigrants from different angles. Although rarely linked, these lines of research offer converging evidence that host country citizenship positively affects the life opportunities of second-generation children, including their education. I will show that citizenship may affect educational outcomes either directly - by increasing children's well-being, aspirations and 
motivation - or indirectly - by improving parents' position in the host country.

\section{The educational outcomes of the second generation}

The second generation now represents a growing and sizeable population in Western societies (OECD, 2012). This population has come of age since the early 1990s in the US (Zhou and Gonzales, 2019) and a few decades later in Europe (Heath et al., 2008), leading to extensive research on how these children find their way into host societies. Their education has received particular attention, as a key indicator of the obstacles and opportunities children of immigrants face growing up.

Scholarship on the educational outcomes of the second generation has grown into a significant area of research, at the intersection of migration studies and the sociology of education (e.g., Crul et al., 2012; Alba and Holdaway, 2013). This area of research has placed a major emphasis on comparing children of immigrants with those of native-born parents, following the idea that this is a good proxy for the level of integration of the second generation (LessardPhillips et al., 2017, p.40). This perspective has highlighted so-called "ethnic inequalities" in educational outcomes: children of immigrants have been shown to be generally disadvantaged relative to their native counterparts, albeit to varying degrees depending on the country of study and children's origin group (Heath et al., 2008; Dustmann et al., 2012). Explaining such inequalities has been high on the research agenda, as unexplained gaps between children of immigrants and that of natives would run counter to meritocratic principles (van De Werfhorst and Van Tubergen, 2007).

A first and important series of studies has focused on disentangling the effect of migrant or ethnic background from that of social class. Indeed, a significant share of the educational disadvantages experienced by children of immigrants can be explained by their parents' social class and level of education (Heath et al., 2008; Levels and Dronkers, 2008; Dustmann et al., 2012). This is unsurprising, as parents' social background has long been identified as a key factor of educational inequalities in the sociology of education (Bourdieu and Passeron, 1990; Willis, 1981), and that immigrant parents tend to come from less advantaged social backgrounds than the native-born. ${ }^{3}$ Fur-

\footnotetext{
${ }^{3}$ This is especially true in Europe where research has mainly focused on the children of former guest-workers who migrated to Europe in the 1960s (see Heath et al., 2008, p.213). This second-generation cohort has transitioned to adulthood in the last two decades, facilitating
} 
thermore, there is evidence that the mechanisms of social reproduction work in the same way for the second generation as it does for children of natives (see Heath and Brinbaum, 2007). There are therefore substantial differences between the gross effects of migration background and its effects net of students' socioeconomic status.

A number of studies have sought to move beyond the "class versus ethnicity debate", shedding light on other relevant characteristics such as the resources in the family environment (van De Werfhorst and Van Tubergen, 2007). Taking parental resources into account is particularly important in the analysis of ethnic inequalities, as immigrant parents may face specific obstacles in effectively supporting their children's educational careers. For example, some studies suggest that parents' limited knowledge of the education system and lack of proficiency in the host country language can have a lasting effect on their children's performance and educational trajectory (van De Werfhorst and Van Tubergen, 2007; Heath et al., 2008; Dustmann et al., 2012; Kilpi-Jakonen and Alisaari, 2021). At the same time, studies have paid more attention to parental characteristics before migration, such as parents' relative level of education in their home country (Feliciano, 2005a,b; Ichou, 2014; van de Werfhorst and Heath, 2019). These developments have enabled researchers to better contextualise the conditions in which children of immigrants attend school and to include more precise measures of their families' actual resources.

Even when researchers are able to control for a wide range of relevant parental characteristics, it is notable that some residual gaps remain between children of immigrants and natives. However, such net effects of ethnic background often go in the opposite direction of its gross effects: among children of similar parental characteristics, children of immigrants tend to outperform their native counterparts. This is especially true for the type of track students follow in secondary education. Indeed, conditional on their school performance, children of immigrants have been consistently found to opt for relatively higher-levels tracks (e.g., van De Werfhorst and Van Tubergen, 2007; Feliciano and Lanuza, 2016; Fernández-Reino, 2016; Dollmann and Weißmann, 2019). These "ethnic advantage" or "immigrant optimism" have received growing attention in the literature in recent years, highlighting the role of expectations and aspirations in the educational trajectories of the children of immigrants (e.g., D'hondt et al., 2016; Hadjar and Scharf, 2019) and the factors that

the analysis of their life trajectories. However, the younger cohorts of children of contemporary immigrants now coming of age in Europe are arguably more diverse (Haas et al., 2019, pp888-892). 


\section{Chapter 2}

condition the transformation of favourable aspirations into academic success (Miyamoto et al., 2020; Dollmann and Weißmann, 2019).

Overall, the literature on the second generation is instructive in several ways. First, its successive developments have shed light on the specific educational experiences of the children of immigrants. As Luthra et al. (2018b) argue, children of immigrants are not just like their native counterparts: being born from people who grew up in foreign places and had to adapt in a new society creates an essential "background difference", inherent in the migration experience itself (p.27). Second, this literature has become increasingly sensitive to the considerable variation within the second generation, showing that children of immigrants fare differently depending on their parents' migration background (Heath et al., 2008; Zhou and Gonzales, 2019).

However, the systematic comparison of children of immigrants with those of natives in quantitative studies comes with an important limitation. The inclusion of immigrants and non-immigrants in the same models indeed constraints the selection of variables to characteristics common to both groups (see, e.g., Dronkers and Fleischmann, 2010, p.187). This is problematic because a number of characteristics of the second generation are associated with the migration experience of their parents, and are thus not applicable to the children of natives. Such characteristics include parents' migration history, their settlement process, and their conditions of residence in the host country. For example, very few studies have analysed the relevance of parents' length of residence in the host country for the second generation (OECD, 2017a, pp.44-45). The focus on the "majority/minority dichotomy" (Lessard-Phillips et al., 2017, p.40) has arguably contributed to put aside another characteristic that primarily concerns immigrants' children: their citizenship status. As I will show below, only a limited number of studies have analysed the effect of citizenship on the educational outcomes of the second generation.

There may be other reasons for this overall lack of attention to citizenship status, which are worth mentioning at this point. First, children's citizenship status is not relevant in countries with unconditional ius soli provisions, whereby all children born in the country have automatic rights to citizenship. This is notably the case in the United States, where the literature on the second-generation has been most extensive. In fact, most key works of the US literature on the second-generation ignore citizenship or take it for granted (Luthra et al., 2018b, p.154). This implicit assumption that alien status is unproblematic has arguably influenced studies on the European con- 
text, although most European countries do not offer unconditional ius soli. ${ }^{4}$

Second, important data limitations have made it difficult to analyse the citizenship status of the children of immigrants. Some data sources do simply not include information on nationality. In others, nationality is the only way to identify children of immigrant descent, in the absence of information on (see e.g., Fibbi et al., 2007; Bolzman et al., 2003, for the Swiss case). This has a major drawback, as children of immigrants who acquire host country citizenship at birth cannot be differentiated from children of native descent. In addition, some data sources do not include children's or their parents' country of birth (see e.g., Parameshwaran and Engzell, 2015), whereas it is necessary to take into account both nationality and migration status to identify the second generation (Heath et al., 2008, p.214).

On a more conceptual level, this lack of attention may also stem from the way in which citizenship of children is conceived in liberal democracies. According to Cohen (2005), minors hold an "ill-defined partial membership", marked by ambiguity:

"Children are simultaneously assumed to be citizens - they hold passports and except in the rarest of cases receive at least one nationality at birth - and judged to be incapable of citizenship in that they cannot make the rational and informed decisions that characterise self-governance." (Cohen, 2005, p.221)

As minor children do not have the right to vote and have restricted access to the labour market, their citizenship status is partly abstract and some of its benefits are intangible. However, as I will show below, burgeoning areas of research suggest that citizenship is important for the children of immigrants, even if they do not fully enjoy the rights attached to it until they reach the age of majority.

\section{The direct effects of naturalisation on educational outcomes}

Until recently, few studies on the second generation have focused on - or at least considered - the citizenship status of the children of immigrants. This led the OECD to note in a 2017 report on the intergenerational mobility of the children of immigrants that "there is currently no evidence whether parental naturalisation (...) may impact their children's outcomes" (OECD, 2017a,

\footnotetext{
${ }^{4}$ With the exception of Moldova, no European country offers unconditional ius soli since it was abolished in the UK (1983) and in Ireland (2006) (de Groot and Vonk, 2018, p.331).
} 


\section{Chapter 2}

p.45). However, a closer examination of the literature brings more nuanced conclusions. While there is not a unified field of research on the relation between citizenship and education of the second generation, different bodies of literature have addressed this issue to varying degrees. In what follows, I will review and connect three main areas of research that contribute to a better understanding of the potential effects of naturalisation on the educational outcomes of the second generation. Although these areas of research have mostly developed in isolation, I will show that they provide a fairly coherent picture of how host country citizenship may positively affect educational outcomes.

\section{The legal status of the 1.5 generation in the United States}

There is an important line of research in North America focusing on the life trajectories of youth who initially came in the US as unauthorised migrants. These youth are often described as the 1.5 generation: they are not born in the country of destination but migrated at a young age, typically before 12 (Rumbaut, 2004). ${ }^{5}$

Although this line of research focuses on the 1.5 generation, it is informative for several reasons. First, the 1.5 generation in the U.S resembles the second generation in Europe, in that both populations live in their country of residence without the benefit of birthright citizenship (Luthra et al., 2018b, p.156). Second, although this literature has dedicated much attention to the effects of illegality and undocumented status, it offers interesting perspectives on how legal insecurity affects the well-being and opportunities of immigrant children in general (Gonzales, 2011; Cebulko, 2014; Enriquez, 2017). Finally, more and more studies not only look at the differences between documented and undocumented immigrants but also consider citizenship as an important axis of stratification (Menjívar, 2006; Cebulko, 2014; Patler, 2017).

These studies shed light on important mechanisms through which legal status affects children's or adolescents' well-being and life chances. Legal insecurity and the fear of deportation have been shown to shape the lives of immigrant youth in important ways (Gonzales, 2011; Cebulko, 2014). Undocumented youth have to deal with the stigma of illegality and set up strategies

\footnotetext{
${ }^{5}$ In his landmark study, Rumbaut (2004) defines the 1.5 generation as those who arrive in the destination country during middle school, between 6 and 12 years old. Other authors, however, define the term "1.5 generation" in a more flexible way and include youth who arrived in their late adolescence, up to the age of 15-16 (e.g., Enriquez, 2017; Cebulko, 2014).
} 
to overcome the legal obstacles in their school and work trajectories. In particular, Gonzales (2011) observes that undocumented status often prevents youth's efforts at school from being rewarded in the labour market, generating frustration and demotivation: "the assumed link between educational attainment and material and psychological outcomes after school is broken" (p.616).

Illegality affects various social aspects of immigrant youth's lives, and prevents them from moving through rites of passage that are usually associated with their age (Gonzales, 2011; Cebulko, 2014). This experience of exclusion leads to important triggers of stress and has been shown to severely impair psychological well-being, while transition to lawful presence is associated with a lower probability of stress and negative emotions (Patler and Pirtle, 2018). Exclusion also affects immigrant youth's sense of belonging: as Cebulko (2014) notes, without legal status undocumented youth do not identify as "Americans", even when they feel very "Americanised". Lack of wellbeing and anxiety can both impede educational progress, as mental heath has been shown to affect academic functioning and how students take advantage of learning opportunities in school (for an overview, see Rose et al., 2017, p.2324).

These findings are largely specific to the experience of being undocumented in the US. However, research has increasingly emphasised the need to move beyond the "legal-illegal binary" (Cebulko, 2014, p.145) to draw attention to the multiple categories of legal membership created by immigration and citizenship policies (Cebulko, 2014; Gonzales, 2011; Menjívar, 2006). In a context where the rights of all non-citizens are being eroded, "citizenship - in addition to legal status - has become an important axis of stratification" (Patler, 2017 , p.4). Indeed, while legal non-citizens may be less at risk of deportation than undocumented immigrants, they may still experience insecurity and exclusion (Cebulko, 2014; Menjívar, 2006). Following Gonzales' (2011) argument, the lack of citizenship may also limit the returns to education, as it restricts access to a number of high-skilled jobs. Furthermore, the lack of citizenship may undermine the sense of inclusion in the host society. As argued by Luthra et al. (2018b), "as products of receiving-society schools, [immigrant offspring] have already been socialised for citizenship" (p.74) but lack the de jure status.

Studies looking more specifically at the differences between undocumented residents, legal non-citizens and U.S citizens support the idea of a "citizenship advantage" in education (Patler, 2017). Patler (2017) and Bean et al. 


\section{Chapter 2}

(2011) highlight a hierarchy of educational success, where undocumented students perform the worse while U.S citizenship confers the highest educational premium. Citizenship is found to positively affect the number of years of schooling (Bean et al., 2011), high school completion and enrolment into post-secondary school (Patler, 2017).

Both studies conceptualise citizenship within the framework of membership exclusion, according to which the lack of legal status excludes immigrants from social membership and leads to processes of delayed incorporation (see Bean et al., 2015). This theoretical framework has been designed primarily to analyse how children of unauthorised Mexican immigrants fare in education. As such, it focuses mainly on the effects of legalisation through the acquisition of legal permanent residency, devoting less attention to the acquisition of US citizenship. Furthermore, the mechanisms through which legal status affects children's educational outcomes remain unclear. In the following paragraphs, I draw on another line of research in Europe that specifically studies the effects of citizenship on the second generation.

\section{The citizenship of the second generation in Europe}

In addition to the US literature on the 1.5 generation, there are a number of studies on the citizenship of the second generation in Europe. These studies have taken a different view of children's citizenship status, aligned with the specificities of the European context. Contrary to the US, being born in a European country is not (or is no longer) enough to make a child one of its citizens (Honohan and Rougier, 2018). Children of immigrants have rights to the citizenship of their parents, not their country of birth, which puts them in a similar position to that of the 1.5 generation in the US. At the same time, while the size of Europe's unauthorised immigrant population has been growing in recent years, it is still less than half the number in the US (Pew Research Center, 2019). As a result, the European literature has devoted relatively more attention to citizenship than to legal status, compared to the other side of the Atlantic.

There are a few qualitative studies that analyse the relevance and value of citizenship for second-generation children in countries where the ius sanguinis principle prevails (Colombo, 2015; Colombo et al., 2011; Frauenfelder, 2007; Ribert, 2009). Colombo (2015) focuses on children of immigrants born and raised in Italy who are not (yet) Italian citizens, while Frauenfelder (2007) traces the naturalisation process of second-generation youth in Switzerland. 
These studies shed valuable light on the multiple facets of host country citizenship for the children of immigrants. Citizenship may be acquired on practical grounds, such as gaining access to internships in the banking sector in Switzerland or avoiding the complications of the Italian administrative system. However, host country citizenship also assumes "a wider meaning, that goes beyond the specific restrictive situation generated by the law and bureaucratic rules" (Colombo et al., 2011, p.339).

Colombo et al. (2011) observe that for second-generation youth, becoming Italian citizens is a condition for full and effective participation in social life. First, having a host country passport opens up new horizons in terms of geographical and social mobility, whether for school trips or future job opportunities. Second, the political rights attached to citizenship guarantee the possibility to act as a self-monitored actor and defend their interests, notably through voting. This confirms earlier work from Ribert (2000) in France, showing that second-generation youth see the acquisition of French identity papers as marking access to adulthood and to full formal equality with those who are born in France to native parents. In that sense, acquiring host country citizenship enables children of immigrants to assert their rights and offers a form of protection against potential exclusion (Ribert, 2000; Frauenfelder, 2007, p.326)

Finally, citizenship can be an element of identification with the host country, although, as Colombo et al. (2011) nuance it, "citizenship (...) represents just one of the multiple forces at work in the construction of the sense of belonging" (p.344). Becoming a citizen can help second-generation youth to feel "at home", by changing their relationships with the host society and its institutions, such as when they interact with the police or the administration (Ribert, 2000; Frauenfelder, 2007). It can also help immigrant offspring to acquire a de jure status that reflects their everyday experience and practices in the host country, while maintaining a strong emotional bond with the country of origin of their parents (Ribert, 2009; Frauenfelder, 2007; Colombo, 2015).

Altogether, these findings indicate that host country citizenship matters for children of immigrants: it not only broadens their opportunities, but also contributes to a sense of security, autonomy and self-fulfilment. This provides important insights into the specificities of host country citizenship (notably vis-à-vis permanent residence) and the ways it can affect educational outcomes. If naturalised children do indeed feel more protected and motivated than their non-citizen counterparts, this may have a positive effect on how they perform in education and navigate the school system. 


\section{Chapter 2}

Another lesson from these studies is that while citizenship status matters, it is not a panacea. Indeed, becoming a citizen guarantees full formal membership but does not protect against all forms of discrimination. Although children of immigrants acquire host country citizenship, they may still not be recognised as "real" citizens in their daily lives or more generally in public and political discourses (Duyvendak, 2011; Frauenfelder, 2007, p.334). This is because other personal characteristics such as the skin colour or the sound of family name are enduring - and more visible - attributes shaping immigrant offspring's everyday interactions and access to resources (Cebulko, 2018; Erdal et al., 2018). In the last section of this chapter, I discuss in more detail the possible interactions of citizenship status with class and race.

\section{Citizenship and educational outcomes of the second generation in Europe}

Next to these qualitative studies, there is a series of quantitative studies that specifically examine the effects of citizenship status on educational outcomes in Europe (Fibbi et al., 2007; Kilpi-Jakonen, 2014; Felfe et al., 2020; CyganRehm, 2018; von Haaren, 2016). This line of research, especially in its latest developments, has devoted particular attention to identifying an independent effect of citizenship, net of selection effects. It is indeed a methodological challenge to determine a causal impact of citizenship on education, as naturalisation is a complex and costly procedure into which immigrants selfselect. A major threat to identification is due to common-cause confounding bias: parents acquiring host country citizenship tend to be positively selected for education, income and country-specific skills (Peters et al., 2016; Jensen et al., 2019; Hainmueller et al., 2018), which are in turn commonly associated with children's educational attainment. Parental naturalisation can also reflect high levels of integration or parents' willingness to integrate (Donnaloja, 2020), which means that parents who seek to become citizens may orient their children to the host society and its education system in specific ways, independent of their naturalisation process. When estimating the effect of citizenship, the parental characteristics involved in naturalisation decisions should thus be included as control variables; however, some of these characteristics are typically unobserved or unobservable in quantitative data. This implies that (part of) the association between citizenship and education observed in nonexperimental studies may be due to unobservable selection.

The first studies on the topic indicate that children who are host country citizens have better educational outcomes than non-citizens. At the same 
time, citizens are found to come from a more privileged socio-economic background, suggesting selection effects (Kilpi-Jakonen, 2014; Fibbi et al., 2007). However, the authors observe that the positive effect of host country citizenship persists on some educational outcomes, even when important parental characteristics are controlled for. While this suggests that the observed relationship between citizenship and education is not solely driven by selection, this result could also be due to residual unobserved confounding factors at the family level.

The most recent studies develop innovative empirical strategies to isolate the effect of citizenship from unobserved family factors (Felfe et al., 2020; CyganRehm, 2018; von Haaren, 2016). The authors use the introduction of partial ius soli in Germany in 2000 as a natural experiment to assess the effect of exogenous variation in the birthright citizenship status of children of immigrants. The results indicate an independent - and sizeable - effect of the acquisition of German citizenship at birth on children's educational outcomes in both the short and long term (Felfe et al., 2020; Cygan-Rehm, 2018). ${ }^{6}$ While this is consistent with previous work (Kilpi-Jakonen, 2014; Fibbi et al., 2007), it should be stressed that extrapolating these results beyond the German case is difficult. The authors only measure the impact of the automatic acquisition of German citizenship at birth, while most European countries do not offer such ius soli provisions. Furthermore, their research strategy is hardly replicable in other countries since birthright citizenship provisions are fairly stable over time in Western Europe (Vink and de Groot, 2010, 720). In the Chapter 5 of this dissertation, I develop a novel identification strategy to isolate the effect of citizenship in the absence of a natural experiment.

Overall, existing research suggests that citizenship has positive effects on various indicators of educational attainment, such as pre-school enrolment and grade retention in primary school (Felfe et al., 2020), track enrolment in secondary education, (Kilpi-Jakonen, 2014; Cygan-Rehm, 2018; Felfe et al., 2020) and continuation to university (Fibbi et al., 2007). On a theoretical level, there are several reasons for a causal relationship between citizenship and education.

\footnotetext{
${ }^{6}$ Von Haaren (2016) uses the same citizenship reform in Germany to measure the effect of an exogenous variation in parents' eligibility for naturalisation. The author observes that parents' eligibility status has a positive effect on children's educational attainment, but, contrary to Felfe et al. (2020) and Cygan-Rehm (2018), this effect is non-statistically significant. Von Haaren concludes that the effect is fully driven by self-selection into naturalisation. However, the lack of statistical significance may also be due to the imprecision of the estimation and the use of a weak instrument (see p.17).
} 


\section{Chapter 2}

Previous studies typically conceptualise citizenship acquisition within the framework of human capital theory (Becker, 1993) and the human skill formation model (Cunha and Heckman, 2007). The effect of host country citizenship is described as a positive shock to the long-term rate of return on investment in children's human capital (e.g., Felfe et al., 2020; Cygan-Rehm, 2018). Because citizenship provides unrestricted access to the host country labour market, early parental inputs in children's education should yield higher returns. Parents whose children are host country citizens are thus incentivised to make early investments in their children's education, such as to have them participate to non-compulsory pre-school (Felfe et al., 2020). In line with this argument, children who automatically get host country citizenship at birth are found to have better behavioral, socio-emotional and health outcomes in the short run compared to those who do not (Avitabile et al., 2014; Felfe et al., 2020). This hypothesis of higher early parental investments in human capital is further supported by studies showing that ius soli provisions decrease immigrant families' out-migration propensity (Sajons, 2016) and fertility (Avitabile et al., 2014) in the short-run.

This theoretical argument of higher labour market returns is also used to explain the higher likelihood of host country citizens of choosing the general rather than vocational track in secondary school compared to their noncitizen peers (Felfe et al., 2020; Cygan-Rehm, 2018; Kilpi-Jakonen, 2014). For example, Kilpi-Jakonen (2014) notes in her study of the Finnish case that "choosing general education reflects a greater willingness to invest in human capital accumulation" (p.1094). As education yields higher returns on the labour market for those who are host country citizens, it is expected to increase students' motivation to embark on longer and/or more prestigious educational careers.

More generally, host country citizenship expands the opportunities of secondgeneration students, which may give them - and their parents - higher educational aspirations and expectations. This would be consistent with the literature on the so-called "immigrant optimism hypothesis" (see Feliciano and Lanuza, 2016), and in particular with the work of Fernández-Reino (2016), which shows that the higher probability of choosing academic rather than vocational qualifications among students of migration background in the UK is partly mediated by their more ambitious school expectations.

However, the exact mechanisms through which citizenship fosters children's school careers remain unclear. Previous studies are based on the underlying assumption that immigrant parents are able to make successful investments 
in their children's education, and to translate their aspirations and expectations into effective educational decisions. Such an assumption overlooks the various obstacles immigrant families may face in making informed investments in a foreign educational context. To varying degrees, educational systems require information and knowledge for parents to guide their children (Pfeffer, 2008). Importantly, recent studies suggest that parents' knowledge about the education system may be an under-investigated mechanism of social inequalities (see van De Werfhorst and Van Tubergen, 2007; Forster and van de Werfhorst, 2019). This mechanism should be particularly relevant in countries with stratified education systems containing many pathways and furcations.

Parents are not equally equipped to navigate the school system and effectively guide their children, notably because they do not have the same access to knowledge and information. First, parents' ability depends on their own educational attainment and socioeconomic position, from which they derive content and strategic knowledge (Pfeffer, 2008, p.545). Second, they rely on networks - and in particular, relationships with other parents - to access relevant information channels and social capital (Coleman, 1988). Besides, immigrant parents' investments may be constrained by specific factors, such as language barriers or difficulties in transferring their own educational experience and knowledge to a new context. There is evidence that immigrant parents face more barriers to involvement in their children's schools than native parents (Turney and Kao, 2009), which reduces their opportunities to build school-specific social capital and interact with school staff and other parents.

As a result, while citizenship may shift the preferences of immigrant families towards greater investment in host country education, "parents and their children rely on a variety of resources to realise these preferences" (Pfeffer, 2008, p.3, emphasis added). This raises another question: does the acquisition of host country citizenship help parents circumvent some of the obstacles they face in supporting their children's performance at school? A large body of literature looking at the relationship between host country citizenship and the socioeconomic integration of immigrants suggests that such a mechanism may be at work (e.g., Hainmueller et al., 2017; Avitabile et al., 2013; Peters, 2018). In the next section, I draw in particular on the literature on the naturalisation of first-generation immigrants to explore potential indirect effects of citizenship acquisition on educational outcomes, which are mediated by parents' improved position in the host society. 


\section{Chapter 2}

The various studies referred to in this section, both qualitative and quantitative, overall converge on the idea that citizenship has an independent and direct effect on educational attainment. A key theoretical expectation is that citizenship contributes to the development of long-term goals and aspirations among the children of immigrants, resulting in better educational outcomes and more ambitious educational choices. Yet, an alternative or additional mechanism for a direct effect of citizenship could be related to discrimination: citizenship may affect the way others - and especially teachers - treat children of immigrants. For example, teachers' assessment of students' performance might be influenced by their citizenship status, in a similar way as it can be influenced by students' gender or socioeconomic status (Timmermans et al., 2018).

The hypothesis of discrimination against non-citizens has been considered in some studies (Kilpi-Jakonen, 2014; Cygan-Rehm, 2018), but has not received much empirical support so far. Kilpi-Jakonen (2014) does not find a significant effect of Finnish citizenship on the grades assigned by teachers, while Felfe et al. (2020) observe that teachers' track recommendation is not significantly affected by the introduction of birthright citizenship in Germany. From a theoretical point of view, one could expect more visible characteristics such as the skin colour to play a more important role in discrimination than citizenship status, especially in an institution where citizenship status does not condition access to or use of resources. In the rest of the dissertation, I therefore do not consider the mechanism of discrimination further.

\section{The indirect intergenerational effects of naturalisation}

The integration of immigrant populations into host societies has received much public and policy attention. Among the heated debates on integration policies, one involves the effects that naturalisation has on immigrants' political, social and economic participation. Usually, there are two opposing paradigms about the relationship between citizenship and integration (Hainmueller et al., 2017). On the one hand, the "crown paradigm" postulates that naturalisation does not enhance integration, but is simply a reward for those who have reached the end point of the integration process. By contrast, naturalisation propels the integration process according to the "catalyst paradigm", as "it provides immigrants with the necessary incentives and resources to integrate and invest in a future in the host country" (Hainmueller et al., 2017, p.256). 
An extensive literature has emerged on how naturalisation affects the socioeconomic outcomes of immigrants (for a full overview, see Peters and Vink, 2016). Overall, results provide support for the catalyst paradigm: naturalisation is shown to have an independent effect on various indicators of socioeconomic and cultural integration. However, that parents' improved position in the host society may in turn affect their children's opportunities has not yet been examined, either theoretically or empirically. This lack of attention is surprising, given that it has long been established in other fields that changes in parents' outcomes have feedback effects on their children's development, notably through changes in parental resources and behaviour (see, e.g., Elder, 1994). Following the principle of linked lives, I argue that the interdependence within the family should be taken into account to comprehensively assess the effects of citizenship acquisition. In this section, I review two types of parental resources associated with citizenship acquisition: the ones that parents acquire or develop as a result of naturalisation, and the ones they acquire during the naturalisation process itself.

\section{Spillover effects of citizenship acquisition}

An important part of the studies of naturalisation analyses its impact on economic outcomes, such as wages and employment (e.g., Gathmann and Keller, 2018; Peters et al., 2017, 2020; Steinhardt, 2012; Helgertz et al., 2014). Results suggest that naturalised immigrants experience a "citizenship premium" in the labour market, with naturalisation facilitating access to employment and giving significant boosts in earnings (Gathmann and Keller, 2018; Steinhardt, 2012; Peters et al., 2017). This citizenship premium is generally attributed to the fact that host country citizenship provides unrestricted access to the labour market, and sends a positive signal to (potential) employers.

Parents' access to the labour market contributes greatly to the income and financial stability of the family, which in turn may play a role in children's educational attainment. Based on their income, parents can invest more or less of their disposable resources in their children's performance. Income enables them to purchase materials, experiences and services that directly or indirectly foster their children's cognitive ability and educational attainment (see, e.g., Schulz et al., 2017). Although income is generally weakly correlated with levels of educational attainment, experience of persisting poverty does impact children's outcomes (Schöb, 2001). As immigrants tend to be at 


\section{Chapter 2}

a higher risk of poverty than natives (Blume et al., 2007), experiencing a citizenship premium in the labour market may be particularly relevant for improving the living conditions of immigrants' children. Parents' access to the labour market also contributes to parents' socioeconomic position, which, as mentioned above, has been shown to be a key factor in explaining inequalities in educational attainment, including among children of immigrants (van De Werfhorst and Van Tubergen, 2007; Heath and Brinbaum, 2007, p.295).

What is more, a recent line of research suggests that naturalisation facilitates access to the housing market. In the Netherlands, naturalised immigrants have been found to be $26 \%$ more likely to be homeowner (Peters, 2020), and $40 \%$ more likely to move out of immigrant-concentrated neighbourhoods (Leclerc et al., 2021). This may be an additional mechanism through which naturalisation indirectly affects educational outcomes, as neighbourhood characteristics exert an influence on children's and adolescents' educational development (see Nieuwenhuis et al., 2021). Furthermore, homeownership provides long-term financial benefits (Peters, 2020, p.1240) and can participate to the settlement process of immigrants (Chiswick and Miller, 2009).

Next to financial and employment stability, there is evidence that naturalisation promotes the social and political integration of immigrants. Hainmueller et al. (2017) show for the Swiss case that naturalised citizens have a higher score on a social integration scale, which includes interactions with the local community and the reading of Swiss newspapers. Such activities provide parents with additional resources to assist their children's educational career. Contacts with native parents can indeed give access to relevant networks and information flows, while acquaintance with the host country context and language can foster parents' advice ability and facilitate their participation in school decisions.

Several reasons may explain why naturalisation fosters immigrants' social integration. As we have seen, host country citizenship shifts the time horizon of immigrants and ensures that they will reap the long-term benefits of increased investments in their political and social integration. Naturalisation may also affect the way they feel perceived, or are perceived, by natives, and lead to increased attachment to the host society. This is consistent with evidence that host country citizenship generally favours both plans to stay in the host country and the likelihood of doing so (Hainmueller et al., 2017; Sajons, 2016; Hoon et al., 2020). In addition, previous work suggests that naturalisation fosters immigrants' identification with the host country (Fick, 2016; Donnaloja, 2020) and their political participation (Hainmueller et al., 2015). 
Altogether, these results indicate that naturalisation may increase the sociocultural resources available to children and foster parents' ability to provide advice through better acquaintance with the host country and its language. This is arguably an important mechanism because, as Chapter 3 shows, a substantial share of the second generation only acquire citizenship through their parents' naturalisation, either before their birth or via co-naturalisation. Yet, in a few countries such as Germany, children of immigrants may automatically get host country citizenship at birth if their parents meet certain residence requirements. In such cases, can we expect parents to develop similar resources although they do not necessarily become citizens themselves? Sajons (2019) observes that birthright citizenship for children did not change the labour market behaviours of immigrant fathers, while it reduced the labour market attachment of mothers. This is not in line with the findings that naturalisation improves the labour market outcomes of immigrants, especially women (e.g., Gathmann and Keller, 2018). However, Avitabile et al. (2013) show that birthright citizenship for children has similar effects as parental naturalisation on their level of social integration: immigrant parents whose children are granted German citizenship at birth are found to be more likely to interact with native Germans, use the German language and read German newspapers.

The findings of Avitabile et al. (2013) underline the presence of interpersonal dynamics at the family level (Street, 2014; Soehl et al., 2018): children's citizenship status seems to have an effect on parents' practices and resources, regardless of the citizenship status of the latter. This suggests that children' increased opportunities in the host society affect parents' investments and orientation to the host country. In other words, as Avitabile et al. (2013) note, "immigrants might decide to integrate more with the culture of the host country because their children will be growing up as German citizens, speaking German, and adopting German habits" (p.786).

In summary, the acquisition of host country citizenship - whether by parents or by children alone - is expected to provide immigrant families with resources that are relevant for children's educational attainment. Naturalisation thus not only improves the position of immigrants in the host society, but may also, indirectly, foster their children's educational outcomes. This points to a potential intergenerational effects of naturalisation: the benefits of naturalisation are passed on from parents to children, via the resources parents can invest in their children's education. 


\section{Chapter 2}

\section{Anticipated effects of citizenship acquisition}

Previous research typically analyses the effects of naturalisation from the moment immigrants legally and officially become citizens. Yet, some studies suggest that the citizenship premium may actually develop faster before the actual change of nationality (Peters et al., 2017, 2020). This may sound counter-intuitive, or be hastily interpreted as evidence of selection into naturalisation (see Peters et al., 2017, p.6). However, there are several reasons to argue that immigrants benefit from naturalisation before it is formally approved and recorded.

As Peters et al. (2017) notes, "citizenship acquisition is not an abrupt legal status transition, but rather a process" (p.6) that starts when immigrants decide to seek host country citizenship. In that sense, prospective citizens may already anticipate the future opportunities associated with host country citizenship, and take steps to take full advantage of them, such as by improving their language skills (Peters et al., 2017). Furthermore, with the introduction of language and integration requirements in most European countries over the last two decades (Goodman, 2010), prospective citizens need to meet increasingly demanding requirements. Immigrants seeking host country citizenship may therefore not only want but also need to invest in their human capital before naturalisation.

Following this line of argument, immigrant parents may acquire or further develop relevant skills during the naturalisation process itself. Naturalisation procedures typically require at least basic language proficiency and some familiarity with the host country institutions. Going through such procedures may therefore provide naturalisation candidates with country-specific resources and knowledge, which may be transferable to other domains. For example, a study from Patler et al. (2020) shows that US citizens have higher levels of legal and procedural knowledge to challenge workplace abuses than documented non-citizens and undocumented immigrants. The authors conclude that workplace agency may be associated with the naturalisation process:

"Citizen workers, in contrast [to noncitizens], may be more likely to have access to information about and experiences with government agencies - either through experiences with privileges afforded uniquely to citizens, or through the naturalisation process itself - and, therefore, experience less fear accessing such services." (Patler et al., 2020, p.16, emphasis added). 
In the same vein, one could expect naturalised parents to be better equipped to navigate complex institutions such as the school system. Their interactions with host country administrations during the naturalisation process may increase their ability to overcome bureaucratic hurdles and negotiate their way through, especially when they do not comply with teachers' assessment and recommendations. Such a mechanism would be all the more relevant in countries where civic integration tests include specific questions about host country institutions, such as in the Netherlands. ${ }^{7}$ In the empirical Chapter 4, I analyse in more detail the extent to which the acquisition of Dutch citizenship increases immigrant families' ability to navigate a complex education system and make use of its flexibility.

In other words, the resources and skills immigrant parents acquire during and in response to the naturalisation process are likely to have positive implications for their children's educational outcomes. While it is beyond the scope of this dissertation to isolate such anticipated effects of host country citizenship acquisition, I argue that it is a promising avenue for future research. If the decision to naturalise does indeed contribute to changes in immigrants' outcomes - in addition to the effects of the formal acquisition of host country citizenship - this has important implications for how we should define and measure the effects of naturalisation. In particular, this means that a strict comparison of immigrants' outcomes before and after the actual change in nationality may overlook the effects of the naturalisation process itself. This should be kept in mind when analysing the results of the empirical Chapters 4 and 5: children of immigrants who become Dutch citizens in a given year may have been influenced by their family's naturalisation process long before that date.

\section{Timing and effect heterogeneity: effects of citizenship over the life course}

Previous work on citizenship and education has mainly focused on whether citizenship has an independent effect on educational outcomes. Because naturalisation is a selective process that not all immigrants are able or willing to

\footnotetext{
${ }^{7}$ In the Netherlands, naturalisation candidates need to take a civic integration examination that includes a "knowledge of the Dutch society" component. This part consists of questions about Dutch customs and the functioning of the main institutions in the Netherlands, including the school system. See more details and example questions on https: //www. naarnederland.nl/en/exampleexams [accessed July 19, 2021].
} 


\section{Chapter 2}

undertake, there is a high risk of bias when measuring the effect of citizenship on education. This makes it particularly important to disentangle the effect of citizenship from that of other confounding factors. Yet, the focus on causation has overshadowed other relevant questions, such as when and for whom citizenship matters.

Existing studies tend to assume that the effect of citizenship is uniform over time and across individuals. However, there are reasons to think that the mechanisms presented above do not apply equally to all children of immigrants: citizenship acquisition may be more relevant at certain stages of their life than others, and may be contingent upon some of children's characteristics and resources. In the next paragraphs, I build on the literature on naturalisation of first-generation immigrants to highlight two understudied aspects of the relevance of citizenship for the second generation, namely timing and effect heterogeneity.

\section{The timing of citizenship acquisition}

Previous studies generally use a static approach to citizenship. They identify whether children of immigrants are citizens at a given date, but do not consider when they became citizens. There are several explanations for this. First, information on the exact naturalisation date is not always available, especially when using cross-sectional data (Patler, 2017). Second, researchers have generally focused on citizenship acquisition at an early age, whether at birth (Felfe et al., 2020; Avitabile et al., 2014) or before school enrolment (Cygan-Rehm, 2018). This is mainly driven by methodological considerations, since the change in citizenship status should be observed before the outcome to avoid reverse causality. By contrast, the few studies that consider citizenship acquisition in early adulthood cannot "disentangle the observed link between positive selection on educational achievement and naturalisation" (Fibbi et al., 2007, p.1132). Furthermore, a number of studies focus on the introduction of conditional ius soli in Germany, and thus exclusively analyse acquisition of German citizenship at birth (Felfe et al., 2020; Avitabile et al., 2014).

While it is crucial to deal with reverse causality, it is also important to consider the implications of such methodological choices. Even in countries with conditional ius soli, children acquire automatic birthright citizenship only if 
their parents fulfil certain residency requirements. ${ }^{8}$ Those whose parents have not resided long enough in the host country before their birth are not eligible and may therefore naturalise later. Furthermore, as Chapter 3 shows for the Netherlands, in the absence of ius soli, a substantial share of children of immigrants only acquire host country citizenship in late childhood or early adolescence, through co-naturalisation with their parents. Some may even remain foreign citizens after they reach the age of majority, as highlighted by Frauenfelder (2007) and Colombo et al. (2011). There is therefore significant variation in children's age at naturalisation, which is not reflected in previous research. This variation raises questions about the effect of the timing of citizenship acquisition: is becoming a citizen more important at an early age than at an older age? Are children who acquired host country citizenship from birth more oriented towards the host society than those who become citizens later? These questions have received very little theoretical or empirical attention - if any at all.

Nevertheless, the literature on naturalisation of the first generation provides valuable insights into the effect of timing of citizenship acquisition. A number of studies show that the earlier immigrants are eligible to apply for citizenship and the quicker they naturalise, the more relevant citizenship is for their socioeconomic integration (e.g., Gathmann and Keller, 2018; Peters et al., 2017). Furthermore, citizenship matters more for social integration when it is acquired early in the settlement process, rather than later (Hainmueller et al., 2017). Hainmueller et al. (2017) note that "this [timing] effect is strong in the sense that even a few years earlier can make a real difference for long-term social integration" (p.273). Immigrants who naturalise shortly after they are eligible are incentivised to make early investments in their human capital and country-specific skills (Peters et al., 2017; Hainmueller et al., 2017). Conversely, naturalisation may lose part of its relevance after a long period of residence, when immigrants have less time to enjoy the benefits of citizenship.

There are reasons to think that the timing of naturalisation not only matters for immigrants, but also for their children. First, as described above, children

\footnotetext{
${ }^{8}$ In the German case, ius soli provisions apply only to children whose parents have lived in Germany for at least eight years before their birth. As Sajons (2019) notes, this entails that findings derived from the 2000 citizenship reform only apply to immigrant families who have stayed in Germany for a long time (see p.16). In other words, the German studies (e.g., Felfe et al., 2020; Cygan-Rehm, 2018) measure the effect of citizenship when it is acquired at a time when most of the integration process has already taken place. This implies a risk of downward bias because, as described below, citizenship may have a stronger effect at the beginning of the integration process.
} 


\section{Chapter 2}

may indirectly benefit from their parents' economic and social integration. In that sense, the faster parents naturalise and orient themselves towards the host society, the greater the spillover effect of naturalisation on their children's educational outcomes. This would be particularly relevant if parents naturalise before their children start their school career, as increased familiarity with the host country context and institutions may help them guide their children through the education system.

Second, the effect of citizenship is expected to vary over the life trajectory of children. Following the life course perspective, citizenship acquisition may have a different meaning depending on the life-stage in which children of immigrants experience the naturalisation process (Wingens et al., 2011a). Children who acquire host country citizenship from birth or at a very young age may experience secure belonging (see Erdal et al., 2018, pp.715-718), while those growing up as foreign citizens in their country of birth and residence may face legal uncertainty and a number of barriers prior to naturalisation. Not "feeling at home", even temporarily, can have a long-lasting impact on children's well-being and performance at school (Cebulko, 2018).

As a result, I hypothesise that the earlier second-generation children acquire host country citizenship, the greater their advantage over their non-Dutch counterparts in terms of educational attainment. This timing effect may not be linear: while I expect the effect of naturalisation to decrease as children grow older, there may be breakpoints at children's main stages of life. On the one hand, the lack of host country citizenship may not be salient for children of immigrants, until they are old enough to "discover" it and face situations where they suffer its consequences, in early adulthood (see Gonzales, 2011, p.609). On the other hand, a few studies suggest that children of immigrants may experience feelings of exclusion at a relatively young age. For example, there is evidence that non-citizen students have difficulties participating to international school trips due to burdensome visa procedures (e.g., Colombo et al., 2011, p.340). The host country passport (or lack thereof) may also become salient when children travel across borders with their families (Ribert, 2000, p.140). Thus, overall, it remains unclear at what point(s) citizenship plays a role in children's life course.

In the empirical part of this dissertation, I first distinguish in Chapter 4 secondgeneration students based on whether they have acquired Dutch citizenship at birth or after birth, before entering secondary education. This enables me to assess whether there are substantial differences between the two groups, following the idea that those who are Dutch from birth should experience the 
greatest advantage in education. In Chapter 5, I then place the timing of citizenship acquisition at the heart of the analysis by modeling the effects of age at naturalisation on the school performance of second-generation students at the end of primary school.

\section{Heterogeneous effects of citizenship acquisition}

In addition to timing, another under-explored aspect pertains to effect heterogeneity. The literature on naturalisation of the first generation provides consistent evidence that citizenship matters more for some immigrants than for others (Hainmueller et al., 2017; Peters et al., 2016). For example, previous studies point to higher returns to naturalisation among immigrants from less developed countries and/or marginalised groups in the host country (Hainmueller et al., 2017; Vink et al., 2013; Peters et al., 2016; Helgertz et al., 2014). This suggests that the catalyst effect of naturalisation is most effective for immigrants who otherwise lack the resources to achieve a stable socioeconomic position in the host society (Hainmueller et al., 2017). This is particularly true as regards access to employment, as becoming a citizen may enable those who are discriminated against in the labour market to send positive signals to their potential employers (Helgertz et al., 2014). By contrast, immigrants with recognised qualifications who face limited ethnic prejudice may have a stable labor market attachment, regardless of their legal status.

Previous work thus suggests that host country citizenship interacts with other characteristics of immigrants, such as their country of origin, social class and race $^{9}$. Such interaction effects have rarely been considered when analysing the relevance of citizenship for the children of immigrants. In the US, where most attention has been devoted to the experience of illegality, legal status is often conceived as a "master status" that transcends other social locations (see Enriquez, 2017; Cebulko, 2018). However, recent studies take an intersectional approach and suggest that race, class and gender shape young people's experiences and the way they navigate illegality (Enriquez, 2017). In her study of 1.5-generation Brazilian young adults, Cebulko (2018) observes that "being light-skinned, well-educated, and from middle-class families can positively impact immigrant experiences relative to other unauthorised 1.5generation immigrants" (p.237). Race and social class therefore interact with

\footnotetext{
${ }^{9}$ In this dissertation, I define race as a socially defined construct, with no biological basis, that underpins a system in which individuals are classified and treated differently based on observable characteristics such as their skin colour, hair type or accent (see, e.g., Essed et al., 2019, for a discussion of this notion in the European context).
} 


\section{Chapter 2}

legal status: a privileged position in the host society can partially compensate for the lack of authorised immigration status.

Such an intersectional lens is still largely absent from research analysing the effect of citizenship on second generation educational outcomes. Although most studies include children of immigrants from a wide range of socioeconomic and educational backgrounds, the effect of citizenship is generally assumed to be uniform. There are nevertheless a few notable exceptions. Bean et al. (2011) compare the educational attainment of children of immigrants from several national-origin groups and show that pathways to legalisation and naturalisation exert a different effect depending on parents' migration and social background. While delayed legalisation and naturalisation hamper the educational attainment of youth of Mexican origin, they exert little effects on the attainment of the children of highly educated Asian immigrants who entered the US legally. In a similar vein, Cygan-Rehm (2018) tests whether second-generation students respond differently to the acquisition of host country citizenship at birth depending on whether their parents are EU citizens or not. Naturalisation may be of little value for children of immigrants who already enjoy the rights and benefits attached to EU citizenship; however, Cygan-Rehm does not find conclusive evidence of such interaction effects.

\section{Interaction effects between citizenship and socioeconomic resources}

Studies analysing interaction effects with citizenship typically use parents' country or region of origin as a proxy for their migration experience and social position in the host country (see Bean et al., 2011; Cygan-Rehm, 2018). However, this approach does not enable researchers to identify precisely which parental characteristics citizenship interacts with. For example, do parental income or level of education equally matter? And to what extent do socioeconomic and cultural resources compensate for the lack of host country citizenship? A study from Dronkers and Fleischmann (2010) provides some valuable insights. The authors analyse the educational attainment of secondgeneration students in a European comparative perspective. Although their research objective is to measure the effects of macro-level indicators, the authors do consider the effects of host country citizenship at the individual level as well as its interaction with parental level of education. Their findings point to a negative interaction between citizenship and level of education for females. That is to say, host country citizenship exerts a positive effect on ed- 
ucational attainment for female students whose parents are lowly educated, while its effect is slightly negative for those whose parents have completed tertiary education. The effect is less precisely estimated for males, but the results also suggest some interaction effects between citizenship and parental level of education.

That citizenship mostly (or only) matters for children whose parents are lowly educated is consistent with the above finding that naturalisation primarily matters for disadvantaged immigrants. This suggests that host country citizenship acts as a compensatory mechanism, which facilitates the settlement and integration process of immigrant families facing a difficult reception context. In particular, citizenship may mainly matter for parents who otherwise lack the social, cultural and economic resources to assist their children's educational careers. Dronkers and Fleischmann (2010) provide preliminary evidence that such a mechanism is at play for female students, but more research is needed to understand these dynamics. Other parental characteristics, such as parents' position in the labor market and housing market, may also intersect with citizenship status. In the Chapter 5 of this dissertation, I test interaction effects between citizenship and various indicators of the family's socioeconomic position to shed further light on the factors that condition the relevance of citizenship for the second generation.

\section{A moderating effect of gender?}

In addition to socioeconomic background, other characteristics such as gender may moderate the relationship between citizenship and education. The findings of Dronkers and Fleischmann (2010) suggest that male and female students do not equally benefit from naturalisation. However, other studies conclude that the effect of citizenship acquisition is similar for both sexes (Cygan-Rehm, 2018; Kilpi-Jakonen, 2014). From a theoretical point of view, the mechanisms are also still unclear. There is evidence that gender modulates the relationship between naturalisation and the socioeconomic outcomes of immigrant parents, particularly because immigrant men and women differ in their labour force attachment (e.g., Gathmann and Keller, 2018; Helgertz and Bevelander, 2017). Similar mechanisms could be relevant at children's level, if, for example, male and female students tend to value host country citizenship differently. However, qualitative studies have not reported such differences to date (e.g., Colombo, 2015; Frauenfelder, 2007; Ribert, 2009). 


\section{Chapter 2}

Another mechanism could be that immigrant parents react differently to the citizenship status of their children, as a recent study by Dahl et al. (2020) suggests. The authors observe in the German case that the introduction of ius soli in 2000 had a differential impact on various indicators of well-being and parental support for male and female students. The authors interpret these findings as evidence that immigrant parents constrain their daughters' integration into German society to keep them in a traditional culture, while they allow their sons to take advantage of the opportunities tied with German citizenship. Yet, such effects are only found for Muslim students and the authors focus on the automatic acquisition of German citizenship at birth, which leaves open the question of whether the alleged mechanisms apply when children acquire host country citizenship at the initiative of their parents. In summary, the results about a potential moderating effect of gender are still ambiguous and require further research.

\section{When citizenship intersects with race}

Finally, previous work suggests that citizenship status may intersect with race in different ways (Cebulko, 2018; Erdal et al., 2018). On the one hand, host country citizenship may help those who face racial prejudice to partially overcome discrimination. Ribert (2000) and Frauenfelder (2007) show that becoming a citizen of the host country can subtly change the way children perceive themselves and the way they interact with others. For example, children who are constantly referred to their foreign origin because of their skin colour may use citizenship as a way to remind native people of the legitimacy and validity of their presence (Frauenfelder, 2007, p.327). Host country citizenship may also facilitate their interactions with the administration, the police, or potential employers, as they feel it protects them from certain forms of discrimination (Ribert, 2000; Frauenfelder, 2007). As one young person interviewed by Ribert put it, "you do not look like a Frenchman but you are French" (p.238). In that sense, host country citizenship can alleviate the sense of exclusion that some children of immigrants feel in their interactions with natives and host country institutions. This echoes the study of Erdal et al. (2018) in Norway, which shows that for some respondents the "passport [...] became symbolic of being a Norwegian citizen - of being a Norwegian - regardless of its holder's personal appearance" (p.714, emphasis added). According to this line of reasoning, host country citizenship would be particularly important for children of immigrants who face high levels of prejudice, while it would make little difference to those whose belonging is rarely questioned. 
On the other hand, inverse mechanisms could be at work if citizenship status is overpowered by race. The acquisition of host country citizenship may indeed alleviate some of the disadvantages faced by the children of immigrants, without mitigating the effects of their most visible characteristics (Frauenfelder, 2007; Ribert, 2009, 2000; Della Puppa and Sredanovic, 2017). Children who are identified as foreigners due to their physical appearance, clothing or name may remain so even after becoming fully-fledged citizens. According to Erdal et al. (2018), this explains why respondents might describe the host country passport as a mere "piece of paper": "People are going to ask you where you are from regardless'" (p.715). Obtaining citizenship may therefore have a limited performative effect for those who are not seen as host country citizens anyway (see also Della Puppa and Sredanovic, 2017, p.377). Conversely, it may be a final step completing the assimilation of those who are $d e$ facto perceived as citizens, but only lack the de jure status (Erdal et al., 2018, p.717).

Previous studies show that these two mechanisms are not antagonistic but rather coexist (Frauenfelder, 2007; Erdal et al., 2018; Ribert, 2000). Yet, the conditions under which they prevail remain unclear, and previous research has not investigated the implications for the school outcomes of the children of immigrants in particular. Further empirical work, both quantitative and qualitative, is needed to map the complex interactions between citizenship status and race as well as their effects on education.

To date, there is consistent evidence in the literature on the second generation that differences in educational attainment are largely - if not primarily - attributable to social class rather than ethnic background (see Heath et al., 2008). This is particularly true for the Netherlands, for which van De Werfhorst and Van Tubergen (2007) observe that differences in school achievement and track are almost entirely driven by variation in students' parental resources. If students' ethnic background does not directly affect educational outcomes, it is unlikely that it modulates the relationship between citizenship and education. As a result, I only focus on the interactions between citizenship and parental socioeconomic characteristics in Chapter 5.

\section{Conclusion}

In this chapter, I discussed different bodies of literature relevant for the study of the relationship between citizenship and education. The different sections 


\section{Chapter 2}

bring together diverse areas of research which, to date, have mostly developed in isolation. I used the life course perspective as a conceptual glue, drawing on the notions of linked lives, trajectories, agency and context to develop a more unified theoretical framework for the drivers and effects of citizenship acquisition by children of immigrants. The second section linked research on migrant families to citizenship studies to better contextualise the conditions under which second-generation children may acquire the citizenship of their country of birth. In doing so, I shed light on understudied family and macro-level dynamics in immigrant naturalisation, which I discuss in more detail in Chapter 3.

In the third section, I drew on different bodies of literature that approached the life outcomes of children of immigrants from different but complementary perspectives. On the one hand, the literature on the second generation tends to analyse their educational outcomes without considering children's

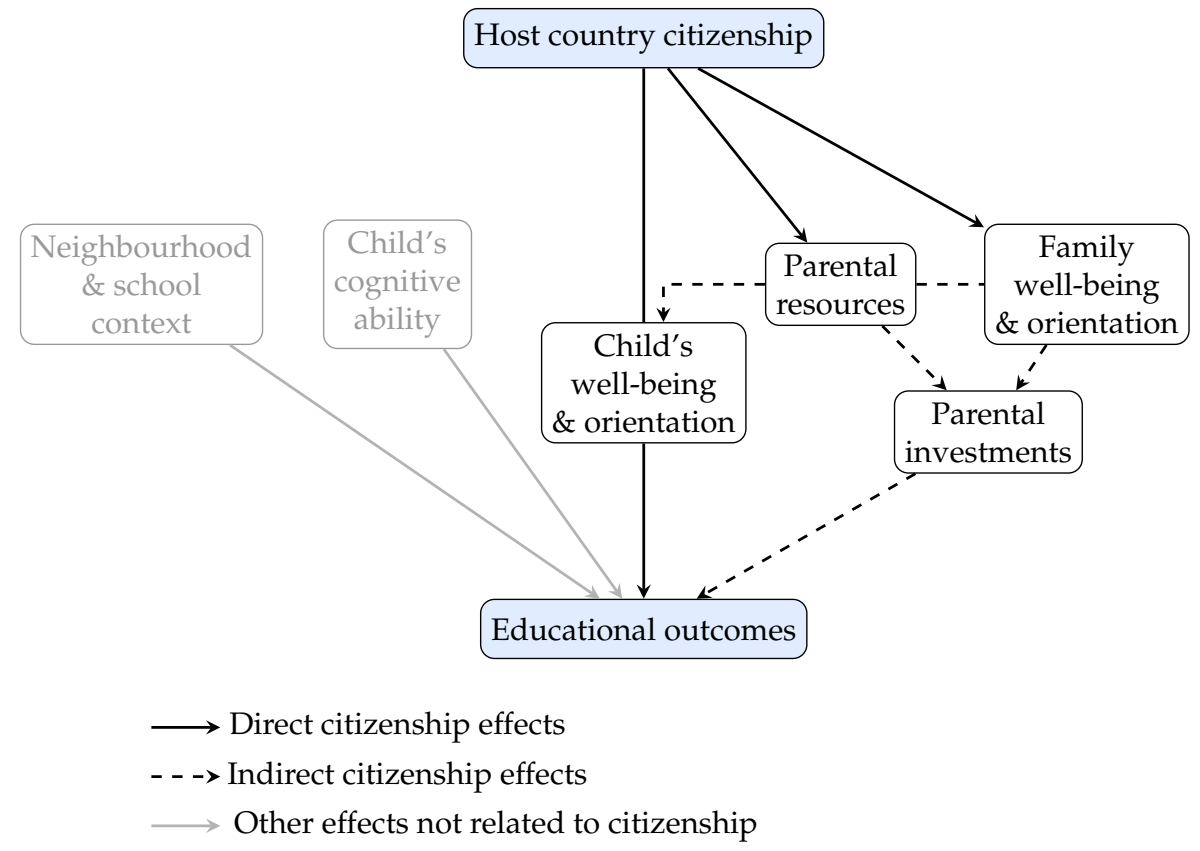

Figure 2.1: Diagram for the direct and indirect effects of host country citizenship on educational outcomes. 
citizenship. On the other hand, studies focusing on the legal status of the descendants of immigrants rarely isolate its effects on educational outcomes alone. At the intersection is a series of quantitative studies analysing the effect of citizenship on educational outcomes, from which this dissertation directly follows on. I showed that this existing research can be integrated into a more comprehensive theoretical framework that draws from the sociology of education as well as from migration and citizenship studies.

Figure 2.1 represents schematically the main theoretical channels I explored in this chapter for the effects of citizenship. First, the acquisition of host country citizenship may have a direct effect on the educational outcomes of the second generation, by increasing their well-being, aspirations and motivation to succeed in school. Second, or alternatively, citizenship may indirectly affect educational outcomes through parents' improved position in the host society. Better access for parents to socioeconomic resources and increased orientation to the destination country can enable them to invest more in their chil-

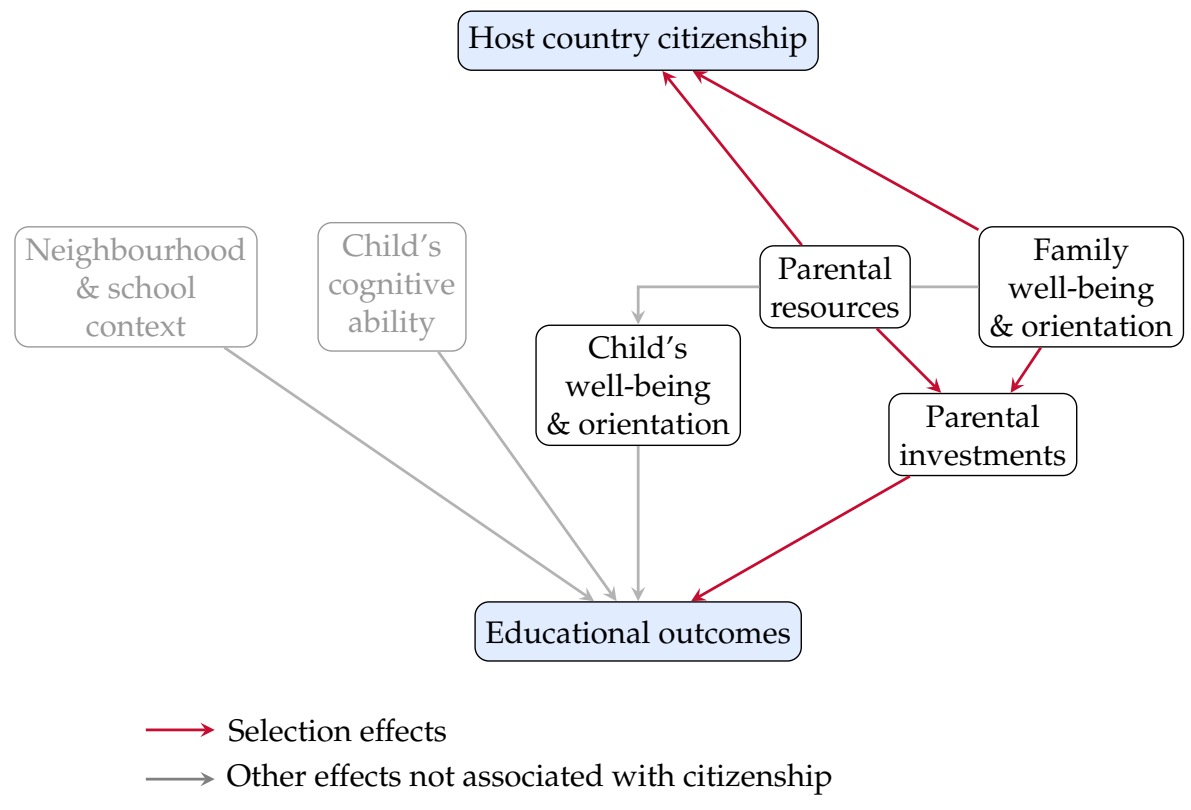

Figure 2.2: Diagram for selection effects between host country citizenship and educational outcomes. 


\section{Chapter 2}

dren's educational careers. These two mechanisms illustrate, better than previous theoretical approaches, the interplay between children's own agency and their dependence on their family context. In Chapter 4, I build on this theoretical framework to analyse whether Dutch citizens of immigrant descent navigate the school system differently from their foreign citizen peers.

In the last section, I added a layer of complexity to this model by introducing potential interaction effects with the timing of citizenship acquisition and the social background of the family. I expect both the direct and indirect effects of citizenship to be greater the earlier the citizenship of the host country is acquired and the more modest the family background; two hypotheses that will be tested in Chapter 5. I also discussed an alternative mechanism that would account for a positive association between citizenship and education. Figure 2.2 illustrates possible selection effects, with parents' resources and orientation affecting both their naturalisation propensity and the school performance of their children. In Chapter 5, I develop an analytical strategy to assess the extent to which such a mechanism might confound the observed relationship between citizenship and education.

With this chapter, I aimed to offer solid theoretical foundations for an independent effect of citizenship on school outcomes. However, it is important to note that the analyses presented hereafter will not always allow to identify or isolate the mechanisms at play. In particular, the data used do not make it possible to distinguish between direct and indirect effects, nor to operationalise and measure complex concepts such as "orientations" or "well-being". Nevertheless, I argue that a comprehensive theoretical framework is crucial to elaborate well-grounded hypotheses and interpret the empirical results. Furthermore, conceptual clarity is key for future work to further disentangle the different channels that link citizenship and education. 


\section{The intergenerational impact of naturalisation reforms: the citizenship status of the children of immigrants in the Netherlands, 1995-2016}

This chapter is adapted from: Labussière, M. and Vink, M. (2020). The intergenerational impact of naturalisation reforms: the citizenship status of children of immigrants in the Netherlands, 1995-2016. Journal of Ethnic and Migration Studies, 46(13):2742-2763. 


\section{Introduction}

In recent decades, naturalisation requirements have become increasingly strict in Europe (Vink and de Groot, 2010), with prospective citizens often required to meet language and country-specific requirements (Goodman, 2010). At the same time, being born in a European country is not - or is no longer - enough to make a child one of its citizens, owing to the predominance of ius sanguinis citizenship provisions whereby children have rights to the citizenship of their parents, not their country of birth (Honohan and Rougier, 2018, p.350). In this context, children of immigrants rely on their parents' ability and desire to naturalise if they are to acquire the citizenship of the host country (Honohan and Rougier, 2018, p.335). Therefore, restrictive naturalisation reforms not only affect immigrants' propensity to naturalise, as previous research has shown (e.g., Peters et al., 2016), but we can also expect such reforms to prevent their children from becoming citizens of their country of birth and residence. ${ }^{1}$ This potential intergenerational impact seems of crucial importance in European countries where the so-called second generation represents a sizeable and growing proportion of the population (Heath et al., 2008).

To our knowledge, such intergenerational effect of naturalisation reforms has never been investigated. Overall, children's citizenship has not received much attention, making it difficult to assess who acquires host country citizenship among second-generation children, let alone when and under which conditions. This lack of attention is puzzling considering growing evidence of the detrimental effects of legal insecurity on young people's well-being and their opportunities for the future (Cebulko, 2014; Patler, 2017; Bean et al., 2011; Colombo et al., 2011; Felfe et al., 2020). Analysing the potential intergenerational effects of naturalisation reforms requires a better understanding of how children's citizenship relates to the legal status of their parents, which departs from the traditional individual- and adult-centred perspective prevailing in citizenship studies (Soehl et al., 2018; Street, 2014; Cohen, 2005).

Building on recent developments in the field (Street, 2014; Soehl et al., 2018; Street, 2013), we propose to explore the intra-family dynamics at play in the

\footnotetext{
${ }^{1}$ This paper only focuses on children who were born in the host country and leaves aside the so-called "1.5 generation", i.e. children who were born in a foreign country before migrating at a young age. Although the 1.5 generation may also be affected by restrictive naturalisation laws, the specific requirements it faces in terms of citizenship acquisition warrant a separate analysis. The term "children of immigrants" thus exclusively refers to the second generation. Note that the term identifies individuals in their capacity as offspring of immigrants rather than as minors.
} 
naturalisation of immigrants' children. We discern two approaches that families take to naturalisation, differentiating whether parents seek citizenship for all members (complementary) or for their children only (differentiated). Based on these approaches, we analyse to what extent naturalisation reforms influence patterns of citizenship acquisition by second-generation children. Thanks to its methodological approach, this paper also contributes to work on the impact citizenship reforms have on the propensity of immigrants to naturalise (Stadlmair, 2017; van Oers, 2013; Vink et al., 2013; Green, 2012; Mazzolari, 2009). Our use of longitudinal micro-level data and event history models enables us to move beyond the mere description of naturalisation trends and makes it possible to analyse how legal requirements affect naturalisation propensity over time. Depending on the kinds of barriers they face to acquiring host country citizenship, we expect immigrants either to postpone making an application to meet the new requirements or to be put off from applying altogether. We argue that such a distinction is both conceptually useful and empirically necessary in assessing the long-term consequences of naturalisation laws.

We focus on the Netherlands to illustrate the intergenerational impact of naturalisation reforms in Western Europe. We do so for two reasons. First, the Netherlands is representative for most European countries where, in order to acquire citizenship, children of immigrants primarily rely on their parents' naturalisation (Honohan and Rougier, 2018). Second, various naturalisation reforms in the Netherlands over the past three decades reflect those issues most widely debated in Western Europe: dual citizenship acceptance, on the one hand, and language and civic knowledge requirements for naturalisation, on the other (Goodman, 2010; van Oers, 2013, pp.41-66). In this paper we focus on two significant reforms in particular: the end of a temporary dual citizenship liberalisation in 1997, and the introduction of a language and naturalisation test in 2003. Drawing on register data from Statistics Netherlands, we analyse the naturalisation propensity of children born between 1995 and 2010 to two foreign-born parents. Using Cox regression models, we show that the Dutch naturalisation reforms are associated with a lower naturalisation propensity among second-generation children, with a much stronger though less lasting effect for the 2003 reform. Whereas the prohibition of dual nationality seems to dissuade some immigrant families from naturalising, the integration requirements mainly postpone naturalisation of children to a later date. In addition, a cause-specific hazards model shows that children are more likely to naturalise with only one of their parents instead of both when they are eligible after the implementation of the reforms, suggesting that nat- 


\section{Chapter 3}

uralisation laws also affect immigrant families' naturalisation patterns.

\section{Becoming a Dutch citizen}

According to the Migrant Integration Policy Index 2015 (MIPEX), Dutch law can be considered as "slightly favourable" in terms of access to nationality. ${ }^{2}$ MIPEX takes into account several dimensions, including eligibility criteria, naturalisation requirements, and attitude towards dual citizenship. Compared to other European countries, both the minimum length of required legal residence of five years (three years if married to a Dutch citizen) and the A2 language proficiency requirement are considered moderate. However, acquiring Dutch citizenship is still not easy. The language exam incorporates a "knowledge of Dutch society" component, which candidates have to prepare on their own (van Oers, 2013, pp.60-64). Furthermore, the costs of both the examination and the courses candidates often need to take have to be paid by candidates themselves, which can act as a substantial financial barrier (van Oers, 2013, pp.60-64). Finally the Netherlands does not recognise dual citizenship; it requires (with some exceptions) candidates to renounce their existing nationality in order to acquire Dutch citizenship (Vink and de Groot, 2010, p.721).

\section{Evolution of Dutch citizenship law: the 1997 and 2003 reforms}

This current citizenship regime is the result of significant changes over recent decades. As in a number of other countries in Western Europe (Vink and de Groot, 2010), access to citizenship in the Netherlands has been reformed, especially since the 1990s (van Oers, 2013, pp.41-66). Two institutional changes are of particular interest for this paper. The first was the reintroduction in 1997 of a requirement that candidates for Dutch citizenship renounce their current nationality. Between 1992 and 1997, this dual citizenship restriction had been temporarily abolished, which is likely to have contributed to a considerable rise in the number of naturalisations (van Oers et al., 2009, p.17; Mazzolari, 2009). The second key change was the introduction of a naturalisation test in 2003 with the passing of the revised Dutch Nationality Act. This act reflected a growing emphasis, which can also be observed in other countries, on the notion of "active citizenship" and on the

\footnotetext{
${ }^{2}$ Retrieved from http://www.mipex.eu/access-nationality [accessed May 29, 2019].
} 
importance of immigrants taking responsibility for their own integration trajectories (Goodman, 2010, p.766; van Oers, 2013, p.48). The act raised and formalised the level of skills candidates required for naturalisation, and it also brought a substantial increase in naturalisation fees. Added to the administrative cost of the procedure $-€ 336$ for one person and $€ 427$ for a couple applicants had to pay to take the naturalisation test $(€ 260){ }^{3}$ The new law led to a significant and seemingly permanent decrease in the number of naturalisations, with a particularly detrimental effect on vulnerable groups (van Oers, 2013, pp.147-217). To our knowledge, however, no study has analysed how these reforms affected the acquisition of Dutch citizenship by children of immigrants.

\section{Acquiring Dutch citizenship when born in the Netherlands}

The legal provisions concerning the acquisition of Dutch citizenship are marked by the country's ius sanguinis tradition, which determines citizenship by descent rather than by place of birth (Vink and de Groot, 2010). The main consequence for individuals born in the Netherlands to immigrant parents is that they do not get automatic birthright citizenship. Instead, they may get Dutch citizenship through four main procedures, depending on the legal status of their parents and on whether they are below or above the age of majority (Figure 3.1).

The first option is to automatically receive Dutch citizenship by descent if at least one parent has naturalised before the child's birth, though specific provisions apply if this is the father. Second, the children of immigrants can be included in the naturalisation procedure of (one of) their parents as minors. And third, they can apply for citizenship autonomously from the age of 18 onwards. In the latter case, young people born in the Netherlands may benefit from the simplified "option procedure", provided that they have been living in the Netherlands since birth. Acquiring Dutch citizenship by option procedure has several advantages compared to the naturalisation procedure: it is less costly, ${ }^{4}$ quicker, ${ }^{5}$ and does not involve a civic integration test. How-

\footnotetext{
${ }^{3}$ See the overview of naturalisation costs over time in the Supplementary Materials (section VI).

${ }^{4}$ In 2003 the option procedure cost $€ 128$, against $€ 336$ for a single naturalisation application (see section VI in the Supplementary Materials). While the latter continuously increased over time to $€ 881$ in 2019 , the fees for the option procedure have remained relatively stable ( $€ 187$ in 2019).

${ }^{5}$ Waiting times are a maximum of 13 weeks for the option procedure, versus 12 months for the naturalisation procedure (van Meeteren et al., 2013, p.129).
} 


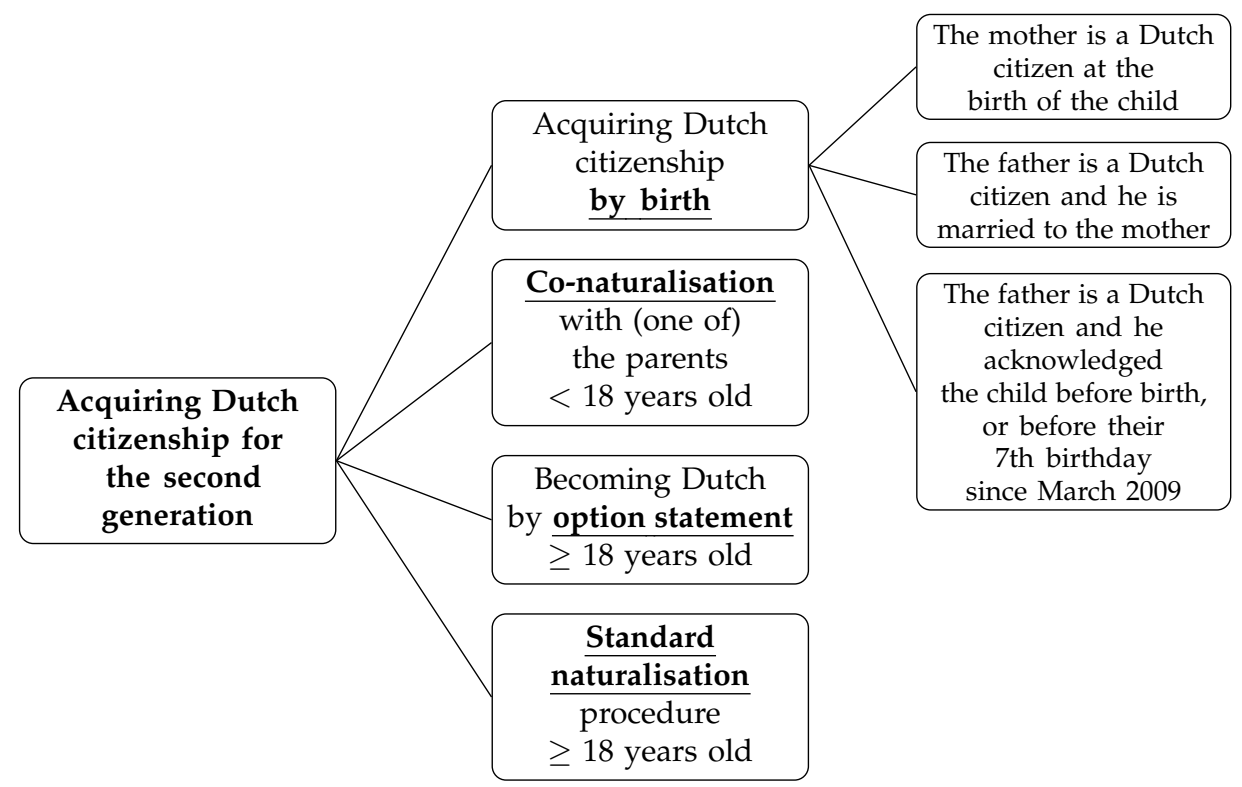

Figure 3.1: Main procedures for the acquisition of Dutch citizenship by immigrants' children born in the Netherlands. 
ever, the condition of continuous residence in the Netherlands is a potential obstacle, one that especially affects children whose families have moved between countries at various times during their upbringing (van Geel and Mazzucato, 2018). In all four procedures, it is important to note that the children of immigrants are exempted from the requirement to renounce their nationality. By contrast, their parents "must be willing to renounce" their existing citizenship to be eligible for Dutch naturalisation, providing an additional obstacle for individuals who wish to maintain a formal citizenship link with their country of origin (Soehl et al., 2018, p.14; van Oers et al., 2009, pp.1719). Interestingly, relatively few children make use of the option procedure: between 2005 and 2009, applications submitted for Dutch citizenship on the grounds of continuous residence in the Netherlands since birth (article 6.1a RWN) represented between 4.6 and $6.6 \%$ of all applications (IND Informatieen Analyse Centrum, 2011, p.26). ${ }^{6}$ This suggests that children largely depend on their parents when it comes to becoming a Dutch national, calling for a conceptualisation of citizenship acquisition at the family level.

\section{Analytical framework}

\section{Bringing back the family}

Becoming a Dutch citizen confers a number of rights, namely the rights to vote in national elections, to join the armed forces, and to access various highranking positions in the law and public sectors. It also provides the right to a Dutch passport, which allows for considerable international mobility. This is especially valuable for citizens of non-EU countries, who are granted the right to move, work and reside in every country within the EU and then to return to the Netherlands after having been abroad for an unlimited period of time.

While immigrants value these benefits differently according to their background and preferences, they also base their decision to seek Dutch citizenship on a number of constraining factors, since the naturalisation procedure

\footnotetext{
${ }^{6}$ Unfortunately, the IND does not provide information about the number of applications submitted by second-generation individuals. The given percentage is therefore an approximation of how frequently Dutch citizenship is acquired on the grounds of continuous residence among the second generation. Yet, the idea that children largely rely on their parents to acquire Dutch citizenship is confirmed by our descriptive statistics (Table A2), which show that $96 \%$ of those who become Dutch after birth do so before the age of 18 .
} 


\section{Chapter 3}

involves substantial financial and non-financial costs. Owing to this selfselection process, a number of characteristics have been shown to be associated with naturalisation propensity (for an overview, see Peters and Vink, 2016, p.363-364). Among the most common factors, income, level of education, length of residence and marriage are all positively associated with naturalisation. Immigrants' country of origin, which shapes the relative attractiveness of host country citizenship, has also been found to be an important factor, together with other contextual variables related to the origin and destination countries (Vink et al., 2013).

Following the approach of Yang (1994), most studies model naturalisation as an individual decision, based on a cost-benefit calculation. Even when family characteristics are included, such as the presence of a spouse or of children (e.g., Peters et al., 2016), the decision to naturalise is not conceptualised at the family-level. As Street (2014) argues based on the German case, this methodological individualism limits our understanding of citizenship acquisition among immigrants and does not adequately account for recent trends in naturalisation rates. By contrast, an altruistic model where parents may decide to naturalise for the sake of their children better explains why the partial introduction of ius soli in 2000 was followed by a decrease in naturalisation rates in Germany. Soehl et al. (2018) have further highlighted the importance of family dynamics, showing that having a parent who naturalised in the same year is the most important factor in explaining the naturalisation propensity among 1.5 generation young adults in Los Angeles. While these recent developments in the literature show that intra-family dynamics do matter, we still know very little about how immigrant parents perceive host country citizenship for themselves and their children, let alone how these perceptions result in different family patterns of naturalisation.

As a first analytical step towards a better understanding of family dynamics in naturalisation decisions, we distinguish between two main approaches families take to naturalisation. The first approach, which we shall term complementary, derives from Street's (2014, p.287) idea that citizenship may be a complementary good within the family, i.e., that it confers higher utility if consumed by all family members. A complementary approach to naturalisation stresses the idea of interdependence between family members. It translates into a preference for co-naturalisation of the whole family whenever possible. This is particularly important when it comes to international mobility, as parents may only be able to reap the benefits of the host country passport if all family members possess a passport as well, so as to be mobile together. The significant costs associated with naturalisation may also be- 
come more affordable if shared, ${ }^{7}$ as suggested by qualitative evidence from Austria (Street, 2013).

The second approach that families take to naturalisation we term differentiated. A differentiated approach means that only some family members seek to naturalise. It emphasises the idea that while children largely depend on their parents when it comes to naturalisation, they have, at the same time, different motivations and interests in obtaining host country citizenship. Since they have lived in the host country since birth and have gone through its education system, children of immigrants are likely to be proficient in the host language and to subscribe to forms of belonging and self that are different from their parents (Kalmijn, 2019, p.1422; Heath et al., 2008, pp.222-24; Colombo et al., 2011). They are more likely than their parents to reap the long-term benefits of host country citizenship, with naturalisation sometimes yielding limited returns for parents, especially when they have already secured permanent resident status. The idea that children do not necessarily face the same trade-offs as their parents is supported by the evidence of an "intergenerational motive" for naturalisation (Street, 2014), with parents naturalising solely for the sake of their children in the absence of ius soli provisions. A differentiated approach to naturalisation thus emphasises the different costs and returns family members face vis-à-vis host country citizenship. In the Dutch context, we expect families taking a differentiated approach to naturalisation either to have the children co-naturalise with only one parent (assuming a two-parent household) to contain the overall costs of the procedure, or to rely on the option statement through which only the children would acquire Dutch citizenship.

Overall, we expect parents' choice of whether to naturalise - together or not - with their children or to wait for the option procedure when the children reach the age of majority to be shaped by a number of family-level dynamics. These include parents' socioeconomic resources and migration trajectories, but also family members' levels of attachment to their country of origin and orientation towards the host society. By employing these two main approaches to naturalisation, which call for further refining, we aim to elaborate on the concept of "embedded citizenship choice" suggested by Soehl et al. (2018), which stresses the inherent social dimension of the naturalisation process.

\footnotetext{
${ }^{7}$ In the Netherlands, naturalising together with a partner is far cheaper: in 2003 couples paid $€ 363$ (i.e., $€ 181.50$ each) to submit a joint application, against $€ 272$ to apply on their own. This premium of about $€ 90$ in 2003 has steadily increased over time to reach more than $€ 300$ in 2019 (see Supplementary Materials, section VI).
} 


\section{Chapter 3}

\section{The institutional context and our hypotheses}

Though we expect family to play a crucial role in the naturalisation propensity of the second generation, we also need to explore how decision-making processes take place within the family's broader environment. Whereas a number of studies have highlighted the importance of the institutional context in a cross-country comparison perspective (e.g., Stadlmair, 2017; Vink et al., 2013), less attention has been paid to studying the impact of legal provisions on individual ability or propensity to naturalise over time (Peters et al., 2016; Jensen et al., 2019; Mazzolari, 2009). We have three hypotheses relating to the legal context.

First, we expect naturalisation rates to drop after the implementation of stricter legal requirements. This is because stricter naturalisation laws either reduce the number of eligible candidates or add additional barriers that individuals are no longer able or willing to overcome (Jensen et al., 2019; Goodman, 2010, p.757). While published studies usually observe decreased naturalisation rates after the introduction of stricter regulations (Green, 2012; Perchinig, 2010; van Oers, 2013), with the use of aggregated data it is not possible to analyse how this translates at the individual level: do people give up the idea of becoming citizens of their country of residence, or do they postpone naturalisation to a later date? The answer has consequences when assessing the long-term impact of restrictive naturalisation laws. Based on Goodman's distinction between "restrictive" and "thick" changes 2010, we expect that the impact of citizenship law will differ based on the type of requirements. On the one hand, "restrictive" changes limiting citizenship eligibility may permanently prevent certain categories of immigrants from naturalising. With a prohibition against dual citizenship, those who want to hold on to their existing nationality exclude themselves from becoming citizens of their new country. In the Netherlands, we thus hypothesise that the end of dual-citizenship tolerance in 1997 is associated with a durable drop in naturalisation propensity for families falling under this new requirement (hypothesis 1).

On the other hand, "thicker" definitions of citizenship that increase candidates' obligations (requiring, for example, good language skills or knowledge of the host country) may prevent naturalisation for some, but postpone it for others - for those who need more time and/or additional resources before beginning the naturalisation process. This is what we would expect following the 2003 reform in the Netherlands, which required candidates to pass a language and integration test which they were not necessarily prepared to complete right away. With postponement a possibility, we hypothesise that 
for those who were eligible after the 2003 reform, there is an initial drop in naturalisation rates that at least partly recovers over time (hypothesis 2).

Besides seeing a change in the total number of naturalisations, we also expect stricter requirements to affect the composition of the naturalised population (Hainmueller et al., 2018; van Oers, 2013). As candidates for naturalisation need more resources to go through the procedure (e.g. to finance language or integration courses), we expect naturalised citizens to be positively selected for income and level of education. But how are intra-family dynamics affected by the need for financial and educational resources? We hypothesise that when more restrictive or thicker naturalisation requirements apply, families will find it harder to seek the naturalisation of all family members because of the costs and effort involved. Even if parents have a preference for the complementary approach, they are likely to adopt a differentiated approach when the naturalisation of both parents is too costly. In two-parent households, children may therefore naturalise with only one parent - the parent best equipped to negotiate the naturalisation process and for whom the costs are lowest. The costs may not only involve the time or money required for the application process and integration course, they may also be emotional, such as when parents are required to renounce their home country citizenship (Mazzolari, 2009, p.173). The requirements of naturalisation may thus lead to a strategic division of tasks between parents, which aims to minimise the cost of citizenship acquisition at the family level. When the costs of naturalisation are too great, naturalisation may be postponed to a later date or children may naturalise via the option procedure. Overall, we expect restrictive legal reforms to affect families' decision-making processes, with available resources restricting the preferences families otherwise have for naturalisation. As a result, we expect that families falling under the new requirements of the 1997 and 2003 reforms will be more likely to follow a differentiated approach to naturalisation than a complementary approach, compared to those eligible before (hypothesis 3).

\section{Data and Methodology}

\section{Register data and study population}

Our data are drawn from Dutch administrative registers supplied by Statistics Netherlands. Registers offer longitudinal and individual-level data covering the entire legally resident population of the Netherlands (Bakker et al., 


\section{Chapter 3}

2014a), limiting the possibilities of selection bias and guaranteeing sufficient statistical power. For our research, we followed nearly all immigrants legally residing in the Netherlands from 1995 to 2016 (our observation window), together with their partners and their children. ${ }^{8}$ Our analysis will focus on the children, restricted to the 1995-2010 birth cohorts, which we tracked for a period of 6 (cohort 2010) to 21 (cohort 1995) years.

We define second-generation children as those born in the Netherlands to two foreign-born parents, who themselves are born to at least one foreignborn parent. Children of mixed descent are excluded from the scope of our analysis because, having one native parent, they ought to obtain Dutch citizenship at birth by descent. Children born in the Netherlands from secondgeneration parents - the third generation - are not included either, since they acquire automatic birthright citizenship according to the so-called double ius soli principle. For related reasons, we also exclude children from specific origin groups from the analysis: children originating from the Caribbean territories of the Kingdom of the Netherlands, who are Dutch citizens; and children whose parents come from the former Dutch colonies and thereby had privileged access to Dutch territory and citizenship (van Meeteren et al., 2013, pp.115-116). ${ }^{9}$ Finally, we exclude children who naturalised at a different date than their parents while minors, as well as children whose families engaged in non-standard naturalisation trajectories, involving a loss or renunciation of Dutch citizenship over time $(\mathrm{N}=6,780)$. This leaves us with a final dataset of 287,250 individuals.

Within this population, $66 \%$ of children were Dutch citizens at birth and thus acquired Dutch citizenship by descent through the prior naturalisation of their parents (for descriptive statistics, see Tables A1 and A2 in the Supplementary Materials). Among the remaining children, who are thus foreign citizens at birth, 21\% acquired Dutch citizenship during our observation period (1995 to 2016), representing a naturalisation rate of nearly $62 \%$, while $13 \%$

\footnotetext{
${ }^{8}$ Due to the administrative nature of the data, those identified as "parents" in the dataset are children's legal guardians but not necessarily the ones with whom children are actually living. However, minors can only naturalise together with their legal guardians. Potential divorces or remarriages are also not captured by our data, at least when this does not result in a change in parental authority. Note that children who changed both of their legal guardians during the observation period $(\mathrm{N}=529)$ have not been included in the analysis.

${ }^{9}$ The countries in question are Suriname, Indonesia and Netherlands New Guinea, which are former Dutch colonies, and Aruba and the Netherlands Antilles, which belong to the Kingdom of the Netherlands.
} 
were still foreign citizens in $2016 .{ }^{10}$ These proportions change slightly if we only measure naturalisation for those who are eligible during the observation period, $3 \%$ of the children never being eligible due to their parents' limited length of residence in the Netherlands. Among those who naturalised, 96\% did so before age 18, in line with our hypothesis that children mainly depend on their parents to acquire host country citizenship.

Furthermore, the patterns of acquisition of Dutch citizenship evolved substantially over time. As Figure 3.2 shows, there is an upward trend in the percentage of children who are Dutch citizens at birth, which is consistent with the fact that immigrants eligible for naturalisation in the 1990s could acquire Dutch citizenship under favourable conditions; their children born in the early 2000s were more likely than their older peers to acquire Dutch citizenship at birth by descent.

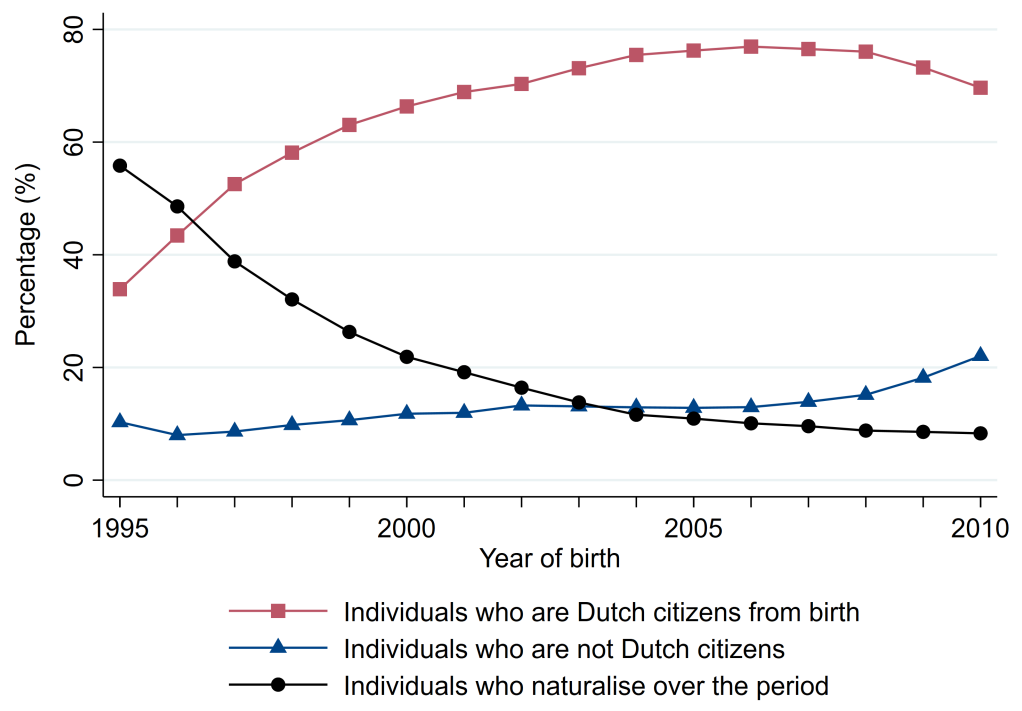

Figure 3.2: Dutch citizenship acquisition by immigrants' children born in the Netherlands, by year of birth $(\mathrm{N}=287,250)$.

\footnotetext{
${ }^{10}$ This percentage drops to $9.8 \%$ if we restrict the sample to those born in 1995 and 1996, who had respectively 21 and 20 years to naturalise within our observation window.
} 


\section{Chapter 3}

Figure 3.2 also indicates a decreasing naturalisation propensity, in line with the fact that more and more children are Dutch from birth over the period. However, we also observe an increase in the percentage of children who do not acquire Dutch citizenship at all during the observation period, which may reflect a detrimental effect of the 1997 and 2003 naturalisation reforms. However, the last two curves have to be interpreted with caution due to right censoring: the succeeding birth cohorts have less and less time to naturalise within the observation period. Besides, changes in the composition of the immigrant population may explain at least part of these trends, which requires controlling for other factors. The methodology we develop in the next section will address both points. We first discuss this methodology in general terms, before providing more detail about our specification when presenting our operationalisation and covariates.

\section{Empirical strategy}

To test our first two hypotheses pertaining to children's naturalisation propensity over time, we use event history models. Event history analysis is well suited to analyse the timing and occurrence of an event over time once individuals under observation have entered a specific risk set. In our case, the event of interest is acquisition of Dutch citizenship and entrance into the risk set is based on children's eligibility. Eligibility is defined as follows: children under 18 are eligible as soon as one or both of their parents become eligible (co-naturalisation); those above 18 are eligible if they have resided permanently in the Netherlands since birth (option procedure); otherwise, children are eligible after five years of uninterrupted residence in the Netherlands (standard naturalisation). ${ }^{11}$ Individuals are included in the estimation once they enter the risk set, which means that those who are never eligible during the observation period and those who are Dutch from birth are excluded from the analysis.

The main advantage of this approach is that it takes into account right censoring, which is particularly crucial here as we only observe children during a limited period of time, especially for the younger birth cohorts. To allow for the inclusion of both time-invariant and time-varying covariates when estimating the rate of naturalisation at a given time, we use a Cox proportional

${ }^{11}$ The construction of the eligibility variable is further detailed in the Supplementary Materials (section VII). 
hazard model. For subject $j$, the hazard rate has the following form:

$$
h\left(t \mid x_{j}\right)=h_{0}(t) \exp \left(x_{j} \beta_{x}\right)
$$

where $x$ and $\beta_{x}$ refer to the covariates and their associated coefficients, $t$ to time, and $h_{0}(t)$ is the baseline hazard. The main strength of the Cox model is that it allows us to estimate the effect of the covariates $\beta_{x}$ on $h\left(t \mid x_{j}\right)$ without making assumptions about the functional form of the baseline hazard. However, this flexibility comes at the price of the proportional-hazards assumption: the assumption that all subjects' hazard ratios are proportional and that this proportionality is maintained over time. When the effect of covariates on the hazard varies over time, the proportionality assumption is violated, leading to biased estimates and decreased statistical power (BoxSteffensmeier et al., 2003, p.974). In this paper, we use two techniques to relax this assumption.

The first technique consists in stratifying the model by the non-proportional variable(s), which relaxes the hypothesis that the baseline hazard is the same across strata. The hazard ratio depends then on the specific stratum $s$ to which the subject $j$ belongs:

$$
h\left(t \mid x_{j}\right)=h_{0 s}(t) \exp \left(x_{j} \beta_{x}\right)
$$

Though this allows for more flexibility, this technique is mostly suitable for control variables, as it is no longer possible to directly estimate the effect of the variables used for the stratification. When the proportional-hazards assumption is violated for variables of interest, we instead use time-by-covariate interactions to directly model time dependency. This is the second technique, which leads to the following specification:

$$
h\left(t \mid x_{j}, y_{j}\right)=h_{0 s}(t) \exp \left(x_{j} \beta_{x}+y_{j} \beta_{y}+\alpha_{y} y_{j} f(t)\right)
$$

where $y$ refers to the covariate(s) for which an interaction with time has been added, $\alpha_{y}$ to the time-varying coefficient(s) and $f$ to a function of time. Following Box-Steffensmeier et al. (2003), we have chosen the natural logarithm for $f(\ln (t))$, which reflects a decreasing effect of the covariate(s) over time (further details below). Time-varying coefficients have been added based on an analysis of the Schoenfeld residuals (see Figures A1-A2, Supplementary Materials).

Finally, to test our third hypothesis about the impact of the Dutch legislative reforms on families' approaches to naturalisation, we follow a cause-specific 


\section{Chapter 3}

approach by applying separate Cox regression analyses to different events (Dignam et al., 2012). This method allows differentiating between (1) naturalisation with only one parent and (2) naturalisation with both parents. ${ }^{12}$

\section{Operationalisation and covariates}

Our main variable of interest is children's cohort of eligibility (eligibility cohort), based on the year they first became eligible to seek Dutch citizenship. In order to study the impact of the requirement that candidates for Dutch citizenship both renounce their existing citizenship and complete a civic integration test, we cluster eligibility cohorts into three main categories: eligibility between 1995 and 1997 (when dual nationality was tolerated); eligibility between 1998 and 2002 (when the citizenship renunciation requirement was re-introduced); and eligibility from 2003 (when language and naturalisation tests were introduced). Examining the potential intergenerational impact of the legislative reforms through the lens of eligibility cohorts allows us to assess the impact of the new requirements on the length of time individuals take to become Dutch citizens once they become eligible. While individuals choose their date of application, they can hardly manipulate their eligibility and the specific legislative conditions they will face.

Our approach does have some drawbacks. We do not estimate the impact of the reforms strictly speaking, but rather the effect of being eligible in a specific legislative context, with varying opportunities for facilitated naturalisation. In addition, the longer the duration between the time a person becomes eligible and their actual naturalisation, the more likely candidates are to fall under different requirements. Two factors help to mitigate these limitations. First, an analysis of children's naturalisation propensity shows that the bulk of second-generation children naturalise shortly after eligibility, half of them within seven years (see Figure A3). Secondly, the decreasing relevance of the eligibility cohort over time can be assessed and modelled in a Cox regression. While an analysis of the Schoenfeld residuals confirms that we tend to overestimate the effect of the eligibility cohort over time, with a deviation from the proportional-hazards assumption after approximately 12 years, we can account for this decreasing effect by adding an interaction with the natural logarithm of time in our model.

\footnotetext{
${ }^{12}$ Due to our limited observation window and the fact that most children naturalise as minors, we do not have a sufficient number of independent naturalisations after the age of majority $(\mathrm{N}=2,367)$ to perform a separate analysis.
} 
We control for a set of family characteristics that are usually associated with naturalisation propensity (see Peters et al., 2016). Parents' socioeconomic status is proxied by two categorical variables (mother SES and father SES) that indicate whether the parents are in employment (including self-employment), are social benefit or pension recipients, or lack any registered source of income. ${ }^{13}$ A time-varying dummy EU origin country captures whether, in a given year, mother's or father's country of origin is a member state of the European Union, as naturalisation is expected to be of little value for those who already enjoy the rights and benefits attached to EU citizenship. ${ }^{14}$ To take into account potential dynamics at the family level, and notably the fact that parents may wish to start the naturalisation procedure at the same time, we add a time-varying dummy (both parents eligible) which equals one from the moment both parents are eligible to naturalise. Finally, we include mother's country of origin (origin country) ${ }^{15}$ to account for unobservable immigration and settlement patterns at the country level, together with national regulations concerning citizenship renunciation. Descriptive statistics show substantial variation in naturalisation propensities across countries of origin (see Table A3), which results in a violation of the proportional-hazards assumption when looking at the residuals. As we are not interested in the effect of the origin country per se, we include mother's country of origin as a stratification variable in the model. Fifteen clusters have been distinguished based on the most represented groups in our population (see "country of origin" in Table A1).

For our competing risks specification, we identify whether the child naturalised with only one or with both parents by comparing parents' and children's dates of naturalisation. The variable obtained (naturalisation with whom) is used as a proxy for the family's approach to naturalisation. But this comes with an important caveat. A given family's approach is the result of a decision-making process, though the data do not allow us to unpack this. For example, the co-naturalisation of the child with only one parent may reflect

${ }^{13}$ Data for parental socioeconomic status is only available from 1998 onwards and may be missing over time (e.g., in case of outward migration). Missing values were grouped in the category "SES unknown" and included in all our models.

${ }^{14}$ We expect children whose parents come from an EU country to inherit EU citizenship since all countries of the European Union have ius sanguinis provisions (Honohan and Rougier, 2018, p.150).

${ }^{15}$ Note that $88 \%$ of children have parents who share the same country of origin and that there is a slightly higher number of missing parental identifiers among fathers. As a robustness check, we also conducted the analysis using father's country of origin, which led to highly similar estimates (Table A6). 


\section{Chapter 3}

parents' low interest in having all family members acquire Dutch citizenship, or it may reflect a default choice due to strict naturalisation laws. Though we are not able to identify the driving mechanisms, this imperfect lens helps to open further the "black box" of decisions about naturalisation by drawing attention to the diversity of naturalisation patterns at the family level over time. The descriptive results are interesting in that regard. While 39\% of the children becoming Dutch during the observation period naturalised at the same date as their parents, around $60 \%$ naturalised with only one - the mother or the father in equal proportions (Table A2). Furthermore, this pattern changes quite drastically over the observation period. As Figure 3.3 shows, there is a sharp decrease in the proportion of children naturalising with both parents from 2004 onwards, after which the proportion stagnates between 20-35\%. Conversely, the percentage of children naturalising with only one parent increases during the same period, with a reversal of the trend between fathers and mothers.

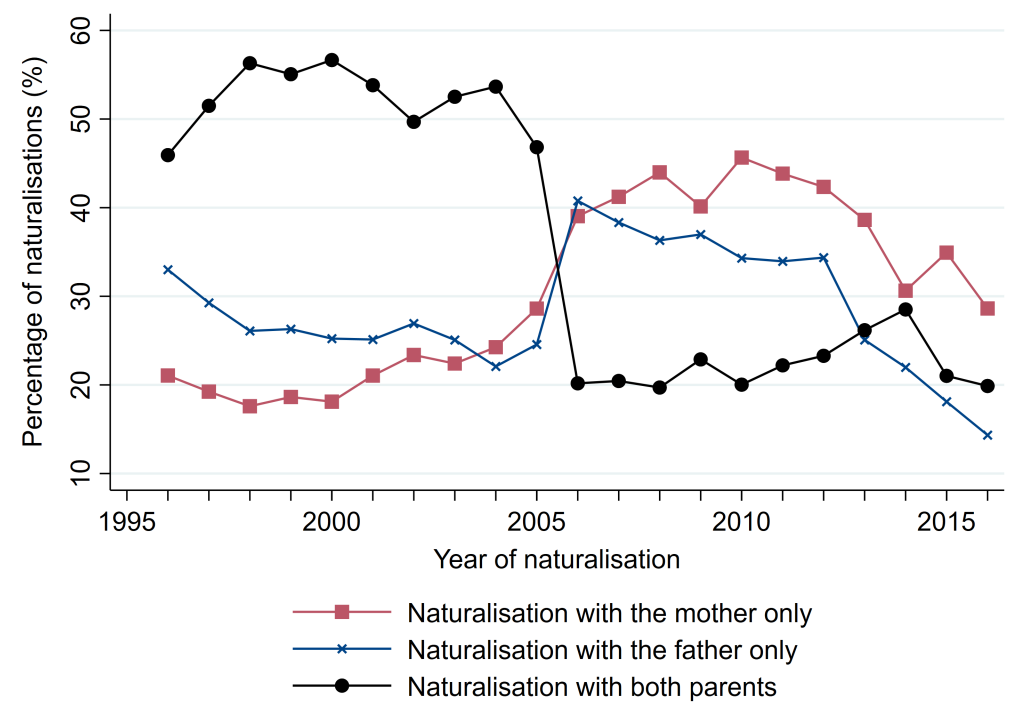

Figure 3.3: Family patterns of naturalisations before the age of majority among immigrants' children born in the Netherlands, by year of naturalisation $(\mathrm{N}=57,884)$. 


\section{Analysis}

\section{Assessing the impact of the eligibility cohort on naturalisation propensity}

Before conducting a Cox regression analysis, it is helpful to estimate the probability that a person will naturalise within a given number of years using the Kaplan-Meier estimator. This method considers right censoring but, contrary to the Cox model, does not require making any assumptions about how covariates change experience of the event (naturalisation). Figure 3.4 shows the distribution of naturalisation time by cohort of eligibility.

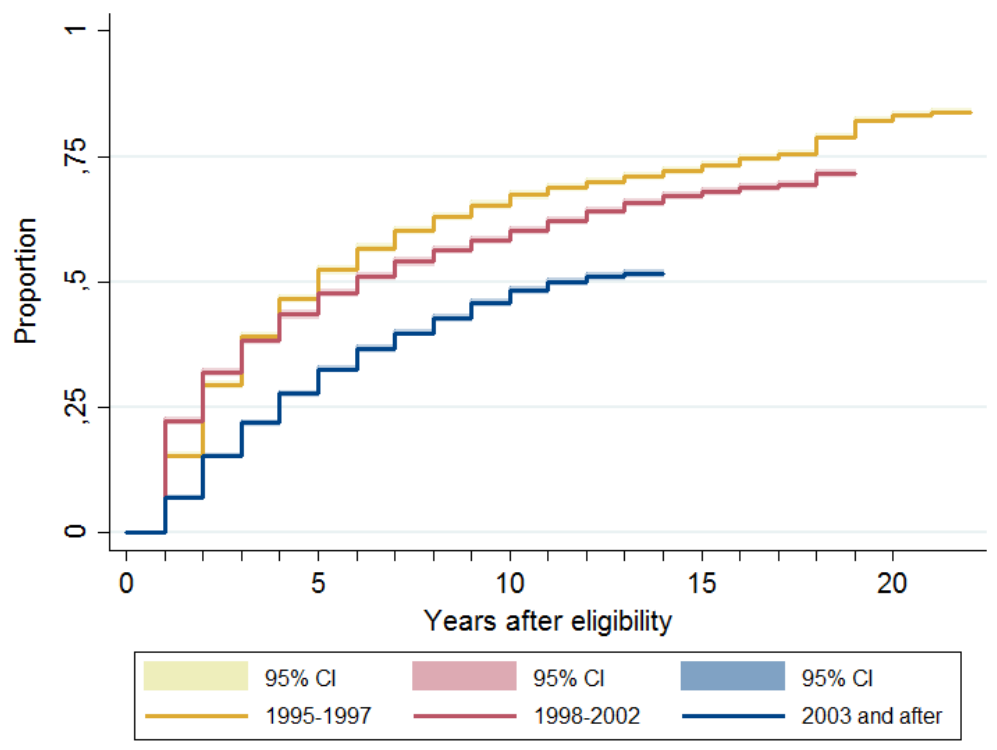

Figure 3.4: Acquisition of Dutch citizenship after birth by immigrants' children born in the Netherlands: Kaplan-Meier failure functions, by cohort of eligibility ( $\mathrm{N}=91,066)$.

Children who became eligible before the 1997 and 2003 reforms have a higher naturalisation propensity than those who became eligible later on. While the length of time between eligibility and naturalisation only slightly increases for those who became eligible between 1998 and 2002, there is a clear gap for those eligible after the 2003 reform. We can see that about half of the children eligible in the first two periods had naturalised within 5 years, whereas 


\section{Chapter 3}

this is only the case for $30 \%$ of those who became eligible in 2003 or afterwards. Notice that these discrepancies do not narrow much over time. The Kaplan-Meier estimates give a first indication of how being in a different eligibility cohort matters for children of immigrants' naturalisation propensity, suggesting a more substantial impact for the 2003 reform.

\begin{tabular}{|c|c|c|c|c|c|c|}
\hline & $\begin{array}{c}\text { Hazard } \\
\text { ratio }\end{array}$ & $\begin{array}{l}\text { Std. } \\
\text { Error }\end{array}$ & $\mathbf{z}$ & $\mathbf{P}>\mathbf{z}$ & \multicolumn{2}{|c|}{$\begin{array}{c}\text { 95\% Conf. } \\
\text { Interval }\end{array}$} \\
\hline & \multicolumn{6}{|c|}{ Main } \\
\hline \multicolumn{7}{|l|}{ Eligibility cohort (ref: 1995-1997) } \\
\hline Eligibility $1998-2002$ & 0.587 & 0.014 & -21.950 & 0.000 & 0.560 & 0.616 \\
\hline Eligibility 2003 and after & 0.199 & 0.006 & -57.250 & 0.000 & 0.188 & 0.210 \\
\hline EU origin country & 0.209 & 0.011 & -28.910 & 0.000 & 0.188 & 0.233 \\
\hline \multicolumn{7}{|l|}{ Mother SES (ref: employed) } \\
\hline Recipient of benefits & 1.014 & 0.014 & 0.980 & 0.326 & 0.986 & 1.042 \\
\hline No income & 0.782 & 0.010 & -18.960 & 0.000 & 0.762 & 0.802 \\
\hline SES unknown & 0.530 & 0.015 & -22.680 & 0.000 & 0.502 & 0.560 \\
\hline \multicolumn{7}{|l|}{ Father SES (ref: employed) } \\
\hline Recipient of benefits & 0.907 & 0.011 & -8.240 & 0.000 & 0.887 & 0.929 \\
\hline No income & 0.501 & 0.011 & -31.580 & 0.000 & 0.480 & 0.523 \\
\hline SES unknown & 0.915 & 0.022 & -3.720 & 0.000 & 0.873 & 0.959 \\
\hline \multirow[t]{2}{*}{ Both parents eligible } & 1.339 & 0.017 & 22.910 & 0.000 & 1.306 & 1.372 \\
\hline & \multicolumn{6}{|c|}{ Interacted with $\ln (t)$} \\
\hline \multicolumn{7}{|l|}{ Eligibility cohort (ref: 1995-1997) } \\
\hline Eligibility 1998-2002 & 1.083 & 0.014 & 5.960 & 0.000 & 1.055 & 1.111 \\
\hline Eligibility 2003 and after & 1.883 & 0.032 & 37.370 & 0.000 & 1.822 & 1.947 \\
\hline Number observations: 717,009 & \multicolumn{3}{|c|}{ Number of failures: 57,493} & \multicolumn{3}{|c|}{ LR Chi2(12): 9623.2} \\
\hline Number of individuals: 91,066 & \multicolumn{3}{|c|}{ Time at risk: 717013} & \multicolumn{3}{|c|}{ Log likelihood: -503890.1} \\
\hline Stratification by country of origin & \multicolumn{6}{|c|}{ Probability > Chi2: 0.000} \\
\hline
\end{tabular}

Table 3.1: Cox proportional-hazard model for the risk of naturalisation among immigrants' children born in the Netherlands $(\mathrm{N}=91,066)$.

We now turn to the Cox proportional-hazard model to see whether this trend is robust when adding covariates. Table 3.1 presents the results of our main Cox model (the coefficients have been exponentiated for ease of interpretation). As explained above, the regression has been stratified by mother's country of origin, and an interaction with the natural logarithm of time has been included for our main variable of interest, the eligibility period. In the first year following eligibility, the hazard rate associated with those eligible in 1998-2002 is 0.58 times that of those who were eligible in the first period, while the ratio goes down to 0.19 for those eligible after 2003. The eligibility 
cohort effect is precisely estimated and its magnitude is comparable to having a father without any registered source of income in the first case, or to having a parent coming from an EU member state in the second case.

Figure 3.5, which plots the hazard ratios over time, shows the results of the eligibility variable interactions with $\ln ($ time). We see that the large detrimental effect attached to the cohorts eligible after 2003 is substantially reduced a few years after eligibility: the hazard ratio comes closer to one over time, suggesting that parents needed more time to meet the stricter requirements of the naturalisation procedure. This delay may be necessary for people to prepare and pass the language and naturalisation test, but it may also allow them to save money for what is now a costlier procedure. The hazard ratio even passes 1 after 12 years, indicating that the cohorts eligible after 2003 need more than ten years to completely catch up with the older eligibility cohorts in terms of naturalisation propensity. Overall, this supports our expectation that naturalisation of children is mainly postponed after the introduction of civic integration requirements (hypothesis 2). However, as reflected in the larger confidence intervals, estimates are less reliable for long durations due to the lack of observations at the upper end. When looking at the lower bound of the confidence interval, the hazard ratio indeed remains below 1 even 15 years after eligibility.

Figure 3.5 offers a different picture of the effect on naturalisation propensity attached to the cohorts eligible between 1998 and 2002. The hazard ratio slightly increases but overall remains between 0.6 and 0.8. Contrary to the 2003 eligibility cohorts, the number of years since eligibility seems to have a limited impact on the hazard ratio, suggesting that some families have been permanently dissuaded from naturalising due to the citizenship renunciation requirement for parents. This is in line with our expectation that the end of dual citizenship tolerance in 1997 deterred families from acquiring Dutch citizenship (hypothesis 1). The moderate size of the effect is in line with the selective targeting of the renunciation requirement, from which a number of nationalities are exempted. By contrast, the 2003 reform offered very little ground for exemptions (van Oers, 2013, pp.61-62), which is consistent with a stronger effect in terms of magnitude. Altogether, these results support the idea that the naturalisation reforms have an effect on children's citizenship acquisition, though this effect differs based on the nature of the requirements that applicants for citizenship face: while we observe a decrease in naturalisation propensity for those who became eligible after the end of dual citizenship tolerance in 1997, there is an increase in the length of time between eligibility and naturalisation for those who became eligible after the 2003 reform. 


\section{Chapter 3}

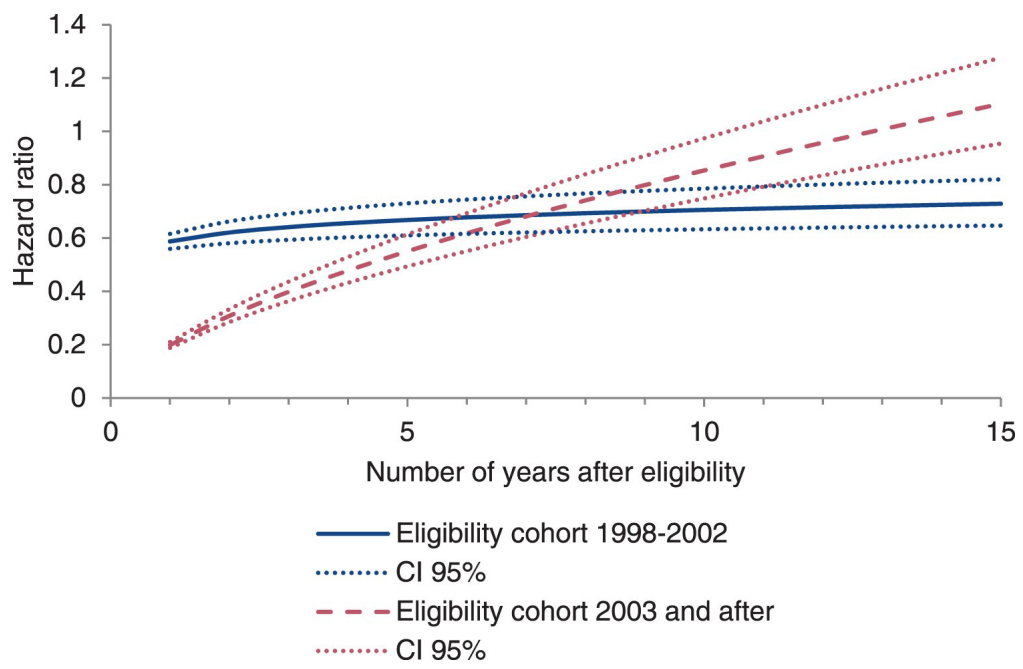

Figure 3.5: Acquisition of Dutch citizenship after birth by immigrants' children born in the Netherlands: odds-ratio associated with eligibility cohort categories (ref. 1995-1997), by years after eligibility $(\mathrm{N}=91,066)$.

Another finding relates to the time-varying dummy both parents eligible, which is positively associated with naturalisation propensity. The hazard rate is multiplied by 1.3 when children's parents are both eligible, suggesting an overall preference for parents to naturalise at the same time. This sheds additional light on the interpersonal dynamics involved in the naturalisation decision at the family-level (Soehl et al., 2018; Street, 2014). Although the data do not allow identification of the mechanisms at play, the substantial cost difference between a single person and a multiple persons request for citizenship in the Netherlands might be one of the reasons. This is in line with earlier qualitative findings (Street, 2013). Finally, we note that the coefficients associated with parents' socioeconomic status are in line with the literature on naturalisation propensity (e.g., Hainmueller et al., 2018): for children of immigrants whose parents are not employed the risk of naturalisation is substantially reduced, down to a hazard ratio of 0.5 for those whose fathers are recipients of benefits.

To assess the robustness of our findings, we compared the results of several alternative specifications. The main model was successively estimated without time-varying coefficients, with clustered standard errors by country of 
origin instead of stratifying, and with a more precise method for handling tied events (see section VIII in the Supplementary Materials). Estimates are fairly comparable across models and do not substantively alter our interpretation. As additional robustness checks, we also conducted the analysis with different eligibility groupings (2-year clusters, Table A4) and without any multi-year eligibility grouping (Table A5). This does not change the results substantially; while naturalisation propensity constantly decreases over time, we observe stair-step effects when comparing the eligibility cohorts 1997 (1997-1998) and 2003 (2003-2004) to the ones that precede.

\section{Differentiated family naturalisation patterns in context}

To test our third hypothesis - that the 1997 and 2003 reforms increased the likelihood of families taking a differentiated approach to naturalisation - we use a proportional cause-specific hazards model where naturalisation with both parents and naturalisation with only one parent are treated as competing events. We followed the same procedure as the main model for the specification; both regressions have been stratified by mother's country of origin and interactions with time have been added for the eligibility cohort following an analysis of the Schoenfeld residuals. The results of the two models are compared in Figure 3.6 (see Tables A7-A8 for full results and section VIII for the robustness checks).

The first year after eligibility, the hazard ratios for the second eligibility category (1998-2002) are similar across the two models. This is not the case for the last category (2003 and after), whose hazard ratio is far smaller when comparing naturalisation with both parents (coefficient estimate of 0.10 ) with naturalisation with one parent (0.29). Figures 3.7a and 3.7b highlight the differences over time, comparing between eligibility cohorts the risk of naturalisation with both parents (Figure 3.7a) and with only one parent (Figure 3.7b). We find that, for those children eligible for citizenship from 2003 onwards, the risk of naturalising with one parent only temporarily decreases (Figure $3.7 \mathrm{~b}$, hazard ratio crosses 1 in less than ten years), while the risk of naturalising with both parents durably diminishes (Figure 3.7a, hazard ratio is below 0.7 after 15 years). We observe a similar pattern for the children who are eligible after the dual citizenship restriction, though to a lesser extent. While the hazard ratio of naturalising with both parents slightly decreases before stagnating around 0.5 (Figure 3.7a), the one of naturalising with one parent converges towards one (Figure 3.7b). Furthermore, comparing the coefficients of the other covariates shows that traditional negative factors for naturalisation 


\section{Chapter 3}

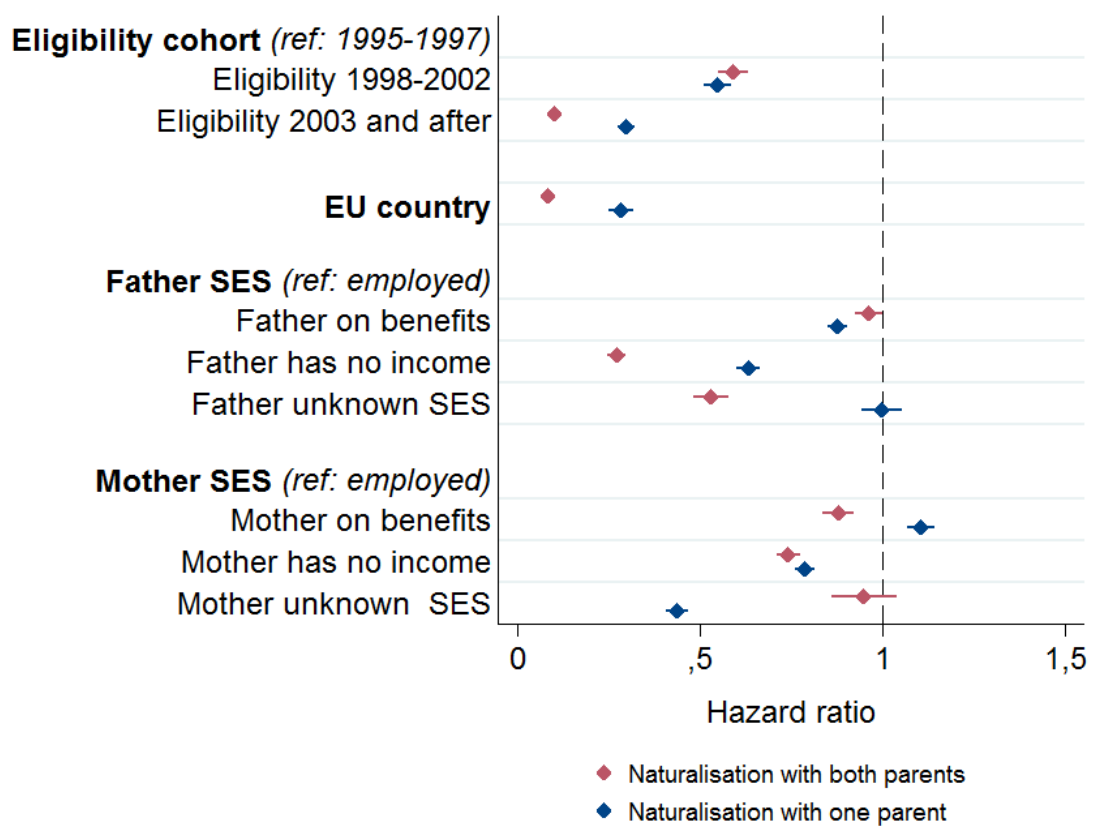

Figure 3.6: Acquisition of Dutch citizenship after birth by immigrants' children born in the Netherlands: coefficient plot for cause-specific hazards models $(\mathrm{N}=91,066)$.

Note: Coefficients associated with eligibility cohorts are main effects (i.e. one year after eligibility); interactions with the logarithm of time are represented on Figure 3.7 (a and $b$ ).

are more negatively associated with the propensity to naturalise with both parents. This is especially true for those children whose father has no registered source of income, compared to those whose father is (self )employed (hazard ratio of 0.27 versus 0.63 , see Figure 3.6).

These results support hypothesis 3 , according to which families falling under the requirements of the 1997 and 2003 reforms are more likely to secure host country citizenship at the lowest cost (via a differentiated approach) than to seek citizenship for all family members (complementary approach). Several mechanisms could be at play. First, the prohibition of dual citizenship may 

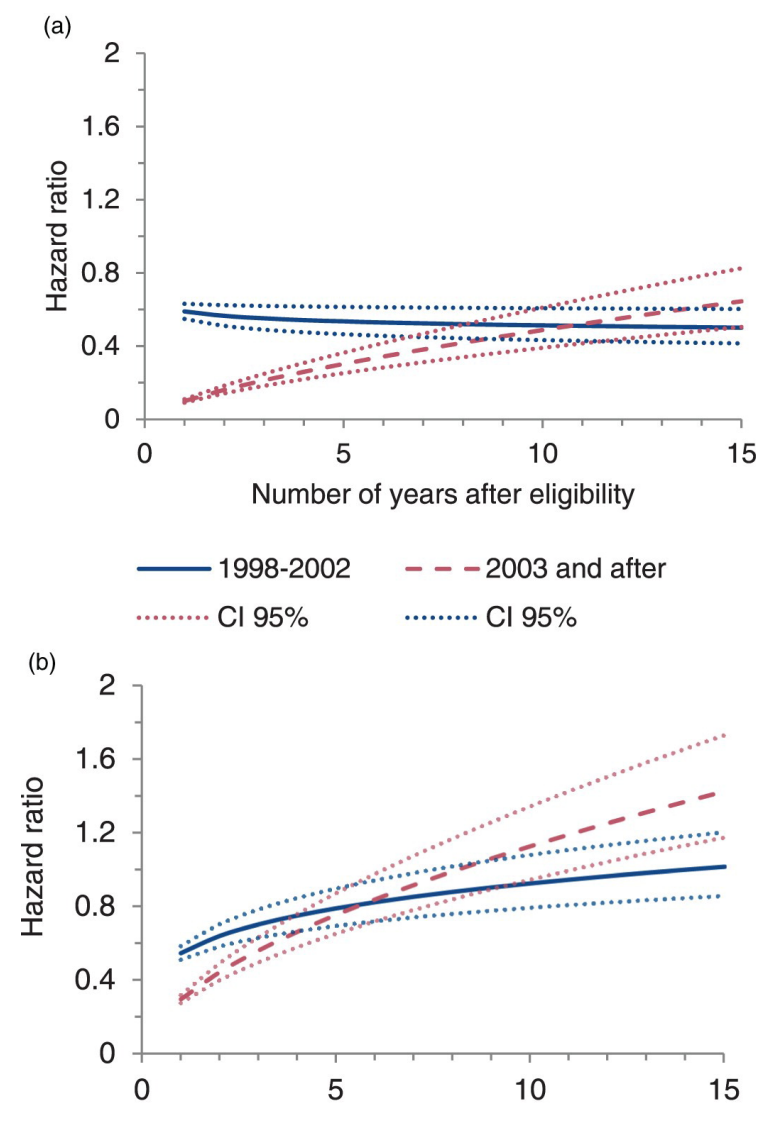

Number of years after eligibility

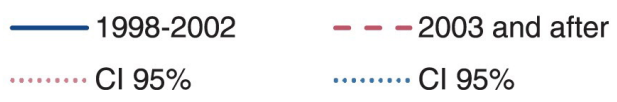

Figure 3.7: (a) Acquisition of Dutch citizenship with both parents among immigrants' children born in the Netherlands: odds ratio associated with eligibility cohort categories (ref. 1995-1997), by years after eligibility $(\mathrm{N}=91,066)$. (b) Acquisition of Dutch citizenship with only one parent among immigrants' children born in the Netherlands: odds ratio associated with eligibility cohort categories (ref. 1995-1997), by years after eligibility $(\mathrm{N}=91,066)$. 


\section{Chapter 3}

increase the emotional cost of naturalisation and prompt only one partner to naturalise, with the other retaining their origin-country citizenship. This would secure dual citizenship at the family level rather than at the individual level and preserve some legal ties with the country of origin. Second, the introduction of civic integration requirements may incentivise families to leave naturalisation to the parent who is the most equipped to navigate the procedure. This would especially apply to households where parents did not arrive in the Netherlands at the same time and/or where they faced different opportunities to learn Dutch and acquire other country-specific skills. Further empirical work, both quantitative and qualitative, is needed to identify the relevant mechanisms. Yet, our preliminary findings suggest that the naturalisation reforms not only influenced whether and when second-generation children acquire Dutch citizenship, but also with whom.

\section{Conclusion}

In countries with a ius sanguinis citizenship tradition, such as the Netherlands, second-generation children mainly depend on their parents to naturalise in order for them to become citizens of their country of birth and residence. We show that restrictive naturalisation laws not only prevent immigrants from accessing host country citizenship, they also make it harder for their children to become citizens of the country in which they were born. This paper has shed light on the intergenerational impact of Dutch naturalisation laws, revealing the detrimental effect that two significant reforms have had on people's propensity to naturalise. While we found that naturalisation propensity durably decreased for those who became eligible for Dutch citizenship after the end of dual citizenship tolerance in 1997, those who became eligible after the introduction of civic integration requirements in 2003 seem to have postponed, rather than completely put off, their applications for citizenship.

The consequences of these delayed or abandoned naturalisation projects for children's well-being and future opportunities remain to be assessed, but several studies point to the impact of legal status on immigrant youth trajectories, perceptions and expectations (Cebulko, 2014; Patler, 2017; Colombo et al., 2011). A limited body of literature has also highlighted the potential positive effect of holding host country citizenship on a variety of educational outcomes (Kilpi-Jakonen, 2014; Felfe et al., 2020; Bean et al., 2011). Altogether, while further research is needed to explore underlying mechanisms, our findings support the idea that naturalisation reforms have a last- 
ing impact on children. Given that most European countries, like the Netherlands, are both characterised by a descent-based birthright regime and have witnessed changing requirements for citizenship over the past decades, the intergenerational consequences of naturalisation reforms merit research beyond the Dutch case.

This paper has also shown that the 2003 reform was associated with a change in immigrant families' naturalisation patterns: children who only became eligible under the stricter requirements were far more likely to naturalise with one parent than with both. To a more limited degree, we observe a similar pattern for those eligible after the restriction on dual citizenship was reintroduced in 1997. These findings are in line with those who have highlighted the importance of analysing immigrant naturalisation at the family level (Street, 2014; Soehl et al., 2018). In a context where candidates for naturalisation are increasingly required to show proof of integration (van Oers, 2013), it is unsurprising that families develop different strategies to cope with the tightening of naturalisation requirements. Fine-grained data and qualitative methods are necessary to shed light on the decision-making processes at play, but this paper shows that a family perspective on naturalisation offers one fruitful avenue for future research in citizenship studies. 



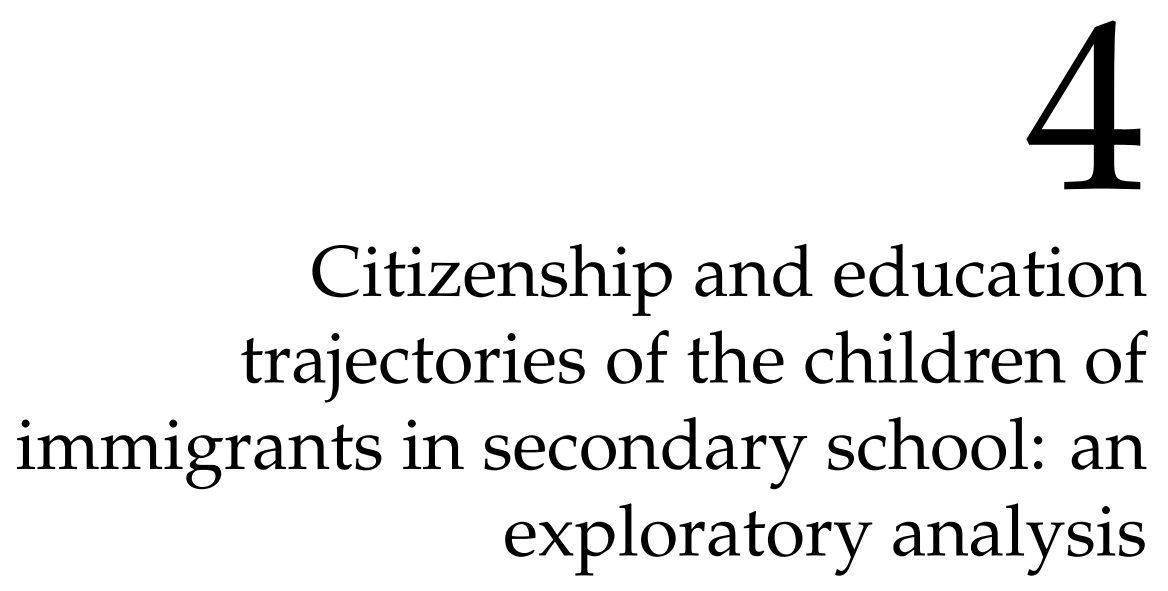

This chapter has been accepted for publication as: Labussière, M., Levels, M., and Vink, M. (2021). Citizenship and education trajectories among children of immigrants: a transition-oriented sequence analysis. Advances in Life Course Research, pages 1-14 (in press). 


\section{Introduction}

Second-generation children, those born in the country to which their parents migrated, now represent a growing and sizeable population in Western societies. Although there is substantial variation in the way these children perform in education across destination countries, extensive evidence suggests that children of immigrants experience disadvantages with respect to their native counterparts in Europe (e.g. Heath et al., 2008; Dustmann et al., 2012). Recently, some literature has shown that one element that may help children of immigrants to overcome some of these obstacles is their access to host country citizenship (Felfe et al., 2020).

In two out of three countries in the world, the children of immigrants do not have rights to the citizenship of their country of birth. They instead rely on their parents' ability and desire to naturalise if they are to acquire the citizenship of their country of birth and residence (Honohan and Rougier, 2018, p355). European countries are no exception: most of them combine ius sanguinis citizenship regimes with varying conditional ius soli provisions. At the same time, naturalisation requirements have become increasingly strict in Europe (Vink and de Groot, 2010). This makes it all the more important to understand whether and how legal status affects children of immigrants' life conditions in general and their educational achievement in particular.

While interest in the citizenship of the second generation is not new (Frauenfelder, 2007; Bolzman et al., 2003; Colombo et al., 2011), only a few quantitative studies do analyse educational outcomes in relation to citizenship (Bean et al., 2011; Cygan-Rehm, 2018; Felfe et al., 2020; Fibbi et al., 2007; Kilpi-Jakonen, 2014). Overall, these studies suggest citizenship has a positive impact on various indicators of educational achievement. However, previous literature tends to focus on isolated educational transitions or outcomes, which neglects how students negotiate their way through a given school system (Boylan, 2020; Goldrick-Rab, 2016). We argue that the effect of citizenship needs to be assessed more comprehensively. From a life course perspective (Elder, 1974), naturalisation can be seen as a process affecting the opportunities and constraints of immigrant families in host societies, which increases their level of agency and their capacities to navigate complex institutions (Wingens et al., 2011b; Patler et al., 2020). We shed light on the resources and skills parents may acquire during and following the naturalisation process, further equipping them to assist their children's school careers in a foreign education system. Such resources are particularly crucial in early-tracking 
and stratified school systems, where immigrant parents may face various obstacles in efficiently guiding their children (Pfeffer, 2008; Dustmann et al., 2012).

Following this life course perspective, we take a dynamic approach to educational attainment to get a more comprehensive insight into the educational trajectories of immigrants' children. We map children of immigrants' educational trajectories using sequence analysis to offer a multidimensional and context-specific indicator of educational attainment. This paper contributes to previous analyses of educational careers using optimal matching (Cayouette-Remblière and Saint-Pol, 2013; Boylan, 2020; Baysu and de Valk, 2012) and applies the transition-oriented optimal matching method introduced byBiemann (2011) to better capture the mobility patterns of students in stratified school systems.

While children of immigrants are often compared with those of native-born residents, we analyse educational trajectories among citizen and non-citizen children of immigrants only. Without diminishing the analytical value of the majority/minority dichotomy (Lessard-Phillips et al., 2017, p40), we argue that analysing legal status contributes to shifting the focus towards the hitherto under-explored heterogeneity within the second-generation category (Chimienti et al., 2019). We focus on children of immigrants born in the Netherlands, a country that is representative of the ius sanguinis citizenship tradition in Europe. We expect citizenship to be especially relevant in complex school systems such as the Dutch one, where information and strategic knowledge are key to move up the education ladder (Forster and van de Werfhorst, 2019).

We follow a full cohort of second-generation students from their first enrolment in secondary education in 2008 until 2016, using central population registers from Statistics Netherlands. Their school trajectories are mapped as sequences of educational transitions and compared by computing a transitionoriented optimal matching distance (Biemann, 2011). School trajectories are then clustered into predominant educational paths using the partitioning around medoids algorithm. Finally, we carry out multinomial logistic regressions to better understand how naturalisation, among other individual and parental characteristics, is related to specific clusters of educational trajectories. 


\title{
Conceptualising the effect of citizenship within the life course of the children of immigrants
}

\author{
The benefits of host country citizenship for immigrants and \\ their children
}

Becoming a citizen of one's country of residence confers a number of rights and benefits. Along with the rights to vote in national elections and to join the armed forces, citizenship opens the doors to various high-ranking positions in the law and public sectors and facilitates access to occupations requiring transnational mobility. More broadly, a host country passport allows for considerable international mobility, which is especially valuable for citizens of non-EU countries.

Previous work has put particular emphasis on the expected labour market benefits of host country citizenship for first-generation immigrants (e.g Gathmann and Keller, 2018). That immigrants' host country citizenship may also affect their children's opportunities is less often considered, although the benefits of citizenship are arguably higher for children than for parents (Avitabile et al., 2013, p.784). When they enter the labour market, the children of immigrants can reap higher and more long-term rewards for skills they have acquired than their parents, who are at a later stage in their careers. Children who are born and educated in the host country are also likely to value the full rights of social and political participation that citizenship brings (Colombo et al., 2011; Frauenfelder, 2007), while their parents may maintain stronger ties with their origin country.

Despite the potential effect of citizenship on the opportunities and well-being of the children of immigrants, the legal status of the second generation has received less attention, in line with the prevalent individual- and adult-centred perspective in citizenship studies (Cohen, 2005; Street, 2014). By contrast, the life course perspective points to the interdependence of individual lives and their embedding within a particular social and institutional context (Wingens et al., 2011b). As Peters et al. (2016) argue, “(...) the relevance and potential impact of citizenship is bound in a mutually shared context with others" (p361), such as one's partner or children. While there is growing evidence that intra-family dynamics are involved in immigrants' naturalisation decisions (Street, 2014; Labussière and Vink, 2020; Soehl et al., 2018), the effect of such decisions on family members has been unexplored so far, both conceptually and empirically. Yet, as we elaborate below, the notion of linked lives 
seems crucial to identify the mechanisms through which citizenship may affect children's educational outcomes.

\section{Education and citizenship of the children of immigrants}

A few studies have analysed the effect of citizenship on the educational opportunities of the children of immigrants. Overall, citizenship is found to be positively associated with a range of outcomes, from pre-school enrolment (Felfe et al., 2020) and time spent in schooling (Bean et al., 2011) to academic (vs. vocational) orientation (Felfe et al., 2020; Kilpi-Jakonen, 2014; CyganRehm, 2018) and enrolment in tertiary education (Fibbi et al., 2007). The main theoretical argument that has been developed so far to explain this "citizenship advantage" (Patler, 2017) in education stems from the human capital theory. A number of authors conceptualise the effect of birthright citizenship as a positive shock to the long-term rate of return on investments in children's human capital (Felfe et al., 2020; Avitabile et al., 2014; Cygan-Rehm, 2018). This, in turn, incentivises parents to make early investments in their children's education, such as to have them participate to non-compulsory pre-school (Felfe et al., 2020). In line with this argument, children who automatically get host country citizenship at birth are found to have better behavioural, socio-emotional and health outcomes in the short run compared to those who do not (Avitabile et al., 2014; Felfe et al., 2020).

While it is plausible that host country citizenship incentivises immigrant parents to offer greater educational opportunities to their children, the way they succeed in doing so remain unclear. Immigrant parents may face multiple obstacles in making informed investments in a foreign educational context. Their investments may be constrained by a number of factors, such as poor language competence, lack of interaction with school personnel or difficulties transferring their own educational experience and country-specific knowledge to a new context (van De Werfhorst and Van Tubergen, 2007). As a result, immigrant parents' level of agency may substantially decrease after migration (Wingens et al., 2011b), undermining their ability to efficiently guide their children through the education system. Such ability is particularly crucial in countries where education is hierarchically structured, as students may need to deviate from established pathways to correct initial misplacement (Crul et al., 2017).

Because of these barriers, parents' higher aspirations for their children may not always translate into greater educational opportunities. Yet, if we look at 


\section{Chapter 4}

naturalisation from a life course perspective, there are reasons to think that host country citizenship does not only increase immigrant families' expectations: it may also give them additional resources to fulfil their aspirations.

\section{Toward a comprehensive theoretical framework}

Following the idea that "citizenship acquisition is not an abrupt legal status transition, but rather a process" (Peters et al., 2017, p.6), we propose to conceptualise the effect of naturalisation more comprehensively. Just as the decision to become a citizen is socially embedded (Street, 2014; Soehl et al., 2018; Labussière and Vink, 2020), its impact may ripple through immigrants' broader social networks, starting with their family. Based on the literature, we can identify three main mechanisms through which naturalisation may affect children of immigrants' educational outcomes.

First, citizenship may benefit children because their parents gain an increased orientation toward the host country as a result of naturalisation. A substantial body of literature has highlighted the "citizenship premium" naturalised immigrants experience in the labour market (e.g. Gathmann and Keller, 2018; Peters et al., 2017; Steinhardt, 2012). Yet, citizenship not only enhances immigrant families' financial and employment stability, there is also evidence that naturalisation acts as a "catalyst" that promotes the social and political integration of immigrants. Naturalisation might indeed not only provide immigrants with greater opportunities, but also shift their time horizon and affect the way they feel perceived, or are perceived, by natives. As Hainmueller et al. (2017) show for the Swiss case, naturalised citizens are more likely to interact with the local community or to follow the country's news. Altogether, naturalisation may increase the economic and sociocultural resources available to children and foster parents' ability to provide advice through better acquaintance with the host country and its language.

Second, parents may acquire or further develop relevant skills for their children's educational success during the naturalisation process itself. Before becoming citizens, immigrant parents have to go through complex procedures that require at least basic language proficiency and some familiarity with the host country institutions (Goodman, 2010; Patler et al., 2020). The naturalisation process thus incentivises parents to make additional investments in their human capital, notably to acquire language and country-specific skills (Peters et al., 2017). This development of human capital during - and in response to 
- the naturalisation process is likely to have positive implications for their children's educational outcomes.

Finally, while the children of immigrants are expected to indirectly benefit from their parents' enhanced skills and resources, they may also be directly impacted by the acquisition of host country citizenship. Becoming a citizen confers them with the same formal rights as natives, and has many implications for their current and future life. Qualitative work has highlighted the relevance of the formal dimension of citizenship for second-generation youth in ius sanguinis regimes (Frauenfelder, 2007; Colombo et al., 2011, pp.337-340), with young people perceiving citizenship as a protection from legal precariousness and a condition for full and effective participation. Children who feel more included in the host society are likely to have higher levels of motivation.

We would not expect these three mechanisms to play out uniformly, as the relevance and meaning of citizenship may vary across the life course. Previous research shows that the timing of naturalisation matters: the earlier immigrants are eligible to apply for citizenship, the more relevant citizenship is for their socioeconomic integration (e.g. Gathmann and Keller, 2018; Peters et al., 2017; Hainmueller et al., 2017). It is reasonable to expect a similar effect for children, as early acquisition of host country citizenship would limit legal uncertainty and possible feelings of exclusion (Colombo et al., 2011). In that sense, citizenship might have a stronger effect when it is acquired at birth than at a later point in life.

These theoretical considerations suggest that citizenship may have far-reaching consequences for children's aspirations and opportunities, notably through positive spillover effects from parents' increased orientation towards the host society. However, it is important to note at this stage that an alternative mechanism may be selection: parents acquiring host country citizenship have been shown to be positively selected for education, income and country-specific skills (Peters et al., 2016; Jensen et al., 2019; Hainmueller et al., 2018), which are also commonly associated with children's educational attainment (e.g. Bernardi and Triventi, 2020). While a few studies are able to identify a causal effect for citizenship (Felfe et al., 2020; Avitabile et al., 2014; Cygan-Rehm, 2018), the exploratory approach chosen in this paper is not adequate to disentangle the mechanisms at play. 


\section{The Dutch context and our hypotheses}

\section{Becoming a Dutch citizen}

The Netherlands is representative of most European countries with its ius sanguinis citizenship tradition (Honohan and Rougier, 2018). Children of immigrants automatically receive Dutch citizenship by descent if at least one of their parents has naturalised before their birth. Otherwise, they may be included in the naturalisation procedure of (one of) their parents while minors, or apply for citizenship autonomously from the age of majority. ${ }^{1}$ A noteworthy aspect, which distinguishes the Netherlands from other countries, is that children of immigrants are not required to renounce their existing nationality, regardless of the procedure under which Dutch citizenship is granted. This may remove an obstacle for parents who want their children to maintain a formal citizenship link with their country of origin. Nevertheless, in such a citizenship regime, second-generation children's citizenship largely depends on parents' desire and ability to naturalise in the first place (Labussière and Vink, 2020).

To become Dutch citizens through naturalisation, foreign citizens need to meet a number of conditions. Importantly, in contrast with their children, first-generation immigrants "must be willing to renounce" their existing citizenship to be eligible for Dutch naturalisation. Beyond its emotional and psychological cost, the renunciation requirement is likely to deprive immigrants of a number of rights in their home countries (Mazzolari, 2009, p.173). Other eligibility criteria include a minimum length of legal residence of five years (three years if married to a Dutch citizen) and a clean criminal record in the five years preceding the application. Moreover, prospective citizens need to complete a civic integration test, and demonstrate language proficiency in written and oral expression/comprehension (CEFR level A2). For the civic integration test, candidates have to prepare a "knowledge of Dutch society" component on their own, with limited teaching materials available (van Oers, 2013, pp.60-64). The introduction of a formal civic integration test in 2003 substantially raised the overall cost of the naturalisation procedure, as candidates have to pay the costs of both the examination and the courses they often need to take.

\footnotetext{
${ }^{1}$ Note that there is an additional procedure for those born in the Netherlands to foreign citizens: at the age of 18, second-generation youth can acquire Dutch citizenship through "option statement" if they have been living in the Netherlands since birth. Although this procedure is simpler, faster and less costly than the standard naturalisation process, relatively few individuals make use of it (see Labussière and Vink, 2020, p.2746).
} 


\section{Going through the Dutch education system}

Research has shown that the educational context influences children's educational achievement (Heath et al., 2008; Baysu and de Valk, 2012; Crul, 2015; Dicks et al., 2019) and mediates the relationship between parental resources and their children's educational success (Bol et al., 2014; van de Werfhorst, 2019). In the Dutch school system, obstacles arise less from the financial cost of education (which is mostly free) than from the complexity of its institutional arrangements (Crul, 2018). It is characterised by a full-curriculum tracking system, where students are placed at an early stage - around age 12 - into a specific track for all subjects. Each track offers students unequal opportunities to access higher education and to move upward through the system (see Figure 4.1): the pre-university track (VWO) and the general track (HAVO) prepare students for a research university (WO) or a university of applied science $(\mathrm{HBO})$ respectively, while the vocational track (VMBO) prepares them for four different levels of senior vocational education (MBO). Track placement is primarily based on a standardised test at the end of primary school, yet research has shown that parental resources shape students' trajectories, with children of highly-educated parents being more likely to be enrolled in a track above the one corresponding to their test scores (Inspectie van het Onderwijs, 2016; Timmermans et al., 2018).

This stratified system comes with a certain degree of flexibility and fluidity. Notably, being enrolled in a given track does not prevent students from moving upward or downward at a later point, a number of "back doors" being provided for that purpose. Moreover, the hierarchy between the three main tracks is mitigated by the high value placed on vocational education, which, in addition, leads to valuable labour market prospects (Inspectie van het Onderwijs, 2016, p.18). Yet, students are not equally likely to move between tracks, especially upward. First, families need quality information to navigate this complex system and to choose tracks with good upstream possibilities (Forster and van de Werfhorst, 2019; Crul, 2018, p8). For example, students can only go from vocational (VMBO) to general education (HAVO) if they have completed the theoretical track within VMBO (theoretische leerweg). Moreover, upward mobility often comes at the price of additional years of schooling. Accessing vocational college $(\mathrm{HBO})$ from a track other than the general or pre-university tracks (HAVO and $\mathrm{VWO}$ ) requires three additional years of schooling, which may act as an obstacle for a number of students and families (Crul, 2015, p334). 
Chapter 4

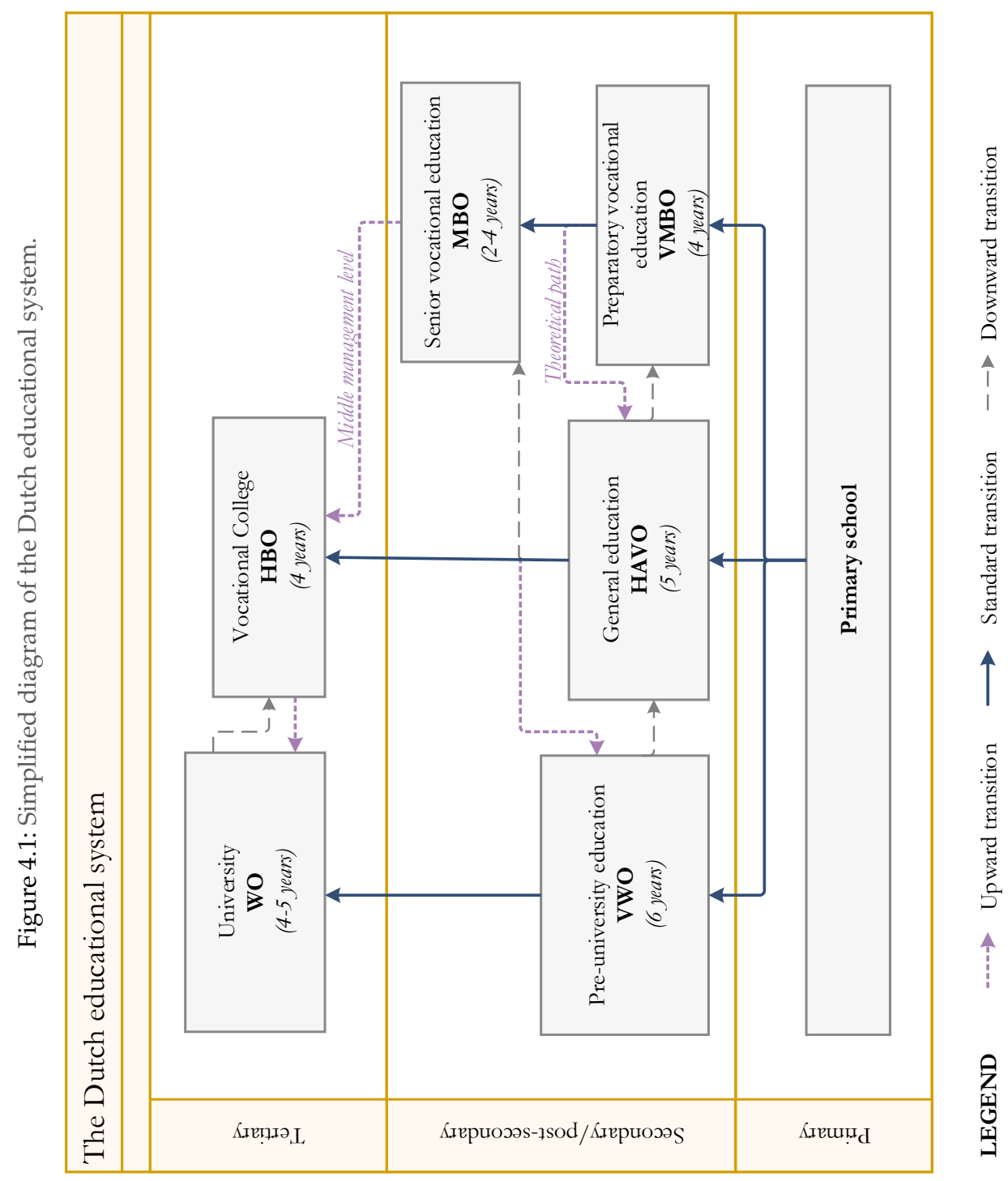


Another specificity of the Dutch system is that not all schools offer the same types of education. Although broad school communities exist, education is largely segregated, even within those broader communities. While some schools offer all tracks from vocational to pre-university education, some only cater for the intermediate (e.g. VMBO/HAVO) or highest levels (e.g. $\mathrm{HAVO} / \mathrm{VWO}$ ). Schools also provide different opportunities to attend bridge classes (brugklas), in which students follow a combination of levels before choosing a final track. The combinations of levels vary greatly across schools, as well as the length of bridge classes, which can last from one to three years. As a result, "not only must parents know about tracking decisions; they must also be aware of what schools can offer in terms of upstream possibilities" (Crul, 2018, p488). Parents who lack the requisite knowledge may inadvertently limit their children's options when choosing a given school. As recent work suggests, knowledge of the educational system especially matters for transitions involving a change of school (Forster and van de Werfhorst, 2019). As a result, transitioning to a higher level after the initial placement not only depends on the student's performance; parents' resources and level of information about the desirable tracks and outcomes also play an important role in securing the best up-streaming possibilities for their children. Forster and van de Werfhorst (2019) have highlighted the specific roles of cultural capital and parental aspirations on the probability of upward transition. With naturalisation increasing both children's long-term educational returns and parents' country-specific resources, we expect naturalised parents not only to have higher expectations, but also to be better equipped to make use of the system's flexibility to provide their children with the best opportunities.

The Dutch educational system also offers possibilities for downward transitions: when students fail to meet the expectations of a given track, they may be invited to move to a lower level. ${ }^{2}$ On the one hand, downward mobility can be perceived as a less desirable option than staying in the current track, since it is likely to result in fewer opportunities for reaching higher education. Families that are well informed and have high educational expectations are therefore likely to enact remedial strategies to compensate for the low performance of their child and avoid downward mobility (Bernardi and Triventi, 2020; Huang, 2020). On the other hand, downward mobility may also be seen as a safety net, one which prevents students from dropping out

\footnotetext{
${ }^{2}$ Grade retention is also a possibility and is common in the Netherlands. In our population of interest, $24 \%$ of children are identified as repeating at least one grade during the observation period. While grade retention is meant to consolidate previous achievements before moving on, transitioning to a lower level is an indication of misplacement.
} 


\section{Chapter 4}

of school altogether when their current track is inappropriate (Kalmijn and Kraaykamp, 2003). In that sense, students experiencing downward mobility may still benefit from some strategic knowledge and make use of the system's "back doors" to remain in education. Conversely, those who leave school without a starting qualification - that is, without a VWO, HAVO or MBOlevel 2 diploma - have limited employment and career prospects (Researchcentrum voor Onderwijs en Arbeidsmarkt, 2009). ${ }^{3}$ Various complexities and ambiguities thus surround downward mobility. So although we expect naturalised children to be less likely to drop out of school, we do not formulate any clear-cut hypothesis for the effect that citizenship has on downward mobility.

\section{Empirical strategy: a transition-oriented sequence analysis}

\section{Optimal Matching between sequences of transitions}

Previous work analysing the impact of citizenship on education typically takes an event-oriented or static approach to educational outcomes. School attainment is either operationalised by specific educational transitions, such as the transition from primary to secondary school, (e.g. Fibbi et al., 2007; Cygan-Rehm, 2018; von Haaren, 2016) or by one-time measures of cognitive or behavioural outcomes (e.g. Felfe et al., 2020; Kilpi-Jakonen, 2014). These approaches have their problems, especially when studying stratified and flexible school systems, where students are mobile between tracks. First, focusing on isolated transitions may be misleading when a substantial number of students do not follow the standard path to which they were initially allocated. Second, students obtaining the same diploma are not necessarily comparable because they may have followed distinct paths, with varying educational and opportunity costs. Transitions therefore need to be embedded in students' broader educational careers, both conceptually and methodologically.

Following the life-course perspective (Elder, 1974), we argue that analysing educational trajectories as a whole provides a more comprehensive picture

\footnotetext{
${ }^{3}$ Education is compulsory (leerplicht) until the age of 16 in the Netherlands. However, between 16 and 18, students have an obligation (kwalificatieplicht) to stay in education if they have not obtained a starting qualification. Furthermore, they receive government support until the age of 23 to get such a qualification.
} 
of educational outcomes. In this paper, we use sequence analysis to identify how second-generation students navigate the Dutch educational system. This longitudinal approach is particularly relevant when studying children of immigrants, since their educational careers have received limited attention so far (Baysu and de Valk, 2012; D’hondt et al., 2016, p227).

The technique of sequence analysis has been increasingly used in the social sciences to analyse social processes in a multidimensional and holistic perspective (Piccarreta and Studer, 2019), following seminal work by Abbott and others (1986;1990). After being coded as sequences of states (see Table 4.1), trajectories are typically compared using the Optimal Matching $(\mathrm{OM})$ distance. OM distance is based on the smallest number of operations required to transform one sequence into another using three types of edit operations: substitution, insertion and deletion. Edit operations are penalised by specific costs fixed by the researcher, and these costs determine the distance's sensitivity to either the timing or the order of events (see Lesnard, 2010). The similarity between each pair of sequences is computed by summing the edit costs for the least costly transformation. Sequences can then be grouped according to their resemblance using standard clustering methods.

Originally developed within biology to compare DNA sequences, OM is now widely used to analyse careers in the social sciences (see Ritschard and Studer, 2018). However, as Biemann (2011) argues, the application of OM to certain types of trajectories is questionable due to important distinctions between DNA sequences and social processes. This is especially the case for careers, which, unlike DNA sequences, grow through time with "a cause and effect relationship between neighbour elements" (Biemann, 2011, p199). For example, the probability of following a given educational track at time $t$ is contingent on the track followed at time $t-1$, which is not reflected in the standard OM approach. As explained by Elzinga and Studer (2015), "OM is contextinsensitive: Each state is handled separately without considering previous or subsequent states" (p6). Furthermore, building trajectories as sequences of states does not allow one to distinguish different types of transitions: the transition from state $\mathrm{A}$ to $\mathrm{B}$ is considered equal to the transition from state $\mathrm{B}$ to A. However, when analysing educational careers, it seems crucial to incorporate distinctions between different types of transitions, such as standard or non-standard, upward or downward.

In contrast to the standard focus on sequences of states, Biemann (2011) suggests building the trajectories as sequences of transitions, which would enable researchers to better capture processes that unfold over time (see Table 4.1). 


\section{Chapter 4}

\begin{tabular}{lccc}
\hline & $t_{1}$ & $t_{2}$ & $t_{3}$ \\
\hline Sequence 1 & $\mathrm{A}$ & $\mathrm{A}$ & $\mathrm{B}$ \\
Sequence 2 & $\mathrm{A}$ & $\mathrm{B}$ & $\mathrm{B}$ \\
Sequence 3 & $\mathrm{A}$ & $\mathrm{A}$ & $\mathrm{A}$ \\
\hline
\end{tabular}

(a) States Approach

\begin{tabular}{lccc}
\hline & $t_{1}$ & $t_{2}$ & $t_{3}$ \\
\hline Sequence 1 & SA & AA & AB \\
Sequence 2 & SA & AB & BB \\
Sequence 3 & SA & AA & AA \\
\hline
\end{tabular}

(b) Transitions Approach

Table 4.1: Examples of artificial sequences built on states (a) and sequences (b). Note: In this example, we observe three sequences at time positions $t_{1}-t_{3}$, with an alphabet of two state elements: $A$ and $B$. Corresponding transition elements are $A A$, $A B, B B, B A, S A, S B$, with $S$ the start of a sequence.

This transition-oriented approach has been shown to better uncover patterns of mobility than the standard approach, and offers more flexibility to define cost schemes based on theoretical expectations (Biemann, 2011). Although promising, the method has not been applied to actual data beyond Biemann's (2011) paper.

One drawback of Biemann's approach is that it complicates the cost settings, as building the sequences based on the transitions considerably increases the size of the alphabet (see Table 4.2). To mitigate this issue, we aggregate similar types of transitions to only distinguish between those that are qualitatively different. As described in more detail below, we consider 12 states and we cluster the associated transitions $(n=132)$ into 8 categories, which brings the substitution costs matrix to a manageable size of $8 \times 8$. This leaves us with $(8+1) * 8 / 2=36$ substitution costs to define (instead of about 9,000 ), that we set based on theoretical expectations.

As our hypotheses mainly relate to the type of transitions that students experience, we base similarity on their mobility profile - that is, on whether they are moving or not between tracks and if so, how - rather than on the specific tracks in which they are enrolled. As a result, the substitution costs are used to further emphasise non-standard transition patterns among students. Indel costs are set so as to allow time warping for standard transitions only, which accounts for potential grade repetition. We therefore give little weight to the location of non-standard transitions, since their timing is not directly relevant to our purpose (see the Supplementary Materials, section II for details).

After coding the trajectories as sequences of transitions and defining the corresponding substitution and insertion-deletion costs, pairwise dissimilarities between the sequences are computed using the optimal matching distance. 


\begin{tabular}{c|cc} 
& $\mathrm{A}$ & $\mathrm{B}$ \\
\hline $\mathrm{A}$ & $c_{A, A}$ & $c_{A, B}$ \\
$\mathrm{~B}$ & $c_{B, A}$ & $c_{B, B}$
\end{tabular}

(a) States Substitution Costs Matrix

\begin{tabular}{c|cccccc} 
& SA & AA & AB & SB & BB & BA \\
\hline SA & $c_{S A, S A}$ & $\cdot$ & $\cdot$ & $\cdot$ & $\cdot$ & $c_{S A, B A}$ \\
AA & $\cdot$ & $\cdot$ & & & & $\cdot$ \\
AB & $\cdot$ & & $\cdot$ & & & $\cdot$ \\
SB & $\cdot$ & & & $\cdot$ & & $\cdot$ \\
BB & $\cdot$ & & & & $\cdot$ & $\cdot$ \\
BA & $c_{B A, S A}$ & $\cdot$ & $\cdot$ & $\cdot$ & $\cdot$ & $c_{B A, B A}$
\end{tabular}

(b) Transitions Substitution Costs Matrix

Table 4.2: Examples of substitution costs matrices based on states (a) and sequences (b).

We then group the sequences according to their dissimilarity using the Partition around Medoids algorithm (Kaufman and Rousseeuw, 1990). This partitioning method groups the sequences into a pre-defined number of clusters, based on the clusters' medoids, defined as the sequences whose average dissimilarity to all other sequences in the cluster is minimal. The global quality of the partition is assessed using the average silhouette width (Rousseeuw, 1987), which indicates the extent to which, on average, sequences are closer to the cases from the same cluster than to those from the next nearest cluster. The silhouette width is also analysed at the cluster level to evaluate the internal cohesion of the partition, as recommended by Piccarreta and Studer (2019). Global and local cluster quality are the main criteria for choosing the preferred cluster solution (for details, see the Supplementary Materials, section III).

\section{Data and Population}

We use Dutch administrative registers, supplied by Statistics Netherlands, which offer longitudinal micro-level data covering the entire legally resident population of the Netherlands (Bakker et al., 2014a). For our research, we follow the cohort of second-generation children who were first enrolled in secondary education in 2008. This choice of the cohort is a trade-off between maximising the length of observation while ensuring sufficient data quality, as educational data become increasingly available and reliable over time. We follow students for eight years until 2016, covering their entire time in secondary education as well as part of their trajectories through higher education (if relevant). 


\section{Chapter 4}

We define second-generation children as those born in the Netherlands to two foreign-born parents, who themselves are born to at least one foreignborn parent. Children of mixed descent are excluded from the scope of our analysis because, having one native parent, they ought to obtain Dutch citizenship at birth by descent. Children born in the Netherlands from secondgeneration parents - the third generation - are not included either, since they acquire automatic birthright citizenship according to the so-called double ius soli principle. For related reasons, we also exclude children from specific origin groups: children originating from the Caribbean territories of the Kingdom of the Netherlands, who are Dutch citizens; and children whose parents come from the former Dutch colonies and thereby had privileged access to Dutch territory and citizenship (van Meeteren et al., 2013, p115116). Based on our definition, there are 14,571 second-generation students who were first enrolled into secondary education in 2008.

We further restrict our study population to children who were not in institutional care $(\mathrm{N}=19)$, nor enrolled in special education (Speciaal onderwijs, $\mathrm{N}=16$ ), which is intended for students with learning difficulties or disabilities. Moreover, we exclude students who were enrolled in practical education (Praktijkonderwijs, $\mathrm{N}=948$ ) or adult education (Voortgezet algemeen volwassenenonderwijs, $\mathrm{N}=1,071)$ at some point in their school careers. The reason is that both tracks target very specific groups of students: those with low IQ and learning gaps on the one hand, and the early school drop-outs on the other.

Our final study population consists of 12,505 students. ${ }^{4}$ For our regression models, the sample size decreases to $\mathrm{N}=12,249$ following the exclusion of a few individuals with punctual missing values on some of the sociodemographic variables ( $\mathrm{N}=256,2.0 \%$ ). For descriptive statistics, see Tables B2-B1 in the Supplementary Materials.

\section{Operationalisation in the Dutch educational context}

We follow students' trajectories from the moment they enter secondary school. Table 4.3 indicates the different states we coded to map their educational trajectories. After primary school, Dutch students can be allocated to four different tracks: vocational education (VMBO), general education (HAVO), preuniversity education (VWO), or bridge class, which is a combination of the first three. We code each track into a specific state, as we do for the three

\footnotetext{
${ }^{4}$ We also exclude individuals who die before the end of the observation period $(\mathrm{N}=12)$.
} 
subsequent tracks in secondary or tertiary education: senior vocational education (MBO), vocational college (HBO) and university (WO). Because students may have left education by the end of the observation period or be temporarily registered as being out of school, we identify four additional states: temporary deregistration, outward, dropout, and out of school. ${ }^{5}$

Temporary deregistration We code years as "temporary deregistration" when a student has been temporally deregistered from school while still living in the Netherlands. Temporary deregistration can occur for various reasons: illness, schooling in bordering countries like Belgium or Germany, or enrolment in private institutions, which are not included in the educational registers. Although temporary deregistrations are quite common and concern $9.2 \%$ of the sample, the average duration is short (1.5 years on average).

Outward We code years as "outward" when there is consistent evidence that the student is abroad: the student is not registered as being in education, migration abroad is recorded by the Dutch Immigration and Naturalisation Service (IND), and information is missing from other registers as well. In our sample, $6.1 \%$ of students are identified as leaving the Netherlands at some point during the observation period, for an average duration of three years.

Dropout We code years as "dropout" when we are able to determine that a student has left education without a starting qualification (i.e. VWO, HAVO or MBO-level 2 diploma). A substantial proportion (13.5\%) of students are identified as early school leavers in our sample.

Out of school We code years as "out of school" when we have evidence that the student has left education with a starting qualification. Due to the limited observation period, this only concerns $19.2 \%$ of students in our sample and is associated with short educational trajectories.

Differentiating between these four states is important if we are to uncover the various ways children of immigrants navigate the Dutch school system. Although the data do not enable us to contextualise certain states (notably

\footnotetext{
${ }^{5}$ Note that this also ensures sequences of equal length. There is, however, right-censoring in the definition of some of the state elements, as a student identified as an early school-leaver during the observation period may actually go back to school a few years after the end of observation.
} 


\section{Chapter 4}

temporary deregistration) in more detail, this typology of states gives a comprehensive picture of how an entire school cohort makes their way through secondary education.

Finally, we add an artificial state, "start", which enables us to distinguish whether students enter secondary education through bridge class ("StartBridge"), vocational education ("Start-VMBO"), or through general or preuniversity education ("Start-HAVO/VWO"). Note that the two highest tracks, HAVO and VWO, are merged because the majority of students do not access these tracks directly but rather after one or several years of bridge class.

Table 4.4 shows all the categories of transitions we used to aggregate similar types of transitions. After their initial transition into secondary education, students can follow the standard route and move up to the level that is provided by their track. For example, a student starting in the pre-university track (VWO) is expected to move on to university (WO), while a student entering general education (HAVO) is mainly preparing to attend vocational college (HBO). These are what we refer to as "standard" transitions. On the other hand, students who were initially placed in the wrong track or who gradually fall behind or move ahead of their peers may need to deviate from the standard route. We therefore differentiate between those moving "downward" to a lower track and those moving "upward" to a more general or prestigious track than the one in which they were enrolled the year before. Two additional categories of transitions take into account atypical trajectories. First, we code as "exit" those transitions in which a student begins with a year of emigration ("outward") or temporary school deregistration ("temporary deregistration"), so as to take into account potential discontinuities in school trajectories. Second, in order to identify the early school leavers, we code transitions ending with dropout as a separate category, "dropout". In the Supplementary Materials, Table B4 gives the full matrix we used to shift the sequence elements from states to transitions.

\section{Multinomial logistic regression and covariates}

Following a standard approach in sequence analysis, we use the resulting clusters as a categorical input for multinomial logistic regression analysis. This enables us to assess how clusters are associated with individual and contextual characteristics, although this comes with a number of caveats. One important limitation lies in the fact that we can only analyse how the clusters relate to characteristics that are either constant or measured before the start 


\begin{tabular}{cc}
\hline & States \\
\hline 1 & Start \\
2 & Bridge \\
3 & VMBO \\
4 & HAVO \\
5 & VWO \\
6 & MBO \\
7 & HBO \\
8 & WO \\
9 & Temporary deregistration \\
10 & Outward \\
11 & Dropout without diploma \\
12 & Out of school with diploma \\
\hline
\end{tabular}

Table 4.3: State elements.

\begin{tabular}{lc}
\hline & Transitions \\
\hline 1 & Start VMBO \\
2 & Start Bridge \\
3 & Start HAVO/VWO \\
4 & Standard \\
5 & Downward \\
6 & Upward \\
7 & Exit \\
8 & Dropout \\
\hline
\end{tabular}

Table 4.4: Transition elements.

of the trajectory if we are to avoid anticipatory analysis (Studer et al., 2018, p8). As a result, our time-varying covariates are measured before or shortly after the start of the observation period.

Another caveat relates to causal interpretation. When analysing the relationship between citizenship and educational trajectories, it is important to account for selection into naturalisation: immigrant parents who naturalise are expected to be positively selected for a number of characteristics that are commonly associated with children's educational attainment. Although we are able to control for some of the most important predictors of naturalisation propensity, such as parents' education level or years since migration, the dynamics involved in the naturalisation process are arguably many-fold and largely unobservable, especially when using administrative registers. We therefore use multinomial logistic regression to test associations between citizenship and education, without assuming a cause-and-effect relationship.

\section{Presentation of the covariates}

Variable of interest The citizenship status of second-generation students is our main variable of interest. We distinguish three categories: those who are Dutch from birth ( $45.8 \%$ of the sample), those who naturalise together with their parents before entering secondary education $(39.0 \%)$, and those who are still foreign citizens at that date (15.2\%). In the first 
category, one or both parents naturalised before the child was born. Distinguishing between parental naturalisation before and after birth allows us to analyse the potential effect of the timing of naturalisation.

Educational controls In the sequence analysis, we set the edit function so as to emphasise patterns of (im)mobility relative to a student's initial track. Yet, a student's starting point and subsequent trajectory cannot be fully disentangled, as the initial track determines how far a student can move up or down. As we aim to isolate the effect of citizenship on mobility alone, we control for the initial track in which students are enrolled when entering secondary education. ${ }^{6}$ The variable differentiates between vocational education (VMBO), bridge year, and general/preuniversity education (HAVO/VWO).

Moreover, we expect school trajectory to be influenced by a student's cognitive ability. A student with cognitive potential is more likely to move upward other things being equal. As a proxy for cognitive skills, we use the score obtained in the standardised test at the end of primary school. This comes with a caveat, because scores are only available for students whose schools registered with the main test provider, Cito, representing about $77 \%$ of our sample. We assess the selectivity of this group in the Supplementary Materials (section IV). We use quintiles of Cito score and we group the missing values in a separate category, due to the lack of auxiliary information in the registers to impute the missing scores.

Sociodemographic variables We control for a number of sociodemographic variables that are traditionally associated with educational outcomes. We control for gender, as girls are usually found to outperform boys in education, including among second-generation students (Fleischmann and Kristen, 2014). Two household characteristics are included to proxy the parental time and financial resources available to children: the number of children registered in the household and the type of household, either two- or single-parent. We also include a dummy capturing whether the respondent is first-born, since there is evidence that it confers an advantage in education (see e.g. Kantarevic and Mechoulan, 2006). Finally, we control for whether the child is an EU citizen with a dummy

${ }^{6}$ Note that we set null substitution costs between all the starting transition elements in the substitution costs matrix (see Table B5, Supplementary Materials), which ensures the independence of the outcome from the first education track in the multinomial logistic regression. 
that captures whether mother's or father's country of origin is a member state of the European Union.

Confounding factors Several parental characteristics are expected to be associated with both naturalisation propensity and children's educational outcomes. First, we account for parents' SES status by including two complementary variables: parents' main source of income, which indicates whether the parents are in employment (including self-employment), are social benefit or pension recipients, or lack any registered source of income; and a dummy capturing whether at least one parent is registered as a homeowner. While homeownership status is a good discriminatory factor in the higher end of the SES distribution, the main source of income captures different profiles at the lower end. To approximate the financial resources available to children, we include household standardised disposable income.

We also control for parental education level, albeit imperfectly. Such information tends to be missing and/or unreliable for first generation parents, and is difficult to impute without indication of parents' exact occupation. We take the highest education level obtained among parents, and distinguish between low (primary education), middle (completed some secondary education), and high (bachelor or higher). Missing values, which still represent a non-negligible share $(17.3 \%)$, are coded as a separate category. In the Supplementary Materials (section IV), we describe in more detail the construction and limitations of the variable.

Finally, we use parents' years since migration and the language spoken at home as proxies for the family orientation towards the host country. Parents who have arrived in the Netherlands at a young age are expected to navigate more easily Dutch institutions, especially if they have been enrolled at some point in the education system (Nielsen and Rangvid, 2012). Likewise, those who are proficient in Dutch may be more likely both to naturalise and to assist their children's educational careers effectively (Dustmann et al., 2012).

More details about our covariates are available in the Supplementary Materials, section IV. 


\section{Chapter 4}

\section{Analysis}

\section{Sequence Analysis on educational transitions}

Following the steps set out above, we cluster the sequences based on a transition-oriented approach to OM. We select a cluster solution which optimises both the global quality of the partition and the internal cohesion of all clusters (Piccarreta and Studer, 2019). While the average silhouette width reaches a plateau after eight clusters $(A S W \approx 0.82$, see Figure B3, Supplementary Materials), cases are not adequately classified in some of the associated clusters $(A S W \leq 0.2)$. We therefore prefer a six-cluster solution with a smaller average silhouette width $(A S W=0.78)$, but well-defined clusters $(A S W>0.4)$. From a substantive point of view, the six-cluster solution offers meaningful groups with a sufficient level of detail.

Descriptive information on each of the six clusters is provided in Tables 4.5 and 4.6 , while Figure 4.2 graphically represents the individual sequences within each cluster. In line with our cost setting, students who follow standard trajectories are grouped into the same cluster (cluster 1) and form the largest group $(50.1 \%)$ of the partition. This group is very homogeneous and substantially contributes to the global quality of the partition (see Figure B4, Supplementary Materials). The remaining clusters distinguish students who experienced non-standard transitions during the observation period.

The next cluster represents the second-largest group of the partition, with about $20 \%$ of the students. The medoid sequence is characterised by an upward transition the year before the end of the observation period, and Figure 4.2 shows that there is limited variation in timing. Most of these students

\begin{tabular}{lllrr}
\hline & Label & Medoid & N & \multicolumn{1}{c}{$\%$} \\
\hline 1 & Standard & Start Bridge-S-S-S-S-S-S-S-S & 6,265 & 50.1 \\
2 & Upward & Start Bridge-S-S-S-S-S-S-upward-S & 2,451 & 19.6 \\
3 & Dropout & Start Bridge-S-S-S-S-S-S-dropout-S & 1,647 & 13.2 \\
4 & Discontinued & Start VMBO-S-S-S-S-S-interrupted-S-S & 1,137 & 9.1 \\
5 & Downward & Start Bridge-S-S-S-downward-S-S-S-S & 656 & 5.3 \\
6 & Detour & Start Bridge-S-S-S-downward-S-S-upward-S & 349 & 2.8 \\
& & $\mathbf{1 2 , 5 0 5}$ & $\mathbf{1 0 0 . 0}$ \\
\hline
\end{tabular}

Table 4.5: Cluster description and medoids sequences of the six-cluster solution. Note: "S" stands for "Standard". 
start directly in the vocational track or access this track after bridge class (see the individual sequences based on states elements, Figure B5 in the Supplementary Materials) and experience an upward transition in senior vocational education (MBO), though some move upward a little later. This accounts for the large over-representation of students enrolled in vocational college (HBO) in this cluster: $83 \%$ vs. $30 \%$ in the full sample. A smaller group who access general education (HAVO) after primary school or bridge class is able to make it to university (WO). It is noticeable that this second cluster barely contains any pattern of downward mobility, and that students from this cluster are the less likely to repeat a grade compared to the other clusters. We therefore label these upward transitions.

The third cluster captures sequences that end up with a dropout, typically during the last three years of observation. This cluster, which represents $13.2 \%$ of the sample, includes almost all students identified as early school leavers (Table B8). Most of them start in the vocational track (VMBO) or access this track after one or two years of bridge class and subsequently drop out from senior vocational education (MBO) (Figure B5). This cluster confirms earlier work showing that vocational students are particularly at risk of dropout in the Dutch school system (Inspectie van het Onderwijs, 2016, 2010, p.260), compared to those who follow the general or pre-university tracks. Interestingly, very few individuals experience downward mobility before leaving school without a qualification: less than $2 \%$ of downward transitions are observed at each time point within this cluster (result not shown). This suggests that downward mobility can act as a safety net against dropout for some children of immigrants (Kalmijn and Kraaykamp, 2003). Finally, this cluster includes a slight over-representation of students who are identified as being temporarily deregistered or abroad, indicating that in some cases interruptions or disruptions in the school trajectory prevent students from obtaining their starting qualification. The students in this cluster follow what we call dropout trajectories. 


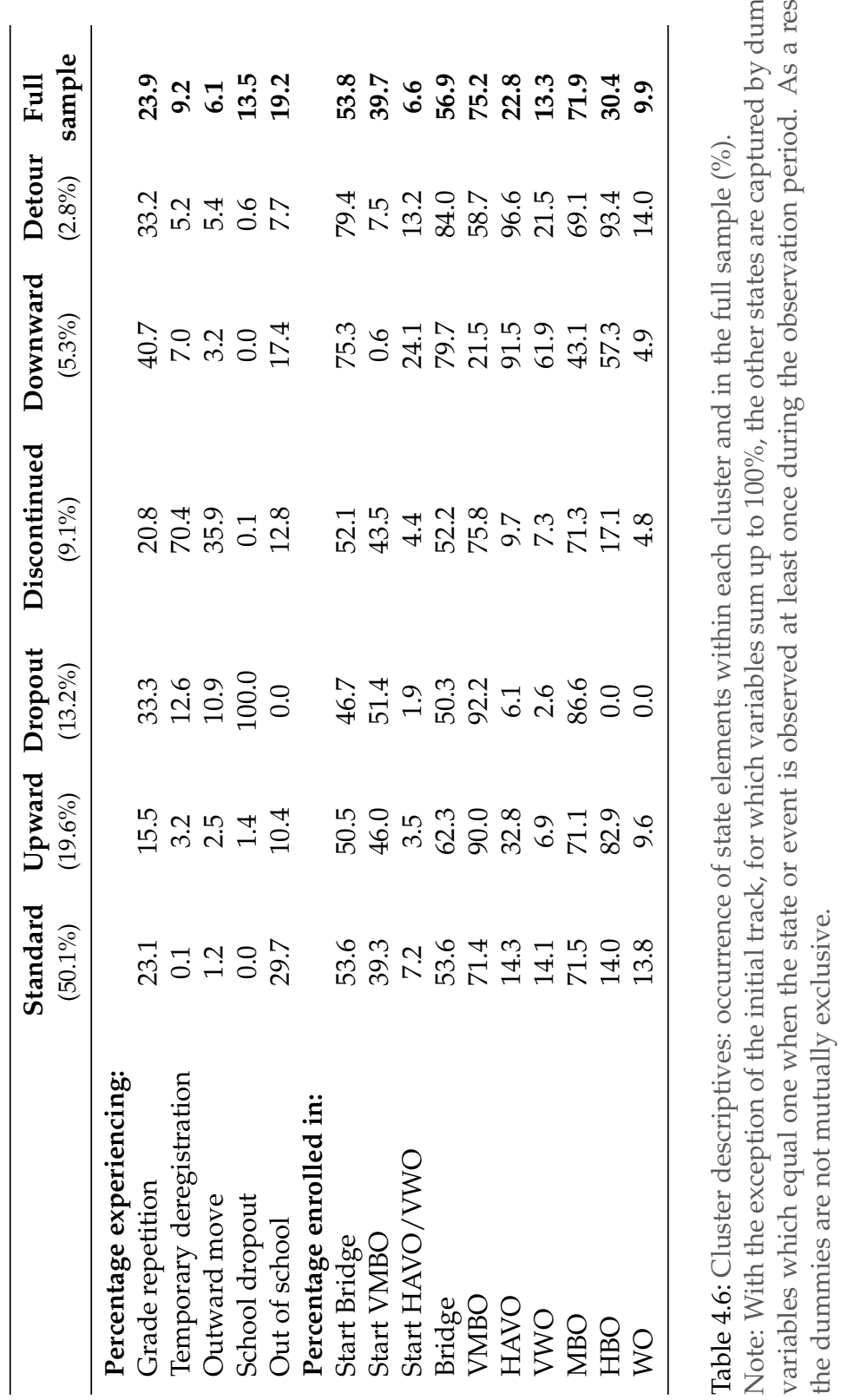


Standard (50.1\%)
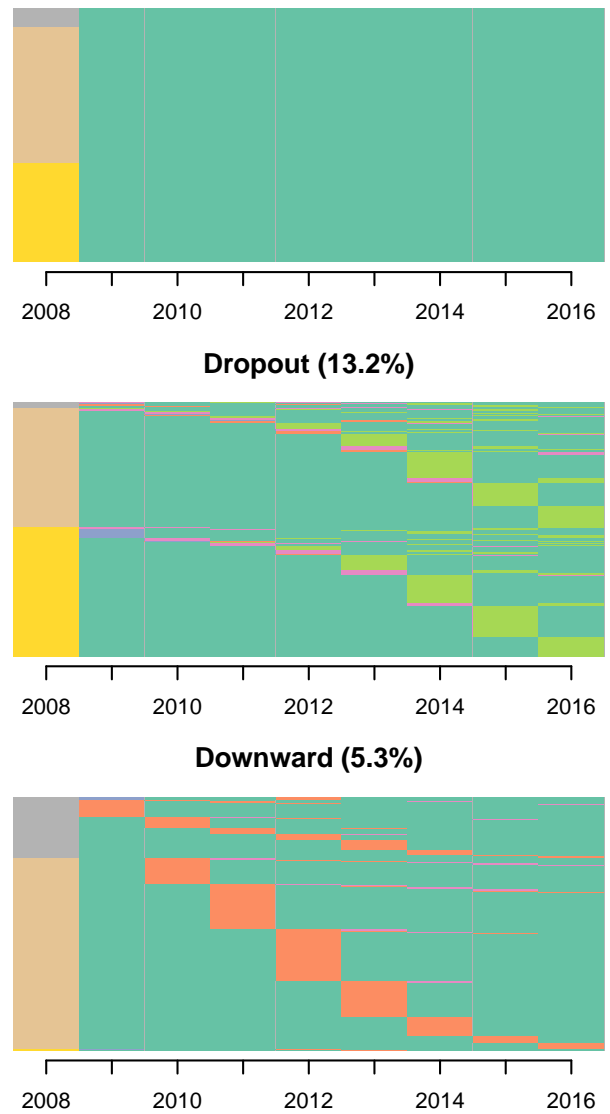

Upward (19.6\%)

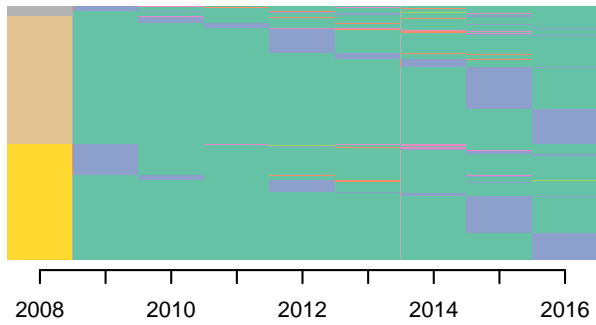

Discontinued (9.1\%)
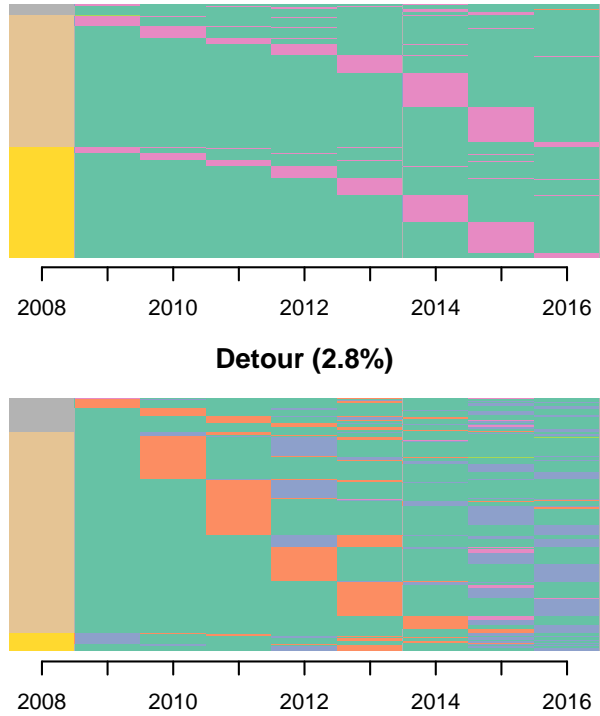

Figure 4.2: Index-plot based on transition elements for the full sample ( $\mathrm{N}=12,505)$. 


\section{Chapter 4}

The fourth cluster groups those who followed standard trajectories but were deregistered from school at some point (9.1\%). Although deregistration may occur at any time, it seems to be more likely towards the end, when students have reached the age of majority. Those who are temporarily deregistered from school or identified as going abroad are clearly over-represented in this category: $70 \%$ of students experience school deregistration and $36 \%$ are identified as being abroad at least one year, versus 9 and $6 \%$ in the full sample, respectively. An important thing to note is that those who leave the Netherlands usually stay abroad several years in a row, while those who are deregistered typically leave school for a year (see Figure B5). As a result, the sequences in this group are not similar with respect to state duration. What is more, temporary deregistration may occur for various reasons, from illness to a school year abroad. Despite its heterogeneity, this cluster sheds light on a specific group of students who do not complete their entire education in the publicly-funded Dutch education system. To stress this pattern of temporary or definitive deregistration, we label these trajectories as discontinued.

The fifth cluster, representing 5.3\% of the sample, contains sequences characterised by a downward transition. While the medoid sequence suggests that this transition typically occurs four years after enrolment into secondary education, the plot of individual sequences shows that there is substantial variation in timing. In this cluster, the vast majority of students started in a bridge class (75\%, Table 4.6) and subsequently went into the general (HAVO) or pre-university track (VWO), while a smaller proportion $(24 \%)$ went directly into those tracks after primary school. Both profiles of students end up moving down later at various points in time. Interestingly, the percentage of students who repeated at least one grade is particularly high in this group: $41 \%$, versus $24 \%$ in the full sample. This suggests that the track to which students were allocated after bridge class or primary school was too ambitious, leading to subsequent grade retention and, ultimately, downward mobility. Consequently, we refer to students in this cluster as being on downward trajectories.

The last cluster includes the smallest group of the partition, representing $2.8 \%$ of the sample $(\mathrm{N}=349)$. The medoid sequence is characterised by both an upward and a downward transitions a few years apart. The individual sequences show that there is substantial variation in timing: in some cases downward moves are quickly corrected by an upward transition, while in others the upward transition occurs towards the end of the observation period. Being upwardly mobile enables these students to stay longer in education and to access vocational college (HBO) or university (WO) in greater pro- 
portions. Notably, in the last year of observation, $75 \%$ of these students were enrolled in vocational college, $13 \%$ in university and $2 \%$ in senior vocational education (MBO) (result not shown). This suggests that these students seek a higher education diploma, although this may come at the price of additional years of schooling. Since these paths towards higher education are marked by initial downward mobility, we label them as detour trajectories. The clusters of detour and upward trajectories illustrate that a substantial number of children of immigrants make use of the school system's flexibility to move higher up the education ladder. This is in line with earlier evidence of "long routes" to higher education in the Netherlands, with children of immigrants needing to "stack" diplomas (diploma stapelaars) to repair their initial placement in the wrong track (Crul, 2015, 2018, p.488).

Altogether, this partition shows that a substantial share of students end up in a different track from the one in which they were initially enrolled; 5.3\% end lower and $22.4 \%$ finish higher (including the detour routes). This highlights the added value of comparing the starting and ending points of educational trajectories instead of focusing on isolated transitions (Boylan, 2020). In addition to offering a comprehensive picture of how the second generation navigates the Dutch education system, this transition-oriented approach enables us to effectively reduce the complexity the Dutch education system while emphasising non-standard moves. However, it is important to stress that although our clusters are analytically meaningful, cluster membership "cannot be univocally interpreted" (Piccarreta and Studer, 2019, p5). In line with the cost setting described above, our clusters are primarily defined based on the sequencing of the transitions, to the detriment of other dimensions such as the timing and duration (Studer and Ritschard, 2016, p.483). While this is suitable for our research purposes, it should be considered when interpreting the regression results.

\section{Multinomial logistic regression results}

We next turn to the multinomial logistic regression to assess the association between educational trajectories and individual and family characteristics. The six-cluster solution presented above serves as a dependent variable with six possible outcomes. Because we are interested in the odds of experiencing an alternative pathway within the Dutch education system, we use the standard paths as the base outcome. Before discussing our main model, it is helpful to add the different sets of covariates in a stepwise fashion to contextualise cluster membership with regard to our main variable of interest. 


\section{Chapter 4}

Figure 4.3 shows the variation of the coefficients attached to citizenship using four nested specifications, while Table B10 in the Supplementary Materials provides full details on the complete regression model including all covariates.

In Model 1, only citizenship is added to the model, with the foreign citizens as a reference group. Compared to the foreign citizens, second-generation children who are Dutch from birth and those who naturalise before entry into
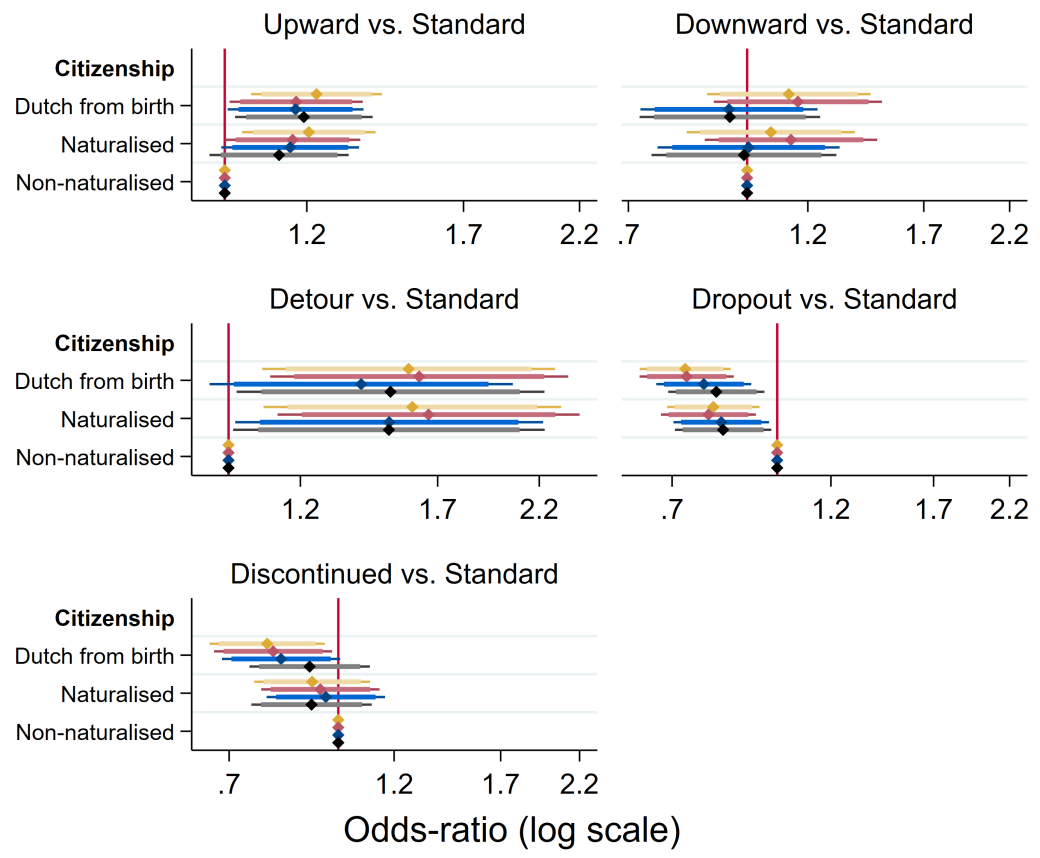

- Model 1 - Model 2 Model 3 - Model 4

Figure 4.3: Plot of the odds of experiencing different trajectories in secondary and tertiary education, by citizenship status.

Note: This plot represents coefficient estimates and confidence intervals at the $90 \%$ (thick) and 95\% (thin) levels. Model 1 only includes citizenship; we introduce step by step the sociodemographic variables (Model 2), the educational controls (Model 3) and the confounding factors (Model 4). The coefficients can also be seen on Table B11 in the Supplementary Materials. 
secondary school have a higher chance of experiencing upward or downward transitions than they do of following a standard path. At the same time, they are more likely to follow the standard path than dropout or discontinued trajectories. While the coefficient estimates for citizenship only change slightly when adding the sociodemographic variables (Model 2), there is a more substantial shift when adding the educational controls (Model 3). If we account for the score obtained at the end of primary school and the initial track, those who acquire Dutch citizenship are no longer more likely to follow a downward trajectory than a standard path (the odds ratio shrinks to around 1). The coefficients also decrease for the detour path relative to the standard one, though more moderately. Detailed regression results show that those in the two higher quintiles of Cito score are much more likely to follow a downward trajectory versus a standard one than those in the first quintile. This suggests that students going down in the course of their educational careers, such as those following a detour or downward trajectory, were initially allocated to a too ambitious track based on the high score they received in the Cito test. The introduction of the educational controls also decreases the magnitude of the coefficient attached to the dropout trajectory. This is related to the fact that those who directly enter the general (HAVO) or pre-university (VWO) tracks have a much lower probability of experiencing a dropout versus a standard path than those who start in vocational education or - to a lesser extent - in bridge class.

Interestingly, there is little change in the coefficients when adding the confounding factors (Model 4). Only the coefficient associated with discontinued trajectories substantially decreases for the Dutch from birth. Detailed regression results suggest that the effect of citizenship was confounded with parental years since migration in Model 3: children whose parents have stayed more than 15 years in the Netherlands are substantially less likely to experience discontinued trajectories, regardless of their citizenship status.

Overall, citizenship seems to have a moderate protective effect against dropout, while it increases the odds of deviating from the standard path through upward transitions. The latter is especially true for detour trajectories: compared to foreign citizens, those acquiring Dutch citizenship are substantially more likely to experience both downward and upward mobility than to follow the standard path, with an odds-ratio around 1.5. Those with Dutch citizenship are also more likely to follow an upward trajectory as opposed to the standard path, yet the coefficient is smaller in magnitude, and confidence intervals show that only limited effects are reasonably compatible with the data. 


\section{Chapter 4}

Another noteworthy aspect concerns the timing of citizenship: there are limited differences between those who are Dutch from birth and those who naturalise before 12. The confidence intervals indeed largely overlap for most outcomes, suggesting that, if any, differences in timing are limited. This indicates that, contrary to our expectations, acquiring Dutch citizenship at birth does not offer significant advantages over naturalising before entry into secondary education. One possible explanation is that children benefit from the naturalisation process from the moment their parents seek Dutch citizenship, i.e. possibly several years before the family actually naturalises. If so, those who naturalise in their childhood would experience similar integration dynamics to those who obtain Dutch citizenship at birth. While this would be consistent with previous evidence of anticipatory mechanisms in the naturalisation process (Peters et al., 2017), more research is needed to understand the mechanisms involved.

To assess the magnitude of the effects of citizenship more precisely, we calculate average marginal effects (AMEs), plotted in Figure 4.4. AMEs show how the predicted probability of each outcome varies as legal status changes, holding the other variables at their observed values. Getting Dutch citizenship at birth or before the age of 12 increases the probability that a student will be an upward mover by 3.1 and 2.1 percentage points, respectively. Interestingly, this effect size is comparable to that of the effect of parental level of education: children whose parents have a middle or higher education diploma are more likely to follow the upward track by around 2 percentage point, compared to those whose parents only completed primary education (see Table B13). By contrast, citizenship acquisition only increases the likelihood of taking a detour trajectory by around 1 percentage point. As for downward mobility, citizenship does not seem to have any effect. These average marginal effects provide suggestive evidence that naturalised parents are better equipped to help their children move upward after their initial track placement, in line with our hypothesis. However, this advantage could also be driven by unobserved heterogeneity at the family level. Furthermore, the absence of an effect on downward trajectories calls for a deeper understanding of the mechanisms at play. This differential effect may be explained by the fact that schools are a driving force for downward transitions, as in the Netherlands schools gain financially if students graduate within the allocated time span. Conversely, upward transitions may depend more heavily on initiatives that families take.

While the acquisition of Dutch citizenship does not affect the likelihood of following downward transitions, it does influence the probability that a student will leave school prematurely. Compared to foreign citizens, students 


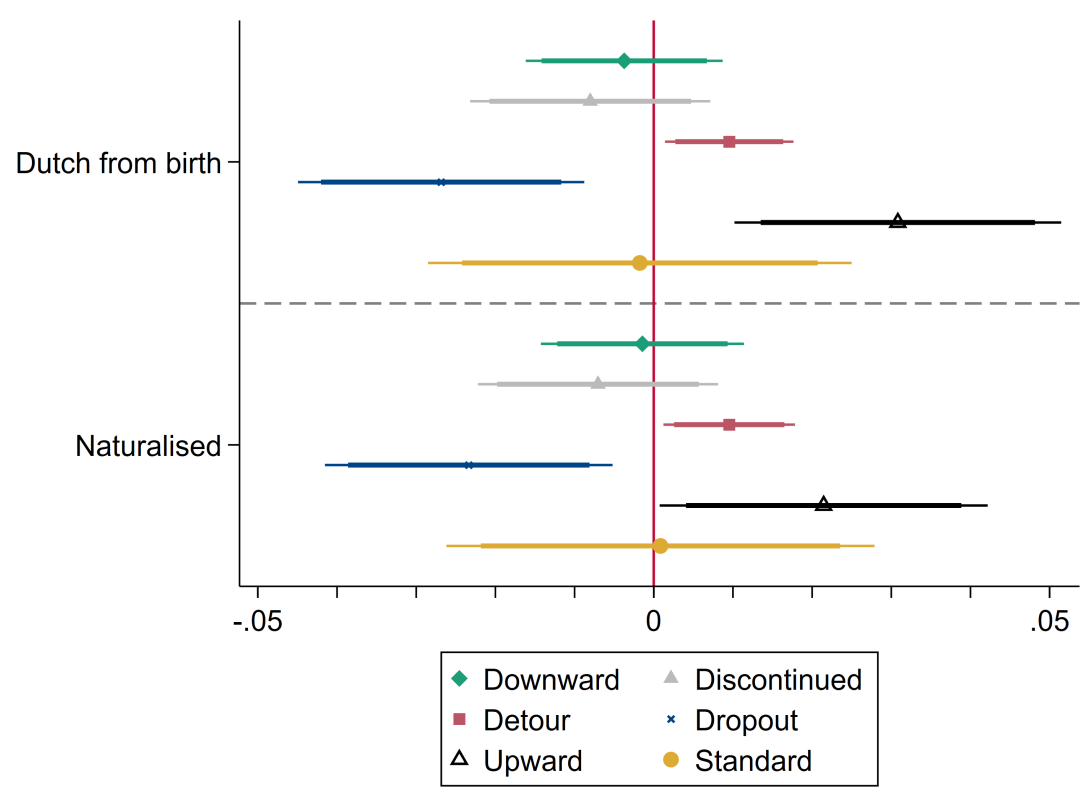

Figure 4.4: Plot of the average marginal effects of Dutch citizenship predicting trajectory in secondary and tertiary education (ref. Non-naturalised).

Note: This plot represents coefficient estimates and confidence intervals at the $90 \%$ (thick) and 95\% (thin) levels.

who acquire Dutch citizenship at birth or before the age of 12 are less likely to experience dropout by 2.7 and 2.3 percentage points, respectively. Although the size of the effect is moderate, it is in the same order of magnitude as that of other important predictors. By way of comparison, students whose parents have a secondary qualification or higher education diploma are less likely to experience dropout by 1.8 and 3.8 percentage points, respectively (Table B13). These results suggest that Dutch citizenship, especially if acquired at birth, has a protective effect against dropout. Naturalised parents may be more informed about the consequences of school dropout for their children's future labour market outcomes, or they may have higher aspirations for their children. While we are not able to tease out these mechanisms, our results overall indicate that citizenship is associated with students' ability to remain in education. 


\section{Chapter 4}

\section{Complementary analysis}

Because AMEs tend to miss variability in effects across cases (Williams, 2012), we also compute marginal effects at representative values (MERs) of the key predictors, such as parental education and years since migration (see Tables B15-B14, Supplementary Materials). While MERs suggest that the relevance of citizenship varies according to parents' resources, differences are rather limited (generally below 1 percentage point) and do not alter our interpretation.

We also use an alternative specification to assess potential biases in our estimations of the effect of citizenship on educational trajectories. As mentioned above, the empirical strategy followed in this paper does not allow the inclusion of time-varying covariates. This is particularly problematic for estimating the effect of citizenship status, since a number of students naturalise during the observation period (See Table B3, Supplementary Materials). Some of the students we categorise as non-naturalised in the main analysis may be already on their way to becoming Dutch when entering secondary education, which may lead to downward bias in the estimated effect. To calculate an upper bound for the effect of citizenship, we use an alternative specification where we define all students who acquire citizenship after birth within the observation period as naturalised. This leads to very similar patterns to those observed in the main analysis, with the difference that the estimated effects for citizenship are substantially larger in magnitude (see Figure B6, Supplementary Materials).

\section{Conclusion}

In most countries, second-generation children do not get automatic birthright citizenship but rather depend on their parent's ability and desire to naturalise if they are to become citizens of their country of birth and residence. While naturalisation requirements have been increasingly strict over recent decades (Goodman, 2010; Vink and de Groot, 2010), we still know little about whether and how citizenship status matters for children of immigrants in ius sanguinis regimes (Labussière and Vink, 2020). Following recent developments in the literature (Felfe et al., 2020; Bean et al., 2011; Kilpi-Jakonen, 2014; Fibbi et al., 2007), this paper focuses on the Netherlands to analyse the extent to which children of immigrants who acquire host country citizenship are better able to navigate a complex and stratified education system. 
A life course perspective sheds light on the multi-faceted process immigrants go through when seeking host country citizenship. While migration may deeply affect individuals' agency over their life course (Wingens et al., 2011b), naturalisation opens up new opportunities in host societies and may foster the ability of immigrant families to navigate complex institutions (Patler et al., 2020). Importantly, the resources and skills they develop during and following the naturalisation process may help them identify desirable tracks for their children and take advantage of the system's flexibility, which is of particular importance in educational contexts combining early selection and between-school tracking (Pfeffer, 2008; Crul, 2018). This paper calls for a more dynamic and comprehensive approach to naturalisation, and adds to the burgeoning literature exploring the influence of migration on youth educational opportunities in a life course perspective (e.g. Soehl et al., 2018; Baysu and de Valk, 2012).

Our paper also contributes to a better operationalisation of educational trajectories using a transition-oriented sequence analysis. Unlike event-oriented approaches to educational outcomes, we map the school careers of a full cohort of second-generation students from their entry into secondary education in 2008 to 2016. This enables us to focus on long-term pathways and to better reflect the complexity of educational careers (Boylan, 2020). Drawing on the transition-oriented approach developed by Biemann (2011), we also offer a context-sensitive method of highlighting (im)mobility patterns based on theoretical expectations. While the identification of broad types of educational trajectories has been sufficient for our purposes, this method has potential for generating more fine-grained typologies of educational careers. In that respect, we argue that transition-oriented sequence analysis may prove especially fruitful for future research on educational trajectories within stratified systems.

In addition to standard paths through the Dutch education system, we identify five clusters of alternative pathways: downward, upward, discontinued, dropout and detour, with the latter referring to those who experience first a downward and then an upward transition. This partition indicates that while a substantial proportion of students (27.6\%) make use of the system's back doors to move between tracks, another significant share $(22.3 \%)$ spends time temporarily or permanently away from the Dutch public school system. In the regression analysis, citizenship stands out as a significant predictor of one's trajectory through secondary and tertiary education. Students who acquire Dutch citizenship before they enter into secondary education are between 2 and 3 percentage points more likely to follow an upward tra- 


\section{Chapter 4}

jectory than those who are still foreign citizens when they start secondary school. Conversely, Dutch citizens are about 2.5 percentage points less likely to dropout.

As can be expected when seeking such a comprehensive and multidimensional indicator of educational attainment, other factors, such as cognitive ability or family characteristics, play an equal or larger role than citizenship. Besides, our set of covariates is far from exhausting the range of relevant characteristics: register data do not offer information on students' aspirations and parents' expectations (D'hondt et al., 2016; Boylan, 2020), and we are not able to incorporate characteristics beyond the household to account for potential peer and neighbourhood effects. We therefore interpret our results as preliminary and suggestive evidence that the acquisition of Dutch citizenship influences the way children of immigrants navigate the school system.

While further research is needed to assess the relevance of host country citizenship for children and tease out the mechanisms through which it affects educational outcomes, our findings support the idea that children who are foreign citizens in their country of birth have fewer educational opportunities. Given that most European countries, like the Netherlands, are characterised by a descent-based birthright regime, the potential effect of naturalisation on the life paths of the second generation merits research beyond the Dutch case. 


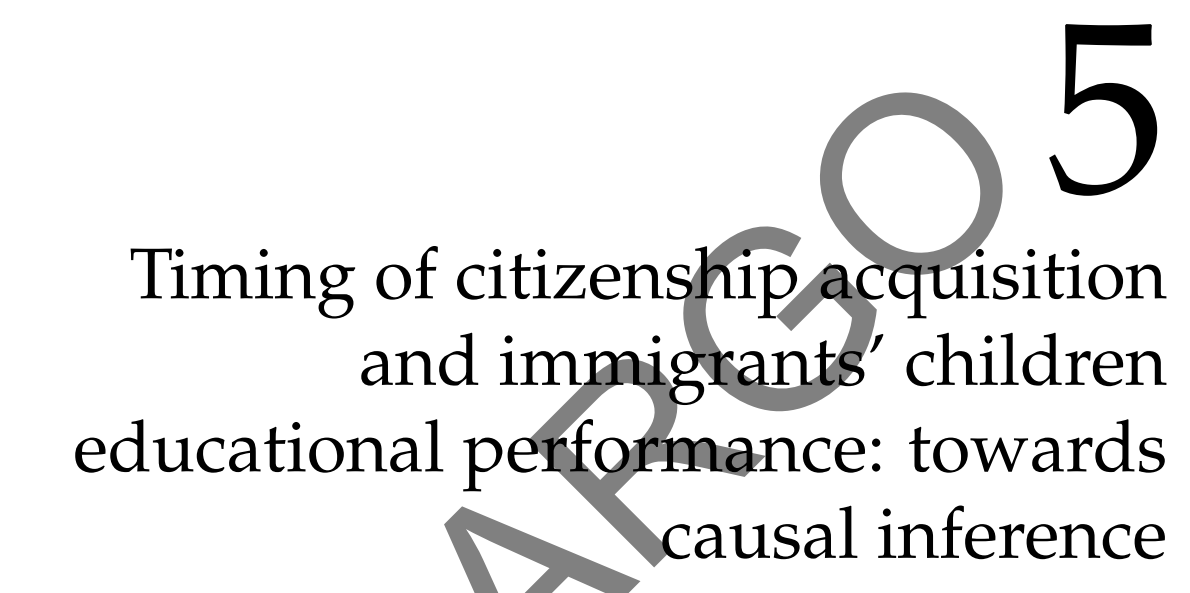

This chapter is submitted for publication as a single author paper and is currently under review. 
Conclusions 


\section{Introduction}

In recent decades, immigrants' access to the citizenship of their country of residence has been increasing restricted in Western Europe (Vink and de Groot, 2010; van Oers, 2013; Jensen et al., 2019). In a number of countries, this can be traced to the moralisation and emotionalisation of what it means to be a citizen (Schinkel and Van Houdt, 2010; van Houdt et al., 2011; Duyvendak, 2011, p.94). Whereas citizenship used to be understood as a right to membership by virtue of residence in the country, it is increasingly conceived as a status to be earned or deserved (van Houdt et al., 2011, p.420). Prospective citizens need to prove that they are worthy of becoming citizens by fulfilling a series of criteria, typically including evidence of self-sufficiency, integration and allegiance to the country of residence through acceptance of its assumed values and norms. Previous literature has documented the detrimental impact of stricter naturalisation requirements on the ability and propensity of immigrants to acquire host country citizenship, showing that it disproportionately affects those with low levels of income and education (Peters, 2018; Jensen et al., 2019; Vink et al., 2021).

The fact that such restrictions in access to host country citizenship may not only affect immigrants but also their children has been largely overlooked so far, both from a research and a policy perspective. Yet, in most European countries, the children of immigrants mainly depend on their parents if they are to acquire the citizenship of their country of birth and residence. This is because ius soli citizenship provisions, whereby children have automatic rights to the citizenship of their country of birth, are the exception rather than the rule (Honohan and Rougier, 2018). In the absence of ius soli, children of immigrants whose parents are not able or willing to naturalise may remain foreign citizens, and thus be offered fewer opportunities in their country of residence. Surprisingly, very little is known about the extent of this phenomenon. A limited number of studies suggest that host country citizenship has a positive impact on the educational outcomes of children of immigrants (Fibbi et al., 2007; Avitabile et al., 2014; Kilpi-Jakonen, 2014; Cygan-Rehm, 2018; Felfe et al., 2020). However, such studies mostly focus on whether citizenship matters, at the expense of why, when and under which conditions citizenship is relevant for the children of immigrants.

This dissertation has aimed to contribute to this emerging literature by examining the patterns and effects of citizenship acquisition among children of immigrants in the Netherlands. It focused on the so-called second generation; the children of immigrants who are born in the Netherlands to two 
foreign-born parents. In a ius sanguinis citizenship regime as in the Netherlands, native-born children of immigrants depend primarily on their parents to naturalise in order to become Dutch citizens. This dissertation examined how these legal provisions affect access to Dutch citizenship for the children of immigrants born in the Netherlands between 1995 and 2010. Drawing on the life course perspective, it then conceptualised and assessed the effects of children's citizenship status on their opportunities in the Dutch education system. For this purpose, I used administrative register data from Statistics Netherlands, which track full cohorts of native-born children of immigrants from birth to early adulthood.

The central research question was:

To what extent does citizenship status affect the educational outcomes of native-born children of immigrants?

The research question was broken down in a number sub-questions, which are addressed in the three empirical chapters (3-5) of this dissertation:

1. Who acquires host country citizenship among second-generation children in the Netherlands, when and under which conditions? To what extent is children's access to host country citizenship affected by the implementation of restrictive naturalisation laws? (Chapter 3)

2. How do the children of immigrants navigate the Dutch secondary school system, and is host country citizenship associated with specific educational trajectories? (Chapter 4)

3. To what extent are the effects of citizenship on education driven by parental selection into naturalisation? Does the effects of citizenship vary over time and across individuals? (Chapter 5)

The following sections reflect on the main findings of this research. I first outline the main contributions of the thesis to the analysis of the citizenship of immigrants' children, before discussing some of the main limitations and suggesting avenues for future research. 


\section{Main contributions to the literature}

\section{Theoretical contributions}

The effects of citizenship on the educational outcomes of children of immigrants have already received some attention in previous work (Felfe et al., 2020; Cygan-Rehm, 2018; Kilpi-Jakonen, 2014; Fibbi et al., 2007; Bean et al., 2011; Patler, 2017). This literature has primarily focused on identifying whether citizenship has an independent effect on children's outcomes. This focus is justified, as there is a great potential for endogeneity in the relationship between citizenship and education: parents who are willing and able to naturalise may be better equipped to support their children's performance at school even before naturalisation, due to the selective nature of the process. Yet, this focus has arguably led previous studies to overlook other important dimensions. First, the question of why citizenship would matter has received relatively less attention, resulting in often narrow conceptualisations of the mechanisms by which citizenship would affect education. Second, only a handful of studies do analyse when and for whom citizenship matters (see Cygan-Rehm, 2018; Dronkers and Fleischmann, 2010, for exceptions). Consequently, knowledge about the factors that condition the relevance of citizenship for children is still limited.

One reason for these gaps may be that, from a conceptual point of view, the study of the citizenship of children of immigrants lies at the intersection of different bodies of literature, which have hitherto largely remained disconnected. On the one hand, the literature on the educational outcomes of children of immigrants in Europe has paid very limited attention to their citizenship status. As a result, while there is extensive evidence that some secondgeneration students face significant barriers in education (Heath et al., 2008; Alba and Holdaway, 2013; Dustmann et al., 2012), citizenship has rarely been considered as a potential mitigating factor (see Dronkers and Fleischmann, 2010, for an exception). On the other hand, citizenship studies have highlighted the relevance of host country citizenship for the socioeconomic and cultural integration of immigrants. However, studies of immigrant naturalisation are generally individual- and adult-centred, ignoring the role and place of children in the naturalisation process (Peters et al., 2016; Street, 2014). Besides, there are also important qualitative studies analysing how secondgeneration children experience host country citizenship - or the lack thereof (Colombo, 2015; Frauenfelder, 2007; Ribert, 2000). While valuable in understanding what citizenship means to children, these studies do not specifically 
consider whether and how becoming a citizen influences their educational aspirations and school decisions.

In Chapter 2 of this dissertation, I showed that it is necessary to combine these various strands of literature to understand why, when and for whom citizenship matters. Building on the work of Peters (2018), I used the sociological life course paradigm as a conceptual glue to bring together the insights from previous studies into a more comprehensive theoretical framework. Three principles of the life course approach have proved particularly useful in enhancing our understanding of the patterns and effects of host country citizenship for immigrants' children.

\section{Linked lives}

The principle of linked lives, which emphasises the embedding of human life courses in family and social relationships, was essential for analysing the citizenship status of children. Because children primary rely on their parents to become citizens of their country of residence, family dynamics are key to understanding both the patterns and effects of citizenship acquisition by the children of immigrants. In the first place, the interdependence between family members calls for a conceptualisation of immigrant naturalisation propensity at the family level, beyond the standard individual-centred approach prevailing in citizenship studies (Street, 2014). While previous work had already paid valuable attention to the interpersonal dynamics involved in naturalisation decisions (Street, 2013, 2014; Soehl et al., 2018), Chapter 3 went further in conceptualising different family approaches to citizenship acquisition, based on observed parent-child naturalisation patterns. The focus on children's dependence on their parents enabled me to hypothesise and test an intergenerational impact of naturalisation laws, which had been neglected so far in the literature on immigrant naturalisation.

In the second place, the interaction processes between parents and children need to be taken into account in order to conceptualise the effects of citizenship in a comprehensive way. Previous quantitative studies have relied mainly on human capital theory to explain the impact of citizenship on education, limiting host country citizenship acquisition to a positive shock to labour market returns to education (Felfe et al., 2020; Cygan-Rehm, 2018; Kilpi-Jakonen, 2014). Such a perspective tends to overlook two complementary insights from the second generation literature and citizenship studies. These are, respectively, the specific obstacles that immigrant families face in 


\section{Chapter 6}

making successful investments in a foreign educational context (Heath et al., 2008; Crul et al., 2012; Alba and Holdaway, 2013); and the resources that parents develop following the acquisition of host country citizenship (Hainmueller et al., 2017; Avitabile et al., 2013; Peters, 2018). To my knowledge, no research has so far considered the potential spillover effects of parental naturalisation on their children's outcomes. In Chapters 4 and 5, I hypothesised and provided evidence that host country citizenship not only raises the educational expectations of immigrant families: it also gives them relevant resources to realise these expectations in a foreign education system. I argue that these indirect effects of citizenship explain better than previous approaches why naturalised children navigate the complex system of Dutch secondary education more easily than their non-citizen counterparts.

\section{Context and agency}

A second principle of the life course approach that was relevant to this thesis is the analysis of the interplay between context and agency. Immigrant families may face significant institutional constraints in the host society, which limit their ability to control and plan their lives (Wingens et al., 2011a). This institutional context is marked by immigration and citizenship laws, which shape the opportunities available to foreign residents and the legal status to which they are entitled (de Hart et al., 2013). It is also characterised by the structure of the education system, whose institutional arrangements can make it difficult for immigrant parents to support their children's educational achievement (Blossfeld et al., 2016; van de Werfhorst, 2019). At the same time, immigrant families have agency: they pursue their goals and actively organise their lives according to the constraints they face (Wingens et al., 2011a). In particular, they develop resources, strategies and tactics to adapt to an often changing environment (Sredanovic, 2020; de Hart et al., 2013). The life course perspective emphasises the need to analyse context and agency in a relational way, in order to understand how individual lives interact with macro-level processes (Mayer, 2004).

In this dissertation, I devoted specific attention to embedding the actions of immigrant families within broader institutional dynamics, while highlighting their active role. In Chapter 3, I analysed the naturalisation patterns of immigrant families in a context of changing naturalisation reforms. Although the introduction of stricter requirements has placed additional constraints on prospective citizens, I developed and tested original hypotheses about how 
families adapt to these restrictions to minimise the cost of citizenship acquisition at the family level. In Chapters 4 and 5, I then turned to the education system to determine whether host country citizenship increases the level of agency of immigrant families, and helps them navigate complex institutions. By doing so, I contribute to an emerging body of literature showing that legal status is associated with immigrants' levels of everyday agency (see Patler et al., 2020). Overall, the joint attention to constraints and opportunities enabled me to avoid two important pitfalls in the study of immigrant families: that of assuming "disproportionate agency" (Sredanovic, 2020; Bloemraad, 2002, p.196) on the one hand, and that of denying agency to immigrants on the other (de Hart et al., 2013).

\section{A life-course process}

Finally, this dissertation draws on the notion of life course, which highlights the temporal dynamics of individuals' biographies (Wingens et al., 2011a). I show that conceptualising the effects of citizenship over the life course is important in two ways. Firstly, recent work on immigrant naturalisation suggests that citizenship acquisition should not be conceived as an abrupt transition, but rather as a process that develops over time (Peters et al., 2017; Hainmueller et al., 2017). While immigrants can only enjoy the rights and benefits of host country citizenship after they have officially become citizens, the effects of citizenship should not be limited to a one-off "before-after" impact. There is indeed evidence that the naturalisation process can trigger both anticipated and long-term effects on the integration trajectories of immigrants (Peters et al., 2017; Hainmueller et al., 2017). This led me to pay attention not only to the final legal transition, but also to the resources and knowledge that parents may acquire as a result of the naturalisation process itself. So far, both anticipated and long-term effects of naturalisation have mostly been analysed in the perspective of immigrants' own integration outcomes (ibid.). In Chapters 4 and 5, I argued that such effects may also be relevant for their children's educational outcomes.

Secondly, the notion of life course invites us to analyse citizenship acquisition in the context of human biographies. While the literature on immigrant naturalisation shows that the effects of host country citizenship vary depending on when and by whom it is acquired (Hainmueller et al., 2017; Peters, 2018; Vink et al., 2021), studies on the second generation generally assume that citizenship has a uniform impact on children's educational outcomes (see 


\section{Chapter 6}

Cygan-Rehm, 2018; Dronkers and Fleischmann, 2010, for exceptions). This calls for a better contextualisation of citizenship effects, paying greater attention to the factors that may condition the relevance of citizenship for the second generation. In Chapter 5, I therefore formulated and tested hypotheses about the potential timing and interaction effects of citizenship for the second generation, adding new layers of complexity to previous conceptualisations of citizenship for children of immigrants.

\section{Substantive findings}

To answer the research question, this dissertation consists of three empirical chapters that are based on published or submitted research articles. Chapter 3 focused on the patterns of citizenship acquisition of children of immigrants in the Netherlands, in a context of changing naturalisation requirements. Results highlight two interrelated dynamics. First, a descriptive overview of the modes of acquisition of Dutch citizenship among children of immigrants indicates that the vast majority (96\%) of children relied on their parents to become Dutch, either by descent or by co-naturalisation. This calls for a conceptualisation of children's naturalisation at the family level, in line with recent developments in the field of citizenship studies (Street, 2014; Soehl et al., 2018). Second, Cox proportional hazard models show that the introduction of stricter naturalisation requirements in 1997 and 2003 had negative effects on the naturalisation propensity of children: those whose parents were eligible before the implementation of the reforms have a higher naturalisation propensity than those who became eligible later on. This is consistent with earlier findings on the detrimental effects of dual citizenship restrictions and integration requirements on immigrant naturalisation (Peters et al., 2016; van Oers, 2013; Stadlmair, 2017; Vink et al., 2021). However, unlike previous studies, the use of time-by-covariate interactions allows me to highlight specific temporal patterns depending on the nature of the requirements: while the dual citizenship restriction deters families from naturalising in the long run, mandatory civic integration requirements see them postpone naturalisation. This shows that reforms increasing the obligations of prospective citizens do not necessarily prevent naturalisation, but can postpone it to a later date. Furthermore, a competing-risk model indicates that children whose parents only became eligible under stricter requirements were much more likely to naturalise with one parent than with both, suggesting that families develop strategies to cope with the tightening of naturalisation requirements. These results confirm the hypothesis of an intergenerational impact of naturalisation 
reforms, and emphasise the inherent social dimension of the naturalisation process (Street, 2014; Soehl et al., 2018; Sredanovic, 2020; Della Puppa and Sredanovic, 2017): family and contextual dynamics both shape the naturalisation decision of parents, and influence when and with whom children become host country citizens.

Findings in Chapter 3 suggest that a number of immigrant families have either postponed or put off their application for Dutch citizenship since the mid-1990s. Chapters 4 and 5 aimed to assess the consequences for their children's opportunities in the Dutch society: does citizenship - or the lack thereof - affect the educational outcomes of the children of immigrants?

Chapter 4 took an exploratory approach to analyse whether Dutch citizenship is associated with specific educational pathways in the Dutch school system. The focus on trajectories rather than on isolated transitions or outcomes offers a comprehensive picture of how the second generation navigates the Dutch education system, highlighting a great diversity of pathways. In addition to standard paths through the Dutch education system, I identified five clusters of alternative trajectories: downward, upward, discontinued, dropout and detour, with the latter referring to those who experience first a downward and then an upward transition. Sequence analysis confirms the added value of mapping the complete educational trajectories of students in a stratified and flexible system such as Dutch secondary education: a substantial share of students (28\%) end up in a different track from the one in which they were initially enrolled. Sequence analysis also makes it possible to measure the prevalence of non-standard trajectories in the Dutch system, such as the so-called "long routes" to university described in qualitative studies (Pásztor, 2012; Crul et al., 2017). However, the most important finding is that Dutch citizenship is associated with some of the trajectories students follow in secondary education: students who acquire Dutch citizenship at birth or before the age of 12 are more likely to move upward through the system by 3.1 and 2.1 percentage points, respectively. Dutch citizenship also seems to have a protective effect against dropout: it decreases the likelihood of leaving school early by 2.7 percentage points when acquired at birth (and 2.3 percentage points when acquired before age 12). In contrast, Dutch citizenship is not significantly associated with the probability of following a downward trajectory. These results suggest that children of immigrants who acquired Dutch citizenship have better access to back doors and safety nets in the education system, which is consistent with the hypothesis that these students and their parents are better equipped to navigate secondary education. Finally, Chapter 4 provides preliminary findings about the timing of citizenship 
acquisition: I find that acquiring Dutch citizenship at birth does not seem to offer significant advantages over naturalising between birth and entry into secondary education.

In Chapter 5, I delved deeper into the potential timing effects of naturalisation. I compared the results of a standardised test at the end of primary school between siblings who acquired Dutch citizenship at a different age. This empirical strategy has two main advantages. First, focusing on the age at naturalisation allows for a more detailed analysis of the timing of naturalisation than in Chapter 4, where I only distinguished between citizenship acquisition at birth and before the age of 12. Second, a family fixed-effects approach neutralises the effects of invariant family characteristics that can confound the relationship between citizenship and education. While Chapter 4 measured associations without assuming a cause-and-effect relationship, Chapter 5 goes further in identifying a causal impact of naturalisation on education. Results show that second-generation students who acquired Dutch citizenship in early childhood outperform their non-citizen peers by about 0.1 standard deviations on the standardised test. Importantly, the between-within model indicates that these results are not significantly biased by the omission of time-constant parental characteristics. This result is supported by a bounding analysis, which reveals that selection on unobservables would have to be three times more important as the selection on observables to explain away the positive effect of naturalisation. An important implication of these findings is that the relationship between citizenship and education is not only driven by selection, confirming the hypothesis of an independent effect of citizenship on education. The magnitude of the coefficients also indicates that citizenship has a substantial positive effect on test scores, comparable to that of other important predictors of educational achievement. These empirical findings are consistent with prior work using alternative identification strategies for the effect of host country citizenship (Felfe et al., 2020; CyganRehm, 2018; Avitabile et al., 2014). Yet, Chapter 5 also shows that the effect of citizenship acquisition is not uniform. The later students acquire Dutch citizenship, the weaker their advantage over their non-citizen peers in terms of test scores. Advantage decreases sharply after the age of 7, and becomes marginal when students acquire Dutch citizenship shortly before or after taking the standardised test. This suggests that children of immigrants most benefit from host country citizenship when their parents naturalise in early childhood, before they enter primary education. Furthermore, interaction effects between citizenship status and parental characteristics indicate substantial effect heterogeneity: the acquisition of Dutch citizenship mostly matters for 
children whose parents have at most a secondary education qualification and do not have access to homeownership. This is consistent with the hypothesis that citizenship mainly acts as a compensatory mechanism, fostering the educational performance of children when other parental resources are lacking. Such findings are in line with the literature on immigrant naturalisation, which shows that the effects of naturalisation for immigrants' economic and social integration are most effective when it is acquired early and by immigrants who otherwise lack the resources to achieve a stable socioeconomic position in the host society (Gathmann and Keller, 2018; Hainmueller et al., 2017; Peters et al., 2020). In other words, Chapter 5 confirms that naturalisation promotes the educational success of children, but points out that this is mostly the case for those who acquire Dutch citizenship in early childhood and whose parents are disadvantaged in the labour and housing markets.

The three empirical chapters provide several avenues for answering the research question. Chapter 3 first indicates that there is substantial variation in the citizenship status of native-born children of immigrants in the Netherlands. This variation is linked to the fact that children mostly acquire Dutch citizenship through co-naturalisation with their parents, who themselves depend on the naturalisation laws in force. In a context of increasingly stringent requirements, some children were denied early access to Dutch nationality if not access at all. Chapters 4 and 5 then provide convergent evidence that citizenship status is associated with various educational outcomes of the children of immigrants in the Netherlands: their school achievement (Chapter 5) and the way they navigate Dutch secondary and tertiary education (Chapter 4). While previous literature has consistently shown that citizenship favours students' placement in a higher track (Felfe et al., 2020; Cygan-Rehm, 2018; Kilpi-Jakonen, 2014), the effects of citizenship on school achievement had received less attention so far (see Kilpi-Jakonen, 2014, for an exception). Another consistent finding relates to the magnitude of the effects: citizenship advantage in education is significant, generally comparable to that of other important predictors of educational performance. While key family characteristics such as parents' level of education often have a greater effect, host country citizenship has nevertheless the potential to mitigate some of the obstacles children of immigrants may face in education.

Chapters 4 and 5 also bring complementary insights into the effects of citizenship. On the one hand, Chapter 4 highlights that citizenship is not only associated with students' initial placement after primary school (Felfe et al., 2020; Cygan-Rehm, 2018; Kilpi-Jakonen, 2014), but also with their wider mobility trajectory in secondary education. This suggests that host country citi- 


\section{Chapter 6}

zenship durably influences the educational aspirations of immigrant families, and gives them resources to realise them despite the complexity of the education system. On the other hand, Chapter 5 focuses on a single educational outcome but takes the identification strategy further, by identifying whether the observed relationship between citizenship and education is confounded by unobserved heterogeneity at the family level. While previous studies have justifiably focused on isolating the causal effect of host country citizenship (Felfe et al., 2020; Cygan-Rehm, 2018), the identification strategy used in this chapter also allows me to estimate the strength of parental self-selection into naturalisation. Results suggest that the main confounders are included in my models, which lends credence to the findings obtained in Chapter 4. Taken together, the two chapters further indicate that host country citizenship affects students' education on several level: it influences students' initial tracking into secondary education, through its effects on test scores, as well as how they subsequently orient themselves in secondary education and possibly correct an initial misplacement. This confirms the added value of conceptualising the effects of citizenship from a life course perspective, which takes into account the internal dynamics of students' educational pathways in stratified education systems.

Finally, Chapters 4 and 5 move beyond the question of whether citizenship matters to examine the factors that condition the relevance of citizenship acquisition. Chapter 4 suggests that there are no significant differences between acquiring Dutch citizenship at birth or later before entry into primary education for the type of trajectory that students follow thereafter. Using a more precise measure of the timing of naturalisation, Chapter 5 provides additional insights: while those who acquire Dutch citizenship from birth or in early childhood have a comparable advantage in school achievement, those who naturalise in the years before they enter secondary education perform similarly to their non-citizen counterparts. With its early-tracking education system, the Netherlands requires parents to be involved in their children's education from the beginning of their school careers (Crul, 2018; Inspectie van het Onderwijs, 2016). Naturalisation may therefore provide parents with helpful resources to navigate this complex system when acquired at an early stage, but may be less relevant when acquired after their children have made key educational transitions in early adolescence. Chapter 5 further shows that the effects of citizenship are conditioned by the other characteristics of children, such as their parents' level of education: host country citizenship does not add to the effects of other parental resources, but rather compensate for their absence. This is consistent with earlier findings that citizenship es- 
pecially matters for the integration of immigrants who face structural constraints in the host society (Hainmueller et al., 2017; Peters, 2020). The fact that similar mechanisms hold for their children is in line with the hypothesis of indirect citizenship effects, mediated by parents' improved position in the host society.

Overall, Chapters 4 and 5 provide a nuanced answer to the research question: the acquisition of host country citizenship does affect the educational outcomes of native-born children of immigrants, but not at any time and for all. Indirectly, these chapters also provide preliminary answers to the question left open in Chapter 3, which highlighted the detrimental effect of recent naturalisation laws on the acquisition of citizenship by children of immigrants. Immigrant parents who were only eligible after the 1997 and 2003 reforms have tended to postpone or abandon the naturalisation of their family, but what were the possible implications for their children's opportunities in the Netherlands? The findings mentioned above suggest that naturalisation reforms had an indirect impact on their children's educational outcomes. In particular, simple delays in the acquisition of host country citizenship can have significant adverse effects if naturalisation is postponed to a time when children are already enrolled in school. Furthermore, previous findings suggest that the 1997 and 2003 restrictive naturalisation reforms predominantly affected the life chances of children from disadvantaged backgrounds. This should be taken into account when assessing the overall impact of restrictive naturalisation reforms: such reforms not only decrease the naturalisation propensity of immigrants who need it the most (Peters, 2018; Jensen et al., 2019; Vink et al., 2021), but also indirectly denies citizenship to children who would benefit the most from it.

\section{Methodological contributions}

In the empirical chapters, I devoted specific attention to designing empirical strategies that align with the theoretical orientation of the dissertation. The use of administrative register data from Statistics Netherlands was important in this respect, for two main reasons. First, the longitudinal nature of the data enabled me to analyse the effects of citizenship over the life course of children of immigrants, in line with the sociological life course paradigm. Second, register data provide a comprehensive coverage of the Dutch secondgeneration population legally residing in the Netherlands. The use of data on the whole population - instead of a survey sample - allowed the implementation of identification strategies that require high statistical power. These 


\section{Chapter 6}

valuable features of the data were combined with recent methodological developments to operationalise the theoretical framework as precisely as possible. As I detail below, this contributed to the dissemination of methods that had previously received little attention in the various fields of study in which this dissertation is embedded.

In Chapter 3, I used the Cox proportional hazard model. This model is commonly used to study the association between the time to a certain event and one or more predictor variables. Yet, one important assumption of this model is that the hazard ratios of all individuals are proportional and that this proportionality is maintained over time. This assumption is violated when the effects of the covariates on the hazard vary over time. This is notably the case when estimating the effect of the cohort of eligibility of immigrant parents: the longer the time between eligibility and actual naturalisation, the more likely candidates are to fall under different requirements. To address this issue, I used time-by-covariate interactions to explicitly model the decreasing influence of the eligibility cohort over time (Box-Steffensmeier et al., 2003; Keele, 2010; Bellera et al., 2010). Unlike the more commonly used stratification technique (e.g., Vink et al., 2021), time-by-covariate interactions capture the temporal dynamics involved in non-proportional covariates. This proved to be especially relevant in the analysis of restrictive naturalisation reforms. The interactions suggested that while certain cohorts of eligibility are durably excluded from naturalisation, others mostly delay it over time. This finding has important implications for understanding the temporal dynamics of policy effects, and more generally invites future studies to pay more attention to non-proportional covariates in Cox regression models.

Chapter 4 employed sequence analysis to compare the educational trajectories of children of immigrants. A standard approach is to code the trajectories as sequences of states and to compare them using the Optimal Matching (OM) distance (Ritschard and Studer, 2018). Previous studies analysing educational trajectories have generally coded students' pathways as sequences of school tracks, so as to identify the students who attended similar courses of study (e.g., Baysu and de Valk, 2012; Boylan, 2020). However, OM approach is context-insensitive: it considers each state separately, without considering previous or subsequent states (Elzinga and Studer, 2015, p.6). This does not adequately reflect the dynamics of students' educational pathways, where the track followed at time $t$ influences the tracks accessible at time $t+1$, and the meaning of the transition between $t$ and $t+1$. This is why I followed Biemann's (2011) suggestion to code educational trajectories as sequences of transitions instead of sequences of states. The advantage of this approach is 
that it makes it possible to differentiate between different types of transitions in secondary education, and to identify students who have followed similar patterns of mobility. This is particularly relevant to operationalise the notion of "navigating" the education system, since OM cost setting can be set in such a way as to highlight atypical trajectories where students move away from their initial course of study. Applied to the Dutch context, transitionoriented OM offered an unprecedented image of how second-generation students make their way into secondary education. While this method had never been used beyond Biemann's study (2011), I showed its potential to generate meaningful typologies of educational careers within stratified systems.

In Chapter 5, I used a family fixed-effects approach to identify the effects of naturalisation net of parental self-selection into naturalisation. The idea to compare siblings in order to neutralise the effects of unobserved timeinvariant characteristics at the family level is not new (e.g., Böhlmark, 2008; Nielsen and Rangvid, 2012; Sigle-Rushton et al., 2014). Previous studies typically use sibling fixed-effects models, which only estimate within-effects, i.e., the effects of the covariates within families. This approach has the advantage of removing the risk of heterogeneity bias. Yet, it also comes with limitations: sibling fixed-effects models do not allow the estimation of variables that are constant between siblings (such as time-invariant family characteristics), and do not explicitly model heterogeneity bias (Bell and Jones, 2015). By contrast, the between-within model developed by Mundlak (1978) and Allison (2009) makes it possible to assess the extent to which the coefficients are biased when unobserved heterogeneity is not modelled. I argue that this is more informative than testing only between selection and causation. Unfortunately, despite recent methodological developments and discussions on the between-within model (Sjölander et al., 2013; Brumback et al., 2017), it is still very little used in empirical research, especially in the social sciences (see Zorn, 2001, for an exception).

\section{Limitations and avenues for further research}

Analysing the relationship between citizenship and education of children of immigrants has posed a number of methodological problems and limitations, not all of which could be resolved in the context of this thesis. In the following, I discuss some of these limitations and how they might lead to fruitful ideas for future research. 


\section{Chapter 6}

\section{Limitations in data and operationalisation}

While administrative register data offer undeniable advantages for analysing the citizenship of children of immigrants, they also have limitations that have influenced the operationalisation of the main hypotheses of this thesis.

\section{Parental characteristics as both confounders and mediators}

One theoretical contribution of this dissertation was to emphasise that parental characteristics may act both as confounders and mediators in the relationship between citizenship and education (see Figures 2.1-2.2 on p.82). On the one hand, the positive association between citizenship and education may be due to unobserved parental characteristics that influence both parents' naturalisation propensity and their children's educational outcomes, thus providing a classic case of common-cause confounding bias (Elwert and Winship, 2014). On the other hand, I argued that naturalisation may have an indirect effect on educational outcomes, through the improved position of parents in the host society. This suggests that parental characteristics after naturalisation mediate part of the effects of citizenship on education. To jointly identify such confounding and mediated effects, the timing of measurement of parental characteristics is key: the potential confounders should be measured before naturalisation, while the potential mediators should be measured after naturalisation.

Although the differentiation between confounding and mediated effects is crucial for causal identification, it was not possible to distinguish them empirically with the available data. The reason is that most parental characteristics that are expected to act as confounders and/or mediators are not available before the early 2000s, when most of the children in the study population have already naturalised. ${ }^{1}$ For example, parents' socioeconomic status is only available from 1999, while information on household income and homeownership status of parents is recorded from 2003. As a result, including parental characteristics measured before naturalisation was in general not possible. ${ }^{2}$

\footnotetext{
${ }^{1}$ This is especially true for Chapters 4 and 5 , for which I restricted the research population to those born in the second-half of the 1990s in order to observe their educational outcomes in secondary education (see Figure 1.1, p.28).

${ }^{2}$ Nonetheless, I did robustness checks in Chapter 5 using parents' socioeconomic status measured at the time of naturalisation or shortly thereafter (depending on children's date of naturalisation), since this variable is available since 1999. The results indicate that the effects of age at naturalisation are slightly higher when parents' socioeconomic status is measured
} 
In all models of Chapters 3 and 4, I included parental characteristics measured in the last year of primary school (when time-varying). This introduces a risk of over-adjustment bias, because these variables may mediate (part of) the relationship between citizenship and education (see, e.g., Schulz et al., 2017, p.2202, for an illustration of this point). As a result, the estimated effects of citizenship acquisition should be interpreted as direct - and not total - effects. This choice was dictated by the priority given to identifying the effects of citizenship net of confounding factors; nevertheless, the potential mediating role of parental characteristics deserves more attention. While this thesis took a first step in that direction, a joint analysis of mediating and confounding effects requires more comprehensive data and dedicated methods.

\section{The timing of citizenship acquisition}

This thesis provided a better understanding of the effects of the timing of citizenship acquisition, indicating that children of immigrants who become Dutch in late childhood benefit less from citizenship than those who become Dutch at birth or in later years. Yet, it did not investigate timing effects during adolescence, when second-generation youth reach an age where lack of citizenship status may be a more salient issue. This is due to two reasons. On the one hand, it is important to observe changes in citizenship status before the outcome is measured, to avoid reverse causality. On the other, the educational registers did not contain adequate variables for measuring the academic performance of students during secondary school. For example, students' grades were not systematically recorded or reliable for the observed period. It was therefore not possible to find indicators of academic performance that were either comparable within individuals over time ${ }^{3}$, or comparable between students enrolled in different fields of study.

Because of these data constraints, I only investigated the effects of citizenship when it is acquired before entering secondary education (i.e., around ages 12-13). This may introduce two sources of downward bias in the analysis. Firstly, if, as is assumed, naturalisation is a process that starts long before Dutch citizenship is officially acquired, some students who are registered as

at the time at naturalisation, compared to the time of the Cito test. While these preliminary results should be interpreted with great caution, they are in line with the hypothesis that parental characteristics measured after naturalisation act as mediators (analysis not shown).

${ }^{3}$ Note that this is the reason why I did not employ standard individual fixed-effects for analysing the effects of citizenship on education. 


\section{Chapter 6}

foreign citizens at the end of primary school may still be on their way to becoming Dutch, thus already enjoying some of the direct or indirect benefits of the naturalisation process. As these students are included in the group of the non-naturalised students, the estimated effect of citizenship acquisition may be biased downwards. Secondly, the lack of citizenship status may have more adverse effects on the well-being and perceived opportunities of young people than on children (Gonzales, 2011; Cebulko, 2014). This is because adolescents may become more aware of the implications of their citizenship status as they realise that certain doors are either open or closed to them (ibid.). Furthermore, the children of immigrants who are still foreign citizens in their late teens may be so because their parents face significant obstacles in naturalising. As citizenship is expected to matter especially for those families (Hainmueller et al., 2017; Peters, 2018; Chapter 5), there may be even greater gaps between those who are citizens and those who are not in late adolescence than in childhood. ${ }^{4}$ However, the effects of citizenship acquisition in late adolescence and early adulthood cannot be adequately analysed with our data and therefore remain a matter of speculation. Future research should further investigate the timing effects of citizenship acquisition, using educational outcomes measured later in time.

\section{The heterogeneous effects of citizenship acquisition}

This dissertation provided preliminary insights into the factors that condition the relevance of host country citizenship for children, highlighting compensatory mechanisms similar to those found with first-generation immigrants (Chapter 5). In particular, I showed that citizenship acquisition is most important for children whose parents have low levels of education and/or limited access to homeownership. However, limited information on the sociodemographic characteristics and resources of parents made it difficult to fully assess the interaction effects between naturalisation and parental background. First, measuring the level of education of immigrant parents generally poses serious problems of data accuracy and comparability (see Heath and Brinbaum, 2007, pp.295-296). The variables used for parental education in this

\footnotetext{
${ }^{4}$ This is what a robustness analysis conducted in Chapter 4 suggests (see p.144): the effects of citizenship are substantially larger in magnitude when I include in the group of naturalised students the children of immigrants who became Dutch over the whole observation period until 2016 - and not only before the end of primary education. While this alternative specification is not robust to reverse causality, it arguably provides an upper-bound for the effect of naturalisation.
} 
dissertation are not an exception in this respect: information on education level is disproportionately missing for immigrants in the Dutch registers, and tends to be underestimated because education abroad or at private institutions is difficult to take into account (see p.260 for more details on this point). Although I used an imputed variable with the most recent data to maximise accuracy, I cannot exclude the possibility of substantial measurement error.

Second, measures of parental social background are often imprecise for the children of immigrants, as their parents' position in the host society does not always give a true indication of the family's level of resources (Ichou, 2014; Engzell and Ichou, 2020). Finding adequate proxies of parental background has been particularly difficult in the Dutch registers, as there is no exploitable nomenclature for socio-professional categories. Statistics Netherlands defines the socioeconomic status of a person according to their main source of income, thus distinguishing between those whose main economic activity is (self-)employment, those who receive benefits and those who do not have any declared source of income. This variable captures different profiles at the lower end of the socioeconomic status distribution, but is not a good discriminatory factor in the higher end. For this reason, I included information on whether parents are renters or not, as access to homeownership can be selective in the Netherlands, especially for immigrants (see Peters et al., 2020, pp.1241-1242). These two variables, combined with the household disposable income, only imperfectly reflect the family's socioeconomic and educationally relevant resources. As a result, it would be relevant for future work to investigate the interaction effects between citizenship and parental social background using more precise measures of parents' resources in the host society. This would make it possible to identify more precisely the dimensions of social origin that interact with naturalisation, beyond the preliminary results of this dissertation.

Finally, potential interaction effects between citizenship and race have not been empirically tested in this thesis. As there is substantial evidence in qualitative studies that such interaction effects exist (Ribert, 2000; Frauenfelder, 2007; Della Puppa and Sredanovic, 2017; Erdal et al., 2018), it could be fruitful for further research to model and measure the potential mediating role of race on the relationship between citizenship and the life outcomes of children of immigrants, especially in areas where they are likely to face discrimination. 


\section{Chapter 6}

\section{Unobserved conditions of immigration, settlement and naturalisation}

This dissertation set out to explore the heterogeneity of the second generation, reflecting the diversity of their backgrounds and trajectories. Yet, some important characteristics relating to their parents' arrival and settlement conditions could not be included in our analyses, due to insufficient or missing data. This is the case of the migration motive of parents, which would make it possible to identify the status under which they entered the Netherlands. Such information is important because the adaptation and integration of immigrants into the host society is affected by their migration history and initial settlement conditions. For example, there is evidence that refugees face specific pre- or post-migration stressors in the Netherlands, which hamper their chances of success on the labour market (Bakker et al., 2014b; de Vroome and van Tubergen, 2010). Refugees tend to experience higher level of mental health problems (ibid), which may affect their ability to support their children at school. The immigration status of parents upon arrival may therefore capture otherwise unobserved characteristics of immigrant families. However, although the migration motive is recorded in the Dutch registers, the variable suffers from a significant lack of completeness. While Statistics Netherlands provides an imputed version of this variable, the lack of external information to determine immigrants' migration motives suggests substantial measurement error. As a result, I preferred not to use this variable. When relevant, I controlled for parents' country of origin directly so as to account for unobservable immigration and settlement patterns at the country level. Though imperfect, this approach is justified by the fact that immigrants who arrive as asylum seekers in the Netherlands disproportionately come from well-identified countries of origin (Engbersen et al., 2007, pp.402-493).

Another important aspect of the settlement conditions of immigrant families is the type of residence permit they have. While temporary residence permits are associated with frequent administrative renewal procedures and legal uncertainty, permanent residency offers a certain level of security and access to Dutch citizenship. ${ }^{5}$ This information was not available in the Dutch administrative registers, which resulted in two main limitations. First, not controlling for the type of residence permit of children and their families introduces

\footnotetext{
${ }^{5}$ Note that immigrants detaining a temporary residence permit with a non-temporary purpose of stay are also entitled to naturalisation. See the following link https://ind.nl/en/dutch-citizenship/Pages/ Becoming-Dutch-temporary-non-temporary-purposes-of-stay.aspx [accessed July 19, 2021] for more information.
} 
unobserved heterogeneity in the analysis of citizenship acquisition. For example, naturalisation may yield limited returns for immigrant parents who have secured permanent residence without difficulty - especially if they have to renounce their existing nationality for this purpose. Conversely, Dutch citizenship may be especially valuable for immigrant families that have experienced prolonged periods of insecurity, as some research suggests (Bakker et al., 2014b). In this sense, the past and current residence permits of family members give precious information on their settlement conditions, and would enable researchers to gain a more detailed insight into the mechanisms that condition the relevance of citizenship. Second, information on the type of residence permit would have allowed for a more precise measure of parents' date of eligibility for naturalisation. Indeed, immigrants should have a permanent residence permit at the time of naturalisation, or a temporary permit with a non-temporary purpose of stay. As this information was missing, the eligibility variable constructed in Chapter 3 may overestimate the proportion of eligible families: some immigrant parents who have resided in the Netherlands for more than five years may in fact not be eligible because they have not yet obtained one of the required residence permits. Unfortunately, it is not possible to assess the prevalence of these cases with the available data, nor to estimate the bias that such an overestimation might introduce into the analysis.

Finally, information on the naturalisation applications of prospective citizens would have been necessary to model the naturalisation process in the empirical chapters. While stressing the need not to reduce naturalisation to the formal transition of legal status, I was not able to operationalise this broader conceptualisation with the available data. Estimating the start of the application procedure is difficult, as the time to become Dutch by naturalisation varies - from 6 months up to a year, according to van Meeteren et al. (2013, p.129). Furthermore, information on when naturalisation candidates enrolled in naturalisation or integration courses and passed the tests is important to estimate more accurately the actual duration of the naturalisation procedure. While such statistics are available at the aggregate level (see, e.g., van Oers, 2013, Chapters 3 and 7), they are not recorded in the individual administrative registers. More precise measures of the timing and duration of the naturalisation process would allow for a more refined analysis of the effects of citizenship, including possible anticipated effects initiated by immigrants' decision to naturalise.

Overall, these data constraints limited the identification of the mechanisms involved. However, it is important to note that such variables are also rarely 


\section{Chapter 6}

available in surveys, including those focused on the children of immigrants (e.g., CILS4EU, 2017). Therefore, I strongly encourage future data collections initiatives on the second generation to pay greater attention to the immigration and settlement conditions of immigrant parents. This has important consequences for the way they value and access citizenship in the host country, but also for the opportunities available to their children more generally.

\section{Extending the analytical scope of the thesis}

The data and quantitative approach followed in this dissertation provided valuable insights into the relationships between citizenship and education in the Netherlands. Yet, a systematic analysis of the relevance of host country citizenship for native-born children of immigrants would require expanding the scope of the analysis in at least three respects, which I detail in the following paragraphs.

\section{Labour market and other life outcomes}

This dissertation has focused on the educational outcomes of the children of immigrants for two main reasons. First, in post-industrial societies, education is a crucial means of social advancement for the children of immigrants (Levels and Dronkers, 2008; Crul, 2015; Crul et al., 2017). Students' educational background does not only determine the qualifications they can use in the labour market, but also shapes their networks and levels of cultural capital (Crul et al., 2017). Second, because the second generation is still relatively young in Western Europe, data on their experience in the labour market was scarce until recently (Heath et al., 2008, p.218). With some exceptions (Fibbi et al., 2007; Liebig and von Haaren, 2011), studies analysing the relevance of citizenship for children of immigrants thus focused on their educational outcomes. I followed the same direction in this thesis, as I could not fully cover the labour-market transitions of the considered birth cohorts, especially for those following long educational trajectories.

However, investigating the effects of citizenship on the labour market outcomes of native-born children of immigrants could be a fruitful line of research. There is indeed a growing body of literature showing that children of immigrants face important barriers in the labour market (see Heath et al., 2008, pp.226-227, for an overview). Importantly, some studies indicate that 
children of immigrants experience significant disadvantages in terms of earnings, access to employment and discrimination, to a similar extent as their parents (Carlsson, 2010; Algan et al., 2010). At the same time, the literature on immigrant naturalisation suggests that host country citizenship facilitates access to the labour market of first generation immigrants (Peters et al., 2017), and has a positive impact on earnings (Steinhardt, 2012), especially for those facing structural barriers (Helgertz et al., 2014; Peters et al., 2020).

The citizenship premium for immigrants in the labour market is generally attributed to three main mechanisms: host country citizenship provides unlimited access to the labour market, reduces administrative costs for companies, and sends positive signals to current and potential employers (Liebig and von Haaren, 2011). Whether such mechanisms also apply to their children remain the subject of speculation. Can host country citizenship help alleviate some of the obstacles that the second generation face in the labour market? The few existing studies only provide preliminary answers. While Fibbi et al. (2007) and Liebig and von Haaren (2011) find no substantial association between citizenship and the probability of (un)employment, Liebig and von Haaren show that host country citizenship is associated with a higher probability of employment in high-skilled jobs in countries with ius sanguinis citizenship regimes such as Switzerland and Austria. In particular, the authors find that naturalised children of immigrants are more likely to be employed in the public sector; this is consistent with the fact that host country citizenship is often required for some high-level positions in the public sector. Some qualitative studies conducted in Switzerland also show that native-born children of immigrants need Swiss citizenship to work in certain sectors, or to obtain an apprenticeship (Frauenfelder, 2007; Imdorf, 2019). To establish these results more firmly, a more systematic and tailored analysis of the relationship between citizenship and labour market outcomes of the second generation is needed.

Beyond the labour market, other life outcomes may be associated with the citizenship status of children of immigrants. A line of research has investigated whether host country citizenship is associated with values, national identification and political participation of first-generation immigrants (e.g., Donnaloja, 2020; Fick, 2016; Manning and Roy, 2010; Bevelander and Veenman, 2006); but, to my knowledge, no similar studies have been dedicated to their children. However, qualitative studies suggest that the possession or lack of host country citizenship influences how second-generation youth feel included (or not) in the host society (Colombo, 2015; Frauenfelder, 2007; Ribert, 2009). Although attitudes and feelings are difficult to capture in quan- 


\section{Chapter 6}

titative data, it would be interesting to analyse whether the acquisition of host country citizenship promotes political participation among children of immigrants. On another note, growing attention has been paid to the relationship between citizenship and international mobility. While previous research suggests that the acquisition of host country citizenship generally decreases the likelihood of immigrant families to outmigrate (Hoon et al., 2020; Sajons, 2016), specific data on the second generation are scarce, despite increasing attention to the transnational mobility of migrant youth (e.g., van Geel and Mazzucato, 2021; Ogden and Mazzucato, 2021). As citizenship significantly facilitates international mobility, its role in youth engagements and relationships here and there may merit research.

\section{The need for a comparative perspective}

In line with the life course perspective, this dissertation conceptualised host country citizenship in the Dutch institutional context. Two elements received particular scrutiny: citizenship and naturalisation laws, on the one hand, and the characteristics of the education system, on the other. There are reasons to think that these institutional conditions at least partly shape the observed effects of citizenship on education. First, citizenship advantage can be expected to vary according to the level and nature of naturalisation requirements that prospective citizens must meet. As Peters (2018) argues, applicants' investments in the naturalisation process may pay off when the requirements are affordable and help them acquire relevant host country-specific knowledge. Conversely, very liberal or selective conditions may deter immigrants from engaging in the naturalisation process - or from naturalising at all. As the Netherlands occupies an intermediate position in the European landscape with regard to access to citizenship ${ }^{6}$, I expect the acquisition of host country citizenship to be especially relevant in the Dutch case. Second, I hypothesised that citizenship is of particular importance in stratified and early-tracking education systems, in which students heavily rely on the resources and involvement of their parents.

A rigorous assessment of these two assumptions requires a different approach and design than that used in this dissertation. Indeed, the focus on a single

\footnotetext{
${ }^{6}$ In 2019, Dutch law was considered as "halfway favourable" in terms of access to nationality according to the Migrant Integration Policy Index 2019 (MIPEX). Retrieved from https: //mipex.eu/access-nationality [accessed July 19, 2021].
} 
destination country limits the assessment of the role of the institutional context. Although there is some variation in Dutch naturalisation laws over the period under consideration, the multiplication of reforms every few years especially in the 2000s - makes it difficult to distinguish the effects of specific naturalisation requirements separately. In a similar way, there were no radical changes in educational arrangements that I could have used to test whether the characteristics of the school system condition the relevance of host country citizenship for children of immigrants. A systematic analysis of the role of the institutional context thus requires a comparative perspective and a crossnational design, which are still relatively rare in the literature on immigrant naturalisation (see Helgertz et al., 2014; Vink et al., 2021, for exceptions).

I therefore encourage future research to compare the Dutch case with other national contexts that vary on one of the two institutional dimensions considered. Sweden, for example, had naturalisation requirements similar to those of the Netherlands in the 1990s-2000s (Bernitz, 2012), but has a contrasting education system, with a low differentiation between tracks and late selection (OECD, 2015). This could be a relevant case for analysing whether naturalised children of immigrants still enjoy a comparative advantage in education in a comprehensive education system. Conversely, countries such as Austria and Switzerland have more restrictive naturalisation policies, but relatively similar education systems. In such countries, the percentage of non-naturalised children of immigrants is among the highest in the OECD (Liebig and von Haaren, 2011, p.43). At the same time, the Austrian and Swiss education systems are complex and highly stratified (OECD, 2017b; Pfeffer, 2008, p.564). They could provide an appropriate benchmark to assess whether naturalised children of immigrants have a greater or lesser advantage in education when naturalisation is a highly selective process. Comparing countries is certainly a difficult task, which relies on finding comparable data and research populations. Nevertheless, previous cross-national studies on the children of immigrants highlight the analytical value of such a comparative approach (e.g., Crul et al., 2012; Alba and Holdaway, 2013; Kalter et al., 2018), and should encourage researchers to further investigate the relevance of the institutional context - including the citizenship context - on the opportunities of the second generation. 


\section{Chapter 6}

\section{The complementary contribution of qualitative studies}

This dissertation has followed a quantitative approach to analyse the relationship between citizenship and education of the children of immigrants. This approach was justified by the lack of statistical data and analysis on the citizenship status of the second generation. Measuring the prevalence of nonnaturalised children of immigrants, as well as the possible consequences of their citizenship status for their educational educational outcomes, is informative from a research and policy perspective. In particular, this thesis has shown that a substantial share $(10 \%)$ of second-generation youth are still foreign citizens at the age of majority (Chapter 3 ) and that the lack of Dutch citizenship is associated with substantial educational difficulties, both in terms of educational paths (Chapter 4) and outcomes (Chapter 5). Yet, this dissertation provides only a limited insight into the underlying mechanisms: by design, the quantitative nature of the data makes it difficult to investigate the why questions. The family decision-making process leading to the naturalisation of children cannot be directly observed, while the mechanisms by which citizenship affects their educational outcomes remain largely hidden.

In contrast, qualitative data provide insights into how immigrants perceive and experience host country citizenship. They allow researchers to open the black box of naturalisation decisions (e.g., Della Puppa and Sredanovic, 2017; Sredanovic, 2020; Street, 2013, 2014), and to delve into the diverse meanings that naturalised individuals attach to citizenship (e.g., Erdal et al., 2018; Nunn et al., 2016; Sredanovic, 2020). In this thesis, qualitative studies on the relevance of naturalisation for the second generation were instrumental in including the youth perspective on citizenship (Colombo, 2015; Colombo et al., 2011; Frauenfelder, 2007; Ribert, 2000). This perspective was largely absent from existing research on the effects of citizenship on education, which focused instead on parental investments in human capital (Felfe et al., 2020; Cygan-Rehm, 2018; Avitabile et al., 2014). In that sense, engaging with qualitative work was key to lay the foundations for a more comprehensive theoretical framework.

However, I was not able to incorporate qualitative data to the analysis, for two main reasons. First, the preparation and use of register data require significant investment, which is worth fully utilising. Second, data on citizenship do not generally provide opportunities for mixed-methods analysis (see Street, 2013, 2014, for valuable exceptions). Moreover, while a growing number of qualitative studies have adopted a family approach to natu- 
ralisation and highlighted its intergenerational dimension (Della Puppa and Sredanovic, 2017; Sredanovic, 2020), research from the perspective of the children of immigrants is still rare (Erdal et al., 2018). This dissertation therefore calls for a more integrated approach to second generation citizenship, which takes full advantage of qualitative and quantitative knowledge.

To conclude, this dissertation has laid the groundwork for an in-depth analysis of the relevance of host country citizenship for the native-born children of immigrants. It combined a life course perspective with rich quantitative data and advanced methods to uncover patterns of naturalisation among the second generation in the Netherlands, and assess the effects of these patterns on their educational outcomes. Although host country citizenship is certainly not a panacea, the results suggest that early acquisition of Dutch citizenship has the potential to alleviate some of the disadvantages faced by secondgeneration children, especially in families with low levels of socioeconomic resources. Future research could strengthen these findings in different ways. While more detailed data on the settlement and naturalisation trajectories of immigrant families would improve the identification and characterisation of citizenship effects, a comparative and mixed-methods research agenda would broaden the analytical scope of the thesis. In addition, the effects of citizenship on other life outcomes, beyond education, deserve greater attention. In a context where the integration and the feelings of belonging of the second generation are often questioned (Duyvendak, 2011; Ribert, 2009), it seems all the more crucial to consider the possible contradiction between these children's physical and social presence in the host country and their status as foreign citizens. 



\section{Bibliography}

Abbott, A. and Forrest, J. (1986). Optimal Matching for Historical Sequences. Journal of Interdisciplinary History, 16(3):471-494.

Abbott, A. and Hrycak, A. (1990). Measuring Resemblance in Sequence Data: An Optimal Matching Analysis of Musicians' Careers. American Journal of Sociology, 96(1):144-185.

Adviescommissie Onderzoek Culturele Minderheden (ACOM) (1979). Advies Onderzoek Minderheden. Technical report, Staatsuitgeverij, Gravenhage.

Alba, R. D. and Foner, N. (2015). Strangers no more: immigration and the challenges of integration in North America and Western Europe. Princeton University Press, Princeton, New Jersey.

Alba, R. D. and Holdaway, J., editors (2013). The children of immigrants at school: a comparative look at integration in the United States and Western Europe. New York University Press, New York.

Algan, Y., Dustmann, C., Glitz, A., and Manning, A. (2010). The Economic Situation of First and Second-Generation Immigrants in France, Germany and the United Kingdom. The Economic Journal, 120(542):4-30.

Allison, P. D. (2009). Fixed effects regression models. Number 160 in Quantitative applications in the social sciences. SAGE, Los Angeles.

Altonji, J., Elder, T., and Taber, C. (2005). Selection on Observed and Unobserved Variables: Assessing the Effectiveness of Catholic Schools. Journal of Political Economy, 113(1):151-184.

Avitabile, C., Clots-Figueras, I., and Masella, P. (2013). The Effect of Birthright Citizenship on Parental Integration Outcomes. The Journal of Law and Economics, 56(3):777810 .

Avitabile, C., Clots-Figueras, I., and Masella, P. (2014). Citizenship, Fertility, and Parental Investments. American Economic Journal: Applied Economics, 6(4):35-65.

Bakker, B. F., van Rooijen, J., and van Toor, L. (2014a). The System of social statistical datasets of Statistics Netherlands: An integral approach to the production of register-based social statistics. Statistical Journal of the IAOS, (4):411-424.

Bakker, B. F. M. (2012). Estimating the validity of administrative variables. Statistica Neerlandica, 66(1):8-17. 


\section{Bibliography}

Bakker, L., Dagevos, J., and Engbersen, G. (2014b). The Importance of Resources and Security in the Socio-Economic Integration of Refugees. A Study on the Impact of Length of Stay in Asylum Accommodation and Residence Status on SocioEconomic Integration for the Four Largest Refugee Groups in the Netherlands. Journal of International Migration and Integration, 15(3):431-448.

Barbiano di Belgiojoso, E. and Ortensi, L. E. (2019). Satisfied after all? Working trajectories and job satisfaction of foreign-born female domestic and care workers in Italy. Journal of Ethnic and Migration Studies, 45(13):2527-2550.

Bauböck, R., editor (2006). Migration and Citizenship : Legal Status, Rights and Political Participation. Amsterdam University Press, Amsterdam.

Baysu, G. and de Valk, H. (2012). Navigating the school system in Sweden, Belgium, Austria and Germany: School segregation and second generation school trajectories. Ethnicities, 12(6):776-799.

Bean, F. D., Brown, S. K., and Bachmeier, J. D. (2015). Parents without papers: the progress and pitfalls of Mexican-American integration. Russell Sage Foundation, New York.

Bean, F. D., Leach, M. A., Brown, S. K., Bachmeier, J. D., and Hipp, J. R. (2011). The Educational Legacy of Unauthorized Migration: Comparisons across U.S.-Immigrant Groups in how Parents' Status Affects Their Offspring. International Migration Review, 45(2):348-385.

Becker, G. S. (1993). Human capital: a theoretical and empirical analysis, with special reference to education. The University of Chicago Press, Chicago, 3rd edition.

Bell, A. and Jones, K. (2015). Explaining Fixed Effects: Random Effects Modeling of Time-Series Cross-Sectional and Panel Data. Political Science Research and Methods, 3(1):133-153.

Bellera, C. A., MacGrogan, G., Debled, M., de Lara, C. T., Brouste, V., and MathoulinPélissier, S. (2010). Variables with time-varying effects and the Cox model: some statistical concepts illustrated with a prognostic factor study in breast cancer. BMC medical research methodology, 10:20-20.

Bernardi, F. and Triventi, M. (2020). Compensatory advantage in educational transitions: Trivial or substantial? A simulated scenario analysis. Acta Sociologica, 63(1):40-62.

Bernitz, H. (2012). Country report : Sweden. Country Reports, European University Institute, GLOBALCIT, EUDO Citizenship Observatory.

Bevelander, P. and Veenman, J. (2006). Naturalization and employment integration of Turkish and Moroccan immigrants in the Netherlands. Journal of International Migration and Integration / Revue de l'integration et de la migration internationale, 7(3):327349. 
Biemann, T. (2011). A Transition-Oriented Approach to Optimal Matching. Sociological Methodology, 41(1):195-221.

Bloemraad, I. (2002). The North American Naturalization Gap: An Institutional Approach to Citizenship Acquisition in the United States and Canada. The International Migration Review, 36(1):193-228.

Blossfeld, H.-P., Buchholz, S., Skopek, J., and Triventi, M. (2016). Models of Secondary Education and Social Inequality. Edward Elgar Publishing.

Blume, K., Gustafsson, B., Pedersen, P. J., and Verner, M. (2007). At the Lower End of the Table: Determinants of Poverty among Immigrants to Denmark and Sweden. Journal of Ethnic and Migration Studies, 33(3):373-396.

Bol, T., Witschge, J., Van de Werfhorst, H. G., and Dronkers, J. (2014). Curricular Tracking and Central Examinations: Counterbalancing the Impact of Social Background on Student Achievement in 36 Countries. Social Forces, 92(4):1545-1572.

Bolzman, C., Rosita, F., and Marie, V. (2003). Secondas - secondos : le processus d'intégration des jeunes adultes issus de la migration espagnole et italienne en Suisse. Seismo, Zurich.

Bonjour, S. and de Hart, B. (2021). Intimate citizenship: introduction to the special issue on citizenship, membership and belonging in mixed-status families. Identities, 28(1):1-17.

Bourdieu, P. and Passeron, J. C. (1990). Reproduction in education, society, and culture. Theory, culture \& society. Sage in association with Theory, Culture \& Society, Dept. of Administrative and Social Studies, Teesside Polytechnic, London ; Newbury Park, Calif, 1990 ed edition.

Box-Steffensmeier, J. M., Reiter, D., and Zorn, C. (2003). Nonproportional Hazards and Event History Analysis in International Relations. Journal of Conflict Resolution, 47(1):33-53.

Boylan, R. L. (2020). Predicting Postsecondary Pathways: The Effect of Social Background and Academic Factors on Routes through School:. Socius, 6(1):1-25.

Brumback, B. A., Li, L., and Cai, Z. (2017). On the use of between-within models to adjust for confounding due to unmeasured cluster-level covariates. Communications in Statistics - Simulation and Computation, 46(5):3841-3854.

Brzinsky-Fay, C., Kohler, U., and Luniak, M. (2006). Sequence analysis with Stata. Stata Journal, 6(4):435-460.

Bushin, N. (2009). Researching family migration decision-making: a children-infamilies approach: Children and Migration Decision-Making. Population, Space and Place, 15(5):429-443. 


\section{Bibliography}

Böhlmark, A. (2008). Age at immigration and school performance: A siblings analysis using swedish register data. Labour Economics, 15(6):1366-1387.

Büchner, C. and Velden, R. v. d. (2013). How Social Background Affects Educational Attainment Over Time in the Netherlands. In Jackson, M., editor, Determined to Succeed? Performance versus Choice in Educational Attainment, pages 89-115. Stanford University Press.

Carlsson, M. (2010). Experimental Evidence of Discrimination in the Hiring of Firstand Second-generation Immigrants: Ethnic Discrimination in Hiring. LABOUR, 24(3):263-278.

Cayouette-Remblière, J. and Saint-Pol, T. d. (2013). Le sinueux chemin vers le baccalauréat : entre redoublement, réorientation et décrochage scolaire. Economie et Statistique, 459(1):59-88.

Cebulko, K. (2014). Documented, Undocumented, and Liminally Legal: Legal Status During the Transition to Adulthood for 1.5-Generation Brazilian Immigrants. The Sociological Quarterly, 55(1):143-167.

Cebulko, K. (2018). Privilege without papers: Intersecting inequalities among 1.5generation Brazilians in Massachusetts:. Ethnicities, 18(2):225-241.

Chimienti, M., Bloch, A., Ossipow, L., and de Wenden, C. W. (2019). Second generation from refugee backgrounds in Europe. Comparative Migration Studies, 7(40):1-15.

Chiswick, B. R. and Miller, P. W. (2009). Citizenship in the United States: the roles of immigrant characteristics and country of origin. In Constant, A. F., Tatsiramos, K., and Zimmermann, K. F., editors, Research in Labor Economics, volume 29, pages 91-130. Emerald Group Publishing Limited.

CILS4EU (2017). Children of Immigrants Longitudinal Survey in Four European Countries. Codebook. Wave 3 - 2012/2013, v3.3.0., Mannheim University, Mannheim.

Cohen, E. F. (2005). Neither Seen Nor Heard: Children's Citizenship in Contemporary Democracies. Citizenship Studies, 9(2):221-240.

Coleman, J. S. (1988). Social Capital in the Creation of Human Capital. American Journal of Sociology, 94:95-120.

Colombo, E. (2015). Complicating citizenship. How children of immigrants in Italy represent belonging and rights. In Marback, R., editor, Generations. Rethinking age and citizenship, pages 134-156. Wayne State University Press, Detroit.

Colombo, E., Domaneschi, L., and Marchetti, C. (2011). Citizenship and multiple belonging. Representations of inclusion, identification and participation among children of immigrants in Italy. Journal of Modern Italian Studies, 16(3):334-347. 
Cook, J. A. (2020). Navigating legality: transnational mixed-status families and the U.S. family-based immigration system. Journal of Ethnic and Migration Studies, pages 1-18 (epub ahead of print).

Cox, D. R. (1972). Regression Models and Life-Tables. Journal of the Royal Statistical Society. Series B (Methodological), 34(2):187-220.

Crul, M. (2015). Is Education the Pathway to Success? A Comparison of Second Generation Turkish Professionals in Sweden, France, Germany and The Netherlands. European Journal of Education, 50(3):325-339.

Crul, M. (2018). How key transitions influence school and labour market careers of descendants of Moroccan and Turkish migrants in the Netherlands. European Journal of Education, 53(4):481-494.

Crul, M. and Schneider, J. (2010). Comparative integration context theory: participation and belonging in new diverse European cities. Ethnic and Racial Studies, 33(7):1249-1268.

Crul, M., Schneider, J., Keskiner, E., and Lelie, F. (2017). The multiplier effect: how the accumulation of cultural and social capital explains steep upward social mobility of children of low-educated immigrants. Ethnic and Racial Studies, 40(2):321-338.

Crul, M., Schneider, J., and Lelie, F., editors (2012). The European second generation compared: does the integration context matter? IMISCOE research. Amsterdam University Press, Amsterdam.

Cunha, F. and Heckman, J. (2007). The Technology of Skill Formation. American Economic Review, 97(2):31-47.

Cygan-Rehm, K. (2018). Estimating the effect of early-childhood citizenship on education using policy changes as instruments. Applied Economics Letters, 25(20):14261431.

Dahl, G., Felfe, C., Frijters, P., and Rainer, H. (2020). Caught between Cultures: Unintended Consequences of Improving Opportunity for Immigrant Girls. Working Paper w26674, National Bureau of Economic Research, Cambridge, MA.

de Groot, G.-R. and Vonk, O. (2018). Acquisition of Nationality by Birth on a Particular Territory or Establishment of Parentage: Global Trends Regarding Ius Sanguinis and Ius Soli. Netherlands International Law Review, 65:319-335.

de Hart, B. (2010). Children's Citizenship, Motherhood and the Nation-State. In Schrover, M. and Yeo, E., editors, Gender, migration, and the public sphere, 1850-2005, Routledge research in gender and history, pages 97-117. Routledge, New York. 


\section{Bibliography}

de Hart, B., van Rossum, W. M., and Sportel, I. (2013). Law in the Everyday Lives of Transnational Families: An Introduction. Oñati Socio-Legal Series, 3(6):991-1003.

de Vroome, T. and van Tubergen, F. (2010). The Employment Experience of Refugees in the Netherlands. The International Migration Review, 44(2):376-403.

de Waal, T. M. (2017). Conditional belonging. A legal-philosophical inquiry into integration requirements for immigrants in Europe. PhD thesis, University of Amsterdam.

Della Puppa, F. and Sredanovic, D. (2017). Citizen to Stay or Citizen to Go? Naturalization, Security, and Mobility of Migrants in Italy. Journal of Immigrant $\mathcal{E}$ Refugee Studies, 15(4):366-383.

Dicks, A., Dronkers, J., and Levels, M. (2019). Cross-Nationally Comparative Research on Racial and Ethnic Skill Disparities: Questions, Findings, and Pitfalls. In Stevens, P. A. J. and Dworkin, A. G., editors, The Palgrave Handbook of Race and Ethnic Inequalities in Education, pages 1183-1215. Palgrave Macmillan US, Cham.

Dignam, J. J., Zhang, Q., and Kocherginsky, M. (2012). The use and interpretation of competing risks regression models. Clinical cancer research: an official journal of the American Association for Cancer Research, 18(8):2301-2308.

Dollmann, J. and Jacob, K. (2014). The Children of Immigrants Longitudinal Survey in Four European Countries (CILS4EU): Efforts, Challenges, and Success in Primary Data Collection. In NORFACE, editor, Migration: Paths of Exploration, number Spring 2014 in Research Programme on Migration. NORFACE, London.

Dollmann, J. and Weißmann, M. (2019). The Story after Immigrants' Ambitious Educational Choices: Real Improvement or Back to Square One? European Sociological Review, 36(1):32-47.

Donnaloja, V. (2020). British and disengaged: national identification and political engagement before and after naturalisation. Journal of Ethnic and Migration Studies, 46(13):2723-2741.

Dronkers, J. and Fleischmann, F. (2010). The Educational Attainment of Second Generation Immigrants from Different Countries of Origin in the EU Member-States. In Dronkers, J., editor, Quality and Inequality of Education, pages 163-204. Springer Netherlands, Dordrecht.

Dronkers, J. and Vink, M. P. (2012). Explaining access to citizenship in Europe: How citizenship policies affect naturalization rates. European Union Politics, 13(3):390412.

Drouhot, L. G. and Nee, V. (2019). Assimilation and the Second Generation in Europe and America: Blending and Segregating Social Dynamics Between Immigrants and Natives. Annual Review of Sociology, 45(1):177-199. 
Dustmann, C., Tommaso, F., and Gianandrea, L. (2012). Educational achievement of second-generation immigrants: an international comparison. Economic Policy, 27(69):143-185.

Dutch Government (1983). Minderhedennota. Technical Report 20-1, Tweede Kamer 1982-1983.

Dutch government (1994). Integratiebeleid etnische minderheden: contourennota. SDU Uitgeverij Plantijnstraat, Gravenhage.

Duyvendak, J. W. (2011). Feeling at Home in the Nation? Understanding Dutch Nostalgia. In Duyvendak, J. W., editor, The Politics of Home, pages 84-105. Palgrave Macmillan UK, London.

Díaz McConnell, E. and Yellow Horse, A. J. (2020). Vulnerable and Resilient: Legal Status, Sources of Support, Maternal Knowledge, and the Family Routines of Mexican and Central American-origin Mothers in Los Angeles. International Migration Review, 55(2):514-546.

D’hondt, F., Van Praag, L., Van Houtte, M., and Stevens, P. A. (2016). The attitude-achievement paradox in Belgium: An examination of school attitudes of ethnic minority students. Acta Sociologica, 59(3):215-231.

Elder, G. H. J. (1974). Children of the great depression: social change in life experience. University of Chicago Press, Chicago.

Elder, G. H. J. (1985). Perspectives on the life course. In Elder, G. H. J., editor, Life course dynamics: Transitions and trajectories, 1968-1980, pages 23-49. Cornell University Press, Ithaca.

Elder, G. H. J. (1994). Time, Human Agency, and Social Change: Perspectives on the Life Course. Social Psychology Quarterly, 57(1):4-15.

Elwert, F. and Winship, C. (2014). Endogenous Selection Bias: The Problem of Conditioning on a Collider Variable. Annual Review of Sociology, 40(1):31-53.

Elzinga, C. H. and Studer, M. (2015). Spell Sequences, State Proximities, and Distance Metrics. Sociological Methods \& Research, 44(1):3-47.

Emonds, V. and van Tubergen, F. (2015). Mixed Parents, Mixed Results: Testing the Effects of Cross-nativity Partnership on Children's Educational Attainment. Sociological Perspectives, 58(2):145-167.

Engbersen, G., van der Leun, J., and de Boom, J. (2007). The Fragmentation of Migration and Crime in the Netherlands. Crime and Justice, 35(1):389-452.

Engzell, P. and Ichou, M. (2020). Status Loss: The Burden of Positively Selected Immigrants. International Migration Review, 54(2):471-495. 


\section{Bibliography}

Enriquez, L. E. (2017). A 'master status' or the 'final straw'? Assessing the role of immigration status in Latino undocumented youths' pathways out of school. Journal of Ethnic and Migration Studies, 43(9):1526-1543.

Entzinger, H. (2014). The Rise and Fall of Multiculturalism: The Case of the Netherlands. In Joppke, C. and Morawska, E., editors, Toward Assimilation and Citizenship, pages 59-86. Palgrave Macmillan UK, London.

Erdal, M. B., Doeland, E. M., and Tellander, E. (2018). How citizenship matters (or not): the citizenship-belonging nexus explored among residents in Oslo, Norway. Citizenship Studies, 22(7):705-724.

Essed, P., Farquharson, K., Pillay, K., and White, E. J., editors (2019). Relating Worlds of Racism: Dehumanisation, Belonging, and the Normativity of European Whiteness. Springer International Publishing, Cham.

Esser, H. (2006). Migration, language and integration. Technical report, WZB, Berlin.

Everitt, B., editor (2011). Cluster analysis. Wiley series in probability and statistics. Wiley, Chichester, West Sussex, U.K, 5th ed edition.

Felfe, C., Rainer, H., and Saurer, J. (2020). Why Birthright Citizenship Matters for Immigrant Children: Short- and Long-Run Impacts on Educational Integration. Journal of Labor Economics, 38(1):143-182.

Feliciano, C. (2005a). Does Selective Migration Matter? Explaining Ethnic Disparities in Educational Attainment among Immigrants' Children. International Migration Review, 39(4):841-871.

Feliciano, C. (2005b). Educational selectivity in U.S. Immigration: How do immigrants compare to those left behind? Demography, 42(1):131-152.

Feliciano, C. and Lanuza, Y. R. (2016). The Immigrant Advantage in Adolescent Educational Expectations. International Migration Review, 50(3):758-792.

Fernández-Reino, M. (2016). Immigrant optimism or anticipated discrimination? Explaining the first educational transition of ethnic minorities in England. Research in Social Stratification and Mobility, 46:141-156.

Fibbi, R., Lerch, M., and Wanner, P. (2007). Naturalisation and Socio-Economic Characteristics of Youth of Immigrant Descent in Switzerland. Journal of Ethnic and Migration Studies, 33(7):1121-1144.

Fick, P. (2016). Does Naturalization Facilitate Integration?: A Longitudinal Study on the Consequences of Citizenship Acquisition for Immigrants' Identification with Germany. Zeitschrift für Soziologie, 45(2):107-121. 
Finotelli, C., La Barbera, M., and Echeverría, G. (2017). Beyond instrumental citizenship: the Spanish and Italian citizenship regimes in times of crisis. Journal of Ethnic and Migration Studies, 44(14):2320-2339.

Fleischmann, F. and Kristen, C. (2014). Gender Inequalities in the Education of the Second Generation in Western Countries:. Sociology of Education, 87(3):143-170.

Forster, A. G. and van de Werfhorst, H. G. (2019). Navigating Institutions: Parents' Knowledge of the Educational System and Students' Success in Education. European Sociological Review, 36(1):48-64.

Frauenfelder, A. (2007). Les paradoxes de la naturalisation: enquête auprès de jeunes issus de l'immigration. Questions sociologiques. Harmattan, Paris.

Gans, S., Linder, F., and Mooren, F. v. (2015). Gebruikershandleiding Onderwijsinformatie uit het SSB.

Gardner, K. (2012). Transnational Migration and the Study of Children: An Introduction. Journal of Ethnic and Migration Studies, 38(6):889-912.

Garrouste-Norelius, C., European Commission, and Joint Research Centre (2010). 100 years of educational reforms in Europe: a contextual database. Publications Office of the European Union, Luxembourg.

Gathmann, C. and Keller, N. (2018). Access to Citizenship and the Economic Assimilation of Immigrants. The Economic Journal, 128(616):3141-3181.

Gilbertson, G. and Singer, A. (2003). The emergence of protective citizenship in the USA: naturalization among Dominican immigrants in the post-1996 welfare reform era. Ethnic and Racial Studies, 26(1):25-51.

Gilman, S. E. and Loucks, E. B. (2014). Another casualty of sibling fixed-effects analysis of education and health: An informative null, or null information? Social Science $\mathcal{E}$ Medicine, 118:191-193.

Goldrick-Rab, S. (2016). Following Their Every Move: An Investigation of Social-Class Differences in College Pathways:. Sociology of Education, 79(1):67-79.

Gomensoro, A. and Bolzman, C. (2016). Les trajectoires éducatives de la seconde génération. Quel déterminisme des filières du secondaire I et comment certains jeunes le surmontent? Swiss Journal of Sociology, 42(2):291-311.

Gonzales, R. G. (2011). Learning to Be Illegal: Undocumented Youth and Shifting Legal Contexts in the Transition to Adulthood. American Sociological Review, 76(4):602619. 


\section{Bibliography}

Goodman, S. W. (2010). Integration Requirements for Integration's Sake? Identifying, Categorising and Comparing Civic Integration Policies. Journal of Ethnic and Migration Studies, 36(5):753-772.

Goodman, S. W. (2019). The Civic Integration Turn. In Weinar, A., Bonjour, S., and Zhyznomirska, L., editors, The Routledge handbook of the politics of migration in Europe, Routledge international handbooks, pages 167-178. Routledge, London New York, NY, first published edition.

Green, S. (2012). Much ado about not-very-much? Assessing ten years of German citizenship reform. Citizenship Studies, 16(2):173-188.

Groenewold, G. and Lessard-Phillips, L. (2012). Research methodology. In Crul, M., Schneider, J., and Lelie, F., editors, The European second generation compared: does the integration context matter?, IMISCOE research, pages 39-56. Amsterdam University Press, Amsterdam.

Haagsman, K. (2015). Parenting across borders : effects of transnational parenting on the lives of Angolan and Nigerian migrant parents in The Netherlands. PhD thesis, Maastricht University, Netherlands.

Haas, H., Czaika, M., Flahaux, M., Mahendra, E., Natter, K., Vezzoli, S., and VillaresVarela, M. (2019). International Migration: Trends, Determinants, and Policy Effects. Population and Development Review, 45(4):885-922.

Hadjar, A. and Scharf, J. (2019). The value of education among immigrants and nonimmigrants and how this translates into educational aspirations: a comparison of four European countries. Journal of Ethnic and Migration Studies, 45(5):711-734.

Hainmueller, J., Hangartner, D., and Pietrantuono, G. (2015). Naturalization fosters the long-term political integration of immigrants. Proceedings of the National Academy of Sciences, 112(41):12651-12656.

Hainmueller, J., Hangartner, D., and Pietrantuono, G. (2017). Catalyst or Crown: Does Naturalization Promote the Long-Term Social Integration of Immigrants? American Political Science Review, 111(02):256-276.

Hainmueller, J., Lawrence, D., Gest, J., Hotard, M., Koslowski, R., and Laitin, D. D. (2018). A randomized controlled design reveals barriers to citizenship for lowincome immigrants. Proceedings of the National Academy of Sciences, 115(5):939-944.

Heath, A. and Brinbaum, Y. (2007). Guest editorial: Explaining ethnic inequalities in educational attainment. Ethnicities, 7(3):291-304.

Heath, A. F., Rothon, C., and Kilpi, E. (2008). The Second Generation in Western Europe: Education, Unemployment, and Occupational Attainment. Annual Review of Sociology, 34(1):211-235. 
Helgertz, J. and Bevelander, P. (2017). The Influence of Partner Choice and Country of Origin Characteristics on the Naturalization of Immigrants in Sweden: A Longitudinal Analysis. International Migration Review, 51(3):667-700.

Helgertz, J., Bevelander, P., and Tegunimataka, A. (2014). Naturalization and Earnings: A Denmark-Sweden Comparison. European Journal of Population, 30(3):337359.

Hoem, J. M. and Kreyenfeld, M. (2006). Anticipatory analysis and its alternatives in life-course research: Part 1: Education and first childbearing. Demographic Research, 15:461-484.

Homuth, C., Welker, J., Will, G., and Von Maurice, J. (2020). The Impact of Legal Status on Different Schooling Aspects of Adolescents in Germany. Refuge: Canada's Journal on Refugees, 36(2):45-58.

Honohan, I. and Rougier, N. (2018). Global Birthright Citizenship Laws: How Inclusive? Netherlands International Law Review, 65:337-357.

Hoon, M. d., Vink, M., and Schmeets, H. (2020). A ticket to mobility? Naturalisation and subsequent migration of refugees after obtaining asylum in the Netherlands. Journal of Ethnic and Migration Studies, 46(7):1185-1204.

Huang, M.-H. (2020). Compensatory advantage and the use of out-of-school-time tutorials: A cross-national study. Research in Social Stratification and Mobility, 66:114 (epub ahead of print).

Ichou, M. (2014). Who They Were There: Immigrants' Educational Selectivity and Their Children's Educational Attainment. European Sociological Review, 30(6):750765 .

Imdorf, C. (2019). Sélection, discrimination et reproduction sociale par les entreprises formatrices. In Bonoli, L., Berger, J.-L., and Lamamra, N., editors, Enjeux de la formation professionnelle en Suisse Le "modèle" suisse sous la loupe, pages 181-198. Éditions Seismo SA, Zurich et Genève.

IND Informatie- en Analyse Centrum (2011). Trendrapportage Naturalisatie VI. Aaanvragen en verkrijgen van het Nederlanderschap door naturalisatie en optie. Ontwikkelingen in de periode 2005-2009. Technical report, Immigratie- en Naturalisatiedienst.

Inspectie van het Onderwijs (2010). De Staat van het Onderwijs. Onderwijsverslag 2008-2009. Technical report, Inspectie van het Onderwijs, Utrecht, The Netherlands.

Inspectie van het Onderwijs (2016). De Staat van het Onderwijs. Onderwijsverslag 2014-2015. Technical report, Inspectie van het Onderwijs, Utrecht, The Netherlands. 


\section{Bibliography}

Ip, D., Inglis, C., and Wu, C. T. (1997). Concepts of Citizenship and Identity among Recent Asian Immigrants in Australia. Asian and Pacific Migration Journal, 6(3-4):363384.

Jensen, K. K., Mouritsen, P., Bech, E. C., and Olsen, T. V. (2019). Roadblocks to citizenship: selection effects of restrictive naturalisation rules. Journal of Ethnic and Migration Studies, 47(5):1047-1065.

Kalmijn, M. (2019). Contact and conflict between adult children and their parents in immigrant families: is integration problematic for family relationships? Journal of Ethnic and Migration Studies, 45(9):1419-1438.

Kalmijn, M. and Kraaykamp, G. (2003). Dropout and Downward Mobility in the Educational Career: An Event-History Anaylsis of Ethnic Schooling Differences in the Netherlands. Educational Research and Evaluation, 9(3):265-287.

Kalter, F., Jonsson, J. O., Van Tubergen, F., and Heath, A. F., editors (2018). Growing up in diverse societies: the integration of the children of immigrants in England, Germany, the Netherlands and Sweden. Number 215 in Proceedings of the British Academy. Published for the British Academy by Oxford University Press, Oxford, first edition edition.

Kantarevic, J. and Mechoulan, S. (2006). Birth Order, Educational Attainment, and Earnings: An Investigation Using the PSID. The Journal of Human Resources, 41(4):755-777.

Kappelhof, J. W. S. (2015). Surveying ethnic minorities: the impact of survey design on data quality. PhD thesis, Utrecht University.

Kaufman, L. and Rousseeuw, P. J. (1990). Partitioning around medoids (program PAM). In Finding groups in data. An introduction to cluster analysis, pages 68-125. John Wiley \& Sons, New-York.

Keele, L. (2010). Proportionally Difficult: Testing for Nonproportional Hazards in Cox Models. Political Analysis, 18(2):189-205.

Keskiner, E. and Crul, M. (2017). How to reach the top? Fields, forms of capital, and strategies in accessing leadership positions in France among descendants of migrants from Turkey. Ethnic and Racial Studies, 40(2):283-300.

Kilpi-Jakonen, E. (2014). Citizenship and Educational Attainment amongst the Second Generation: An Analysis of Children of Immigrants in Finland. Journal of Ethnic and Migration Studies, 40(7):1079-1096.

Kilpi-Jakonen, E. and Alisaari, J. (2021). Does the language spoken at home matter for the education, wellbeing, and sense of belonging of the children of immigrants? And does the answer depend on how we analyse it? preprint, SocArXiv. 
Kleinepier, T. and de Valk, H. (2016). Ethnic differences in family trajectories of young adult women in the Netherlands: Timing and sequencing of events. Demographic Research, 35:671-710.

Kleinepier, T., de Valk, H. A. G., and van Gaalen, R. (2015). Life Paths of Migrants: A Sequence Analysis of Polish Migrants' Family Life Trajectories. European Journal of Population, 31(2):155-179.

Kofman, E. (2004). Family-related migration: a critial review of European Studies. Journal of Ethnic and Migration Studies, 30(2):243-262.

Kofman, E., Kraler, A., Kohli, M., and Schmoll, C. (2011). Introduction. Issues and Debates on Family-related Migration and the Migrant Family: A European Perspective. In Kofman, E., Kraler, A., Kohli, M., and Schmoll, C., editors, Gender, Generations and the Family in International Migration, pages 13-54. Amsterdam University Press.

Kraus, E. K. (2019). Family formation trajectories across borders: A sequence analysis approach to Senegalese migrants in Europe. Advances in Life Course Research, 42:113.

Kristen, C. (2008). Primary School Choice and Ethnic School Segregation in German Elementary Schools. European Sociological Review, 24(4):495-510.

Labussière, M., Levels, M., and Vink, M. (2021). Citizenship and education trajectories among children of immigrants: a transition-oriented sequence analysis. Advances in Life Course Research, pages 1-14 (in press).

Labussière, M. and Vink, M. (2020). The intergenerational impact of naturalisation reforms: the citizenship status of children of immigrants in the Netherlands, 1995-2016. Journal of Ethnic and Migration Studies, 46(13):2742-2763.

Lange, C., Kamalkhani, Z., and Baldassar, L. (2007). Afghan Hazara Refugees in Australia: Constructing Australian Citizens. Social Identities, 13(1):31-50.

Leclerc, C., Vink, M., and Schmeets, H. (2021). Citizenship acquisition and spatial stratification: Analysing immigrant residential mobility in the Netherlands. Urban Studies, pages 1-18 (epub ahead of print).

Lesnard, L. (2010). Setting Cost in Optimal Matching to Uncover Contemporaneous Socio-Temporal Patterns. Sociological Methods \& Research, 38(3):389-419.

Lessard-Phillips, L., Galandini, S., de Valk, H., and Fibbi, R. (2017). Damned If You Do, Damned If You Don't: The Challenges of Including and Comparing the Children of Immigrants in European Survey Data. In Bolzman, C., Bernardi, L., and Le Goff, J.M., editors, Situating Children of Migrants across Borders and Origins, volume 7, pages 25-53. Springer Netherlands, Dordrecht. 


\section{Bibliography}

LeTendre, G. K., Hofer, B. K., and Shimizu, H. (2003). What Is Tracking? Cultural Expectations in the United States, Germany, and Japan. American Educational Research Journal, 40(1):43-89.

Levels, M. and Dronkers, J. (2008). Educational performance of native and immigrant children from various countries of origin. Ethnic and Racial Studies, 31(8):1404-1425.

Levitt, P. (2009). Roots and Routes: Understanding the Lives of the Second Generation Transnationally. Journal of Ethnic and Migration Studies, 35(7):1225-1242.

Levitt, P. and Waters, M. C., editors (2002). The Changing Face of Home: The Transnational Lives of the Second Generation. Russell Sage Foundation.

Liebig, T. and von Haaren, F. (2011). Citizenship and the Socio-economic Integration of Immigrants and their Children. In Naturalisation: A Passport for the Better Integration of Immigrants?, pages 24-60. OECD Publishing, Paris.

Louie, V. (2012). Keeping the Immigrant Bargain: The Costs and Rewards of Success in America. Russell Sage Foundation, New-York.

Luthra, R., Soehl, T., and Waldinger, R. (2018a). Reconceptualizing Context: A Multilevel Model of the Context of Reception and Second-Generation Educational Attainment. International Migration Review, 52(3):898-928.

Luthra, R., Soehl, T., and Waldinger, R. D. (2018b). Origins and destinations: the making of the second generation. Russell Sage Foundation, New York.

Manning, A. and Roy, S. (2010). Culture Clash or Culture Club? National Identity in Britain. The Economic Journal, 120(542):72-100.

Mayer, K. U. (2004). Whose Lives? How History, Societies, and Institutions Define and Shape Life Courses. Research in Human Development, 1(3):161-187.

Mayer, K. U. and Tuma, N. B., editors (1990). Event history analysis in life course research. Life course studies. University of Wisconsin Press, Madison.

Mazzolari, F. (2009). Dual Citizenship Rights: Do They Make More and Richer Citizens? Demography, 46(1):169-191.

Mazzucato, V. (2008). The Double Engagement: Transnationalism and Integration. Ghanaian Migrants' Lives Between Ghana and The Netherlands. Journal of Ethnic and Migration Studies, 34(2):199-216.

Mazzucato, V. and Schans, D. (2011). Transnational Families and the Well-Being of Children: Conceptual and Methodological Challenges. Journal of Marriage and Family, 73(4):704-712. 
Menjívar, C. (2006). Liminal Legality: Salvadoran and Guatemalan Immigrants' Lives in the United States. American Journal of Sociology, 111(4):999-1037.

Menjívar, C. (2012). Transnational Parenting and Immigration Law: Central Americans in the United States. Journal of Ethnic and Migration Studies, 38(2):301-322.

Menjívar, C., Abrego, L. J., and Schmalzbauer, L. (2016). Immigrant families. Immigration \& society series. Polity, Cambridge, UK ; Malden, MA.

Miyamoto, A., Seuring, J., and Kristen, C. (2020). Immigrant students' achievements in light of their educational aspirations and academic motivation. Journal of Ethnic and Migration Studies, 46(7):1348-1370.

Mundlak, Y. (1978). On the Pooling of Time Series and Cross Section Data. Econometrica, 46(1):69-85.

Nauck, B. and Settles, B. H. (2001). Immigrant and Ethnic Minority families: An Introduction. Journal of Comparative Family Studies, 32(4):461-463. Publisher: Dr. George Kurian.

Nielsen, H. S. and Rangvid, B. S. (2012). The impact of parents' years since migration on children's academic achievement. IZA Journal of Migration, 1(1):6.

Nieuwenhuis, J., Kleinepier, T., and van Ham, M. (2021). The Role of Exposure to Neighborhood and School Poverty in Understanding Educational Attainment. Journal of Youth and Adolescence, 50(5):872-892.

Nuffic (2019). Education system, The Netherlands. The Dutch education system described. Technical Report Version 6, The Hague, the Netherlands.

Nunn, C., McMichael, C., Gifford, S. M., and Correa-Velez, I. (2016). Mobility and security: the perceived benefits of citizenship for resettled young people from refugee backgrounds. Journal of Ethnic and Migration Studies, 42(3):382-399.

Oberski, D. L., Kirchner, A., Eckman, S., and Kreuter, F. (2017). Evaluating the Quality of Survey and Administrative Data with Generalized Multitrait-Multimethod Models. Journal of the American Statistical Association, 112(520):1477-1489.

OECD (2012). Untapped skills: realising the potential of immigrant students. Pisa, Programme for International Student Assessment. OECD Publications, Paris.

OECD (2015). Education Policy Outlook: Sweden. Technical report, available at: www.oecd.org/education/policyoutlook.htm.

OECD (2017a). Catching Up? Intergenerational Mobility and Children of Immigrants. OECD. 


\section{Bibliography}

OECD (2017b). Education Policy Outlook: Austria. Technical report, available at: www.oecd.org/education/policyoutlook.htm.

Ogden, L. J. and Mazzucato, V. (2021). Transnational peer relationships as social capital: mobile migrant youth between Ghana and Germany. Journal of Youth Studies, pages $1-18$.

Orupabo, J., Drange, I., and Abrahamsen, B. (2020). Multiple frames of success: how second-generation immigrants experience educational support and belonging in higher education. Higher Education, 79(5):921-937.

Oster, E. (2019). Unobservable Selection and Coefficient Stability: Theory and Evidence. Journal of Business \& Economic Statistics, 37(2):187-204.

Parameshwaran, M. and Engzell, P. (2015). Ethnicity in England: What Parents' Country of Birth Can and Can't Tell Us about Their Children's Ethnic Identification. Journal of Ethnic and Migration Studies, 41(3):399-424.

Patler, C. (2017). Citizen Advantage, Undocumented Disadvantage, or Both? The Comparative Educational Outcomes of Second and 1.5-Generation Latino Young Adults. International Migration Review, 52(4):1080-1110.

Patler, C., Gleeson, S., and Schonlau, M. (2020). Contesting Inequality: The Impact of Immigrant Legal Status and Education on Legal Knowledge and Claims-Making in Low-Wage Labor Markets. Social Problems, pages 1-24 (epub ahead of print).

Patler, C. and Pirtle, W. L. (2018). From undocumented to lawfully present: Do changes to legal status impact psychological wellbeing among latino immigrant young adults? Social Science $\mathcal{E}$ Medicine, 199:39-48.

Pavlopoulos, D. and Vermunt, J. K. (2015). Measuring temporary employment. Do survey or register data tell the truth? Survey Methodology, 41(1):197-214.

Perchinig, B. (2010). Chapter 1. All You Need To Know To Become An Austrian: Naturalisation Policy And Citizenship Testing In Austria. In Ersboll, E., Kostakopoulou, D., and Van Oers, R., editors, A Re-definition of Belonging? Language and Integration Tests in Europe, pages 24-49. Brill | Nijhoff, Netherlands.

Peters, F. (2018). The Citizenship Premium: Immigrant naturalisation and socio-economic integration in the Netherlands. PhD thesis, Maastricht University, Maastricht.

Peters, F. (2020). Naturalization and the transition to homeownership: an analysis of signalling in the Dutch housing market. Housing Studies, 35(7):1239-1268.

Peters, F., Schmeets, H., and Vink, M. (2020). Naturalisation and Immigrant Earnings: Why and to Whom Citizenship Matters. European Journal of Population, 36(3):511545. 
Peters, F. and Vink, M. (2016). Naturalization and the socio-economic integration of immigrants: a life-course perspective. In Freeman, G. P. and Mirilovic, N., editors, Handbook on Migration and Social Policy, pages 362-376. Edward Elgar Publishing, Cheltenham, UK.

Peters, F., Vink, M., and Schmeets, H. (2016). The ecology of immigrant naturalisation: a life course approach in the context of institutional conditions. Journal of Ethnic and Migration Studies, 42(3):359-381.

Peters, F., Vink, M., and Schmeets, H. (2017). Anticipating the citizenship premium: before and after effects of immigrant naturalisation on employment. Journal of Ethnic and Migration Studies, 44(7):1051-1080.

Petersen, A. H. and Lange, T. (2020). What Is the Causal Interpretation of Sibling Comparison Designs? Epidemiology, 31(1):75-81.

Pew Research Center (2019). Europe's Unauthorized Immigrant Population Peaks in 2016, Then Levels Off. Technical report, Pew Research Center.

Pfeffer, F. T. (2008). Persistent Inequality in Educational Attainment and its Institutional Context. European Sociological Review, 24(5):543-565.

Piccarreta, R. and Studer, M. (2019). Holistic analysis of the life course: Methodological challenges and new perspectives. Advances in Life Course Research, 41:1-11.

Poeze, M. and Mazzucato, V. (2016). Transnational Mothers and the Law: Ghanaian Women's Pathways to Family Reunion and Consequences for Family Life. In Kilkey, M. and Palenga-Möllenbeck, E., editors, Family Life in an Age o Migration and Mobility. Global Perspectives through the Life Course, pages 187-211. Palgrave Macmillan, London.

Portes, A. and Fernández-Kelly, P. (2008). No Margin for Error: Educational and Occupational Achievement among Disadvantaged Children of Immigrants. The ANNALS of the American Academy of Political and Social Science, 620(1):12-36.

Pásztor, A. (2012). Imagined futures: why business studies dominate the higher education choices of second-generation Turks in the Netherlands. Ethnic and Racial Studies, 35(4):704-717.

Researchcentrum voor Onderwijs en Arbeidsmarkt (2009). Zonder diploma: aanleiding, kansen en toekomstintensies. Researchcentrum voor Onderwijs en Arbeidsmarkt, Maastricht.

Ribert, E. (2000). Devenir français. In LaSoudière, M. d., editor, Seuils, passages, number 70.2000 in Communications, pages 229-242. Éd. du Seuil, Paris. 


\section{Bibliography}

Ribert, E. (2009). À la recherche du « sentiment identitaire $\gg$ des français issus de l'immigration. Revue française de science politique, 59(3):569-592.

Ritschard, G. and Studer, M. (2018). Sequence Analysis: Where Are We, Where Are We Going? In Ritschard, G. and Studer, M., editors, Sequence Analysis and Related Approaches, volume 10, pages 1-11. Springer International Publishing, Cham.

Rose, T., Lindsey, M. A., Xiao, Y., Finigan-Carr, N. M., and Joe, S. (2017). Mental Health and Educational Experiences Among Black Youth: A Latent Class Analysis. Journal of Youth and Adolescence, 46(11):2321-2340.

Rousseeuw, P. J. (1987). Silhouettes: A graphical aid to the interpretation and validation of cluster analysis. Journal of Computational and Applied Mathematics, 20:53-65.

Rumbaut, R. G. (2004). Ages, Life Stages, and Generational Cohorts: Decomposing the Immigrant First and Second Generations in the United States. The International Migration Review, 38(3):1160-1205.

Sajons, C. (2016). Does granting citizenship to immigrant children affect family outmigration? Journal of Population Economics, 29(2):395-420.

Sajons, C. (2019). Birthright citizenship and parental labor market integration. Labour Economics, 57:1-22.

Schinkel, W. and Van Houdt, F. (2010). The double helix of cultural assimilationism and neo-liberalism: citizenship in contemporary governmentality: The double helix of cultural assimilationism and neo-liberalism. The British Journal of Sociology, 61(4):696-715.

Schisterman, E. F., Cole, S. R., and Platt, R. W. (2009). Overadjustment Bias and Unnecessary Adjustment in Epidemiologic Studies. Epidemiology, 20(4):488-495.

Schulz, W., Schunck, R., Diewald, M., and Johnson, W. (2017). Pathways of Intergenerational Transmission of Advantages during Adolescence: Social Background, Cognitive Ability, and Educational Attainment. Journal of Youth and Adolescence, 46(10):2194-2214.

Schunck, R. (2013). Within and between estimates in random-effects models: Advantages and drawbacks of correlated random effects and hybrid models. The Stata Journal, 13(1):65-76.

Schunck, R. and Perales, F. (2017). Within- and between-cluster effects in generalized linear mixed models: A discussion of approaches and the xthybrid command. The Stata Journal, 17(1):89-115.

Schöb, A. (2001). Educational Opportunities of Children in Poverty. Vierteljahrshefte zur Wirtschaftsforschung, 70(1):172-179. 
Serra Mingot, E. (2018). Protecting across borders: Sudanese families across the Netherlands, the UK and Sudan. PhD thesis, Maastricht University.

Shahrokni, S. (2019). The transnational career aspirations of France's high-achieving second-generation Maghrebi migrants. Journal of Ethnic and Migration Studies, 45(3):437-454.

Sigle-Rushton, W., Lyngstad, T. H., Andersen, P. L., and Kravdal, O. (2014). Proceed With Caution? Parents' Union Dissolution and Children's Educational Achievement: Union Dissolution and Children's Achievements. Journal of Marriage and Family, 76(1):161-174.

Singer, E. (2006). Introduction: Nonresponse Bias in Household Surveys. The Public Opinion Quarterly, 70(5):637-645.

Sjölander, A., Lichtenstein, P., Larsson, H., and Pawitan, Y. (2013). Between-within models for survival analysis. Statistics in Medicine, 32(18):3067-3076.

Smith, N., Lister, R., Middleton, S., and Cox, L. (2005). Young People as Real Citizens: Towards an Inclusionary Understanding of Citizenship. Journal of Youth Studies, 8(4):425-443.

Snijders, T. A. B. and Berkhof, J. (2008). Diagnostic Checks for Multilevel Models. In Leeuw, J. d. and Meijer, E., editors, Handbook of multilevel analysis, pages 141-175. Springer, New York.

Soehl, T., Waldinger, R., and Luthra, R. (2018). Social politics: the importance of the family for naturalisation decisions of the 1.5 generation. Journal of Ethnic and Migration Studies, pages 1-21 (in press).

Sredanovic, D. (2020). The tactics and strategies of naturalisation: UK and EU27 citizens in the context of Brexit. Journal of Ethnic and Migration Studies, pages 1-18 (epub ahead of print).

Stadlmair, J. (2017). Which policies matter? Explaining naturalisation rates using disaggregated policy data. OZP - Australian Journal of Political Science, 46(1):60-73.

Steinhardt, M. F. (2012). Does citizenship matter? The economic impact of naturalizations in Germany. Labour Economics, 19(6):813-823.

Stevens, P. A. J., Clycq, N., Timmerman, C., and Van Houtte, M. (2011). Researching race/ethnicity and educational inequality in the Netherlands: a critical review of the research literature between 1980 and 2008. British Educational Research Journal, 37(1):5-43.

Stewart, E. and Mulvey, G. (2014). Seeking Safety beyond Refuge: The Impact of Immigration and Citizenship Policy upon Refugees in the UK. Journal of Ethnic and Migration Studies, 40(7):1023-1039. 


\section{Bibliography}

Street, A. (2013). Naturalization Dynamics in Immigrant Families. Comparative Migration Studies, 1(1):23-44.

Street, A. (2014). My Child Will Be a Citizen: Intergenerational Motives for Naturalization. World Politics, 66(02):264-292.

Studer, M. and Ritschard, G. (2016). What matters in differences between life trajectories: a comparative review of sequence dissimilarity measures. Journal of the Royal Statistical Society, 179(2):481-511.

Studer, M., Struffolino, E., and Fasang, A. E. (2018). Estimating the Relationship between Time-varying Covariates and Trajectories: The Sequence Analysis Multistate Model Procedure. Sociological Methodology, 48(1):103-135.

Suárez-Orozco, C. and Suárez-Orozco, M. M. (2002). Children of immigration. The developing child series. Harvard University Press, Cambridge, Massachusetts, and London, England.

Tieben, N., de Graaf, P. M., and de Graaf, N. D. (2010). Changing effects of family background on transitions to secondary education in the Netherlands: Consequences of educational expansion and reform. Research in Social Stratification and Mobility, 28(1):77-90.

Timmermans, A. C., de Boer, H., Amsing, H. T. A., and van der Werf, M. P. C. (2018). Track recommendation bias: Gender, migration background and SES bias over a 20-year period in the Dutch context. British Educational Research Journal, 44(5):847874.

Turney, K. and Kao, G. (2009). Barriers to School Involvement: Are Immigrant Parents Disadvantaged? The Journal of Educational Research, 102(4):257-271.

van de Werfhorst, H. G. (2019). Early Tracking and Social Inequality in Educational Attainment: Educational Reforms in 21 European Countries. American Journal of Education, 126(1):65-99.

van de Werfhorst, H. G. and Heath, A. (2019). Selectivity of Migration and the Educational Disadvantages of Second-Generation Immigrants in Ten Host Societies. European Journal of Population, 35(2):347-378.

van de Werfhorst, H. G. and Mijs, J. J. (2010). Achievement Inequality and the Institutional Structure of Educational Systems: A Comparative Perspective. Annual Review of Sociology, 36(1):407-428.

van De Werfhorst, H. G. and Van Tubergen, F. (2007). Ethnicity, schooling, and merit in the Netherlands. Ethnicities, 7(3):416-444. 
van der Erf, R., Heering, L., and Spaan, E. (2006). Country report: Netherlands. In Poulain, M., Perrin, N., and Singleton, A., editors, THESIM: towards harmonised European statistics on international migration, pages 553-564. Presses universitaires de Louvain, Louvain-la-Neuve.

van Geel, J. (2019). Being mobile, becoming educated: young Ghanaians' mobility trajectories and educational experiences between Ghana and the Netherlands. PhD thesis, Maastricht University.

van Geel, J. and Mazzucato, V. (2018). Conceptualising youth mobility trajectories: thinking beyond conventional categories. Journal of Ethnic and Migration Studies, 44(13):2144-2162.

van Geel, J. and Mazzucato, V. (2021). Building Educational Resilience Through Transnational Mobility Trajectories: Young People Between Ghana and The Netherlands. YOUNG, 29(2):119-136.

van Hook, J., Brown, S. K., and Bean, F. D. (2006). For Love or Money? Welfare Reform and Immigrant Naturalization. Social Forces, 85(2):643-666.

van Houdt, F., Suvarierol, S., and Schinkel, W. (2011). Neoliberal communitarian citizenship: Current trends towards 'earned citizenship' in the United Kingdom, France and the Netherlands. International Sociology, 26(3):408-432.

van Meeteren, M., Van de Pol, S., Dekker, R., Engbersen, G., and Snel, E. (2013). Destination Netherlands. History of immigration and immigration policy in the Netherlands. In Ho, J., editor, Immigrants : Acculturation, Socioeconomic Challenges $\mathcal{E}$ Cultural Psychology, pages 113-170. Nova Science Publishers, Inc., New-York.

van Oers, R. (2013). Deserving Citizenship. Brill, Leiden.

van Oers, R., de Hart, B., and Groenendijk, K. (2009). Report on the Netherlands. report, EUDO Citizenship Observatory, http://www.eudocitizenship.eu/admin/?p=file\&appl=countryProfiles\&f=Netherlands.pdf.

van Ours, J. C. and Veenman, J. (2010). How interethnic marriages affect the educational attainment of children: Evidence from a natural experiment. Labour Economics, 17(1):111-117.

van Tubergen, F., Maas, I., and Flap, H. (2004). The Economic Incorporation of Immigrants in 18 Western Societies: Origin, Destination, and Community Effects. American Sociological Review, 69(5):704-727.

Vertovec, S. (1999). Conceiving and researching transnationalism. Ethnic and Racial Studies, 22(2):447-462. 


\section{Bibliography}

Vink, M., Tegunimataka, A., Peters, F., and Bevelander, P. (2021). Long-Term Heterogeneity in Immigrant Naturalization: The Conditional Relevance of Civic Integration and Dual Citizenship. European Sociological Review, pages 1-15 (epub ahead of print).

Vink, M. P. (2007). Dutch 'Multiculturalism' Beyond the Pillarisation Myth. Political Studies Review, 5(3):337-350.

Vink, M. P. and de Groot, G.-R. (2010). Citizenship Attribution in Western Europe: International Framework and Domestic Trends. Journal of Ethnic and Migration Studies, 36(5):713-734.

Vink, M. P., Prokic-Breuer, T., and Dronkers, J. (2013). Immigrant Naturalization in the Context of Institutional Diversity: Policy Matters, but to Whom? International Migration, 51(5):1-20.

von Haaren, F. (2016). Naturalisation and Investments in Children's Human Capital: Evidence from a Natural Experiment. Hannover Economic Papers (HEP) dp-576, Leibniz Universität Hannover, Wirtschaftswissenschaftliche Fakultät.

Ward, J. H. (1963). Hierarchical Grouping to Optimize an Objective Function. Journal of the American Statistical Association, 58(301):236-244.

Wessendorf, S. (2007). 'Roots Migrants': Transnationalism and 'Return' among Second-Generation Italians in Switzerland. Journal of Ethnic and Migration Studies, 33(7):1083-1102.

Wetenschappelijke Raad voor het Regeringsbeleid (WRR) (1979). Etnische Minderheden. Rapporten aan de Regering 17, Staatsuitgeverij, Gravenhage.

Wetenschappelijke Raad voor het Regeringsbeleid (WRR) (1989). Allochtonenbeleid. Rapporten aan de Regering 36, SDU Uitgeverij, Gravenhage.

Williams, R. (2012). Using the margins command to estimate and interpret adjusted predictions and marginal effects. The Stata Journal, 12(2):308-331.

Willis, P. E. (1981). Learning to labor: how working class kids get working class jobs. Columbia University Press, New York.

Wimmer, A. and Glick-Schiller, N. (2002). Methodological nationalism and beyond: nation-state building, migration and the social sciences. Global Networks, 2(4):301334.

Wimmer, A. and Schiller, N. G. (2003). Methodological Nationalism, the Social Sciences, and the Study of Migration: An Essay in Historical Epistemology. The International Migration Review, 37(3):576-610. 
Wingens, M., Windzio, M., de Valk, H., and Aybek, C. (2011a). Chapter 1. The Sociological Life Course Approach and Research on Migration and Integration. In Wingens, M., Windzio, M., de Valk, H., and Aybek, C., editors, A Life-Course Perspective on Migration and Integration, pages 1-26. Springer Netherlands, Dordrecht.

Wingens, M., Windzio, M., Valk, H. d., and Aybek, C., editors (2011b). A life-course perspective on migration and integration. Springer, Dordrecht.

Yang, P. (1994). Explaining Immigrant Naturalization. International Migration Review, 28:449-477.

Yanow, D. and van der Haar, M. (2013). People out of place: allochthony and autochthony in the Netherlands' identity discourse - metaphors and categories in action. Journal of International Relations and Development, 16(2):227-261.

Zhou, M. and Gonzales, R. G. (2019). Divergent Destinies: Children of Immigrants Growing Up in the United States. Annual Review of Sociology, 45(1):383-399.

Zlotnik, H. (1995). Migration and the family: the female perspective. Asian and Pacific migration journal : APMJ, 4(2-3):253-271.

Zorlu, A. and Mulder, C. H. (2011). Ethnic Differences in Leaving Home: Timing and Pathways. Demography, 48(1):49-72.

Zorn, C. (2001). Estimating between- and within-cluster covariate effects, with an application to models of international disputes. International Interactions, 27(4):433445 . 



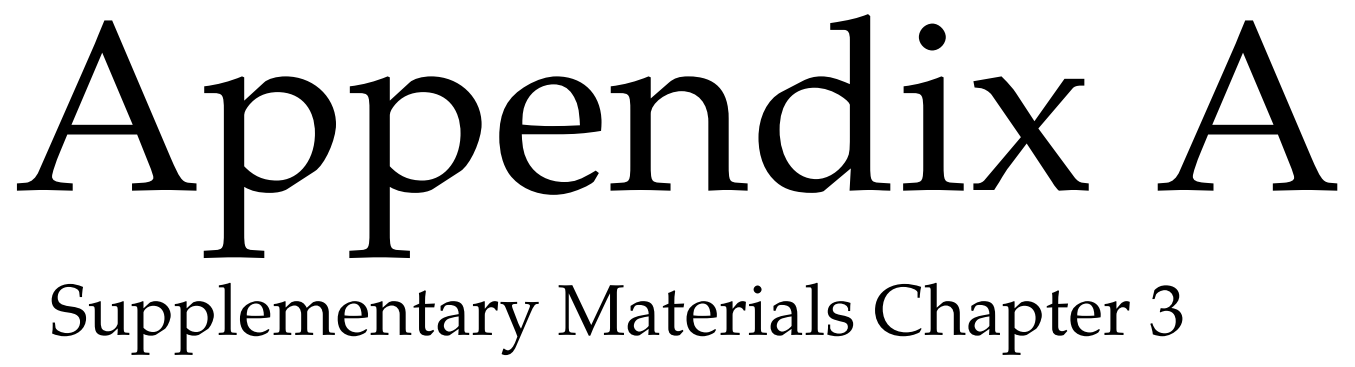




\section{Contents}

I Descriptive statistics ............................. 226

II Alternative specifications for the Cox model ............. 230

III Cause-specific hazard models ........................ 233

IV Schoenfeld residuals .................................. 235

V Kaplan-Meier function .............................. 237

VI Naturalisation fees: historical development 2001-2020 . . . 238

VII Construction of the eligibility variable ................. 240

VIII Robustness checks .................................. 243

\section{Descriptive statistics}

\begin{tabular}{lrr}
\hline & \multicolumn{1}{c}{$\mathbf{N}$} & \multicolumn{1}{c}{$\%$} \\
\hline Male & 147,111 & 51.21 \\
Female & 140,139 & 48.79 \\
Father SES & & \\
Employee or self-employed & 143,164 & 49.84 \\
Reception of benefits & 50,84 & 17.7 \\
No declared income & 18,899 & 6.58 \\
Unknown SES & 74,347 & 25.88 \\
Mother SES & & \\
Employee or self-employed & 53,638 & 18.67 \\
Reception of benefits & 63,364 & 22.06 \\
No declared income & 98,215 & 34.19 \\
Unknown SES & 72,033 & 25.08 \\
EU origin country & & \\
No & 268,955 & 93.63 \\
Yes & 18,295 & 6.37 \\
Country of origin (mother) & & \\
Morocco & 92,275 & 32.12 \\
Turkey & 72,363 & 25.19 \\
Iraq & 10,142 & 3.53 \\
Yugoslavia & 10,735 & 3.74 \\
Somalia & 8,256 & 2.87 \\
& Continued
\end{tabular}

Table A1: Socio-demographic characteristics of the whole sample. 


\begin{tabular}{lrr}
\hline & \multicolumn{1}{c}{$\mathbf{N}$} & \multicolumn{1}{c}{$\%$} \\
\hline Afghanistan & 7,352 & 2.56 \\
former Soviet-Union & 4,615 & 1.61 \\
Poland & 3,043 & 1.06 \\
Great Britain & 2,398 & 0.83 \\
China & 7,211 & 2.51 \\
Germany & 2,598 & 0.9 \\
Iran & 3,192 & 1.11 \\
Angola & 1,561 & 0.54 \\
Other EU countries & 9,362 & 3.26 \\
Other non-EU countries & 52,147 & 18.15 \\
Father's country of origin & & \\
Same as mother's one & 253,791 & 88.35 \\
Different than mother's one & 33,459 & 11.65 \\
Dutch citizenship & & \\
Dutch from birth & 190,014 & 66.15 \\
No naturalisation & 36,985 & 12.88 \\
Naturalisation over the period & 60,251 & 20.98 \\
& 287,25 & \\
\hline
\end{tabular}

Table A1 Continued: Socio-demographic characteristics of the whole sample. 


\begin{tabular}{lrr}
\hline Eligibility period & $\mathbf{N}$ & $\mathbf{\%}$ \\
\hline between 1995 and 1997 & 24,608 & 25.31 \\
between 1998 and 2002 & 29,831 & 30.68 \\
in or after 2003 & 39,496 & 40.62 \\
never eligible & 3,301 & 3.39 \\
TOTAL & 97,236 & \\
\hline
\end{tabular}

(a) Sample A: Those who are not Dutch from birth.

\begin{tabular}{lrr}
\hline Dutch citizenship status & $\mathbf{N}$ & $\mathbf{\%}$ \\
\hline No naturalisation & 33,684 & 35.86 \\
Naturalisation over the period & 60,251 & 64.14 \\
\hline Dummy both parents are eligible & & \\
\hline Never eligible together & 1,854 & 1.97 \\
Eligible together over the period & 92,081 & 98.03 \\
TOTAL & 93,935 & \\
\hline
\end{tabular}

(b) Sample B: Those who are eligible over the period.

\begin{tabular}{lrr}
\hline Naturalisation with whom & $\mathbf{N}$ & $\mathbf{\%}$ \\
\hline Same year than mother & 17,638 & 29.27 \\
Same year than father & 16,945 & 28.12 \\
Same year than both parents & 23,592 & 39.16 \\
Independent year & 2,076 & 3.45 \\
\hline Age at naturalisation & & \\
\hline Before 18 & 57,884 & 96.07 \\
After 18 & 2,367 & 3.93 \\
TOTAL & 60,251 & \\
\hline
\end{tabular}

(c) Sample C: Those who naturalise over the period.

Table A2: Eligibility, citizenship and naturalisation characteristics of restricted samples. 


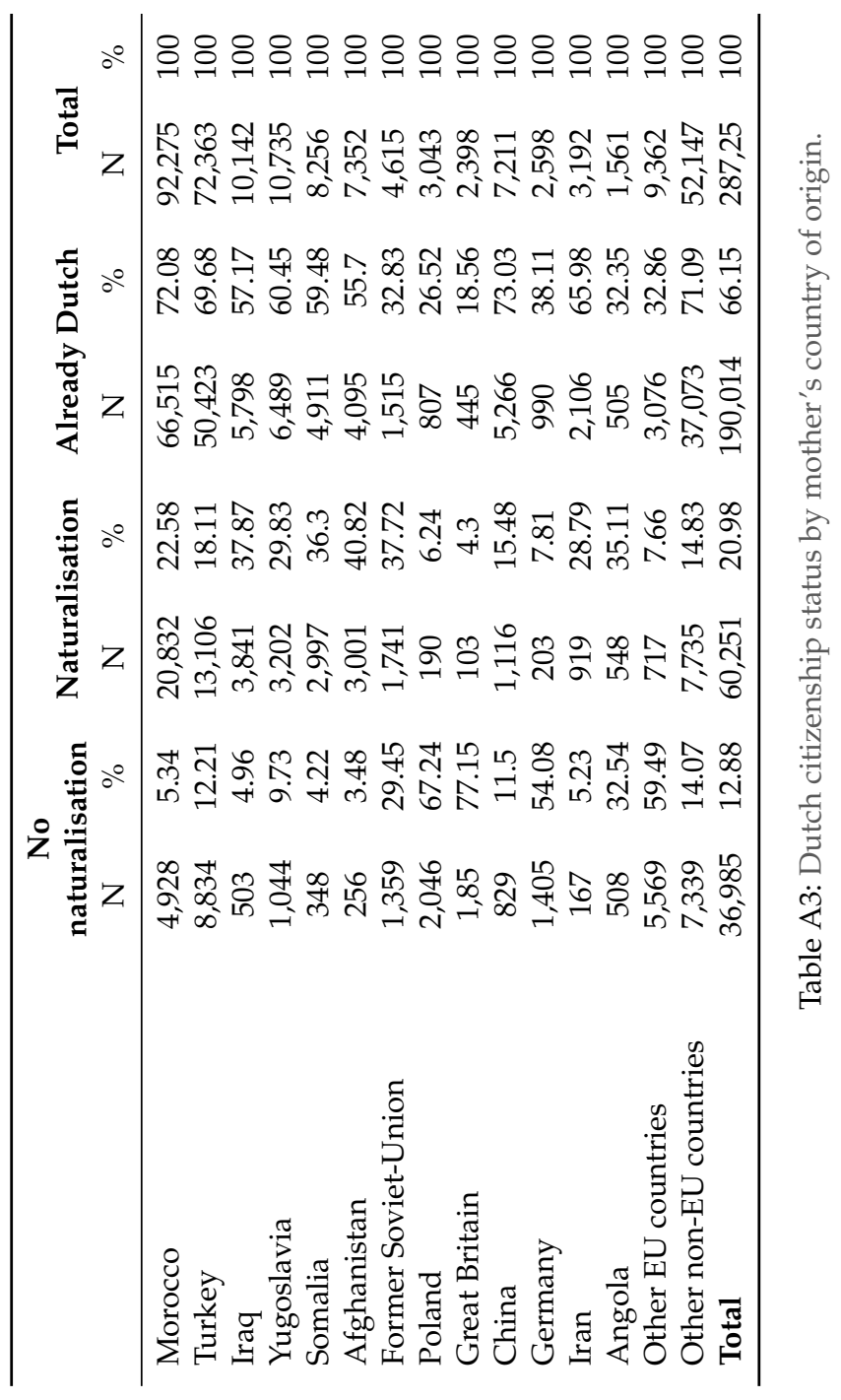




\section{Alternative specifications for the Cox model}

\begin{tabular}{lcccccc}
\hline Variable & $\begin{array}{c}\text { Hazard } \\
\text { rate }\end{array}$ & $\begin{array}{c}\text { Std. } \\
\text { Error }\end{array}$ & $\mathbf{z}$ & $\mathbf{P}>\mathbf{z}$ & $\begin{array}{c}\text { [95\% Conf. } \\
\text { Interval] }\end{array}$ \\
\hline $\begin{array}{l}\text { Eligibility cohort } \\
\text { (ref: 1995-1996) }\end{array}$ & & & & & & \\
$1997-1998$ & 0.827 & 0.011 & -14.300 & 0.000 & 0.805 & 0.849 \\
$1999-2000$ & 0.694 & 0.011 & -22.820 & 0.000 & 0.672 & 0.716 \\
$2001-2002$ & 0.618 & 0.010 & -28.360 & 0.000 & 0.598 & 0.639 \\
$2003-2004$ & 0.462 & 0.009 & -41.270 & 0.000 & 0.446 & 0.480 \\
$2005-2006$ & 0.405 & 0.008 & -47.470 & 0.000 & 0.390 & 0.421 \\
$2007-2008$ & 0.422 & 0.009 & -40.470 & 0.000 & 0.404 & 0.440 \\
2009 and after & 0.377 & 0.008 & -44.980 & 0.000 & 0.361 & 0.393 \\
\hline N observations 717,009 & \multicolumn{7}{c}{ N failures 57,493 } & LR Chi2(12) 8117.5 \\
N individuals 91,066 & Time at risk & Log likelihood -504643.0 \\
& 717013 & Probability $>$ Chi2 0.000 \\
\hline
\end{tabular}

Table A4: Cox proportional-hazard model for the risk of naturalisation by immigrants' children born in the Netherlands - with two-year clusters of eligibility cohorts.

Note: other covariates included are EU origin country, Mother SES, Father SES, Both parents eligible. The model is stratified by mother's country of origin. 


\begin{tabular}{lcccccc}
\hline Variable & $\begin{array}{c}\text { Hazard } \\
\text { rate }\end{array}$ & $\begin{array}{c}\text { Std. } \\
\text { Error }\end{array}$ & $\mathbf{z}$ & $\mathbf{P}>\mathbf{z}$ & $\begin{array}{c}\text { [95\% Conf. } \\
\text { Interval] }\end{array}$ \\
\hline $\begin{array}{l}\text { Eligibility co- } \\
\text { hort } \\
\text { ref: 1995) }\end{array}$ & & & & & & \\
1996 & 0.990 & 0.016 & -0.600 & 0.549 & 0.958 & 1.023 \\
1997 & 0.860 & 0.015 & -8.490 & 0.000 & 0.831 & 0.891 \\
1998 & 0.781 & 0.015 & -13.090 & 0.000 & 0.752 & 0.810 \\
1999 & 0.719 & 0.015 & -15.840 & 0.000 & 0.690 & 0.749 \\
2000 & 0.656 & 0.014 & -19.600 & 0.000 & 0.629 & 0.684 \\
2001 & 0.645 & 0.014 & -19.890 & 0.000 & 0.617 & 0.673 \\
2002 & 0.579 & 0.013 & -23.860 & 0.000 & 0.554 & 0.606 \\
2003 & 0.474 & 0.012 & -30.590 & 0.000 & 0.452 & 0.497 \\
2004 & 0.440 & 0.011 & -32.500 & 0.000 & 0.419 & 0.463 \\
2005 & 0.402 & 0.010 & -37.170 & 0.000 & 0.383 & 0.422 \\
2006 & 0.398 & 0.010 & -36.820 & 0.000 & 0.379 & 0.418 \\
2007 & 0.421 & 0.011 & -32.030 & 0.000 & 0.399 & 0.443 \\
$\geq 2008$ & 0.383 & 0.008 & -45.360 & 0.000 & 0.368 & 0.400 \\
\hline N observations 717,009 & N failures 57,493 & LR Chi2(12) 8174.3 & \\
N individuals 91,066 & Time at risk & Log likelihood -504614.6 \\
& & 717013 & & Probability $>$ Chi2 0.000 \\
\hline
\end{tabular}

Table A5: Cox proportional-hazard model for the risk of naturalisation by immigrants' children born in the Netherlands - with year of eligibility.

Note: other covariates included are EU origin country, Mother SES, Father SES, Both parents eligible. The model is stratified by mother's country of origin. 


\begin{tabular}{|c|c|c|c|c|c|c|}
\hline \multirow{2}{*}{$\begin{array}{l}\text { Variable } \\
\text { Eligibility cohort } \\
\text { (ref: 1995-1997) }\end{array}$} & \multirow[t]{2}{*}{$\begin{array}{c}\text { Hazard } \\
\text { rate }\end{array}$} & \multirow[t]{2}{*}{$\begin{array}{l}\text { Std. } \\
\text { Error }\end{array}$} & \multirow[t]{2}{*}{$\mathbf{z}$} & \multirow[t]{2}{*}{$\mathbf{P}>\mathbf{z}$} & \multicolumn{2}{|c|}{$\begin{array}{l}\text { [95\% Conf. } \\
\text { Interval] }\end{array}$} \\
\hline & & & & & & \\
\hline $1998-2002$ & 0.585 & 0.014 & -22.120 & 0.000 & 0.558 & 0.613 \\
\hline 2003 and after & 0.198 & 0.006 & -57.490 & 0.000 & 0.187 & 0.209 \\
\hline $\begin{array}{l}\text { EU origin country } \\
\text { Mother SES } \\
\text { (ref: employed) }\end{array}$ & 0.336 & 0.015 & -23.840 & 0.000 & 0.307 & 0.368 \\
\hline Benefit recipient & 1.014 & 0.014 & 1.010 & 0.312 & 0.987 & 1.043 \\
\hline No income & 0.782 & 0.010 & -19.010 & 0.000 & 0.762 & 0.802 \\
\hline SES unknown & 0.530 & 0.015 & -22.750 & 0.000 & 0.502 & 0.560 \\
\hline $\begin{array}{l}\text { Father SES } \\
\text { (ref: employed) }\end{array}$ & & & & & & \\
\hline Benefit recipient & 0.906 & 0.011 & -8.330 & 0.000 & 0.886 & 0.928 \\
\hline No income & 0.504 & 0.011 & -31.310 & 0.000 & 0.483 & 0.526 \\
\hline SES unknown & 0.921 & 0.022 & -3.460 & 0.001 & 0.879 & 0.965 \\
\hline $\begin{array}{l}\text { Both parents are eli- } \\
\text { gible }\end{array}$ & 1.352 & 0.017 & 23.710 & 0.000 & 1.319 & 1.387 \\
\hline \multicolumn{7}{|c|}{ Interacted with $\ln (t)$} \\
\hline $\begin{array}{l}\text { Eligibility cohort } \\
\text { (ref: 1995-1997) }\end{array}$ & & & & & & \\
\hline 1998-2002 & 1.085 & 0.014 & 6.140 & 0.000 & 1.057 & 1.114 \\
\hline 2003 and after & 1.884 & 0.032 & 37.460 & 0.000 & 1.823 & 1.948 \\
\hline $\mathrm{N}$ observations 717,009 & & \multicolumn{2}{|c|}{ N failures 57,493} & \multicolumn{3}{|c|}{ LR Chi2(12) 9623.2} \\
\hline $\mathrm{N}$ individuals 91,066 & & \multicolumn{2}{|c|}{$\begin{array}{l}\text { Time at risk } \\
717013\end{array}$} & \multicolumn{3}{|c|}{$\begin{array}{l}\text { Log likelihood }-503890.1 \\
\text { Probability > Chi2 } 0.000\end{array}$} \\
\hline
\end{tabular}

Table A6: Cox proportional-hazard model for the risk of naturalisation by immigrants' children born in the Netherlands - main model with father's country of origin.

Note: the model is stratified by father's country of origin. 


\section{Cause-specific hazard models}

\begin{tabular}{|c|c|c|c|c|c|c|}
\hline Variable & $\begin{array}{c}\text { Hazard } \\
\text { rate }\end{array}$ & $\begin{array}{l}\text { Std. } \\
\text { Error }\end{array}$ & $\mathbf{z}$ & $\mathbf{P}>\mathbf{z}$ & \multicolumn{2}{|c|}{$\begin{array}{l}\text { [95\% Conf. } \\
\text { Interval] }\end{array}$} \\
\hline \multicolumn{7}{|l|}{$\begin{array}{l}\text { Eligibility cohort } \\
\text { (ref: 1995-1997) }\end{array}$} \\
\hline $1998-2002$ & 0.589 & 0.021 & -14.820 & 0.000 & 0.549 & 0.632 \\
\hline 2003 and after & 0.100 & 0.005 & -50.350 & 0.000 & 0.092 & 0.110 \\
\hline $\begin{array}{l}\text { EU origin country } \\
\text { Mother SES } \\
\text { (ref: employed) }\end{array}$ & 0.083 & 0.010 & -20.770 & 0.000 & 0.066 & 0.105 \\
\hline Benefit recipient & 0.877 & 0.022 & -5.330 & 0.000 & 0.836 & 0.921 \\
\hline No income & 0.741 & 0.016 & -13.680 & 0.000 & 0.710 & 0.774 \\
\hline SES unknown & 0.946 & 0.045 & -1.170 & 0.241 & 0.862 & 1.038 \\
\hline \multicolumn{7}{|l|}{$\begin{array}{l}\text { Father SES } \\
\text { (ref: employed) }\end{array}$} \\
\hline Benefit recipient & 0.961 & 0.019 & -2.000 & 0.045 & 0.924 & 0.999 \\
\hline No income & 0.270 & 0.013 & -27.150 & 0.000 & 0.246 & 0.297 \\
\hline SES unknown & 0.529 & 0.024 & -14.130 & 0.000 & 0.484 & 0.578 \\
\hline \multicolumn{7}{|c|}{ Interacted with $\ln (t)$} \\
\hline \multicolumn{7}{|l|}{$\begin{array}{l}\text { Eligibility cohort } \\
\text { (ref: 1995-1997) }\end{array}$} \\
\hline $1998-2002$ & 0.942 & 0.021 & -2.740 & 0.006 & 0.902 & 0.983 \\
\hline 2003 and after & 1.989 & 0.059 & 23.300 & 0.000 & 1.877 & 2.108 \\
\hline $\mathrm{N}$ observations 717,009 & & \multicolumn{2}{|c|}{$\mathrm{N}$ failures 21,857} & \multicolumn{3}{|c|}{ LR Chi2(12) 8646.3} \\
\hline $\mathrm{N}$ individuals 91,066 & & \multicolumn{2}{|c|}{ Time at risk } & \multicolumn{3}{|c|}{ Log likelihood -191099.9 } \\
\hline
\end{tabular}

Table A7: Cause-specific hazards model for the risk of naturalisation by immigrants' children born in the Netherlands - naturalisation with both parents.

Note: the model is stratified by mother's country of origin. 


\begin{tabular}{|c|c|c|c|c|c|c|}
\hline Variable & $\begin{array}{c}\text { Hazard } \\
\text { rate }\end{array}$ & $\begin{array}{l}\text { Std. } \\
\text { Error }\end{array}$ & $\mathbf{z}$ & $\mathbf{P}>\mathbf{z}$ & \multicolumn{2}{|c|}{$\begin{array}{c}\text { [95\% Conf. } \\
\text { Interval] }\end{array}$} \\
\hline \multicolumn{7}{|l|}{$\begin{array}{l}\text { Eligibility cohort } \\
\text { (ref: 1995-1997) }\end{array}$} \\
\hline $1998-2002$ & 0.547 & 0.019 & -17.460 & 0.000 & 0.511 & 0.585 \\
\hline 2003 and after & 0.298 & 0.011 & -32.140 & 0.000 & 0.276 & 0.320 \\
\hline $\begin{array}{l}\text { EU origin country } \\
\text { Mother SES } \\
\text { (ref: employed) }\end{array}$ & 0.284 & 0.017 & -20.780 & 0.000 & 0.252 & 0.319 \\
\hline Benefit recipient & 1.105 & 0.020 & 5.550 & 0.000 & 1.067 & 1.145 \\
\hline No income & 0.788 & 0.013 & -14.310 & 0.000 & 0.762 & 0.814 \\
\hline SES unknown & 0.438 & 0.015 & -23.460 & 0.000 & 0.409 & 0.469 \\
\hline \multicolumn{7}{|l|}{$\begin{array}{l}\text { Father SES } \\
\text { (ref: employed) }\end{array}$} \\
\hline Benefit recipient & 0.876 & 0.013 & -8.630 & 0.000 & 0.851 & 0.903 \\
\hline No income & 0.631 & 0.016 & -18.090 & 0.000 & 0.600 & 0.663 \\
\hline SES unknown & 0.996 & 0.028 & -0.130 & 0.894 & 0.943 & 1.052 \\
\hline \multicolumn{7}{|c|}{ Interacted with $\ln (t)$} \\
\hline \multicolumn{7}{|l|}{$\begin{array}{l}\text { Eligibility cohort } \\
\text { (ref: 1995-1997) }\end{array}$} \\
\hline $1998-2002$ & 1.256 & 0.024 & 11.930 & 0.000 & 1.210 & 1.304 \\
\hline 2003 and after & 1.783 & 0.040 & 25.720 & 0.000 & 1.706 & 1.863 \\
\hline $\mathrm{N}$ observations 717,009 & & \multicolumn{2}{|c|}{$\mathrm{N}$ failures 33,560} & \multicolumn{3}{|c|}{ LR Chi2(12) 3153.7} \\
\hline $\mathrm{N}$ individuals 91,066 & & \multicolumn{2}{|c|}{ Time at risk } & \multicolumn{3}{|c|}{$\begin{array}{l}\text { Log likelihood -295925.0 } \\
\text { Probability > Chi2 } 0.000\end{array}$} \\
\hline
\end{tabular}

Table A8: Cause-specific hazards model for the risk of naturalisation by immigrants' children born in the Netherlands - naturalisation with only one parent.

Note: the model is stratified by mother's country of origin. 


\section{Schoenfeld residuals}

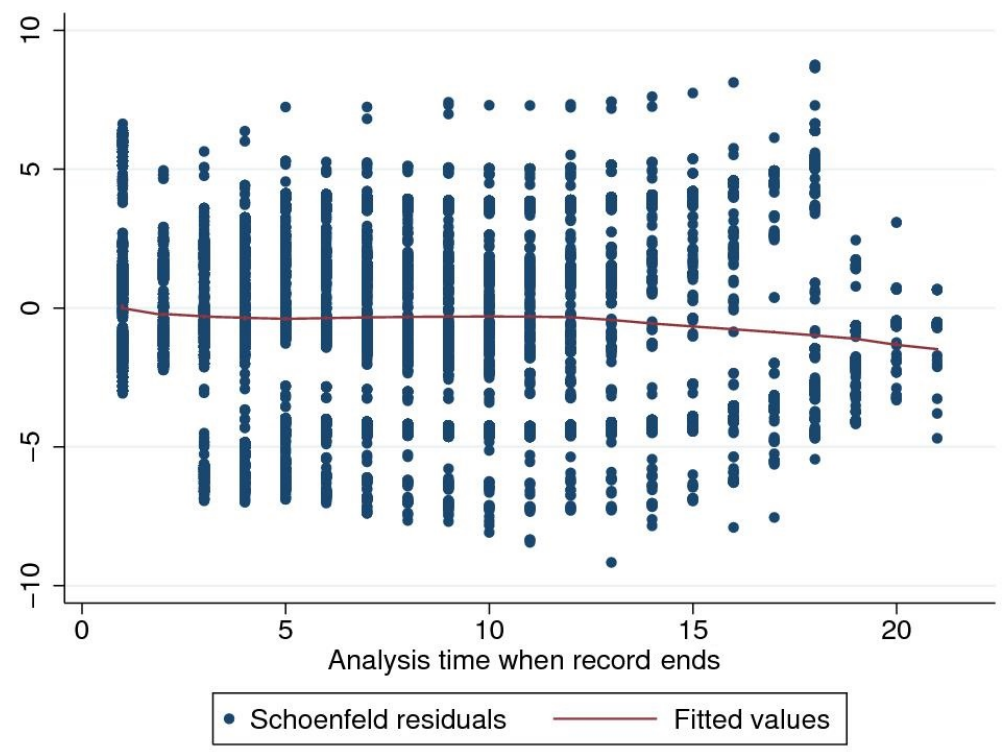

Figure A1: Test of the proportionality assumption for the Cox proportional-hazard model stratified by mother's country of origin without time-by-covariate interactions (model B): Schoenfeld residuals of the eligibility period 1998-2002 (ref. 1995-1997). 


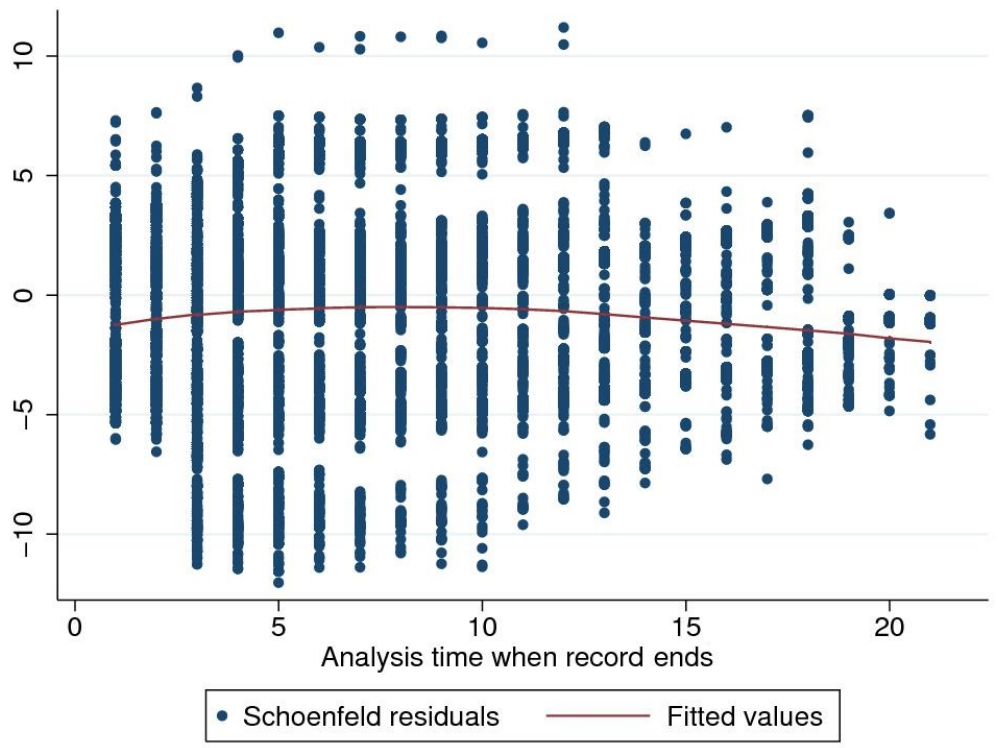

Figure A2: Test of the proportionality assumption for the Cox proportional-hazard model stratified by mother's country of origin without time-by-covariate interactions (model B): Schoenfeld residuals of the eligibility period 2003 and after (ref. 1995-1997). 


\section{Kaplan-Meier function}

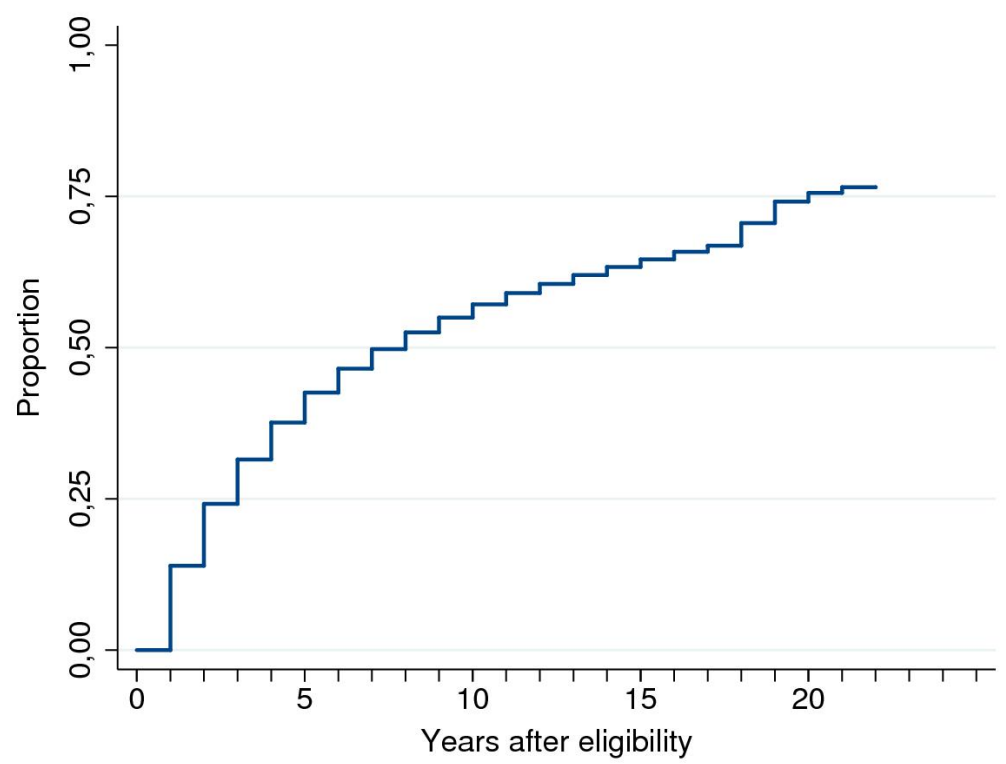

Figure A3: Acquisition of Dutch citizenship after birth by immigrants' children born in the Netherlands: Kaplan-Meier failure function ( $\mathrm{N}=91.066)$. 


\section{Naturalisation fees: historical development 2001-2020}

\begin{tabular}{cccc}
\hline Year & $\begin{array}{c}\text { Naturalisation } \\
\text { request for } \\
\text { one person }\end{array}$ & $\begin{array}{c}\text { Naturalisation } \\
\text { request together } \\
\text { with a partner }\end{array}$ & $\begin{array}{c}\text { Option } \\
\text { procedure } \\
\text { person) }\end{array}$ \\
\hline $\mathbf{2 0 0 1}$ & $€ 226$ & $€ 316$ & N.A. \\
$\mathbf{2 0 0 2}$ & $€ 272$ & $€ 363$ & $€ 110$ \\
$\mathbf{2 0 0 3}$ & $€ 336$ & $€ 427$ & $€ 128$ \\
$\mathbf{2 0 0 4}$ & $€ 344$ & $€ 437$ & $€ 131$ \\
$\mathbf{2 0 0 5}$ & $€ 348$ & $€ 442$ & $€ 132$ \\
$\mathbf{2 0 0 6}$ & $€ 351$ & $€ 446$ & $€ 133$ \\
$\mathbf{2 0 0 7}$ & $€ 358$ & $€ 454$ & $€ 136$ \\
$\mathbf{2 0 0 8}$ & $€ 366$ & $€ 464$ & $€ 139$ \\
$\mathbf{2 0 0 9}$ & $€ 380$ & $€ 492$ & $€ 144$ \\
$\mathbf{2 0 1 0}$ & $€ 567$ & $€ 719$ & $€ 148$ \\
$\mathbf{2 0 1 1}$ & $€ 789$ & $€ 1,008$ & $€ 168$ \\
$\mathbf{2 0 1 2}$ & $€ 798$ & $€ 1,019$ & $€ 170$ \\
$\mathbf{2 0 1 3}$ & $€ 810$ & $€ 1,035$ & $€ 173$ \\
$\mathbf{2 0 1 4}$ & $€ 821$ & $€ 1,048$ & $€ 175$ \\
$\mathbf{2 0 1 5}$ & $€ 829$ & $€ 1,058$ & $€ 177$ \\
$\mathbf{2 0 1 6}$ & $€ 840$ & $€ 1,072$ & $€ 179$ \\
$\mathbf{2 0 1 7}$ & $€ 855$ & $€ 1,091$ & $€ 182$ \\
$\mathbf{2 0 1 8}$ & $€ 866$ & $€ 1,105$ & $€ 184$ \\
$\mathbf{2 0 1 9}$ & $€ 881$ & $€ 1,124$ & $€ 187$ \\
$\mathbf{2 0 2 0}$ & $€ 901$ & $€ 1,150$ & $€ 191$ \\
\hline
\end{tabular}

Table A9: Evolution of administrative fees between 2001 and 2020, by type of citizenship acquisition procedure.

\section{Sources}

2001 Ministerie van Justitie (1999). Vernieuwde Handleiding voor de toepassing van de Rijkswet op het Nederlanderschap 1999, Circulaire aan de Burgemeester (Nr. 763352/99/ind). Staatscourant Nr. 204, 1 september 1999.

Ministerie van Justitie (2002). Verhoging naturalisatietarieven, Tussentijds Bericht Nationaliteiten (TBN 2002/2). Staatscourant Nr. 79, 24 april 2002.

2002 Ministerie van Justitie (2002). Verhoging naturalisatietarieven, Tussentijds Bericht Nationaliteiten (TBN 2002/2). Staatscourant Nr. 79, 24 april 2002. 
2003 De Minister voor Vreemdelingenzaken en Integratie (2003). Verhoging optiegelden en Naturalisatiegelden, Tussentijds Bericht Nationaliteiten (TBN 2003/1). Staatscourant Nr. 75, 16 april 2003.

2004 De Minister voor Vreemdelingenzaken en Integratie (2003). Indexeringsverhoging optiegelden en Naturalisatiegelden, Tussentijds Bericht Nationaliteiten (TBN 2003/4). Staatscourant Nr. 232, 1 december 2003.

2005 De Minister voor Vreemdelingenzaken en Integratie (2004). Tussentijds Bericht Nationaliteiten (TBN 2004/6). Staatscourant Nr. 242, 15 december 2004.

2006 De Minister voor Vreemdelingenzaken en Integratie (2005). Tussentijds Bericht Nationaliteiten (TBN 2005/7). Staatscourant Nr. 223, 16 november 2005.

2007 De Minister voor Vreemdelingenzaken en Integratie (2006). Tussentijds Bericht Nationaliteiten (TBN 2006/8). Staatscourant Nr. 242, 12 december 2006.

2008 Minister van Justitie (2007). Tussentijds Bericht Nationaliteiten (TBN 2007/13). Staatscourant Nr. 238, 7 december 2007.

2009 Minister van Justitie van het Koninkrijk (2008). Tussentijds Bericht Nationaliteiten TBN 2008/7, TBN-A 2008/4, TBN-NA 2008/3, Staatscourant Nr. 232, 28 november 2008.

2010 Minister van Justitie (2009). Besluit van de Minister van Justitie van 30 september 2009, nr. WBN 2009/3, houdende wijziging van de Handleiding voor de toepassing van de Rijkswet op het Nederlanderschap 2003. Staatscourant Nr. 15002, 1 oktober 2009.

2011 Minister van Justitie (2010). Besluit van de Minister van Justitie van 13 september 2010, nummer WBN 2010/11, houdende wijziging van de Handleiding voor de toepassing van de Rijkswet op het Nederlanderschap 2003. Staatscourant Nr. 14796, 1 oktober 2010.

2012 Minister van Binnenlandse Zaken en Koninkrijksrelaties (2011). Besluit van de minister van Binnenlandse Zaken en Koninkrijksrelaties van 5 oktober 2011, nr. WBN 2011/1, houdende wijziging van de Handleiding voor de toepassing van de Rijkswet op het Nederlanderschap 2003. Staatscourant Nr. 18672, 17 oktober 2011.

2013 Minister van Binnenlandse Zaken en Koninkrijksrelaties (2012). Besluit van de Minister van Binnenlandse Zaken en Koninkrijksrelaties van 13 augustus 2012, nummer WBN 2012/6, houdende wijziging van de Handleiding voor de toepassing van de Rijkswet op het Nederlanderschap 2003. Staatscourant Nr. 17435, 29 augustus 2012.

2014 Staatssecretaris van Veiligheid en Justitie (2013). Besluit van de Staatssecretaris van Veiligheid en Justitie van 5 augustus 2013, nummer WBN 2013/4, houdende wijziging van de Handleiding voor de toepassing van de Rijkswet op het Nederlanderschap 2003. Staatscourant Nr. 22989,16 augustus 2013. 
2015 Staatssecretaris van Veiligheid en Justitie (2014). Besluit van de Staatssecretaris van Veiligheid en Justitie van 13 augustus 2014, nummer WBN 2014/6, houdende wijziging van de Handleiding voor de toepassing van de Rijkswet op het Nederlanderschap 2003. Staatscourant Nr. 23950, 22 augustus 2014.

2016 Staatssecretaris van Veiligheid en Justitie (2015). Besluit van de Staatssecretaris van Veiligheid en Justitie van 17 augustus 2015, nummer WBN 2015/5, houdende wijziging van de Handleiding voor de toepassing van de Rijkswet op het Nederlanderschap 2003. Staatscourant Nr. 27136, 31 augustus 2015.

2017 Staatssecretaris van Veiligheid en Justitie (2016). Besluit van de Minister van Veiligheid en Justitie van 19 september 2016, nummer WBN 2016/4, houdende wijziging van de Handleiding voor de toepassing van de Rijkswet op het Nederlanderschap 2003. Staatscourant Nr. 51216, 30 september 2016.

2018 Staatssecretaris van Veiligheid en Justitie (2017). Besluit van de Staatssecretaris van Veiligheid en Justitie van 7 september 2017, nummer WBN 2017/4, houdende wijziging van de Handleiding voor de toepassing van de Rijkswet op het Nederlanderschap 2003. Staatscourant Nr. 52202, 18 september 2017.

2019 Staatssecretaris van Veiligheid en Justitie (2018). Besluit van de Staatssecretaris van Justitie en Veiligheid van 10 september 2018, nummer WBN 2018/3, houdende wijziging van de Handleiding voor de toepassing van de Rijkswet op het Nederlanderschap 2003. Staatscourant Nr. 52221, 20 september 2018.

2020 Staatssecretaris van Veiligheid en Justitie (2019). Besluit van de Staatssecretaris van Justitie en Veiligheid van 3 september 2019, nummer WBN 2019/3, houdende wijziging van de Handleiding voor de toepassing van de Rijkswet op het Nederlanderschap 2003. Staatscourant Nr. 49997, 13 september 2019.

\section{Construction of the eligibility variable}

\section{Definition of eligibility}

To become eligible for Dutch citizenship, several conditions must be satisfied $^{1}$. First, prospective citizens should have lived uninterruptedly in the Netherlands for at least five years, with a valid residence permit. During this

\footnotetext{
${ }^{1}$ See the Immigration and Naturalisation Service, https://ind.nl/en/ dutch-citizenship/Pages/Naturalisation.aspx [accessed May 29, 2019].
} 
five-year period prior to naturalisation, they should not have been convicted or sentenced to a conditional discharge for a crime. Finally, prospective citizens should not have any ongoing criminal proceedings against them when applying for nationalisation. As we do not have access to information about individuals' criminal records, we base eligibility on the sole required length of legal residence in the Netherlands. Parents' eligibility is therefore proxied by the number of years they have stayed in the Netherlands.

\section{From parents to children}

We then construct children's eligibility based on the eligibility of their parents:

- When children are minors, they are considered eligible as soon as (one of) their parents become themselves eligible (co-naturalisation).

- When children are above 18 , they are considered as eligible if they have stayed permanently in the Netherlands since birth (option procedure).

- When children are above 18 and have not stayed permanently in the Netherlands since birth, they are eligible after five years of uninterrupted residence in the Netherlands (standard naturalisation).

\section{Circular migration}

For each parent, a counter counts the number of continuous years of residence in the Netherlands, while a dummy variable equals one when the counter exceeds five years. In case of circular migration, the counter starts again at zero from the moment the individual comes back to the Netherlands. This reflects the requirement of uninterrupted residence in the Netherlands; if immigrants leave the country and are de-registered, they need to wait another five-year period upon their return in the Netherlands to become eligible. There is however one exception to this rule: when individuals have accumulated ten years of - potentially interrupted - residence in the Netherlands, they can become eligible after two years of residence. Unfortunately, this exception is difficult to take into account due to data restriction, since individuals are only observed from 1995 onwards. Besides, these provisions are not very common: 
Appendix A

over the period 2014-2017 they were associated with around 100-150 annual naturalisations, which represents about $1 \%$ of all naturalisations ${ }^{2}$.

${ }^{2}$ See the last report Monitor Naturalisatie en optie, https://ind.nl/Documents/2018\% 20Monitor\%20naturalisatie\%20en\%20optie\%202014-2017.pdf [accessed May 29, 2019]. 


\section{Robustness checks}

Several specifications were compared to assess the robustness of our main model, visualised in Figure A4.

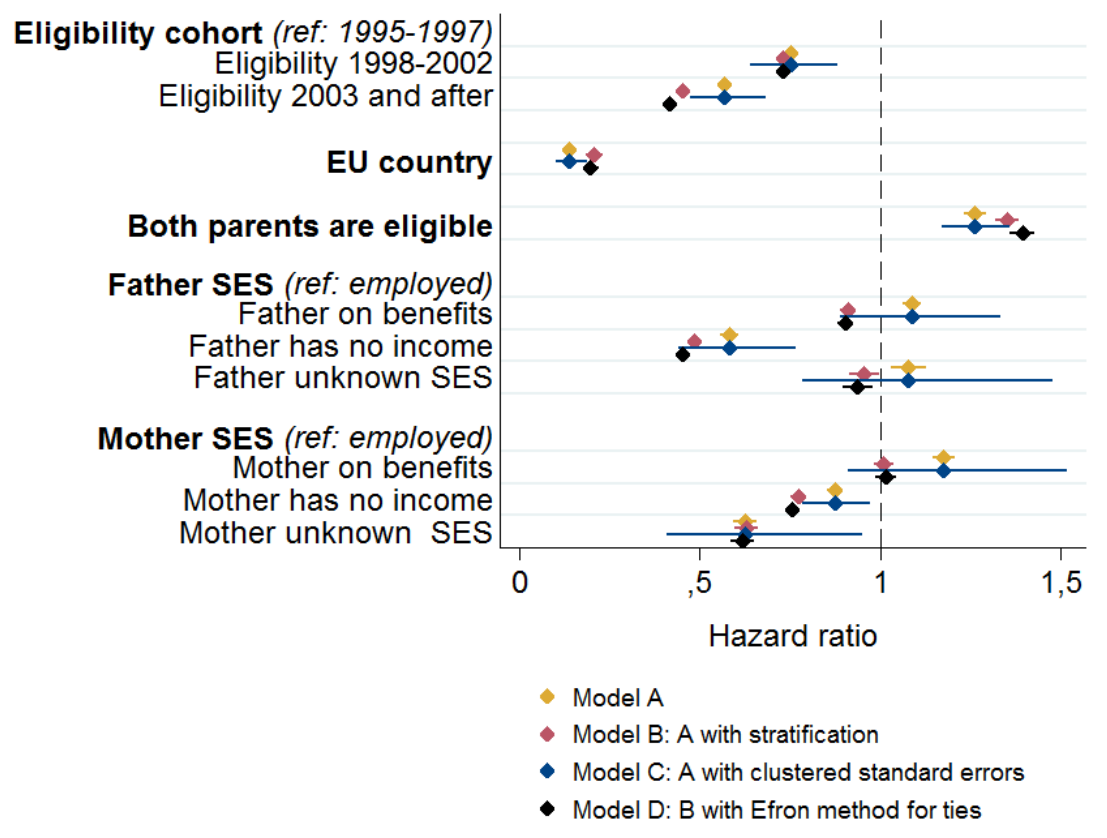

Figure A4: Acquisition of Dutch citizenship after birth by immigrants' children born in the Netherlands: coefficient plot based on Cox regression models A to D.

We first model duration until naturalisation without stratifying by mother's country of origin and without any interaction with time (Model A). While the stratification is added in Model B, we instead cluster the standard errors by country of origin in Model C. This relaxes the hypotheses of independent observations and allows taking into account potential intra-cluster correlation at the country level, without making any assumption about the nature of this correlation. In that sense, Model C is more conservative than Model $\mathrm{B}$ and gives accordingly larger confidence intervals. The estimation of the coefficients for the eligibility cohorts are still sufficiently precise to preserve our earlier interpretation of a detrimental impact of naturalisation laws, but 


\section{Appendix A}

the overlap of the confidence intervals nuances the idea that there is a clear added disadvantage for those eligible from 2003 onwards.

Overall, alternative specifications $A$ to $C$ provide estimates that are quite similar to those obtained in the main model, with the exception of those associated with the last eligibility category. However, these models estimate the effect of the eligibility cohort without time interaction terms, which amounts to estimating an average effect of the eligibility cohort over time, assuming it is constant. Yet, as could be seen in Figure 3.5 (in manuscript), the effect associated with the last eligibility category varies greatly over time, from close to zero to above one, which is rather consistent with an average effect of around 0.5. Besides, Figure 3.5 also shows that between approximately five and ten years since eligibility, the confidence intervals associated with the second and third categories of eligibility partly cross each other, which is in line with the overlapping confidence intervals of Model C. In conclusion, these different models do not substantively alter our prior interpretation.

A last specification deals with the presence of tied events in our dataset, which may be a point of concern. Indeed as naturalisation date is measured in years, we do not precisely identify the ordering of naturalisation times. In Model D, we estimate model B with the Efron method for ties, which is more precise than the standard Breslow approximation. Figure A4 shows that the estimates between models B and D are comparable.

The same procedure has been followed to check the robustness of the causespecific hazards model, the results are displayed on Figure A5. 


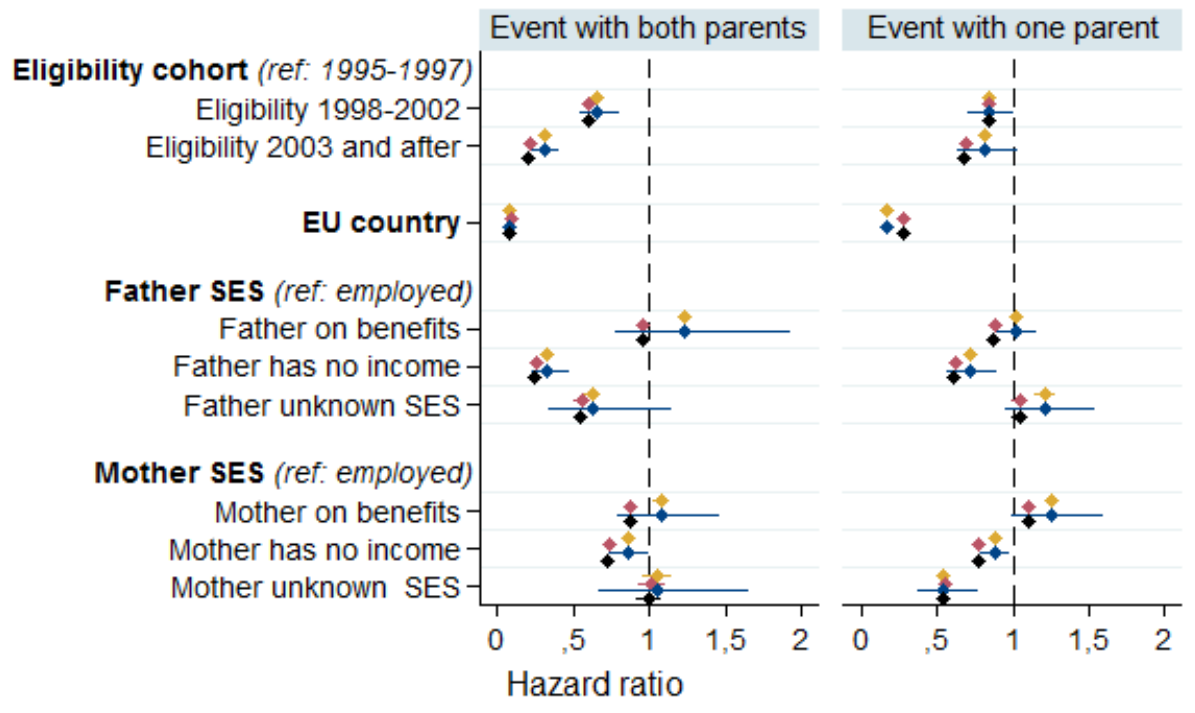

$\rightarrow$ Model A

- Model B: A with stratification

- Model C: A with clustered standard errors

- Model D: B with Efron method for ties

Figure A5: Acquisition of Dutch citizenship after birth by immigrants' children born in the Netherlands: coefficient plot for the cause-specific hazards models A to D. 



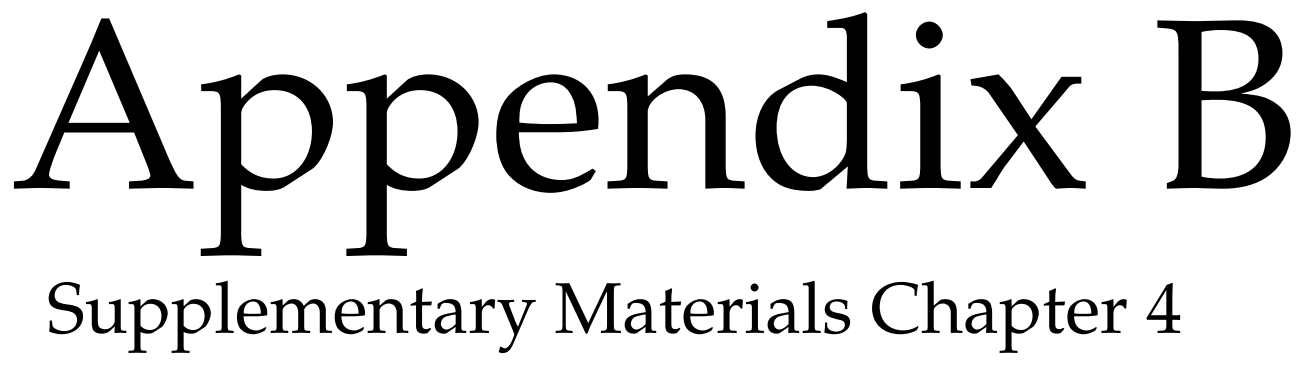




\section{Contents}

\begin{tabular}{|c|c|c|}
\hline $\mathrm{I}$ & Descriptive statistics & 248 \\
\hline II & $\begin{array}{l}\text { Technical Appendix: Optimal matching between sequences } \\
\text { of transitions }\end{array}$ & 252 \\
\hline III & Technical Appendix: Robustness of the cluster solution & 258 \\
\hline IV & Full description of the covariates. & 260 \\
\hline $\mathrm{V}$ & Additional outputs for the sequence analysis . & 264 \\
\hline VI & Full regression models. & 267 \\
\hline VII & Robustness checks. & 274 \\
\hline
\end{tabular}

\section{Descriptive statistics}

\begin{tabular}{lrr}
\hline & $\mathbf{N}$ & $\mathbf{\%}$ \\
\hline Gender & & \\
Male & 6,433 & 51.4 \\
Female & 6,072 & 48.6 \\
Age & & \\
10 & 46 & 0.4 \\
11 & 4,815 & 38.5 \\
12 & 6,571 & 52.6 \\
13 & 1,049 & 8.4 \\
14 and older & 24 & 0.0 \\
First born & & \\
Non first-born & 8,265 & 66,1 \\
First-born & 4,240 & 33,9 \\
Mother's country of birth & & \\
Turkey & 4,519 & 36.1 \\
Morocco & 4,270 & 34.2 \\
Yugoslavia & 530 & 4.2 \\
China & 355 & 2.8 \\
Iraq & 176 & 1.4 \\
Iran & 125 & 1.0 \\
Afghanistan & 92 & 0.7 \\
& Continued
\end{tabular}

Table B1: Overview of the sample with sociodemographic characteristics measured at the start of the observation period. 


\begin{tabular}{|c|c|c|}
\hline & $\mathbf{N}$ & $\%$ \\
\hline Other non-EU countries & 2,036 & 16.3 \\
\hline Other EU countries & 402 & 3.2 \\
\hline \multicolumn{3}{|l|}{ Father's country of birth } \\
\hline Same as mother's one & 11,504 & 92.0 \\
\hline Different from mother's one & 1,001 & 8.0 \\
\hline \multicolumn{3}{|l|}{ Language spoken at home } \\
\hline Dutch & 2,186 & 17.5 \\
\hline Turkish & 2,093 & 16.7 \\
\hline Arabic & 1,588 & 12.7 \\
\hline Other language & 1,224 & 9.8 \\
\hline Dutch and Turkish & 860 & 6.9 \\
\hline Dutch and Arabic & 882 & 7.1 \\
\hline Dutch and other languages & 543 & 4.3 \\
\hline Missing & 3,129 & 25.0 \\
\hline \multicolumn{3}{|l|}{ Household type } \\
\hline Two-parent household - married couple & 9,718 & 77.5 \\
\hline Two-parent household - non-married couple & 506 & 4.0 \\
\hline Single-parent household & 2,257 & 18.1 \\
\hline Missing & 24 & 0.2 \\
\hline \multicolumn{3}{|l|}{ Father SES } \\
\hline Employee & 6,690 & 53.5 \\
\hline Self-employed & 1,295 & 10.4 \\
\hline Reception of benefits & 3,412 & 27.3 \\
\hline No declared income & 653 & 5.2 \\
\hline Missing SECM & 455 & 3.6 \\
\hline \multicolumn{3}{|l|}{ Mother SES } \\
\hline Employee & 4,126 & 33.0 \\
\hline Self-employed & 724 & 5.8 \\
\hline Reception of benefits & 3,958 & 31.7 \\
\hline No declared income & 3,598 & 28.8 \\
\hline Missing SECM & 99 & 0.8 \\
\hline \multicolumn{3}{|l|}{ Homeownership } \\
\hline At least one parent is a homeowner & 4,080 & 32.6 \\
\hline No parent is a homeowner & 8,398 & 67.2 \\
\hline Missing & 27 & 0.2 \\
\hline \multicolumn{3}{|l|}{ Father's education level } \\
\hline Low & 4,759 & 38.1 \\
\hline
\end{tabular}

Table B1 Continued: Overview of the sample with sociodemographic characteristics measured at the start of the observation period. 


\begin{tabular}{lrr}
\hline & $\mathbf{N}$ & $\%$ \\
\hline Middle & 2,169 & 17.4 \\
High & 824 & 6.6 \\
Missing & 4,753 & 38.0 \\
Mother's education level & \\
Low & 6,404 & 51.2 \\
Middle & 1,859 & 14.9 \\
High & 596 & 4.8 \\
Missing & 3,646 & 29.2 \\
Highest education level in the household & & \\
Low & 5,905 & 47.2 \\
Middle & 3,198 & 25.6 \\
High & 1,240 & 9.9 \\
Missing & 2,162 & 17.3 \\
Mother's years since migration & & \\
0-15 & 3,930 & 31,4 \\
16-25 & 5,348 & 42,8 \\
over 25 & 3,227 & 25,8 \\
Father's years since migration & & \\
0-15 & 4,165 & 33,3 \\
16-25 & 4,277 & 34,2 \\
over 25 & 4,063 & 32,5 \\
TOTAL & 12,505 &
\end{tabular}

Table B1 Continued: Overview of the sample with sociodemographic characteristics measured at the start of the observation period.

\begin{tabular}{lcccc}
\hline & Mean & Median & Std. dev. & $\begin{array}{c}\text { Missing } \\
\text { N (\%) }\end{array}$ \\
\hline N. of children in the household & 2.78 & 3.00 & 1.26 & $77(0.6)$ \\
Standardised disposable income $(€)$ & 16229.96 & 14847.00 & 7420.61 & $172(1.4)$ \\
Score obtained at the Cito test & 529.52 & 530.00 & 10.16 & $2889(23.1)$ \\
\hline
\end{tabular}

Table B2: Overview of the sample with numerical characteristics measured at the start of the observation period, excepted the Cito score measured the year before. 
N $\%$

\section{Citizenship status of the child} 2008 (start)

Dutch from birth

$5,724 \quad 45.8$

Naturalised

$4,881 \quad 39.0$

Non-naturalised

$1,900 \quad 15.2$

2016 (end)

Dutch from birth

$5,724 \quad 45.8$

Naturalised individuals

Non-naturalised

$5,941 \quad 47.5$

$840 \quad 6.7$

Table B3: Legal status of the child measured at the start and the end of the observation period.

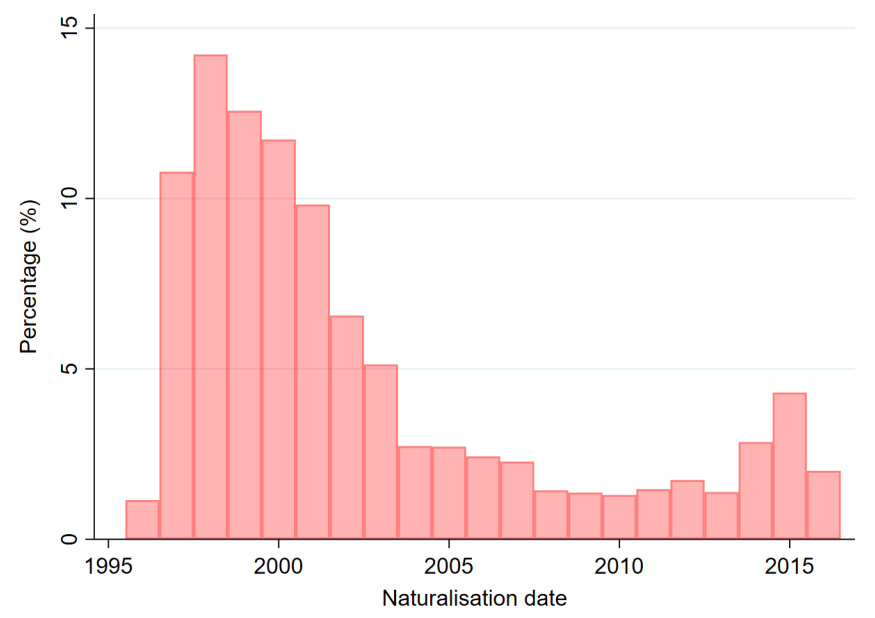

Figure B1: Distribution of naturalisation date (in \%) among the children born as foreign citizens. 


\section{Technical Appendix: Optimal matching between sequences of transitions}

This Appendix describes in more detail the construction of the distance we use for the Optimal Matching (OM) between sequences of transitions. While Table B4 gives the full matrix we use to shift the sequence elements from states to transitions, Tables B5 and B6 indicate the substitution and indel costs we use to assess the level of dissimilarity between sequences.

\section{Alphabet and number of possible transitions}

Before detailing the construction of the distance, it is important to note that Biemann's approach tends to complicate the cost settings. Indeed, compared to the standard approach, building the sequences based on the transitions considerably increases the size of the alphabet (see Table 4.2 for a comparison). However, there are at least two ways to mitigate this issue. First, it is possible, based on theoretical expectations, to reduce the size of the substitution cost matrix by only distinguishing between the states that are qualitatively different and aggregating similar types of transitions (Biemann, 2011, p.215). Second, it is possible to calculate the costs of transitions based on the costs of states using a formula developed by Studer and Ritschard (2016, p.495). In this paper, we use Biemann's theoretical approach to bring further evidence that transition-oriented OM provides "a stronger link between social science theory and methods" (Biemann, 2011, p219).

To implement OM between sequences of transitions, we consider 12 states, including an artificial start state (see details in section 4). This alphabet corresponds to $(11+1) * 11=132$ possible transitions, which requires us to set the substitution costs for $((132+1) * 132) / 2$ or about 9,000 pairs of transitions (assuming that the substitution costs are symmetric). However, if we cluster the transitions into 8 categories, the substitution costs matrix is brought down to a manageable size, with $((8+1) * 8) / 2=36$ costs left to define. ${ }^{1}$

\section{Setting of the substitution and indel costs}

We took into consideration two main aspects when setting the costs. First, the distance should satisfy the axioms of a metric and notably the triangle

\footnotetext{
${ }^{1}$ In practice the number of costs to define is even smaller because transitions including the start state are not substitutable by all other transitions (see Table B5).
} 
inequality, which states that "when two objects ( $x$ and $z$ ) are close to a third object (y), they cannot be remote from each other" (Elzinga and Studer, 2015, p8). This mathematical condition is crucial to ensure that the space in which we quantify the distances exhibits coherence and regularity. Another important aspect is that the cost setting determines the sensitivity of the distance to timing, duration and sequencing (Studer and Ritschard, 2016). By design, $\mathrm{OM}$ between sequences of transitions is sensitive to the latter, i.e. to the order of the distinct successive states. However, the setting of substitution and indel costs enables us to further highlight transition patterns in students' educational trajectories.

Substitution costs We use the substitution costs to further emphasise differences in educational mobility between tracks, so as to identify nonstandard trajectories. Table B5 gives the full substitution costs matrix. The top left block of the matrix indicates that there is no cost in substituting a starting transition by one other, while the bottom right block specifies different costs for substituting subsequent transitions. The two most expensive edit operations are to replace a given transition by an upward $(c=3)$ or dropout $(c=2.5)$ transition, since these are expected to have a lasting impact on students' future career and opportunities. Conversely, substituting a given transition with an exit transition comes at the lowest cost (1.5), so as not to over-emphasise the significance of temporary discontinuities.

Indel costs Table B6 indicates the costs for inserting or deleting each category of transition. When indel operations are used, time is warped so that to align identical transition elements (Lesnard, 2010, p394). In our case, it is important to allow time warping for standard transitions, as students may repeat - or more exceptionally skip - a grade during their educational career. Consequently, we set the indel cost for standard transitions at around $1 / 30$ the largest substitution cost, which is $3^{2}$. For the other categories of transitions, we set large indel costs so that substitutions are always favoured. This ensures that we preserve the sequencing of non-standard transitions. These costs also ensure that the triangular inequality is met.

\footnotetext{
${ }^{2}$ The literature usually recommends to set the indel costs at around $1 / 10$ the largest substitution cost (Brzinsky-Fay et al., 2006, p450). However, considering the length of our observation period, it was necessary to lower this ratio down to $1 / 30$ for decreasing the effect of timing.
} 
Appendix B

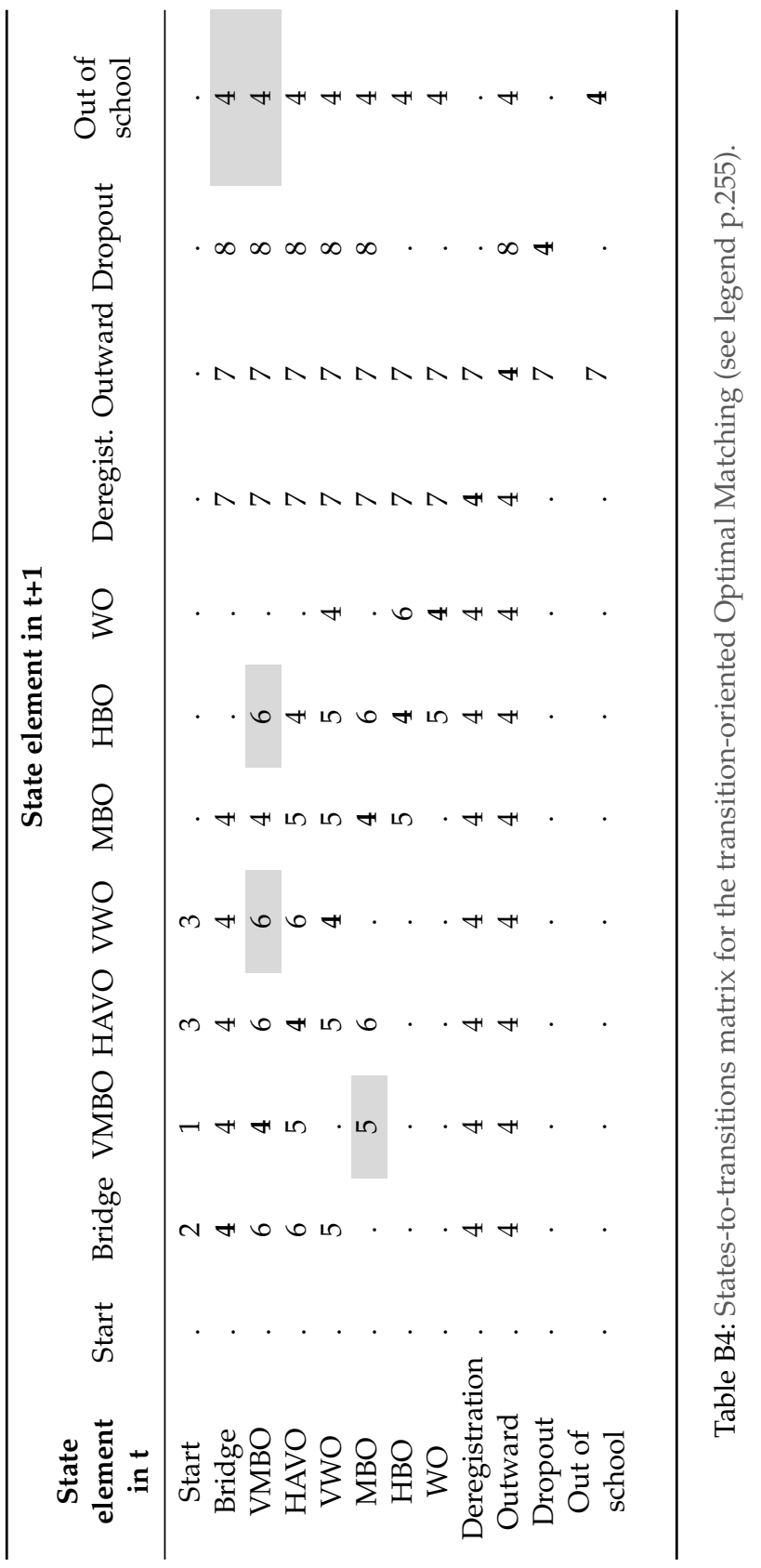


Supplementary Materials Chapter 4

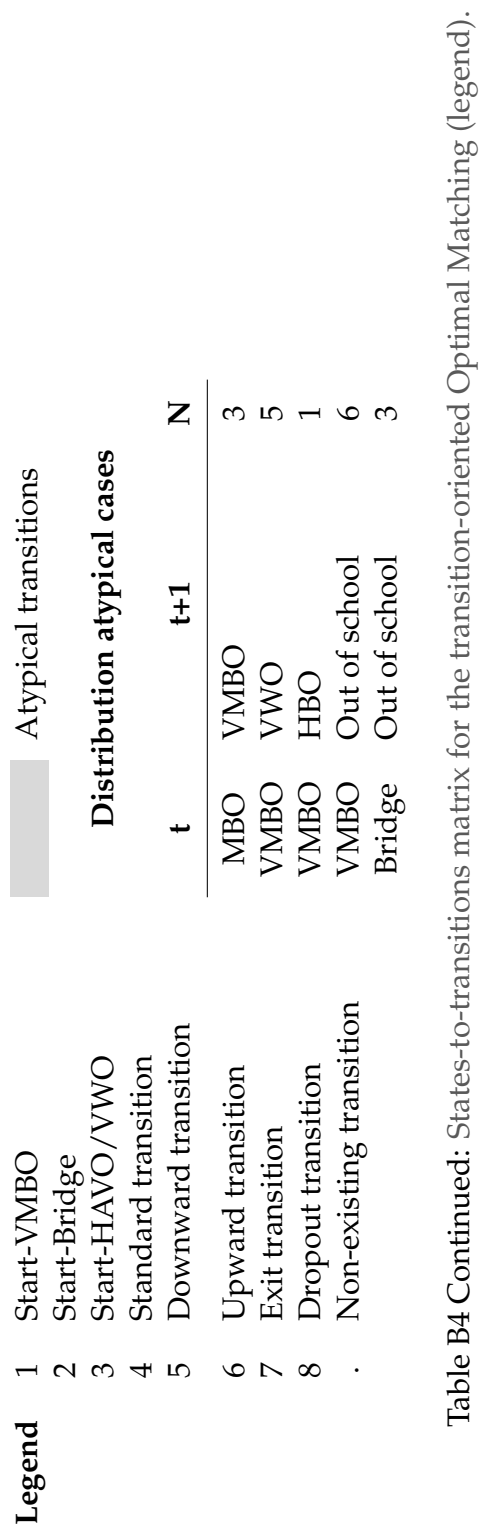




\section{Appendix B}

The underlying rationale for this cost setting is that our aim is to measure similarity between students based on their mobility profiles - that is, on whether they are moving or not between tracks and if so, how - rather than on the specific tracks in which they are enrolled. To put it differently, according to this edit function, we consider that two students starting out in different tracks and being upwardly mobile are more similar than two individuals starting in the same track but following diverging paths. Likewise, the chosen cost setting gives priority to the presence or absence of a given non-standard transition, at the expense of their timing or frequency. We do so because our theoretical mechanisms mainly relate to the type of transitions that students experience, rather than to the number of transitions or their timing. There is indeed ample evidence that in stratified school systems, parents need resources to negotiate a given track for their children. By contrast, little is known about how these resources are related to the timing or the number of non-standard transitions, and whether such patterns are important for the meaning of the transitions.

Finally, it is important to stress that other cost settings could have been used, since the values chosen for the ratios between the costs are arbitrary (Studer and Ritschard, 2016, p491). However, transitions can be ranked according to their nature based on theoretical grounds, which enhances transparency and results in a closer link between theory and method (Biemann, 2011). 

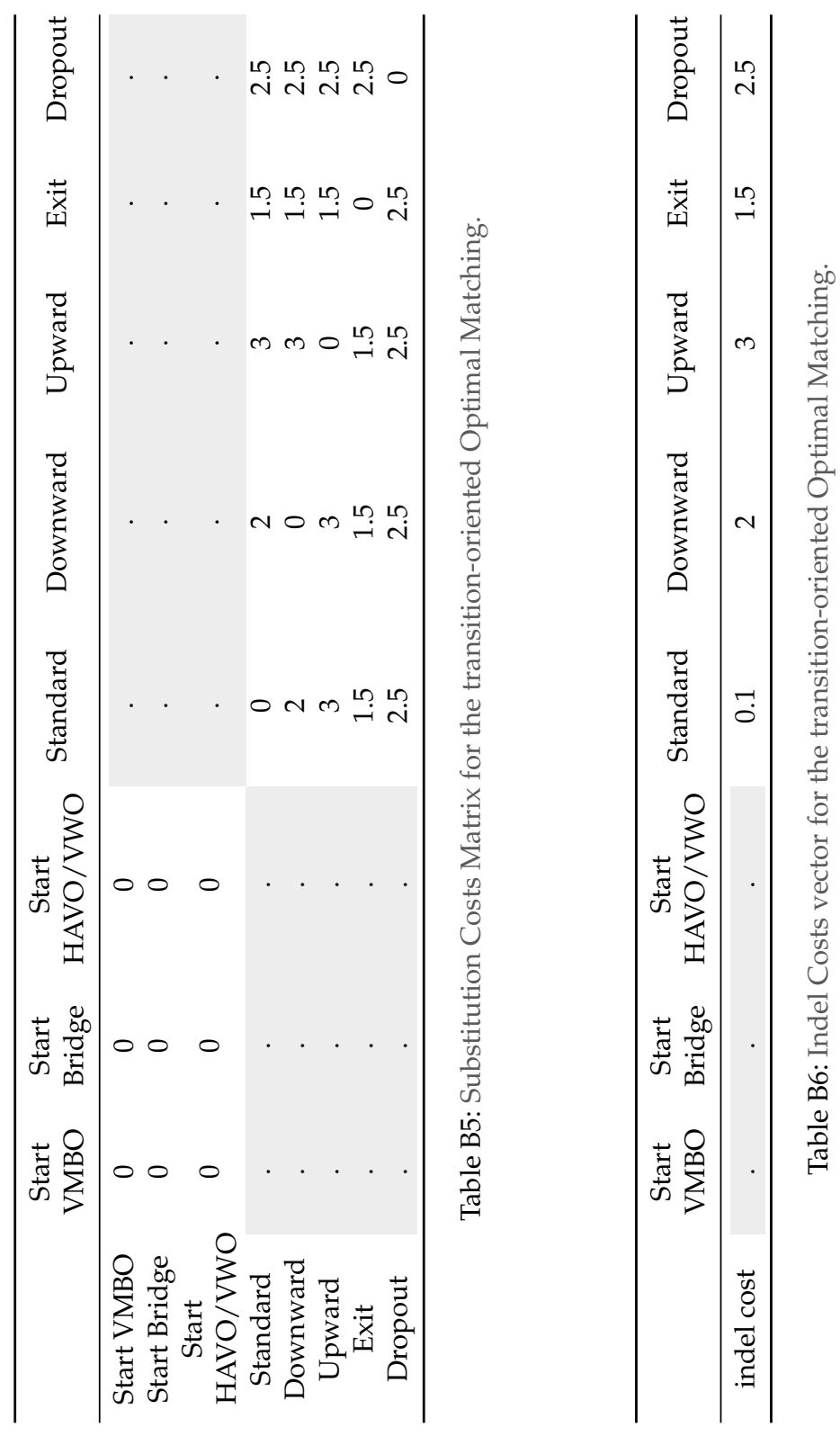


\section{Technical Appendix: Robustness of the cluster solution}

To assess the stability of the partition, we group sequences using two different algorithms:

Ward Ward's algorithm is a hierarchical agglomerative method which joins groups so that to minimise the error-sum-of-squares (Ward, 1963). Although this method is very popular, it has a number of limitations: it assumes that points can be represented in Euclidean space, tends to find same-size and spherical clusters and is sensitive to outliers (Everitt, 2011, p.89).

PAM The Partition around medoids (PAM) is a partitional algorithm developed by Kaufman and Rousseeuw (1990), which groups the sequences into a pre-defined number of clusters, based on the clusters' medoids. This method is less sensitive to outlying values, but assumes that the number of clusters is known a priori.

As Ward's algorithm suggests that the optimal number of clusters is below ten, we implement the PAM algorithm for $k \leq 10$ clusters. We further use the medoids obtained from Ward's partitions as seeds for the partition around medoids algorithm. Yet, we also analyse cluster solutions obtained with seeds generated with a genetic algorithm. While cluster quality is overall equally good (see Figure B2), using the Ward's medoids as starting points slightly increases the analytical quality of the clusters. We therefore refer to PAM based on Ward's medoids in the following.

Overall, results are relatively comparable between Ward's and PAM algorithms, leading to similar cluster partition and interpretation. As Figure B2 shows, the resulting partitions are very similar in terms of global cluster quality. However, Ward's local cluster quality is generally more heterogeneous with a combination of very high- and low-quality groupings: while numerous clusters have an average silhouette width around 0.8 , others have a substantial share of miss-classified cases $(A S W<0)$. We therefore use the PAM algorithm for our main analysis, to ensure a reasonable classification of cases across all clusters. 


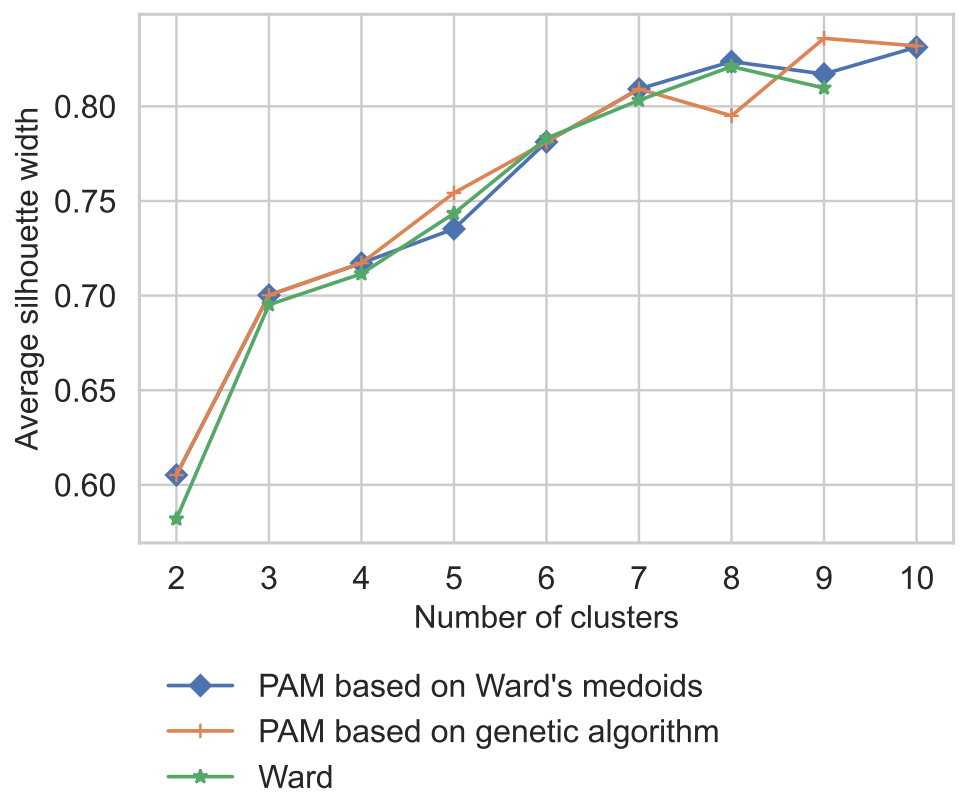

Figure B2: Comparison of the Average silhouette width between three different clustering algorithms. 


\section{Full description of the covariates}

See Table B7 on p.263 for an overview of the full set of covariates.

\section{Note on Cito score}

A substantial share (23\%) of students in our sample did not take the Cito standardised test at the end of primary school. This can be for different reasons: some primary schools do not offer any test (this is common in special primary education, SBO), while others have a different test provider than Cito. Unfortunately, there is very little external information about the profiles of such schools in the considered year. We have checked in our sample whether schools without a Cito test are systematically different from those with a Cito test in terms of their students' sociodemographic characteristics (results available upon request). It seems that students that are enrolled in a school without the test come from a slightly more disadvantaged social background than those who take the test. However, the differences are limited (2 percentage points at most).

\section{Note on parental educational level}

Unfortunately, information on the educational level of first generation parents is very limited in the Dutch register data, especially in the 1990s and 2000s. To maximise the coverage, Statistics Netherlands obtains or derives information on education level from various registers and the Labor Force Survey. ${ }^{3}$ However, although information on education level exists for an increasing share of the population, reaching 58\% in 2012 (Gans et al., 2015), information is still missing for a substantial group of individuals, specifically for older cohorts and immigrants. Moreover, the level of education tends to be underestimated in administrative data because education abroad or at private institutions is difficult to take into account. As a result, an imputed educational level is available in the most recent registers. Since first-generation immigrants are particularly at risk of having their educational level underestimated, we use the imputed level of education whenever available. This

\footnotetext{
${ }^{3}$ This combination of register and survey data requires the use of weights to get a representative measure of education for the entire Dutch population. However, the weights are not meant to ensure representativity for the sub-population of first generation immigrants alone; they have therefore not been used.
} 
measure of education is more reliable but it is also more recent, which introduces a risk of anticipatory analysis, i.e., explaining students' current outcomes by the future characteristics of their parents (see Hoem and Kreyenfeld, 2006). Nevertheless, parents' education level is arguably relatively stable from the moment their children enter secondary education, ${ }^{4}$ which justifies treating it as a time-constant characteristic in the absence of any more reliable information. We take the highest education level obtained among parents, and distinguish between low (primary education), middle (completed some secondary education), and high (bachelor or higher). Missing values, which still represent a non-negligible share $(17.3 \%)$, are coded as a separate category.

\section{Note on parental date of arrival in the Netherlands}

Parents' initial date of arrival is difficult to identify in Dutch register data for several reasons. First, immigrants are only present in the registers when they are registered as residents of the Netherlands, which creates gaps in the event of repeated migration moves. Second, the registers needed for this paper only start in 1995, which means that we can only observe migration moves on a yearly basis from 1995 onwards. This is problematic, because the vast majority $(91.5 \%)$ of immigrant parents in our population of interest arrived in the Netherlands before 1995 at the earliest. We have nonetheless a variable for immigrants' last migration move, which is correct when parents have stayed registered in the Netherlands since 1995. In our sample, 1,319 (10.6\%) mothers and 2,610 (20.9\%) fathers are identified as leaving the Netherlands at some point between 1995 and 2016, and, thus, have an unknown date of arrival in the Netherlands. We replace missing values by a minimum bound: the age of the parents' child. As their children are necessarily born on Dutch soil, we can reasonably assume that the parents arrived in the Netherlands at least at the time of the birth. ${ }^{5}$ On the one hand, this approximation may underestimate the amount of time parents have stayed in the Netherlands. On the other hand, this concerns parents who have moved back and forth to the Netherlands during the childhood or youth of their child. As years since migration is used to proxy the knowledge and language parents acquire over time, it

\footnotetext{
${ }^{4}$ When looking at non-missing cases, $17.0 \%$ of mothers and $18.1 \%$ of fathers have more than one level of education recorded during the period under observation. Note that this gives an upper bound for variation in parental education level over time, because the measure relies on a very detailed classification of educational credentials.

${ }^{5}$ Note that this is more accurate for mothers than for fathers, since parents are not necessarily moving together.
} 


\section{Appendix B}

is arguably reasonable to assume that those who are not permanently settled do not become familiar with the Dutch context to the same extent as those who stay continuously. As a robustness check, we run the models with a separate category for the missing values. While imputation has some effect on the coefficients for years since migration, this does not affect the citizenship coefficients (results available upon request). 


\begin{tabular}{lll}
\hline Variable & Measurement & Description/Caveats \\
\hline Variable of interest & $\begin{array}{l}\text { This variable is based on observed } \\
\text { changes in the respondent's registered } \\
\text { nationalities. It is censored at the start } \\
\text { of the observation period in the main } \\
\text { model. A robustness check includes } \\
\text { the variable censored at the end of the } \\
\text { observation period (see Figure B6). }\end{array}$
\end{tabular}

\section{Sociodemographic variables}

Gender

1. Male

2. Female

$\mathrm{EU} /$ non-EU

Dummy: mother's

or father's country of

birth is a member state

of the European Union.

\section{Number of children in Number}

the household

The variable indicates the number of individuals below 18 living in the same household as the respondent. Note that this may differ from the respondent's actual number of siblings.

$\begin{array}{ll}\text { Type of household } & \text { 1. Two-parent household } \\ \text { 2. Single-parent household }\end{array}$

\section{School controls}

Track at first enrolment

2. VMBO

3. $\mathrm{HAVO} / \mathrm{VWO}$

Cito score

Quintiles + separate category for missing value

See detailed note about the missing values for the Cito score on p.260

\section{Confounding factors}

Father/mother years

1. 15 years or less since migration

2. $16-25$

3. More than 25 years.

1. Low education (primary education)

2. Middle education

Parental education (completed some secondary education)

3. High education

See detailed note about the measurement of immigrants' year of arrival on p.261

(bachelor or higher)

1. (self-)Employed

2. Reception of benefits

Father/mother SES sta-

3. No declared income tus

4. Missing SES

Highest educational degree obtained among parents. See detailed note about the measurement of immigrants' level of education on p.260

Homeownership Dummy: at least one parent is a homeowner

\begin{tabular}{lll}
\hline Family income & Terciles & $\begin{array}{l}\text { Measured after tax and adjusted for } \\
\text { household size and composition }\end{array}$ \\
\hline $\begin{array}{l}\text { Language spoken at } \\
\text { home }\end{array}$ & $\begin{array}{l}\text { 1. (Including) Dutch } \\
\text { 2. Other than Dutch } \\
\text { 3. Unknown }\end{array}$ & $\begin{array}{l}\text { This information is only available for } \\
\text { students who took the Cito test at the } \\
\text { end of primary school. }\end{array}$ \\
\hline
\end{tabular}

In the Dutch registers, SES status is operationalised as the main source of income.

Table B7: Detailed overview of the covariates for the main regression model. 


\section{Additional outputs for the sequence analysis}

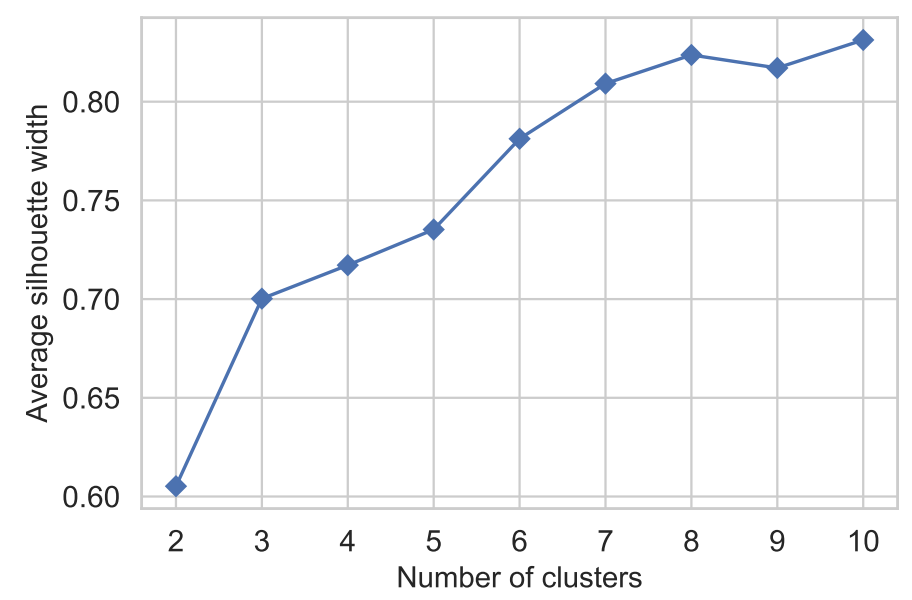

Figure B3: Average silhouette width for the ten first cluster solutions from the Partition around Medoids algorithm.

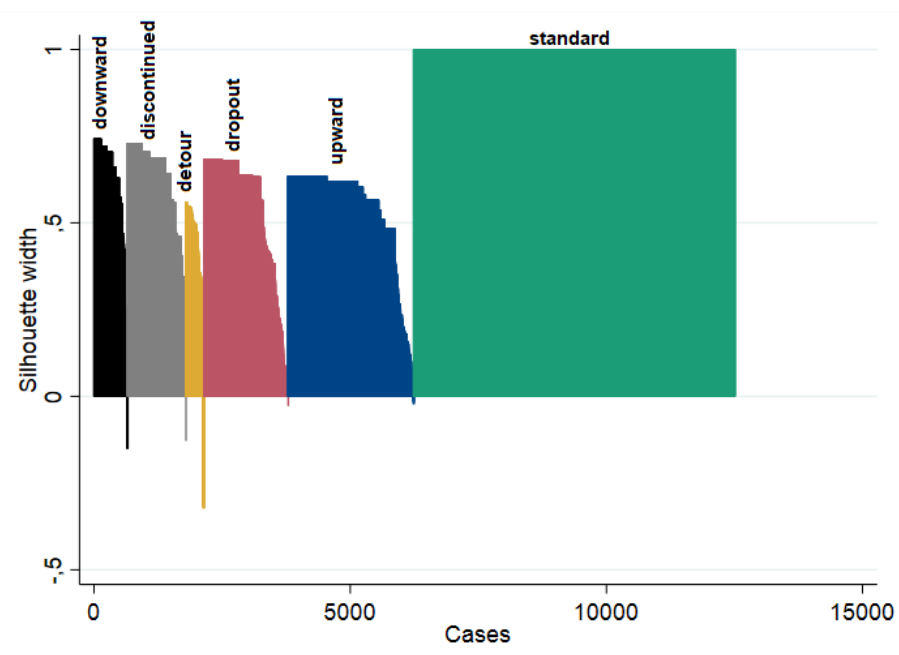

Figure B4: Average silhouette width for the six-cluster solution from the Partition around Medoids algorithm. 
Standard (50.1\%)
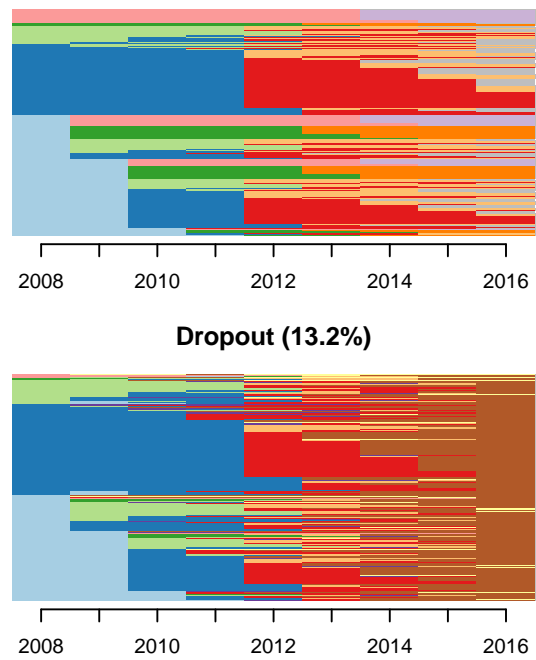

Downward (5.3\%)

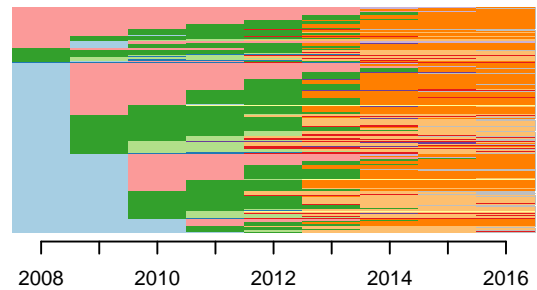

Upward (19.6\%)

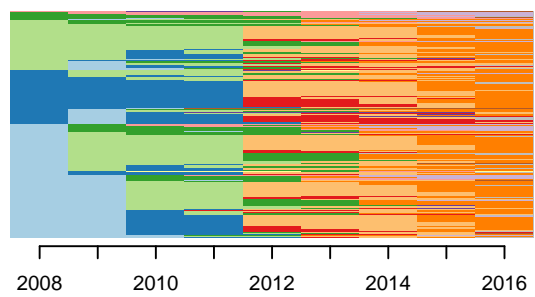

Discontinued (9.1\%)

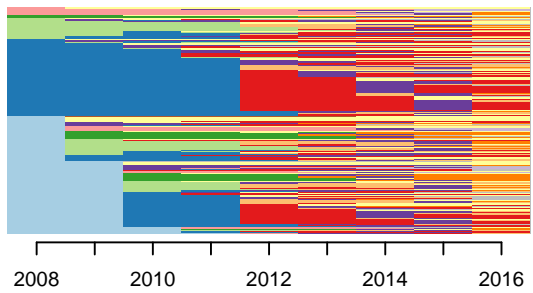

Detour (2.8\%)

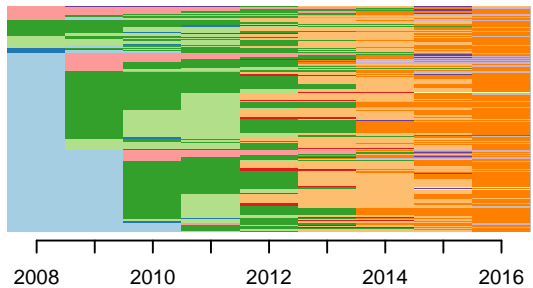

\section{$\square$ Bridge}

P Preparatory vocational (VMBO)

$\square$ Preparatory Vocational + (VMBO-t)

$\square$ General education (HAVO)

ㅁ Pre-university education (VWO)

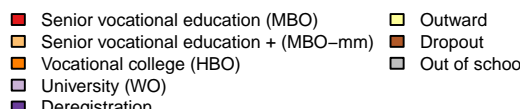

든 Senior vocational education (MBO)

Senior vocational education + (MBO-mm) $\square$ Dropout

$\square$ Vocational college (HBO)

口 Out of school

$\square$ University (WO)

Figure B5: Index-plot based on states elements for the full sample ( $\mathrm{N}=12,505)$. Note: $V M B O-t$ stands for the theoretical path within vocational education, which gives access to general education (HAVO), while $\mathrm{MBO}-\mathrm{mm}$ stands for the middle management level within senior vocational education, which opens the door to vocational college (HBO). 
Additional descriptive statistics for cluster membership

\begin{tabular}{lccccc}
\hline & \multicolumn{5}{c}{ Type of transition } \\
& Standard & Upward & Dropout & Exit & Downward \\
\hline Cluster & & & & & \\
Standard & 50.1 & 0.0 & 0.0 & 0.0 & 0.0 \\
Upward & 19.6 & 85.8 & 2.0 & 6.2 & 12.2 \\
Dropout & 13.17 & 2.3 & 97.8 & 20.4 & 7.3 \\
Discontinued & 9.1 & 0.0 & 0.1 & 68.7 & 0.2 \\
Downward & 5.3 & 0.3 & 0.0 & 3.2 & 52.4 \\
Detour & 2.8 & 11.6 & 0.1 & 1.4 & 27.9 \\
Total & 100.0 & 100.0 & 100.0 & 100.0 & 100.0 \\
\hline
\end{tabular}

Table B8: Type of transition experienced in secondary education by cluster membership (\%).

\begin{tabular}{lcccc}
\hline & Dutch from birth & Naturalised & Non-naturalised & Total \\
\hline Standard & 50.5 & 49.5 & 50.4 & 50.1 \\
Upward & 20.5 & 19.8 & 16.6 & 19.6 \\
Dropout & 12.2 & 13.2 & 16.2 & 13.2 \\
Discontinued & 8.4 & 9.6 & 10.1 & 9.1 \\
Downward & 5.5 & 5.1 & 4.8 & 5.3 \\
Detour & 3.0 & 2.9 & 2.0 & 2.8 \\
Total & 100.0 & 100.0 & 100.0 & 100.0 \\
\hline
\end{tabular}

Table B9: Citizenship status by cluster membership (\%). 


\section{Full regression models}

\begin{tabular}{|c|c|c|c|c|c|}
\hline & Downward & Discontinuous & Detour & Dropout & Upward \\
\hline & \multicolumn{5}{|c|}{ vs. Standard } \\
\hline \multicolumn{6}{|l|}{ Citizenship } \\
\hline Dutch from birth & $\begin{array}{c}0,949 \\
(0,707)\end{array}$ & $\begin{array}{c}0,911 \\
(0,351)\end{array}$ & $\begin{array}{c}1,508 \\
(0,039)\end{array}$ & $\begin{array}{c}0,813 \\
(0,013)\end{array}$ & $\begin{array}{c}1,192 \\
(0,024)\end{array}$ \\
\hline Naturalised & $\begin{array}{c}0,990 \\
(0,946)\end{array}$ & $\begin{array}{c}0,916 \\
(0,384)\end{array}$ & $\begin{array}{c}1,502 \\
(0,044)\end{array}$ & $\begin{array}{c}0,832 \\
(0,028)\end{array}$ & $\begin{array}{c}1,128 \\
(0,126)\end{array}$ \\
\hline \multicolumn{6}{|l|}{ Sociodemographics } \\
\hline \multicolumn{6}{|l|}{$\overline{\text { Gender }}$} \\
\hline Male & ref. & ref. & ref. & ref. & ref. \\
\hline Female & $\begin{array}{c}1,258 \\
(0,008)\end{array}$ & $\begin{array}{c}0,815 \\
(0,003)\end{array}$ & $\begin{array}{c}1,543 \\
(0,000)\end{array}$ & $\begin{array}{c}0,402 \\
(0,000)\end{array}$ & $\begin{array}{c}1,186 \\
(0,001)\end{array}$ \\
\hline \multicolumn{6}{|l|}{ First born } \\
\hline Non first-born & ref. & ref. & ref. & ref. & ref. \\
\hline First-born & $\begin{array}{c}1,060 \\
(0,544)\end{array}$ & $\begin{array}{c}0,770 \\
(0,001)\end{array}$ & $\begin{array}{c}0,955 \\
(0,717)\end{array}$ & $\begin{array}{c}0,875 \\
(0,052)\end{array}$ & $\begin{array}{c}1,011 \\
(0,852)\end{array}$ \\
\hline \multicolumn{6}{|l|}{ country of origin } \\
\hline Non-EU & ref. & ref. & ref. & ref. & ref. \\
\hline EU & $\begin{array}{c}1,329 \\
(0,121)\end{array}$ & $\begin{array}{c}1,459 \\
(0,018)\end{array}$ & $\begin{array}{c}1,224 \\
(0,450)\end{array}$ & $\begin{array}{c}1,003 \\
(0,985)\end{array}$ & $\begin{array}{c}0,746 \\
(0,041)\end{array}$ \\
\hline Number of children & $\begin{array}{c}0,921 \\
(0,058)\end{array}$ & $\begin{array}{c}1,042 \\
(0,208)\end{array}$ & $\begin{array}{c}0,881 \\
(0,023)\end{array}$ & $\begin{array}{c}1,089 \\
(0,002)\end{array}$ & $\begin{array}{c}0,997 \\
(0,895)\end{array}$ \\
\hline \multicolumn{6}{|l|}{ Household type } \\
\hline Two-parent & ref. & ref. & ref. & ref. & ref. \\
\hline Single-parent & $\begin{array}{c}0,821 \\
(0,178)\end{array}$ & $\begin{array}{c}1,517 \\
(0,000)\end{array}$ & $\begin{array}{c}0,858 \\
(0,404)\end{array}$ & $\begin{array}{c}1,593 \\
(0,000)\end{array}$ & $\begin{array}{c}0,993 \\
(0,926)\end{array}$ \\
\hline \multicolumn{6}{|l|}{ School controls } \\
\hline \multicolumn{6}{|l|}{ First enrolment } \\
\hline Bridge & ref. & ref. & ref. & ref. & ref. \\
\hline $\mathrm{VMBO}(+)$ & $\begin{array}{c}0,821 \\
(0,178)\end{array}$ & $\begin{array}{c}1,517 \\
(0,000)\end{array}$ & $\begin{array}{c}0,858 \\
(0,404)\end{array}$ & $\begin{array}{c}1,593 \\
(0,000)\end{array}$ & $\begin{array}{c}0,993 \\
(0,926)\end{array}$ \\
\hline HAVO/VWO & $\begin{array}{c}1,576 \\
(0,000)\end{array}$ & $\begin{array}{c}0,787 \\
(0,173)\end{array}$ & $\begin{array}{c}1,059 \\
(0,753)\end{array}$ & $\begin{array}{c}0,474 \\
(0,000)\end{array}$ & $\begin{array}{c}0,754 \\
(0,035)\end{array}$ \\
\hline Cito score & & & & & \\
\hline First quintile & ref. & ref. & ref. & ref. & $\begin{array}{c}\text { ref. } \\
\text { Continued }\end{array}$ \\
\hline
\end{tabular}




\begin{tabular}{|c|c|c|c|c|c|}
\hline & Downward & Discontinuous & Detour & Dropout & Upward \\
\hline & \multicolumn{5}{|c|}{ vs. Standard } \\
\hline Second CITO quintile & $\begin{array}{c}4,268 \\
(0,062)\end{array}$ & $\begin{array}{l}1,050 \\
(0,663)\end{array}$ & $\begin{array}{c}1,886 \\
(0,249)\end{array}$ & $\begin{array}{c}0,870 \\
(0,133)\end{array}$ & $\begin{array}{c}2,379 \\
(0,000)\end{array}$ \\
\hline Third CITO quintile & $\begin{array}{l}22,70 \\
(0,000)\end{array}$ & $\begin{array}{c}1,151 \\
(0,220)\end{array}$ & $\begin{array}{c}11,48 \\
(0,000)\end{array}$ & $\begin{array}{c}0,900 \\
(0,281)\end{array}$ & $\begin{array}{c}4,057 \\
(0,000)\end{array}$ \\
\hline Fourth CITO quintile & $\begin{array}{l}52,81 \\
(0,000)\end{array}$ & $\begin{array}{c}0,847 \\
(0,217)\end{array}$ & $\begin{array}{c}17,84 \\
(0,000)\end{array}$ & $\begin{array}{c}0,841 \\
(0,119)\end{array}$ & $\begin{array}{c}3,712 \\
(0,000)\end{array}$ \\
\hline Fifth CITO quintile & $\begin{array}{c}45,67 \\
(0,000)\end{array}$ & $\begin{array}{c}0,550 \\
(0,000)\end{array}$ & $\begin{array}{c}10,65 \\
(0,000)\end{array}$ & $\begin{array}{c}0,402 \\
(0,000)\end{array}$ & $\begin{array}{c}0,927 \\
(0,553)\end{array}$ \\
\hline Missing CITO & $\begin{array}{c}37,07 \\
(0,000)\end{array}$ & $\begin{array}{c}0,891 \\
(0,644)\end{array}$ & $\begin{array}{c}11,49 \\
(0,001)\end{array}$ & $\begin{array}{l}1,018 \\
(0,934)\end{array}$ & $\begin{array}{c}1,937 \\
(0,001)\end{array}$ \\
\hline$\frac{\text { Confounding factors }}{\text { Parental education }}$ & & & & & \\
\hline $\begin{array}{l}\text { Low education } \\
\text { Middle education }\end{array}$ & $\begin{array}{c}\text { ref. } \\
1,253 \\
(0,040)\end{array}$ & $\begin{array}{c}\text { ref. } \\
1,076 \\
(0,389)\end{array}$ & $\begin{array}{c}\text { ref. } \\
1,087 \\
(0,564)\end{array}$ & $\begin{array}{c}\text { ref. } \\
0,885 \\
(0,098)\end{array}$ & $\begin{array}{c}\text { ref. } \\
1,130 \\
(0,049)\end{array}$ \\
\hline High education & $\begin{array}{c}0,990 \\
(0,944)\end{array}$ & $\begin{array}{c}0,917 \\
(0,502)\end{array}$ & $\begin{array}{l}1,018 \\
(0,923)\end{array}$ & $\begin{array}{c}0,678 \\
(0,002)\end{array}$ & $\begin{array}{c}1,032 \\
(0,730)\end{array}$ \\
\hline Missing education & $\begin{array}{c}0,784 \\
(0,071)\end{array}$ & $\begin{array}{c}1,001 \\
(0,993)\end{array}$ & $\begin{array}{c}0,959 \\
(0,800)\end{array}$ & $\begin{array}{c}0,909 \\
(0,265)\end{array}$ & $\begin{array}{c}0,956 \\
(0,530)\end{array}$ \\
\hline Homeownership & & & & & \\
\hline Not homeowner & ref. & ref. & ref. & ref. & ref. \\
\hline Homeowner & $\begin{array}{c}0,875 \\
(0,194)\end{array}$ & $\begin{array}{c}1,019 \\
(0,820)\end{array}$ & $\begin{array}{c}0,770 \\
(0,057)\end{array}$ & $\begin{array}{c}0,936 \\
(0,365)\end{array}$ & $\begin{array}{c}1,198 \\
(0,002)\end{array}$ \\
\hline $\begin{array}{l}\text { Mother's SES } \\
\text { (Self-)Employed }\end{array}$ & ref. & ref. & ref. & ref. & ref. \\
\hline Reception of benefits & $\begin{array}{c}0,768 \\
(0,043)\end{array}$ & $\begin{array}{c}0,885 \\
(0,211)\end{array}$ & $\begin{array}{c}0,993 \\
(0,965)\end{array}$ & $\begin{array}{c}1,112 \\
(0,195)\end{array}$ & $\begin{array}{c}0,944 \\
(0,417)\end{array}$ \\
\hline No declared income & $\begin{array}{c}0,959 \\
(0,719)\end{array}$ & $\begin{array}{l}1,077 \\
(0,434)\end{array}$ & $\begin{array}{l}1,197 \\
(0,238)\end{array}$ & $\begin{array}{l}1,080 \\
(0,350)\end{array}$ & $\begin{array}{l}1,094 \\
(0,179)\end{array}$ \\
\hline Missing SES & $\begin{array}{l}1,239 \\
(0,676)\end{array}$ & $\begin{array}{l}1,196 \\
(0,620)\end{array}$ & $\begin{array}{l}1,391 \\
(0,602)\end{array}$ & $\begin{array}{c}1,842 \\
(0,049)\end{array}$ & $\begin{array}{c}0,628 \\
(0,207)\end{array}$ \\
\hline $\begin{array}{l}\text { Father's SES } \\
\text { (Self-)Employed }\end{array}$ & ref. & ref. & ref. & ref. & ref. \\
\hline Reception of benefits & $\begin{array}{c}0,856 \\
(0,206)\end{array}$ & $\begin{array}{c}1,104 \\
(0,263)\end{array}$ & $\begin{array}{c}0,998 \\
(0,991)\end{array}$ & $\begin{array}{l}1,083 \\
(0,283)\end{array}$ & $\begin{array}{c}1,025 \\
(0,705)\end{array}$ \\
\hline No declared income & 1,166 & 1,292 & 1,414 & 1,092 & $\begin{array}{c}0,948 \\
\text { Continued }\end{array}$ \\
\hline
\end{tabular}

Table B10 Continued: Multinomial logistic regression of the odds of experiencing different trajectories through secondary and tertiary education. 


\begin{tabular}{|c|c|c|c|c|c|}
\hline & Downward & Discontinuous & Detour & Dropout & Upward \\
\hline & \multicolumn{5}{|c|}{ vs. Standard } \\
\hline \multirow{3}{*}{ Missing SES } & $(0,437)$ & $(0,081)$ & $(0,169)$ & $(0,513)$ & $(0,674)$ \\
\hline & 1,207 & 0,968 & 1,467 & 1,035 & 1,328 \\
\hline & $(0,505)$ & $(0,863)$ & $(0,230)$ & $(0,828)$ & $(0,059)$ \\
\hline \multicolumn{6}{|l|}{ Family income } \\
\hline First tercile & ref. & ref. & ref. & ref. & ref. \\
\hline \multirow[t]{2}{*}{ Second income tercile } & 0,903 & 0,882 & 1,131 & 0,927 & 1,124 \\
\hline & $(0,381)$ & $(0,149)$ & $(0,406)$ & $(0,298)$ & $(0,073)$ \\
\hline \multirow[t]{2}{*}{ Third income tercile } & 0,732 & 0,963 & 0,960 & 0,885 & 1,131 \\
\hline & $(0,017)$ & $(0,713)$ & $(0,814)$ & $(0,161)$ & $(0,097)$ \\
\hline \multicolumn{6}{|l|}{$\begin{array}{l}\text { Language spoken at } \\
\text { home }\end{array}$} \\
\hline (Including) Dutch & ref. & ref. & ref. & ref. & ref. \\
\hline \multirow[t]{2}{*}{ Other than Dutch } & 0,931 & 0,970 & 0,888 & 1,064 & 1,051 \\
\hline & $(0,461)$ & $(0,705)$ & $(0,346)$ & $(0,370)$ & $(0,391)$ \\
\hline \multirow{2}{*}{ Unknown } & 0,526 & 0,972 & 0,484 & 0,869 & 1,008 \\
\hline & $(0,142)$ & $(0,905)$ & $(0,225)$ & $(0,502)$ & $(0,966)$ \\
\hline \multicolumn{6}{|l|}{ Mother's YSM* } \\
\hline $0-15$ & ref. & ref. & ref. & ref. & ref. \\
\hline \multirow[t]{2}{*}{$16-25$} & 0,785 & 0,637 & 0,766 & 0,949 & 0,843 \\
\hline & $(0,027)$ & $(0,000)$ & $(0,060)$ & $(0,489)$ & $(0,007)$ \\
\hline \multirow[t]{2}{*}{ over 25} & 0,945 & 0,621 & 0,788 & 1,035 & 0,761 \\
\hline & $(0,642)$ & $(0,000)$ & $(0,137)$ & $(0,674)$ & $(0,000)$ \\
\hline \multicolumn{6}{|l|}{ Father's YSM* } \\
\hline $0-15$ & ref. & ref. & ref. & ref. & ref. \\
\hline \multirow[t]{2}{*}{$16-25$} & 1,057 & 0,693 & 0,821 & 0,729 & 1,007 \\
\hline & $(0,629)$ & $(0,000)$ & $(0,189)$ & $(0,000)$ & $(0,910)$ \\
\hline \multirow[t]{2}{*}{ over 25} & 1,046 & 0,623 & 0,906 & 0,839 & 0,879 \\
\hline & $(0,715)$ & $(0,000)$ & $(0,530)$ & $(0,028)$ & $(0,066)$ \\
\hline Observations & 12,249 & & & & \\
\hline
\end{tabular}

Exponentiated coefficients; $p$-values in parentheses

*YSM stands for the number of years since migration

Table B10 Continued: Multinomial logistic regression of the odds of experiencing different trajectories through secondary and tertiary education. 


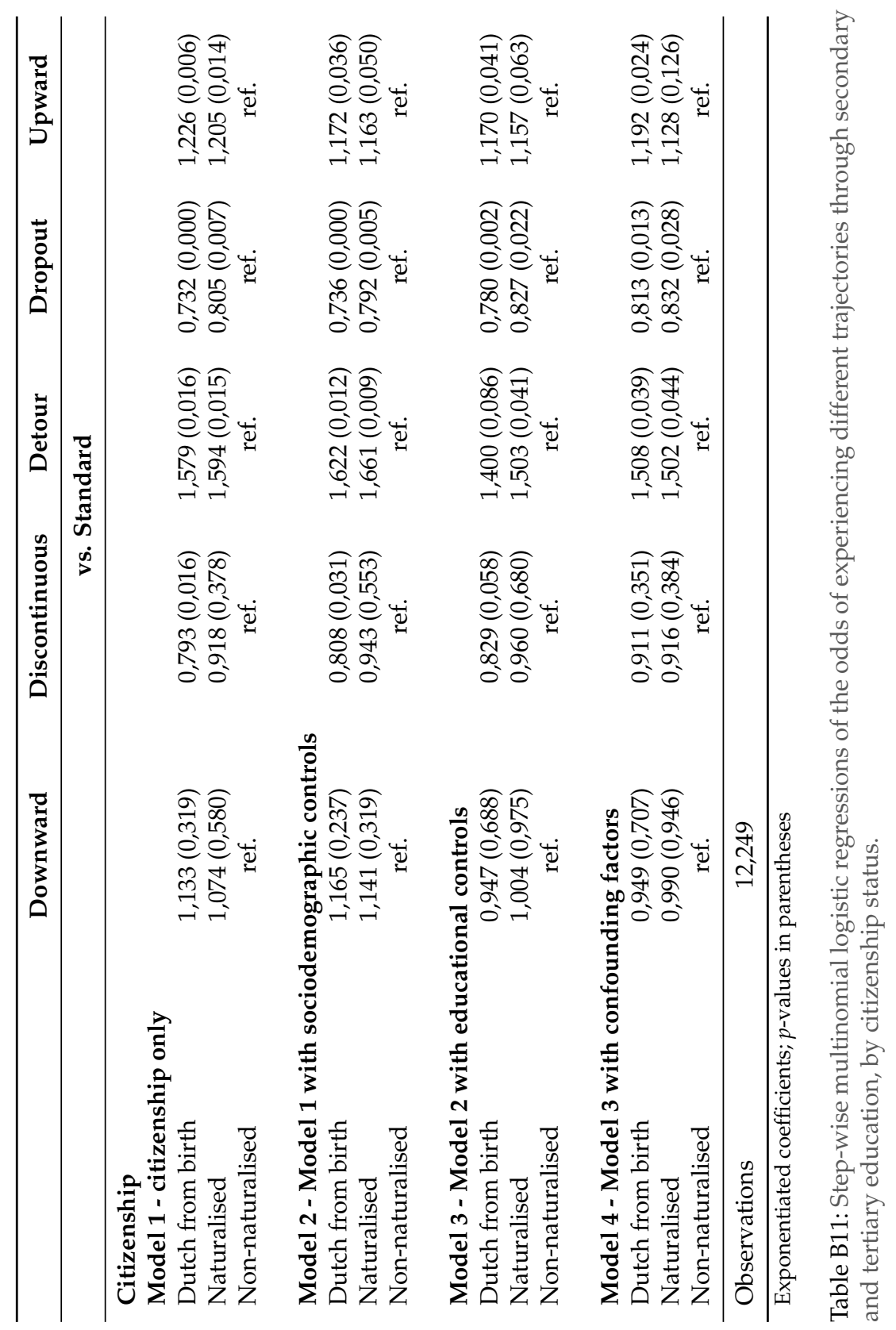




\section{Analysis of the covariates}

Table SB10 enables us to consider the associations between covariates and educational trajectories in more detail. We observe that parental characteristics, especially parents' highest education level, have some effect on the trajectory that one takes through secondary and tertiary education. Notably, students whose parents have a higher education diploma are substantially less at risk of following the dropout trajectory than those whose parents only completed primary education. Compared to the latter, those whose parents have a middle education diploma are also slightly more likely to experience downward or upward transitions as opposed to staying in their initial track.

By contrast, household disposable income is not strongly associated with the type of trajectory a student follows. For example, being in the third income tercile instead of the first one only marginally decreases the odds of following a non-standard trajectory as opposed to the standard path. The most noticeable effect is for the downward movers, suggesting that children whose parents have a comfortable financial position are more likely to remain in their track than to go down, in line with findings in the literature on compensatory advantage (Huang, 2020). In the same vein, there is no noticeable pattern for parental socioeconomic status. Overall, these results are consistent with earlier work on the Dutch case showing that education level is a stronger predictor of educational attainment than occupational status (Tieben et al., 2010). In a context where the direct costs of education have dropped, cultural resources can indeed be expected to take precedence over financial means.

Contrary to expectations, the language spoken at home has no significant effect on the trajectory a student follows. While those who speak Dutch at home are more likely to take a detour than the standard path, the effect is not precisely estimated ( $p=0.346)$. By contrast, parents' years since migration is strongly associated with certain types of trajectory. Notably, students whose mother or father is living in the Netherlands for more than 15 years are substantially less likely to follow a discontinuous trajectory compared to those whose parents arrived more recently.

Finally, the sociodemographic variables have some moderate effects on the trajectories followed. The household type has a notable effect on the likelihood that a student will follow a dropout or discontinued trajectory as opposed to staying in their initial track: those in single-parent households are substantially more likely to leave school without qualifications at some point than those living with both parents (odds ratio of about 1.5). Consistent with 
the idea that those taking a detour might commit significant resources to move upward after an initial downward transition, the odds of following this path as opposed to the standard one decrease as the number of children in the household increases.

\section{Average marginal effects}

\begin{tabular}{lcccc}
\hline Outcome & AME & p-value & \multicolumn{2}{c}{$\mathbf{9 5 \%}$ conf. interval } \\
\hline Dutch from birth (ref. non-naturalised) & & & & \\
Downward & -0.004 & 0.557 & -0.016 & 0.009 \\
Discontinued & -0.008 & 0.300 & -0.023 & 0.007 \\
Detour & 0.010 & 0.021 & 0.001 & 0.018 \\
Dropout & -0.027 & 0.004 & -0.045 & -0.009 \\
Upward & 0.031 & 0.003 & 0.010 & 0.051 \\
Standard & -0.002 & 0.897 & -0.029 & 0.025 \\
Naturalised (ref. non-naturalised) & & & & \\
Downward & -0.001 & 0.827 & -0.014 & 0.011 \\
Discontinued & -0.007 & 0.363 & -0.022 & 0.008 \\
Detour & 0.010 & 0.025 & 0.001 & 0.018 \\
Dropout & -0.023 & 0.012 & -0.042 & -0.005 \\
Upward & 0.021 & 0.042 & 0.001 & 0.042 \\
Standard & 0.001 & 0.951 & -0.026 & 0.028 \\
\hline
\end{tabular}

Table B12: Average marginal effects (AME) of citizenship status predicting pathways into secondary and tertiary education. 


\begin{tabular}{lcccc}
\hline Outcome & AME & p-value & $\mathbf{9 5 \%}$ conf. interval \\
\hline Middle education (ref. low education) & & & & \\
Downward & 0.010 & 0.063 & -0.001 & 0.020 \\
Discontinued & 0.004 & 0.518 & -0.008 & 0.017 \\
Detour & 0.001 & 0.799 & -0.007 & 0.008 \\
Dropout & -0.018 & 0.015 & -0.033 & -0.004 \\
Upward & 0.018 & 0.048 & 0.000 & 0.036 \\
Standard & -0.015 & 0.202 & -0.037 & 0.008 \\
High education (ref. low education) & & & & \\
Downward & 0.001 & 0.882 & -0.011 & 0.013 \\
Discontinued & -0.003 & 0.775 & -0.021 & 0.016 \\
Detour & 0.001 & 0.781 & -0.008 & 0.011 \\
Dropout & -0.038 & 0.000 & -0.060 & -0.017 \\
Upward & 0.015 & 0.266 & -0.011 & 0.041 \\
Standard & 0.024 & 0.150 & -0.009 & 0.057 \\
Missing education (ref. low education) & & & & \\
Downward & -0.009 & 0.082 & -0.020 & 0.001 \\
Discontinued & 0.003 & 0.704 & -0.012 & 0.018 \\
Detour & 0.000 & 0.996 & -0.008 & 0.008 \\
Dropout & -0.008 & 0.347 & -0.026 & 0.009 \\
Upward & -0.002 & 0.813 & -0.022 & 0.017 \\
Standard & 0.017 & 0.190 & -0.009 & 0.043 \\
\hline
\end{tabular}

Table B13: Average marginal effects (AME) of parental education predicting pathways into secondary and tertiary education. 


\section{Robustness checks}

Average marginal effects of citizenship at representative values

\begin{tabular}{llcccc}
\hline Outcome & Language at home & AME & p-value & 95\% conf. interval \\
\hline $\begin{array}{l}\text { Dutch from birth } \\
\text { (ref. non-naturalised) }\end{array}$ & & & & & \\
Downward & Incl. Dutch & -0.004 & 0.553 & -0.018 & 0.010 \\
Downward & Excl. Dutch & -0.004 & 0.566 & -0.017 & 0.009 \\
Discontinued & Incl. Dutch & -0.008 & 0.298 & -0.023 & 0.007 \\
Discontinued & Excl. Dutch & -0.008 & 0.306 & -0.022 & 0.007 \\
Detour & Incl. Dutch & 0.011 & 0.030 & 0.001 & 0.022 \\
Detour & Excl. Dutch & 0.010 & 0.028 & 0.001 & 0.019 \\
Dropout & Incl. Dutch & -0.027 & 0.004 & -0.045 & -0.009 \\
Dropout & Excl. Dutch & -0.028 & 0.004 & -0.047 & -0.009 \\
Upward & Incl. Dutch & 0.030 & 0.004 & 0.010 & 0.050 \\
Upward & Excl. Dutch & 0.031 & 0.003 & 0.010 & 0.052 \\
Standard & Incl. Dutch & -0.002 & 0.887 & -0.029 & 0.025 \\
Standard & Excl. Dutch & -0.002 & 0.910 & -0.028 & 0.025 \\
Naturalised & & & & & \\
(ref. non-naturalised) & & & & & \\
Downward & Incl. Dutch & -0.002 & 0.820 & -0.016 & 0.013 \\
Downward & Excl. Dutch & -0.001 & 0.836 & -0.015 & 0.012 \\
Discontinued & Incl. Dutch & -0.007 & 0.358 & -0.022 & 0.008 \\
Discontinued & Excl. Dutch & -0.007 & 0.368 & -0.021 & 0.008 \\
Detour & Incl. Dutch & 0.011 & 0.033 & 0.001 & 0.022 \\
Detour & Excl. Dutch & 0.010 & 0.032 & 0.001 & 0.020 \\
Dropout & Incl. Dutch & -0.024 & 0.012 & -0.042 & -0.005 \\
Dropout & Excl. Dutch & -0.025 & 0.012 & -0.044 & -0.005 \\
Upward & Incl. Dutch & 0.021 & 0.046 & 0.000 & 0.041 \\
Upward & Excl. Dutch & 0.022 & 0.041 & 0.001 & 0.042 \\
Standard & Incl. Dutch & 0.000 & 0.982 & -0.027 & 0.028 \\
Standard & Excl. Dutch & 0.001 & 0.948 & -0.026 & 0.028 \\
\hline & & & & & \\
\hline
\end{tabular}

Table B14: Average marginal effects (AME) of citizenship at representative values of language spoken at home, predicting pathways into secondary and tertiary education. 


\begin{tabular}{|c|c|c|c|c|c|}
\hline \multirow{2}{*}{$\begin{array}{l}\text { Outcome } \\
\text { Dutch from bir }\end{array}$} & \multirow[t]{2}{*}{ Parental education } & \multirow[t]{2}{*}{ AME } & \multirow[t]{2}{*}{ p-value } & \multicolumn{2}{|c|}{$95 \%$ conf. interval } \\
\hline & & & & & \\
\hline Downward & low & -0.004 & 0.571 & -0.016 & 0.009 \\
\hline Downward & middle & -0.004 & 0.542 & -0.019 & 0.010 \\
\hline Downward & high & -0.004 & 0.530 & -0.017 & 0.009 \\
\hline Discontinued & low & -0.008 & 0.315 & -0.023 & 0.007 \\
\hline Discontinued & middle & -0.009 & 0.282 & -0.024 & 0.007 \\
\hline Discontinued & high & -0.008 & 0.263 & -0.023 & 0.006 \\
\hline Detour & low & 0.009 & 0.023 & 0.001 & 0.018 \\
\hline Detour & middle & 0.010 & 0.023 & 0.001 & 0.018 \\
\hline Detour & high & 0.010 & 0.028 & 0.001 & 0.018 \\
\hline Dropout & low & -0.028 & 0.004 & -0.047 & -0.009 \\
\hline Dropout & middle & -0.026 & 0.004 & -0.043 & -0.008 \\
\hline Dropout & high & -0.022 & 0.005 & -0.037 & -0.007 \\
\hline Upward & low & 0.031 & 0.003 & 0.010 & 0.051 \\
\hline Upward & middle & 0.032 & 0.004 & 0.010 & 0.054 \\
\hline Upward & high & 0.031 & 0.005 & 0.009 & 0.052 \\
\hline Standard & low & 0.000 & 0.975 & -0.027 & 0.026 \\
\hline Standard & middle & -0.003 & 0.816 & -0.030 & 0.024 \\
\hline Standard & high & -0.006 & 0.660 & -0.033 & 0.021 \\
\hline \multicolumn{6}{|c|}{$\begin{array}{l}\text { Naturalised } \\
\text { (ref. non-naturalised) }\end{array}$} \\
\hline Downward & low & -0.001 & 0.841 & -0.014 & 0.011 \\
\hline Downward & middle & -0.002 & 0.813 & -0.016 & 0.013 \\
\hline Downward & high & -0.002 & 0.798 & -0.015 & 0.011 \\
\hline Discontinued & low & -0.007 & 0.378 & -0.022 & 0.008 \\
\hline Discontinued & middle & 0.008 & 0.346 & -0.023 & 0.008 \\
\hline Discontinued & high & -0.007 & 0.326 & -0.022 & 0.007 \\
\hline Detour & high & 0.009 & 0.026 & 0.001 & 0.018 \\
\hline Detour & middle & 0.010 & 0.027 & 0.001 & 0.018 \\
\hline Detour & high & 0.010 & 0.032 & 0.001 & 0.019 \\
\hline Dropout & low & -0.025 & 0.012 & -0.044 & -0.005 \\
\hline Dropout & middle & -0.022 & 0.012 & -0.040 & -0.005 \\
\hline Dropout & high & -0.019 & 0.014 & -0.034 & -0.004 \\
\hline Upward & low & 0.021 & 0.040 & 0.001 & 0.042 \\
\hline Upward & middle & 0.022 & 0.044 & 0.001 & 0.044 \\
\hline Upward & high & 0.021 & 0.054 & 0.000 & 0.043 \\
\hline Standard & low & 0.002 & 0.887 & -0.025 & 0.029 \\
\hline Standard & middle & 0.000 & 0.976 & -0.028 & 0.027 \\
\hline Standard & high & -0.003 & 0.844 & -0.030 & 0.025 \\
\hline
\end{tabular}

Table B15: Average marginal effects (AME) of citizenship at representative values of parental education, predicting pathways into secondary and tertiary education. 


\begin{tabular}{|c|c|c|c|c|c|}
\hline \multirow{2}{*}{$\begin{array}{l}\text { Outcome } \\
\text { Dutch from birth } \\
\text { (ref. non-naturalised) }\end{array}$} & \multirow[t]{2}{*}{ Mother's YSM } & \multirow[t]{2}{*}{ AME } & \multirow[t]{2}{*}{ p-value } & \multicolumn{2}{|c|}{$95 \%$ conf. interval } \\
\hline & & & & & \\
\hline Downward & $0-15$ & -0.004 & 0.539 & -0.017 & 0.009 \\
\hline Downward & $16-25$ & -0.003 & 0.561 & -0.015 & 0.008 \\
\hline Downward & over 25 & -0.004 & 0.578 & -0.017 & 0.010 \\
\hline Discontinued & $0-15$ & -0.010 & 0.278 & -0.029 & 0.008 \\
\hline Discontinued & $16-25$ & -0.007 & 0.304 & -0.021 & 0.007 \\
\hline Discontinued & over 25 & -0.007 & 0.336 & -0.020 & 0.007 \\
\hline Detour & $0-15$ & 0.010 & 0.025 & 0.001 & 0.020 \\
\hline Detour & $16-25$ & 0.009 & 0.023 & 0.001 & 0.017 \\
\hline Detour & over 25 & 0.009 & 0.022 & 0.001 & 0.017 \\
\hline Dropout & $0-15$ & -0.026 & 0.004 & -0.043 & -0.008 \\
\hline Dropout & $16-25$ & -0.027 & 0.004 & -0.045 & -0.009 \\
\hline Dropout & over 25 & -0.028 & 0.004 & -0.048 & -0.009 \\
\hline Upward & $0-15$ & 0.032 & 0.004 & 0.011 & 0.054 \\
\hline Upward & $16-25$ & 0.031 & 0.004 & 0.010 & 0.052 \\
\hline Upward & over 25 & 0.029 & 0.003 & 0.010 & 0.048 \\
\hline Standard & $0-15$ & -0.003 & 0.838 & -0.030 & 0.024 \\
\hline Standard & $16-25$ & -0.002 & 0.863 & -0.029 & 0.024 \\
\hline Standard & over 25 & 0.000 & 0.975 & -0.026 & 0.027 \\
\hline \multicolumn{6}{|c|}{$\begin{array}{l}\text { Naturalised } \\
\text { (ref. non-naturalised) }\end{array}$} \\
\hline Downward & $0-15$ & -0.002 & 0.810 & -0.015 & 0.012 \\
\hline Downward & $16-25$ & -0.001 & 0.831 & -0.013 & 0.011 \\
\hline Downward & over 25 & -0.001 & 0.845 & -0.015 & 0.012 \\
\hline Discontinued & $0-15$ & -0.009 & 0.344 & -0.028 & 0.010 \\
\hline Discontinued & $16-25$ & -0.006 & 0.367 & -0.020 & 0.007 \\
\hline Discontinued & over 25 & -0.006 & 0.393 & -0.019 & 0.008 \\
\hline Detour & $0-15$ & 0.010 & 0.026 & 0.001 & 0.020 \\
\hline Detour & $16-25$ & 0.009 & 0.027 & 0.001 & 0.017 \\
\hline Detour & over 25 & 0.009 & 0.028 & 0.001 & 0.017 \\
\hline Dropout & $0-15$ & -0.022 & 0.012 & -0.040 & -0.005 \\
\hline Dropout & $16-25$ & -0.023 & 0.011 & -0.041 & -0.005 \\
\hline Dropout & over 25 & -0.025 & 0.012 & -0.044 & -0.005 \\
\hline Upward & $0-15$ & 0.023 & 0.042 & 0.001 & 0.044 \\
\hline Upward & $16-25$ & 0.021 & 0.044 & 0.001 & 0.042 \\
\hline Upward & over 25 & 0.020 & 0.041 & 0.001 & 0.039 \\
\hline Standard & $0-15$ & 0.000 & 0.996 & -0.027 & 0.027 \\
\hline Standard & $16-25$ & 0.000 & 0.972 & -0.027 & 0.028 \\
\hline Standard & over 25 & 0.002 & 0.857 & -0.025 & 0.030 \\
\hline
\end{tabular}

Table B16: Average marginal effects (AME) of citizenship at representative values of mother's years since migration (YSM), predicting pathways into secondary and tertiary education. 


\section{Upper bound: with citizenship measured at the end of the observation period}

The empirical strategy followed in the paper does not allow the inclusion of time-varying covariates in order to preserve a temporal order between the covariates and the outcome. This is particularly problematic for our variable of interest, citizenship status, which varies over time (See Table SB3). We therefore use an alternative specification to assess potential biases in our estimations of the effect of citizenship on educational trajectories.

In the main analysis, we only categorised as naturalised those who acquired Dutch citizenship before entering secondary education. However, some students may already be on their way to becoming Dutch and may have acquired citizenship by the beginning of the observation period. What is more, parents who plan to naturalise in the coming years may already be developing their country-specific skills, with beneficial effects for their children's educational orientation and motivation. As a result, we expect the effect of citizenship to be underestimated in the main model.

To estimate an upper bound for the effect of citizenship, we use an alternative specification where we define all students who acquire citizenship after birth within the observation period as naturalised. This reduces the share of nonnaturalised students from $15.2 \%$ to $6.7 \%$ and shifts the focus towards those who are still foreign citizens after the age of majority.

The results of this specification, presented in Figures B6, show very similar patterns to those observed in the main analysis, with the difference that the estimated effects for citizenship are substantially larger in magnitude. In this specification, acquiring Dutch citizenship at birth or during the observation period decreases the chances that a student will follow a dropout trajectory by about 7 percentage points compared to a student who remains a foreign citizen in 2016 (Figure B6). For upward mobility, the average marginal effects both exceed 5 percentage points. Although these results require careful interpretation due to anticipatory analysis (see Hoem and Kreyenfeld, 2006), they are informative in two respects. First, they show that those who are still foreign citizens after the age of majority are at a strong disadvantage in the Dutch education system and have a substantially lower ability to make use of its flexibility. Second, the results further support the idea that differences in the timing of naturalisation are marginal, while there is a significant gap between those who get Dutch citizenship at some point in their youth and those who do not. 


\section{Appendix B}

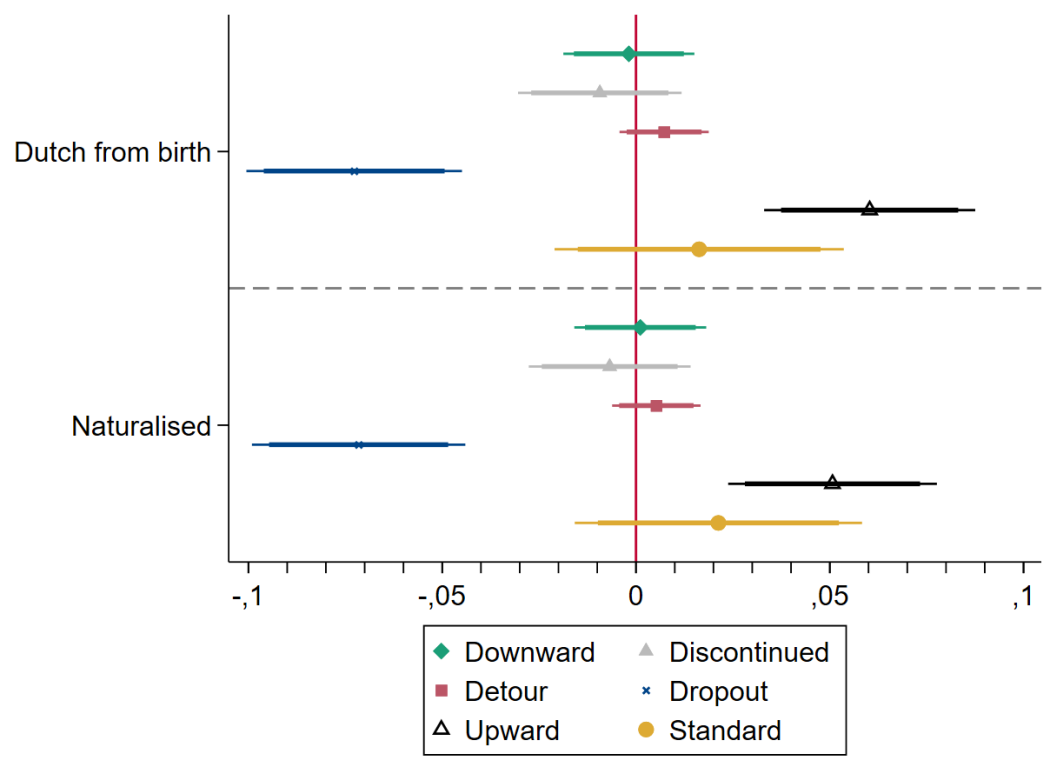

Figure B6: Plot of the average marginal effects of Dutch citizenship (measured at the end of the observation period) predicting trajectories through secondary and tertiary education (ref. non-naturalised).

Note: This plot represents coefficient estimates and confidence intervals at the $90 \%$ (thick) and 95\% (thin) levels. 


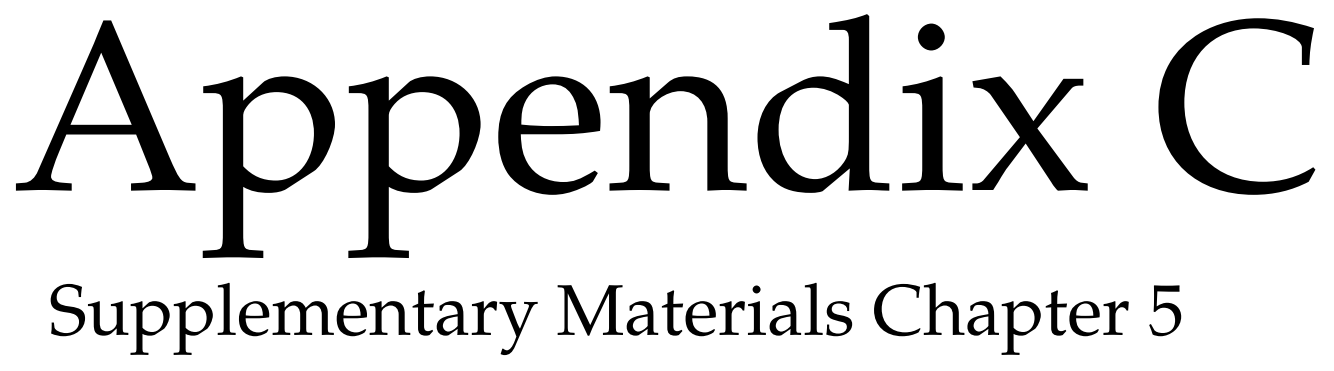




\section{Contents}

\begin{tabular}{|c|c|c|}
\hline I & Covariates description & 280 \\
\hline II & Descriptive Statistics & 284 \\
\hline III & Appendix between-within linear mixed model & 289 \\
\hline IV & Appendix random-effects models & 294 \\
\hline $\mathrm{V}$ & Appendix bounding estimator. & 301 \\
\hline VI & Robustness checks. & 303 \\
\hline
\end{tabular}

\section{Covariates description}

Table C 2 on p.283 gives the detailed coding of the full set of covariates, while I detail below the construction of three important variables: the score obtained at the Cito test (the outcome), age at naturalisation (the variable of interest) and parental level of education (an important confounder).

\section{Cito test scores}

A substantial share (23\%) of students in the sample did not take the Cito standardised test at the end of primary school. This can be for different reasons: some primary schools do not offer any test (this is common in special primary education, SBO), while others have a different test provider than Cito. Unfortunately, there is very little external information about the profiles of such schools in the considered year. I have checked in the sample whether schools without a Cito test are systematically different from those with a Cito test in terms of their students' sociodemographic characteristics (results available upon request). It seems that students that are enrolled in a school without the test come from a slightly more disadvantaged social background than those who take the test. However, the differences are limited ( 2 percentage points at most).

\section{Parental education level}

Unfortunately, information on the educational level of first generation parents is very limited in the Dutch register data, especially in the 1990s and 2000s. To maximise the coverage, Statistics Netherlands obtains or derives 
information on education level from various registers and the Labor Force Survey. ${ }^{1}$ However, although information on education level exists for an increasing share of the population, reaching $58 \%$ in $2012^{2}$, information is still missing for a substantial group of individuals, specifically for older cohorts and immigrants. Moreover, the level of education tends to be underestimated in administrative data because education abroad or at private institutions is difficult to take into account. As a result, an imputed educational level is available in the most recent registers. Since first-generation immigrants are particularly at risk of having their educational level underestimated, I use the imputed level of education whenever available. This measure of education is more reliable but it is also more recent, which introduces a risk of anticipatory analysis, i.e., explaining students' current outcomes by the future characteristics of their parents (see Hoem and Kreyenfeld, 2006). Nevertheless, parents' education level is arguably relatively stable from the moment their children enter secondary education, ${ }^{3}$ which justifies treating it as a time-constant characteristic in the absence of any more reliable information.

\section{Age at naturalisation}

Ideally, naturalisation should be measured before the outcome. However, one caveat is that students do not take the Cito test at the same age (see Table C1). In the Netherlands, entry into compulsory education is based on the age at the start of the school year, which means that each school level consists of at least two birth cohorts (including possible grade-repetition and grade-skipping). I therefore censor age at naturalisation at age 14, when the vast majority of students have already taken the test. This implies that those who naturalise at ages 11-13 may acquire Dutch citizenship shortly after taking the Cito test. Although this introduces a risk of anticipatory analysis in the regression, I do not expect a major bias to the extent the naturalisation process starts at least a year before the respondent officially becomes - and is registered as - a Dutch

\footnotetext{
${ }^{1}$ This combination of register and survey data requires the use of weights to get a representative measure of education for the entire Dutch population. However, the weights are not meant to ensure representativity for the sub-population of first generation immigrants alone; they have therefore not been used.

${ }^{2}$ Gans, S., Linder, F., Mooren, F.v., 2015. Gebruikershandleiding Onderwijsinformatie uit het SSB.

${ }^{3}$ When looking at non-missing cases, $17.0 \%$ of mothers and $18.1 \%$ of fathers have more than one level of education recorded during the period under observation. Note that this gives an upper bound for variation in parental education level over time, because the measure relies on a very detailed classification of educational credentials.
} 
citizen. Yet, as a robustness check, I used an alternative specification where age at naturalisation is censored at age 10 . This ensures temporal consistency but gives a conservative estimate for the age at naturalisation, as those who naturalise after 10 before the Cito test are included in the censored group. As expected, coefficients are smaller in magnitude, but the results do not substantively alter my interpretation (see p.304). I also conducted the analysis with different age groupings (including age dummies), which yield analogous conclusions about the effect of timing (see section VI for all robustness checks).

\begin{tabular}{rrr}
\hline Age & $\mathrm{N}$ & $\%$ \\
\hline$\leq 10$ & 333 & 0.4 \\
11 & 43,660 & 46.0 \\
12 & 45,847 & 48.3 \\
13 & 5,129 & 5.4 \\
$\geq 14$ & 46 & 0.1 \\
Total & 95,015 & 100.00 \\
\hline
\end{tabular}

Table C1: Distribution of age at the time of the test in the full sample of children of immigrants born in the Netherlands taking the Cito test between 2008 and 2015. 


\begin{tabular}{|c|c|c|}
\hline Variable & Operationalisation & Measurement \\
\hline Cito test score & Standardised by year & See note on p.280 \\
\hline $\begin{array}{l}\text { Age at naturalisa- } \\
\text { tion }\end{array}$ & $\begin{array}{l}\text { (1) } 0 \text { (Dutch from birth) } \\
\text { (2) } 1-2 \\
\text { (3) } 3-4 \\
\text { (4) } 5-6 \\
\text { (5) } 7-10 \\
\text { (6) } 11-13 \\
\text { (7) } \geq 14\end{array}$ & $\begin{array}{l}\text { Censored at age } 14 . \\
\text { See the robustness } \\
\text { checks for an alter- } \\
\text { native specification } \\
\text { with the variable } \\
\text { censored at age } 10 \\
\text { (p.303). }\end{array}$ \\
\hline Gender & $\begin{array}{l}\text { (1) Male } \\
\text { (2) Female }\end{array}$ & Time-constant \\
\hline Birth order & $\begin{array}{l}\text { (1) First-born } \\
\text { (2) Non first-born }\end{array}$ & Time-constant \\
\hline Date of birth & Year dummies from 1995 to 2003 & Time-constant \\
\hline $\begin{array}{l}\text { Number of minor } \\
\text { children in the } \\
\text { household }\end{array}$ & Range: $1-7$ & Year of Cito \\
\hline Type of household & $\begin{array}{l}\text { (1) Two-parent household } \\
\text { (2) Single-parent household }\end{array}$ & Year of Cito \\
\hline $\begin{array}{l}\text { Father's and } \\
\text { mother's socioe- } \\
\text { conomic status }\end{array}$ & $\begin{array}{l}\text { (1) Employee or self-employed } \\
\text { (2) Reception of benefits } \\
\text { (3) No declared income } \\
\text { (4) Missing information }\end{array}$ & Year of Cito \\
\hline $\begin{array}{l}\text { Parents' homeown- } \\
\text { ership status }\end{array}$ & $\begin{array}{l}\text { Dummy: at least one parent is a } \\
\text { homeowner }\end{array}$ & Year of Cito \\
\hline Family income & Terciles & Year of Cito \\
\hline $\begin{array}{l}\text { Highest educational } \\
\text { degree among par- } \\
\text { ents }\end{array}$ & $\begin{array}{l}\text { (1) Low education } \\
\text { (primary education) } \\
\text { (2) Middle educa- } \\
\text { tion } \\
\text { (completed some } \\
\text { secondary educa- } \\
\text { tion) } \\
\text { (3) High education } \\
\text { (bachelor or higher) } \\
\text { (4) Missing educa- } \\
\text { tion }\end{array}$ & $\begin{array}{l}\text { Time-constant } \\
\text { See detailed note } \\
\text { about the measure- } \\
\text { ment of immigrants' } \\
\text { level of education } \\
\text { on p. } 280 \text {. }\end{array}$ \\
\hline $\begin{array}{l}\text { Mother's country of } \\
\text { birth }\end{array}$ & $\begin{array}{l}\text { (1) Afghanistan } \\
\text { (2) China } \\
\text { (3) Irak } \\
\text { (4) Iran } \\
\text { (5) Morocco } \\
\text { (6) Other EU countries } \\
\text { (7) Other non-EU countries } \\
\text { (8) Turkey } \\
\text { (9) Yugoslavia }\end{array}$ & $\begin{array}{l}\text { Time-constant } \\
\text { Note: } 90.6 \% \text { of chil- } \\
\text { dren in the sample } \\
\text { have parents orig- } \\
\text { inating from the } \\
\text { same country of } \\
\text { birth. } \\
\end{array}$ \\
\hline
\end{tabular}

Table C2: Information about the coding of all variables. 


\section{Descriptive Statistics}

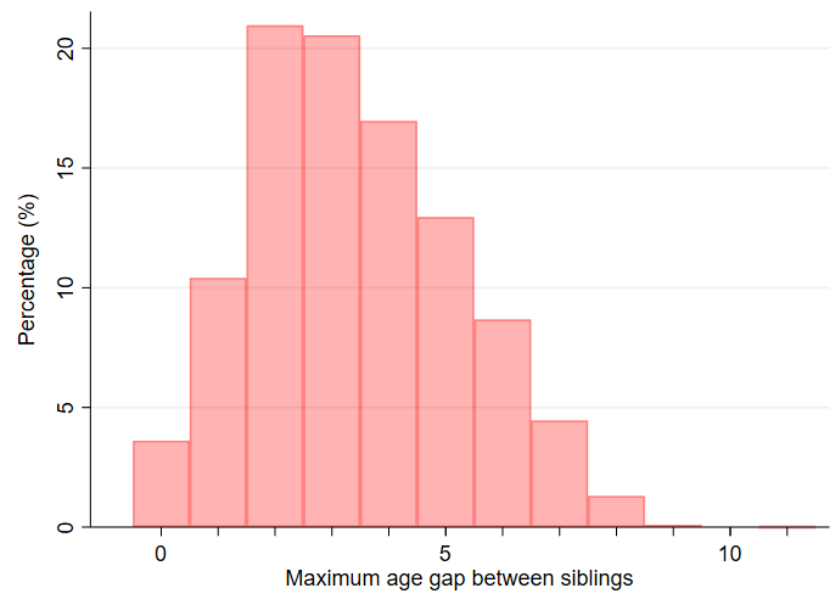

Figure C1: Age difference between siblings in the full sample (N=94,727).

Note: I take the maximum age difference in the families with three siblings or more.

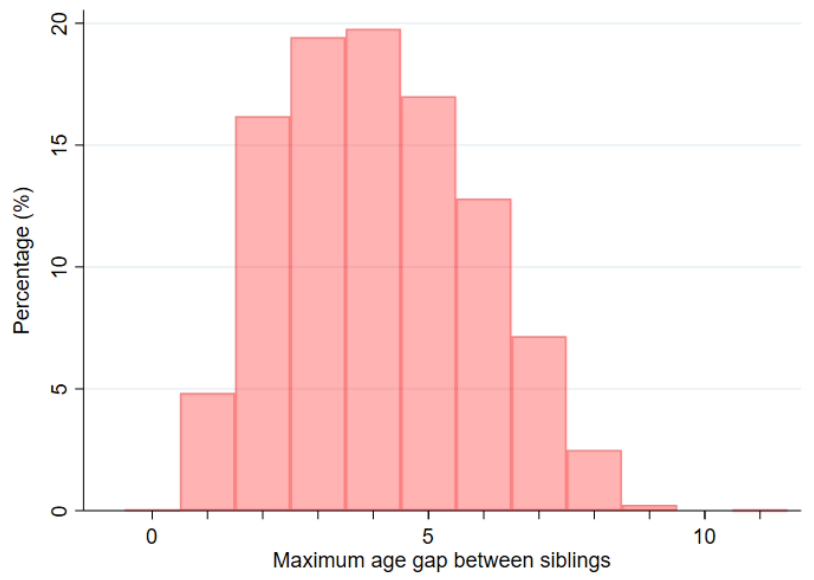

Figure C2: Age difference between siblings in the sample of exposure-discordant families ( $\mathrm{N}=14,393)$.

Note: I take the maximum age difference in the families with three siblings or more. 


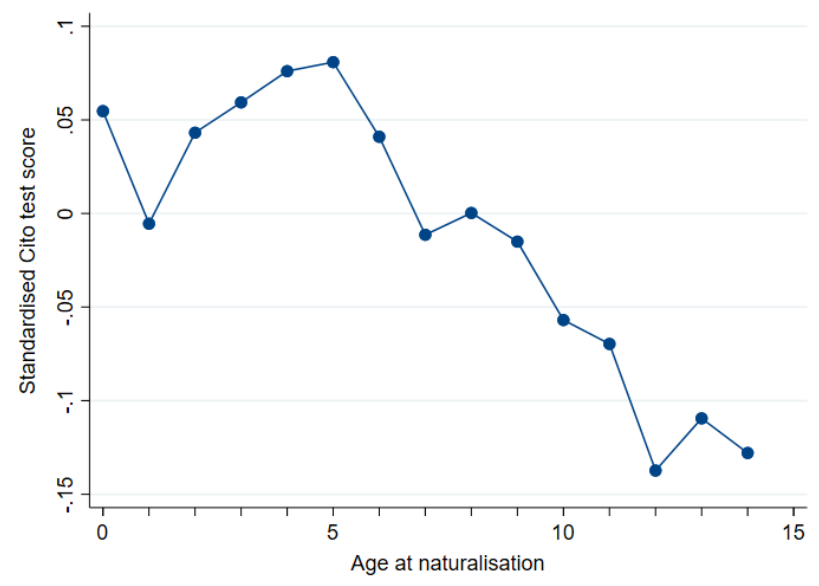

Figure C3: Average standardised Cito test scores for the children of immigrants born in the Netherlands, by age at naturalisation.

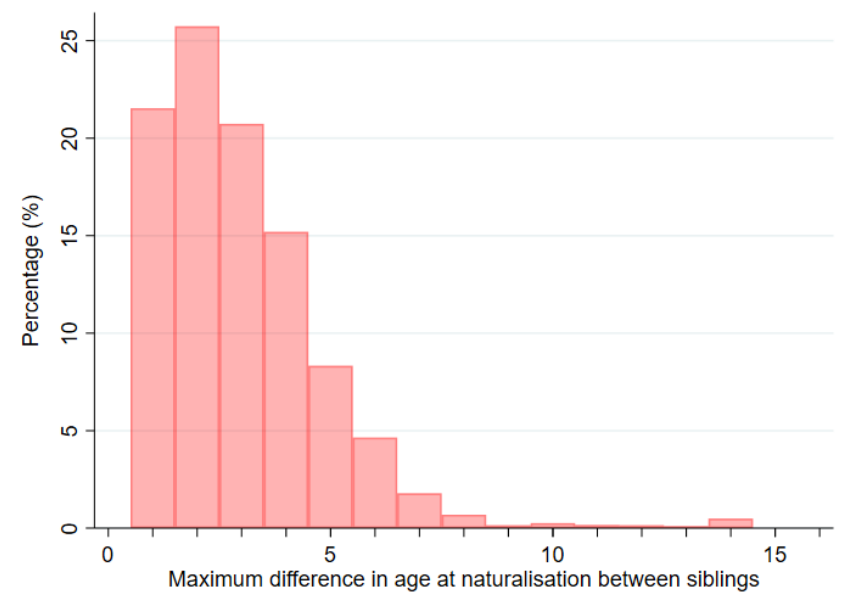

Figure C4: Difference in age at naturalisation between siblings in the sample of exposure-discordant families $(\mathrm{N}=14,393)$.

Note: I take the maximum difference in age at naturalisation in the families with three siblings or more. 


\begin{tabular}{|c|c|c|}
\hline Variable & $\mathrm{N}$ & $\%$ \\
\hline \multicolumn{3}{|l|}{ Gender } \\
\hline Male & 47,390 & 50.0 \\
\hline Female & 47,337 & 50.0 \\
\hline \multicolumn{3}{|l|}{ Birth order } \\
\hline Non first-born & 62,202 & 65.7 \\
\hline First-born & 32,525 & 34.3 \\
\hline \multicolumn{3}{|l|}{ Date of birth } \\
\hline$\leq 1995$ & 5,982 & 6.3 \\
\hline$\overline{1996}$ & 10,561 & 11.2 \\
\hline 1997 & 10,819 & 11.4 \\
\hline 1998 & 11,118 & 11.7 \\
\hline 1999 & 11,547 & 12.2 \\
\hline 2000 & 12,543 & 13.2 \\
\hline 2001 & 12,489 & 13.2 \\
\hline 2002 & 11,957 & 12.6 \\
\hline$\geq 2003$ & 7,711 & 8.1 \\
\hline \multicolumn{3}{|l|}{$\bar{N}$ umber of children } \\
\hline 1 & 9,165 & 9.7 \\
\hline 2 & 30,299 & 32.0 \\
\hline 3 & 30,967 & 32.7 \\
\hline 4 & 16,590 & 17.5 \\
\hline 5 & 5,470 & 5.8 \\
\hline 6 & 1,647 & 1.7 \\
\hline 7 (and more) & 589 & 0.6 \\
\hline \multicolumn{3}{|l|}{ Type of household } \\
\hline Two-parent & 78,115 & 82.5 \\
\hline Single-parent & 16,612 & 17.5 \\
\hline \multicolumn{3}{|l|}{ SES status mother } \\
\hline Employee or self-employed & 36,444 & 38.5 \\
\hline Reception of benefits & 30,341 & 32.0 \\
\hline No declared income & 27,368 & 28.9 \\
\hline Missing information & 574 & 0.6 \\
\hline \multicolumn{3}{|l|}{ SES status father } \\
\hline Employee or self-employed & 59,051 & 62.3 \\
\hline Reception of benefits & 28,071 & 29.6 \\
\hline No declared income & 4,144 & 4.4 \\
\hline Missing information & 3,461 & 3.7 \\
\hline \multicolumn{3}{|c|}{ Parents' homeownership status } \\
\hline
\end{tabular}

Table C3: Descriptive statistics for covariates 


\begin{tabular}{lrr}
\hline Variable & $\mathrm{N}$ & $\%$ \\
\hline Renters & 64,312 & 67.9 \\
Homeowners & 30,415 & 32.1 \\
Household income & & \\
First tercile & 30,786 & 32.5 \\
Second tercile & 31,119 & 32.9 \\
Third tercile & 31,871 & 33.7 \\
Missing Income & 951 & 1.0 \\
Parents' highest educational level & \\
Low & 42,258 & 44.6 \\
Middle & 26,651 & 28.1 \\
High & 12,359 & 13.1 \\
Missing & 13,459 & 14.2 \\
Mother's country of birth & & \\
Afghanistan & 1,756 & 1.9 \\
China & 2,717 & 2.9 \\
Irak & 2,558 & 2.7 \\
Iran & 1,038 & 1.1 \\
Morocco & 33,729 & 35.6 \\
Other EU countries & 2,808 & 3.0 \\
Other non-EU countries & 16,830 & 17.8 \\
Turkey & 29,453 & 31.1 \\
Yugoslavia & 3,838 & 4.1 \\
Total & $\mathbf{9 4 , 7 2 7}$ & $\mathbf{1 0 0 . 0}$ \\
\hline
\end{tabular}

Table C3 Continued: Descriptive statistics for covariates 
Appendix C

\begin{tabular}{cccc}
\hline Age & $\mathrm{N}$ & $\begin{array}{c}\text { \% in the } \\
\text { full } \\
\text { sample }\end{array}$ & $\begin{array}{c}\% \\
\text { among } \\
\text { foreign } \\
\text { citizens } \\
\text { at birth }\end{array}$ \\
\hline 0 & 62,338 & 65.8 & - \\
1 & 3,555 & 3.8 & 11.0 \\
2 & 3,445 & 3.6 & 10.6 \\
3 & 2,815 & 3.0 & 8.7 \\
4 & 2,503 & 2.6 & 7.7 \\
5 & 2,153 & 2.3 & 6.7 \\
6 & 1,697 & 1.8 & 5.2 \\
7 & 1,293 & 1.4 & 4.0 \\
8 & 1,095 & 1.2 & 3.4 \\
9 & 987 & 1.0 & 3.1 \\
10 & 879 & 0.9 & 2.7 \\
11 & 760 & 0.8 & 2.4 \\
12 & 702 & 0.7 & 2.2 \\
13 & 614 & 0.7 & 1.9 \\
14 & 464 & 0.5 & 1.4 \\
15 & 361 & 0.4 & 1.1 \\
16 & 250 & 0.3 & 0.8 \\
17 & 147 & 0.2 & 0.5 \\
18 & 444 & 0.5 & 1.4 \\
19 & 365 & 0.4 & 1.1 \\
20 & 50 & 0.1 & 0.2 \\
21 & 7,810 & 8.2 & 24.1 \\
Total & 94,727 & 100.0 & 100.0 \\
\hline & & & \\
\hline
\end{tabular}

Table C4: Distribution of age at naturalisation in the full sample $(\mathrm{N}=94,727)$. 


\section{Appendix between-within linear mixed model}

\section{Model description}

I analyse the within-family effect of age at naturalisation using the so-called "hybrid" or "correlated random-effects" model (Mundlak, 1978; Allison, 2009). This model separates within- and between-effects in a random-effects framework. Because of this defining feature, it has been increasingly known as the "between-within" model, following a suggestion from Sjölander et al. (2013). Contrary to standard fixed-effects modeling, the between-within model explicitly models heterogeneity bias and does not control out family-invariant covariates (Bell and Jones, 2015).

Let subscript $i$ denotes the individual level and $j$ denotes the family level. A standard random-effects model is:

$$
\left\{\begin{array}{l}
y_{i j}=\beta_{0}^{R E}+\beta_{1}^{R E} x_{i j}+\beta_{2}^{R E} c_{j}+\left(\mu_{j}+\epsilon_{i j}\right) \\
E\left(\mu_{j} \mid x_{i j}, c_{j}\right)=0
\end{array}\right.
$$

where $y_{i j}$ is the educational outcome of child $i$ in family $j, x_{i j}$ a (serie of) covariate(s) measured at the individual level with $\beta_{1}^{R E}$, and $c_{j}$ a (serie of) covariate(s) measured at the family level with $\beta_{2}^{R E}$. The idiosyncratic error $\epsilon_{i j}\left(\sim N\left(0, \sigma_{\epsilon}^{2}\right)\right)$ and the unmeasured cluster-level effect $\mu_{j}\left(\sim N\left(0, \sigma_{\mu}^{2}\right)\right)$ constitute the random part of the model. A main reason why fixed-effects models are usually preferred over random-effects models is that the latter assume that there is no unobserved heterogeneity at the cluster level, i.e., $E\left(\mu_{j} \mid x_{i j}, c_{j}\right)=0$.

By contrast, the between-within approach explicitly models the correlation between $\mu_{j}$ and $x_{i j}$ with the assumption that the unmeasured cluster-level effect depends on the mean values of $x_{i j}: \mu_{j}=\gamma \overline{x_{j}}+\delta_{j}$, with $\delta_{j} \sim N\left(0, \sigma_{\delta}^{2}\right)$. This allows to pick up potential correlation between the unmeasured cluster effect $\mu_{j}$ and the individual-level variables. Following this assumption, equation of model (C.1) can be reformulated by decomposing the individual-level variables into a between- $\left(\overline{x_{j}}=n_{i}^{-1} \sum_{t=1}^{n_{i}} x_{i j}\right)$ and a within-cluster $\left(x_{i j}-\overline{x_{j}}\right)$ component (Allison, 2009; Schunck, 2013, p.66), such that

$$
\left\{\begin{array}{l}
y_{i j}=\beta_{0}^{B W}+\beta_{1}^{B W}\left(x_{i j}-\overline{x_{j}}\right)+\beta_{2}^{B W} c_{j}+\beta_{3}^{B W} \overline{x_{j}}+\left(\delta_{j}+\epsilon_{i j}\right) \\
E\left(\delta_{j} \mid x_{i j}, c_{j}\right)=0
\end{array}\right.
$$




\section{Appendix C}

Under this formulation, the within- $\left(\beta_{1}^{B W}\right)$ and between-cluster $\left(\beta_{3}^{B W}=\beta_{1}^{B W}+\right.$ $\gamma$ ) effects are now clearly separated. $\hat{\beta}_{1}^{B W}$ is identical to the fixed-effects estimator (Mundlak, 1978) and is consistent for $\beta_{1}^{B W}$ under rather general conditions in the linear case such as ours (Brumback et al., 2017, p.3842) ${ }^{4}$. By contrast, $\hat{\beta}_{3}^{B W}$ is not robust to unobserved heterogeneity at the family level: it is biased if $E\left(\mu_{j} \mid x_{i j}, c_{j}\right) \neq 0$ (Schunck and Perales, 2017, p.95).

Calculating the between-cluster effect is informative although the estimator is biased. It informs about the extent to which the estimator $\hat{\beta}_{1}^{R E}$ is biased when unobserved heterogeneity is not modelled (Schunck and Perales 2017, 96). More specifically, testing if $\beta_{1}^{B W}=\beta_{3}^{B W}$ provides a regression-based alternative to the Hausman test: if one cannot reject the hypothesis that the within-cluster and between-cluster effects are equal, (C.2) collapses to the random-effects model (C.1) and there is no evidence against $E\left(\mu_{j} \mid x_{i j}, c_{j}\right)=0$ (Snijders and Berkhof, 2008, p.145).

${ }^{4}$ Brumback et al. (2017, p.3842) show in a generalised linear mixed model framework that the estimator $\hat{\beta}_{1}^{B W}$ is consistent for $\beta_{1}$ regardless of whether $\mu_{j}=\gamma \overline{x_{j}}+\delta_{j}$, under the conditions that the link function is the identity link and that the variance $\operatorname{var}\left(y_{i j} \mid x_{i j}, c_{j}, \mu_{j}\right)$ is constant. 
Full between-within model

\begin{tabular}{|c|c|c|c|c|c|c|}
\hline & \multicolumn{2}{|c|}{ Random-effects } & \multicolumn{2}{|c|}{ Within-effects } & \multicolumn{2}{|c|}{ Between-effects } \\
\hline & $\beta_{1}^{R E}$ & $p$ & $\beta_{1}^{W B}$ & $p$ & $\beta_{3}^{W B}$ & $p$ \\
\hline \multicolumn{7}{|l|}{ Age at naturalisation } \\
\hline Age 0 & & & 0.105 & 0.123 & 0.094 & 0.000 \\
\hline Age 1-2 & & & 0.120 & 0.070 & 0.079 & 0.000 \\
\hline Age 3-4 & & & 0.144 & 0.025 & 0.086 & 0.000 \\
\hline Age 5-6 & & & 0.127 & 0.042 & 0.086 & 0.000 \\
\hline Age 7-10 & & & 0.101 & 0.068 & 0.053 & 0.008 \\
\hline Age 11-13 & & & 0.051 & 0.308 & 0.004 & 0.868 \\
\hline Age $\geq 14$ & & & ref. & ref. & ref. & ref. \\
\hline \multicolumn{7}{|l|}{ Gender } \\
\hline Male & & & ref. & ref. & ref. & ref. \\
\hline Female & & & -0.086 & 0.000 & -0.052 & 0.000 \\
\hline \multicolumn{7}{|l|}{ Birth order } \\
\hline Non first-born & & & ref. & ref. & ref. & ref. \\
\hline First-born & & & 0.013 & 0.299 & 0.080 & 0.000 \\
\hline \multicolumn{7}{|l|}{ Date of birth } \\
\hline$\leq 1995$ & & & ref. & ref. & ref. & ref. \\
\hline$\overline{1996}$ & & & 0.078 & 0.001 & 0.222 & 0.000 \\
\hline 1997 & & & 0.048 & 0.042 & 0.213 & 0.000 \\
\hline 1998 & & & 0.051 & 0.032 & 0.186 & 0.000 \\
\hline 1999 & & & 0.011 & 0.663 & 0.181 & 0.000 \\
\hline 2000 & & & 0.021 & 0.416 & 0.178 & 0.000 \\
\hline 2001 & & & 0.014 & 0.609 & 0.163 & 0.000 \\
\hline 2002 & & & 0.010 & 0.726 & 0.162 & 0.000 \\
\hline$\geq 2003$ & & & 0.063 & 0.046 & 0.330 & 0.000 \\
\hline $\bar{N}$ umber of children & & & 0.016 & 0.157 & -0.037 & 0.000 \\
\hline \multicolumn{7}{|l|}{ Household type } \\
\hline Two-parent households & & & ref. & ref. & ref. & ref. \\
\hline Single-parent household & & & -0.030 & 0.346 & -0.097 & 0.000 \\
\hline \multicolumn{7}{|l|}{ Mother SES status } \\
\hline Employee or self-employed & & & ref. & ref. & ref. & ref. \\
\hline Reception of benefits & & & 0.039 & 0.091 & -0.033 & 0.001 \\
\hline No declared income & & & 0.026 & 0.240 & 0.034 & 0.000 \\
\hline Missing information & & & -0.085 & 0.641 & -0.041 & 0.321 \\
\hline \multicolumn{7}{|l|}{ Father SES status } \\
\hline \multicolumn{7}{|c|}{ Continued } \\
\hline
\end{tabular}




\begin{tabular}{|c|c|c|c|c|c|c|}
\hline & \multicolumn{2}{|c|}{ Random-effects } & \multicolumn{2}{|c|}{ Within-effects } & \multicolumn{2}{|c|}{ Between-effects } \\
\hline & $\beta_{1}^{R E}$ & $p$ & $\beta_{1}^{W B}$ & $p$ & $\beta_{3}^{W B}$ & $p$ \\
\hline Employee or self-employed & & & ref. & ref. & ref. & ref. \\
\hline Reception of benefits & & & -0.016 & 0.445 & -0.040 & 0.000 \\
\hline No declared income & & & 0.009 & 0.779 & 0.017 & 0.323 \\
\hline Missing information & & & -0.052 & 0.327 & -0.007 & 0.715 \\
\hline \multicolumn{7}{|l|}{ Homeownership status } \\
\hline Parents are renters & & & ref. & ref. & ref. & ref. \\
\hline Parents are homeowners & & & -0.053 & 0.161 & 0.110 & 0.000 \\
\hline \multicolumn{7}{|l|}{ Household income } \\
\hline First income decile & & & ref. & ref. & ref. & ref. \\
\hline Second income decile & & & -0.014 & 0.378 & -0.002 & 0.841 \\
\hline Third income decile & & & -0.001 & 0.953 & 0.056 & 0.000 \\
\hline Missing income & & & -0.138 & 0.022 & -0.086 & 0.015 \\
\hline \multicolumn{7}{|l|}{ Highest education level } \\
\hline Low education & ref. & ref. & & & & \\
\hline Middle education & 0.146 & 0.000 & & & & \\
\hline High education & 0.455 & 0.000 & & & & \\
\hline Missing education & 0.131 & 0.000 & & & & \\
\hline \multicolumn{7}{|l|}{ Mother's country of birth } \\
\hline Other EU countries & re.f & ref. & & & & \\
\hline Afghanistan & 0.136 & 0.000 & & & & \\
\hline China & 0.497 & 0.000 & & & & \\
\hline Irak & -0.041 & 0.140 & & & & \\
\hline Iran & 0.066 & 0.062 & & & & \\
\hline Morocco & -0.200 & 0.000 & & & & \\
\hline Other non-EU countries & -0.009 & 0.646 & & & & \\
\hline Turkey & -0.349 & 0.000 & & & & \\
\hline Yugoslavia & -0.073 & 0.003 & & & & \\
\hline Constant & -0.114 & 0.000 & & & & \\
\hline Observations & 94,727 & & & & & \\
\hline Family clusters & 69,894 & & & & & \\
\hline
\end{tabular}

Table C5 Continued: Between-within model for the standardised test scores obtained at the end of primary school by children of immigrants born in the Netherlands.

Note: The between-within model does not estimate separate effects for the variables of parental education and mother's country of birth, since these variables only vary between clusters. The estimated effects for these two variables are the same as those in a standard random-effects model. 
Comparison with a standard OLS model

\begin{tabular}{|c|c|c|c|c|c|c|c|c|}
\hline \multirow[b]{2}{*}{ Age at nat. } & \multicolumn{2}{|c|}{ OLS } & \multicolumn{2}{|c|}{ Random-effects } & \multicolumn{4}{|c|}{ Between-within } \\
\hline & $\beta_{1}^{O L S}$ & $p$ & $\beta_{1}^{R E}$ & $p$ & $\beta_{1}^{W B}$ & $p$ & $\beta_{3}^{W B}$ & $p$ \\
\hline 0 & 0.102 & $(0.000)$ & 0.096 & $(0.000)$ & 0.105 & $(0.125)$ & 0.095 & $(0.000)$ \\
\hline $1-2$ & 0.089 & $(0.000)$ & 0.087 & $(0.000)$ & 0.119 & $(0.070)$ & 0.079 & $(0.000)$ \\
\hline $3-4$ & 0.100 & $(0.000)$ & 0.101 & $(0.000)$ & 0.144 & $(0.025)$ & 0.086 & $(0.000)$ \\
\hline $5-6$ & 0.096 & $(0.000)$ & 0.092 & $(0.000)$ & 0.127 & $(0.043)$ & 0.087 & $(0.000)$ \\
\hline $7-10$ & 0.060 & $(0.000)$ & 0.059 & $(0.001)$ & 0.101 & $(0.069)$ & 0.054 & $(0.007)$ \\
\hline $11-13$ & 0.009 & $(0.700)$ & 0.012 & $(0.600)$ & 0.051 & $(0.308)$ & 0.005 & $(0.859)$ \\
\hline$\geq 14$ & ref. & ref. & ref. & ref. & ref. & ref. & ref. & ref. \\
\hline Observations & \multicolumn{2}{|c|}{94,727} & \multicolumn{2}{|c|}{94,727} & \multicolumn{4}{|c|}{94,727} \\
\hline Family clusters & \multicolumn{2}{|c|}{-} & \multicolumn{2}{|c|}{69,894} & \multicolumn{4}{|c|}{69,894} \\
\hline Covariates & \multicolumn{2}{|c|}{ All ${ }^{*}$} & \multicolumn{2}{|c|}{ All* } & \multicolumn{4}{|c|}{ All* } \\
\hline$R^{2}$ & \multicolumn{2}{|c|}{0.099} & \multicolumn{2}{|c|}{0.098} & \multicolumn{4}{|c|}{-} \\
\hline
\end{tabular}

Table C6: OLS, random-effects and between-within models for the standardised test scores obtained at the end of primary school by children of immigrants born in the Netherlands, by age at naturalisation groups.

*I include all the covariates described in Table C2: gender, birth order, date of birth, household type, mother's and father's SES status, homeownership status, household income, highest educational level among parents and mother's country of origin. 


\section{Appendix random-effects models}

Interactions with parental education

$>$ With naturalisation dummy

\begin{tabular}{lcc}
\hline & $\beta$ & $p$ \\
\hline $\begin{array}{l}\text { Citizenship status } \\
\text { (ref. not naturalised at age 14) }\end{array}$ & & \\
Naturalised before 14 & 0.124 & 0.000 \\
Parental education & & \\
Low education & ref. & $()$. \\
Middle education & 0.150 & 0.000 \\
High education & 0.601 & 0.000 \\
Missing education & 0.269 & 0.000 \\
Interactions citizenship x parental education & & \\
Low education $\times$ Naturalised before 14 & ref. & $()$. \\
Middle education $\times$ Naturalised before 14 & 0.000 & 0.993 \\
High education $\times$ Naturalised before 14 & -0.147 & 0.000 \\
Missing education $\times$ Naturalised before 14 & -0.149 & 0.000 \\
\hline Observations & 94,727 & \\
Family clusters & 69,894 & \\
Covariates & All* & \\
$R^{2}$ & 0.099 & \\
\hline
\end{tabular}

Table C7: Random-effects model for the standardised test scores obtained at the end of primary school by children of immigrants born in the Netherlands, with interactions between naturalisation dummy and parental education.

*All the other covariates described in Table C2 are included: gender, birth order, date of birth, household type, mother's and father's SES status, homeownership status, household income, mother's country of birth. 
$>$ With age at naturalisation

\begin{tabular}{lcc}
\hline & $\beta$ & \\
\hline Age at naturalisation & & \\
Age 0 & 0.131 & 0.000 \\
Age 1-2 & 0.109 & 0.000 \\
Age 3-4 & 0.127 & 0.000 \\
Age 5-6 & 0.101 & 0.000 \\
Age 7-10 & 0.115 & 0.000 \\
Age 11-13 & 0.078 & 0.010 \\
Age $\geq 14$ & ref. & ref. \\
Parents' homeownership status & & \\
Renters & ref. & ref. \\
Homeowners & 0.108 & 0.000 \\
Highest parental education level & & \\
Low education & ref. & ref. \\
Middle education & 0.149 & 0.000 \\
High education & 0.601 & 0.000 \\
Missing education & 0.268 & 0.000 \\
Highest parental education level $\times$ Age at naturalisation & \\
Low education $\times$ Age 0 & ref. & ref. \\
Low education $\times$ Age 1-2 & ref. & ref. \\
Low education $\times$ Age 3-4 & ref. & ref. \\
Low education $\times$ Age 5-6 & ref. & ref. \\
Low education $\times$ Age 7-10 & ref. & ref. \\
Low education $\times$ Age 11-13 & ref. & ref. \\
Low education $\times$ Age $\geq 14$ & ref. & ref. \\
Middle education $\times$ Age 0 & -0.002 & 0.927 \\
Middle education $\times$ Age 1-2 & 0.014 & 0.707 \\
Middle education $\times$ Age 3-4 & 0.014 & 0.712 \\
Middle education $\times$ Age 5-6 & 0.054 & 0.210 \\
Middle education $\times$ Age 7-10 & -0.025 & 0.544 \\
Middle education $\times$ Age 11-13 & -0.048 & 0.372 \\
Middle education $\times$ Age $\geq 14$ & ref. & ref. \\
High education $\times$ Age 0 & -0.148 & 0.000 \\
High education $\times$ Age 1-2 & -0.125 & 0.013 \\
High education $\times$ Age 3-4 & -0.125 & 0.018 \\
High education $\times$ Age 5-6 & -0.107 & 0.062 \\
& & \\
& & \\
& & \\
Hinued
\end{tabular}

Table C8: Random-effects model for the standardised test scores obtained at the end of primary school by children of immigrants born in the Netherlands, with interactions between age at naturalisation and parental education. 


\begin{tabular}{lcc}
\hline & $\beta$ & $p$ \\
\hline High education $\times$ Age 7-10 & -0.222 & 0.000 \\
High education $\times$ Age 11-13 & -0.223 & 0.005 \\
High education $\times$ Age $\geq 14$ & ref. & ref. \\
Missing education $\times$ Age 0 & -0.147 & 0.000 \\
Missing education $\times$ Age 1-2 & -0.116 & 0.009 \\
Missing education $\times$ Age 3-4 & -0.149 & 0.002 \\
Missing education $\times$ Age 5-6 & -0.120 & 0.033 \\
Missing education $\times$ Age 7-10 & -0.194 & 0.000 \\
Missing education $\times$ Age 11-13 & -0.284 & 0.000 \\
Missing education $\times$ Age $\geq 14$ & ref. & ref. \\
\hline Observations & 94,727 & \\
Family clusters & 69,894 & \\
Covariates & All* & \\
$R^{2}$ & 0.099 & \\
\hline
\end{tabular}

Table C8 Continued: Random-effects model for the standardised test scores obtained at the end of primary school by children of immigrants born in the Netherlands, with interactions between age at naturalisation and parental education.

*I include all the covariates described in Table C2. 
Interactions with parental education and homeownership status

With naturalisation dummy

\begin{tabular}{lcc}
\hline & $\beta$ & $p$ \\
\hline $\begin{array}{l}\text { Citizenship status } \\
\text { (ref. not naturalised at age 14) }\end{array}$ & & \\
$\begin{array}{l}\text { Naturalised before 14 } \\
\text { Parental education }\end{array}$ & 0.140 & 0.000 \\
Low education & ref. & $()$. \\
Middle education & 0.140 & 0.000 \\
High education & 0.575 & 0.000 \\
Missing education & 0.248 & 0.000 \\
Parental homeownership status & & \\
Renters & ref. & $()$. \\
Homeowners & 0.197 & 0.000 \\
Interactions citizenship x parental education & & \\
Low education $\times$ Naturalised before 14 & ref. & $()$. \\
Middle education $\times$ Naturalised before 14 & 0.011 & 0.689 \\
High education $\times$ Naturalised before 14 & -0.119 & 0.002 \\
Missing education $\times$ Naturalised before 14 & -0.126 & 0.000 \\
Interactions citizenship x parental homeownership status & & \\
Renters $\times$ Naturalised before 14 & ref. & $()$. \\
Homeowners $\times$ Naturalised before 14 & -0.095 & 0.000 \\
\hline Observations & 94,727 & \\
Family clusters & 69,894 & \\
Covariates & All* & \\
$R^{2}$ & 0.099 & \\
\hline
\end{tabular}

Table C9: Random-effects model for the standardised test scores obtained at the end of primary school by children of immigrants born in the Netherlands, with interactions between naturalisation dummy and parental education and homeownership status. *All the other covariates described in Table C2 are included: gender, birth order, date of birth, household type, mother's and father's SES status, household income, mother's country of birth. 
$>$ With age at naturalisation

\begin{tabular}{lcc}
\hline & $\beta$ & $p$ \\
\hline Age at naturalisation & & \\
Age 0 & 0.150 & 0.000 \\
Age 1-2 & 0.123 & 0.000 \\
Age 3-4 & 0.132 & 0.000 \\
Age 5-6 & 0.115 & 0.000 \\
Age 7-10 & 0.124 & 0.000 \\
Age 11-13 & 0.095 & 0.002 \\
Age $\geq 14$ & ref. & ref. \\
Parents' homeownership status & & \\
Renters & ref. & ref. \\
Homeowners & 0.199 & 0.000 \\
Highest parental education level & & \\
Low education & ref. & ref. \\
Middle education & 0.139 & 0.000 \\
High education & 0.574 & 0.000 \\
Missing education & 0.246 & 0.000 \\
Highest parental education level $\times$ Age at naturalisation & \\
Low education $\times$ Age 0 & ref. & ref. \\
Low education $\times$ Age 1-2 & ref. & ref. \\
Low education $\times$ Age 3-4 & ref. & ref. \\
Low education $\times$ Age 5-6 & ref. & ref. \\
Low education $\times$ Age 7-10 & ref. & ref. \\
Low education $\times$ Age 11-13 & ref. & ref. \\
Low education $\times$ Age $\geq 14$ & ref. & ref. \\
Middle education $\times$ Age 0 & 0.010 & 0.704 \\
Middle education $\times$ Age 1-2 & 0.023 & 0.536 \\
Middle education $\times$ Age 3-4 & 0.017 & 0.670 \\
Middle education $\times$ Age 5-6 & 0.063 & 0.143 \\
Middle education $\times$ Age 7-10 & -0.019 & 0.655 \\
Middle education $\times$ Age 11-13 & -0.036 & 0.497 \\
Middle education $\times$ Age $\geq 14$ & ref. \\
High education $\times$ Age 0 & -0.115 & 0.003 \\
High education $\times$ Age 1-2 & -0.099 & 0.051 \\
High education $\times$ Age 3-4 & -0.110 & 0.039 \\
& & \\
& & \\
& & \\
& & \\
Motinued
\end{tabular}

Table C10: Random-effects model for the standardised test scores obtained at the end of primary school by children of immigrants born in the Netherlands, with interactions between age at naturalisation and parental education and homeownership status. 


\begin{tabular}{|c|c|c|}
\hline & $\beta$ & $p$ \\
\hline High education $\times$ Age 5-6 & -0.081 & 0.163 \\
\hline High education $\times$ Age 7-10 & -0.201 & 0.000 \\
\hline High education $\times$ Age $11-13$ & -0.193 & 0.015 \\
\hline High education $\times$ Age $\geq 14$ & ref. & ref. \\
\hline Missing education $\times$ Age 0 & -0.121 & 0.000 \\
\hline Missing education $\times$ Age 1-2 & -0.096 & 0.034 \\
\hline Missing education $\times$ Age $3-4$ & -0.138 & 0.005 \\
\hline Missing education $\times$ Age 5-6 & -0.098 & 0.083 \\
\hline Missing education $\times$ Age 7-10 & -0.177 & 0.001 \\
\hline Missing education $\times$ Age 11-13 & -0.259 & 0.000 \\
\hline Missing education $\times$ Age $\geq 14$ & ref. & ref. \\
\hline \multicolumn{3}{|c|}{ Parents' homeownership status $\times$ Age at naturalisation } \\
\hline Renters $\times$ Age 0 & ref. & ref. \\
\hline Renters $\times$ Age $1-2$ & ref. & ref. \\
\hline Renters $\times$ Age 3-4 & ref. & ref. \\
\hline Renters $\times$ Age 5-6 & ref. & ref. \\
\hline Renters $\times$ Age 7-10 & ref. & ref. \\
\hline Renters $\times$ Age $11-13$ & ref. & ref. \\
\hline Renters $\times$ Age $\geq 14$ & ref. & ref. \\
\hline Homeowners $\times$ Age 0 & -0.109 & 0.000 \\
\hline Homeowners $\times$ Age $1-2$ & -0.083 & 0.015 \\
\hline Homeowners $\times$ Age 3-4 & -0.026 & 0.498 \\
\hline Homeowners $\times$ Age $5-6$ & -0.088 & 0.039 \\
\hline Homeowners $\times$ Age 7-10 & -0.052 & 0.221 \\
\hline Homeowners $\times$ Age 11-13 & -0.112 & 0.052 \\
\hline Homeowners $\times$ Age $\geq 14$ & ref. & ref. \\
\hline Observations & 94,727 & \\
\hline Family clusters & 69,894 & \\
\hline Covariates & All* & \\
\hline$R^{2}$ & 0.099 & \\
\hline
\end{tabular}

Table C10 Continued: Random-effects model for the standardised test scores obtained at the end of primary school by children of immigrants born in the Netherlands, with interactions between age at naturalisation and parental education and homeownership status.

*I include all the covariates described in Table C2. 


\section{Appendix C}

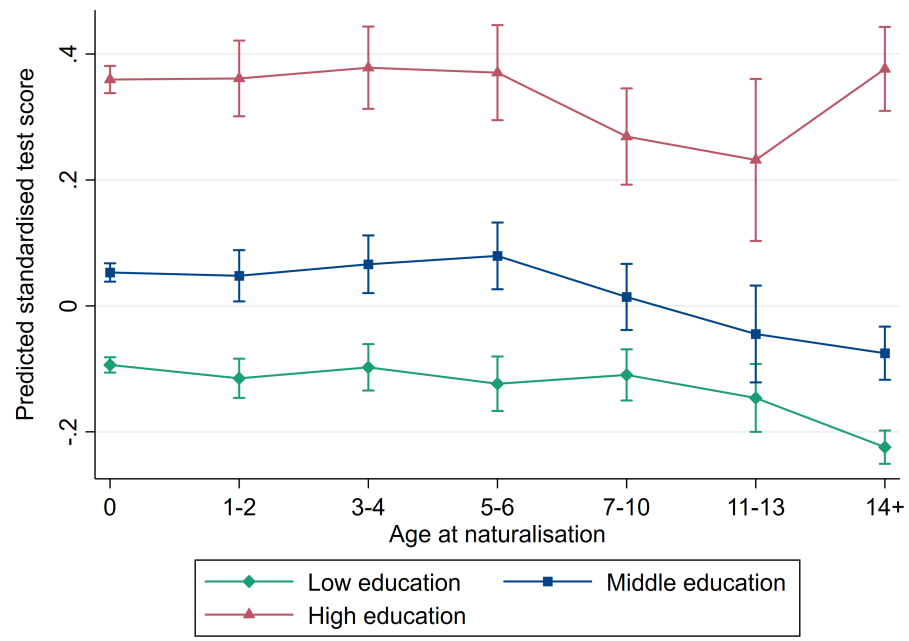

Figure C5: Predicted average standardised test score obtained at the end of primary school by children of immigrants born in the Netherlands, conditionally on age at naturalisation and parents' highest education level.

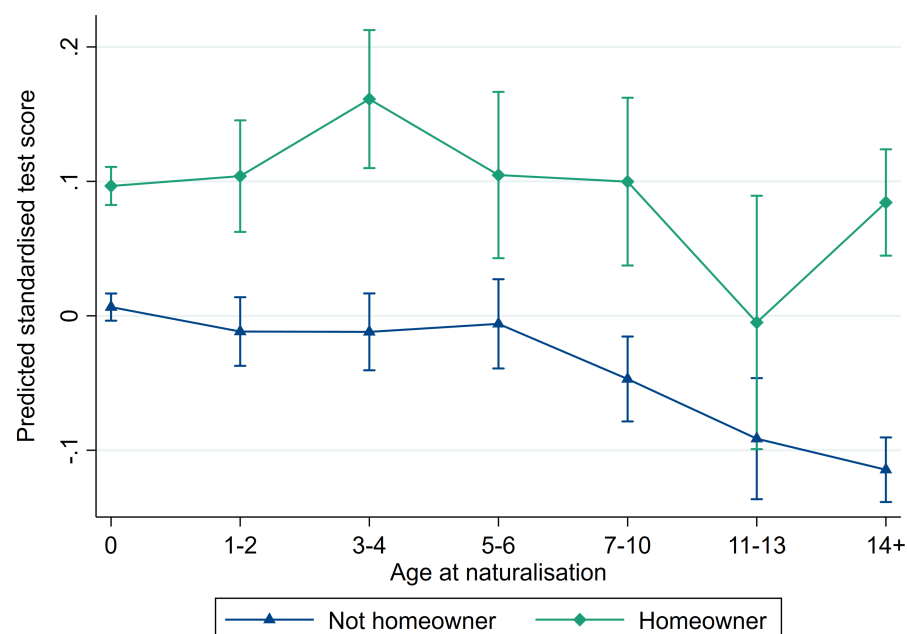

Figure C6: Predicted average standardised test score obtained at the end of primary school by children of immigrants born in the Netherlands, conditionally on age at naturalisation and parents' homeownership status. 


\section{Appendix bounding estimator}

To my knowledge, Oster's bounding technique has not been developed for non-binary categorical treatment variables. I therefore use a dummy variable for the effect of naturalisation, capturing whether the respondent has acquired Dutch citizenship before the age of 14. Table C11 displays the results for the OLS, random-effects and between-within specifications when this dummy is used instead of age at naturalisation groups.

\begin{tabular}{lccccc}
\hline & OLS & Random-effects & \multicolumn{2}{c}{ Between-within } & Test \\
& $\beta_{1}^{O L S}$ & $\beta_{1}^{R E}$ & $\beta_{1}^{W B}$ & $\beta_{3}^{W B}$ & $\beta_{1}^{W B}=\beta_{3}^{W B}$ \\
\hline Naturalisation & 0.095 & 0.089 & 0.073 & 0.089 & - \\
before 14 & $(0.000)$ & $(0.000)$ & $(0.126)$ & $(0.000)$ & $(0.739)$ \\
\hline Observations & 94,727 & 94,727 & 94,727 & \\
Family clusters & - & 69,894 & 69,894 & \\
Covariates & All* & All & All & \\
$R^{2}$ & 0.098 & 0.098 & - & - \\
\hline
\end{tabular}

Table C11: OLS, random-effects and between-within models for the standardised test scores obtained at the end of primary school by children of immigrants born in the Netherlands, by naturalisation dummy.

*I include all the covariates described in Table C2: gender, birth order, date of birth, household type, mother's and father's SES status, homeownership status, household income, highest educational level among parents and mother's country of birth.

To further explore the sensitivity of the results to omitted variable bias, I estimate $\beta^{\star}$ assuming a range of different values for $R_{\max }$ in Table C12. I set $\delta$ to 1 in all specifications because, following Altonji et al. (2005) and as shown by Oster $(2019,197)$, it is a reasonable cutoff when the most important controls are included in the model. It reflects the situation where the observables (e.g. parental education, income) are as important as the unobservables (e.g. parents' language proficiency and orientation towards the host society).

Note on $R_{\max }$ : As an alternative definition for $R_{\max }$, Oster suggests to use sibling correlation as a benchmark (Oster, 2019, p.198). In the present case, sibling correlation in test scores is equal to $\rho=0.52$. However, setting the $R_{\max }$ to this value would far exceed the usual explanatory power of social science models for individual behaviour, which is known to be relatively low (Altonji et al., 2005, p.171). As Table C12 shows below, the results for the 
bounding analysis are not robust to such a high $R_{\max }$.

\begin{tabular}{lcccccc}
\hline & \multicolumn{2}{c}{ Uncontrolled OLS } & & \multicolumn{2}{c}{ Controlled OLS } \\
\cline { 2 - 3 } \cline { 5 - 7 } & $\dot{\beta}$ & $\dot{R}$ & & $\tilde{\beta}$ & $\tilde{R}$ \\
\cline { 2 - 3 } & 0.164 & 0.016 & & 0.097 & 0.098 \\
& $(0.000)$ & & & $(0.000)$ & \\
\hline$R_{\max }$ & 0.13 & 0.15 & 0.17 & 0.19 & 0.2 \\
\hline Bias-adjusted treatment effect $\beta^{\star}$ & 0.071 & 0.052 & & 0.033 & 0.014 & 0.003 \\
& $(0.000)$ & $(0.000)$ & $(0.003)$ & $(0.230)$ & $(0.805)$ \\
\hline
\end{tabular}

Table C12: Bounding the effect of naturalisation on standardised test scores obtained at the end of primary education by children of immigrants born in the Netherlands. Note: p-values are in parentheses (standard-errors are bootstrapped using 1,000 replications). I set $\delta=1$, which reflects the situation where the observables are as important as the unobservables. The controlled regression includes all the covariates described in Table C2. The uncontrolled regression includes gender, birth order and date of birth, which are considered to be unrelated to the selection process. 


\section{Robustness checks}

Family definition based on both parents' identifiers

In the main analysis, I define families based on mothers' personal identifiers only. This is because there are about ten times as many children whose father's identifier is missing at least one year during the observation period as there are children whose mother's identifier is similarly missing. This suggests that children of immigrants are more likely to have a father than a mother who is not continuously registered as a Dutch resident. As continuous residence is a requirement for naturalisation, priority was given to mothers' identifiers.

However, without fathers' identifiers, it is difficult to correctly identify complex family patterns where, for example, siblings are born of the same mother but not of the same father. To ensure that the results are robust to alternative definitions of the family clusters, I use both mothers' and fathers' identifiers in a robustness check. This leads to 70,002 family clusters, versus 69,894 previously when only mothers' identifiers were considered. As Table C13 shows, this leads to very comparable results.

\begin{tabular}{|c|c|c|c|c|c|c|c|}
\hline & \multicolumn{2}{|c|}{ Random-effects } & \multicolumn{2}{|c|}{ Within-effects } & \multicolumn{2}{|c|}{ Between-effects } & \multirow{2}{*}{$\begin{array}{c}\beta_{1}^{W B}=\beta_{3}^{W B} \\
p\end{array}$} \\
\hline & $\beta_{1}^{R E}$ & $p$ & $\beta_{1}^{W B}$ & $p$ & $\beta_{3}^{W B}$ & $p$ & \\
\hline \multicolumn{8}{|l|}{ Age at nat. } \\
\hline Age 0 & 0.098 & 0.000 & 0.101 & 0.143 & 0.097 & 0.000 & 0.946 \\
\hline Age 1-2 & 0.087 & 0.000 & 0.113 & 0.092 & 0.080 & 0.000 & 0.633 \\
\hline Age 3-4 & 0.098 & 0.000 & 0.138 & 0.034 & 0.082 & 0.000 & 0.412 \\
\hline Age 5-6 & 0.090 & 0.000 & 0.117 & 0.065 & 0.087 & 0.000 & 0.653 \\
\hline Age 7-10 & 0.059 & 0.001 & 0.093 & 0.097 & 0.055 & 0.006 & 0.528 \\
\hline Age 11-13 & 0.011 & 0.618 & 0.046 & 0.364 & 0.004 & 0.889 & 0.461 \\
\hline Age $\geq 14$ & ref. & ref. & ref. & ref. & ref. & ref. & \\
\hline Observations & \multicolumn{2}{|c|}{94,727} & \multicolumn{4}{|c|}{94,727} & \\
\hline Family clusters & \multicolumn{2}{|c|}{70,002} & \multicolumn{4}{|c|}{70,002} & \\
\hline Covariates & \multicolumn{2}{|c|}{ All* } & \multicolumn{4}{|c|}{ All $^{*}$} & \\
\hline
\end{tabular}

Regression coefficients, $p$-values in parentheses

Table C13: Random-effects and between-within models for the standardised test scores obtained at the end of primary school by children of immigrants born in the Netherlands, by age at naturalisation.

*I include all the covariates described in Table C2. 
Age at naturalisation censored at age 10

Ideally, naturalisation should be measured before the outcome. However, one caveat is that students do not take the Cito test at the same age (see Table C1). In the Netherlands, entry into compulsory education is based on the age at the start of the school year, which means that each school level consists of at least two birth cohorts (including possible grade-repetition and grade-skipping). I therefore censor age at naturalisation at age 14, when the vast majority of students have already taken the test. This implies that those who naturalise at ages 11-13 may acquire Dutch citizenship shortly after taking the Cito test. Although this introduces a risk of anticipatory analysis - i.e., explaining students' current results by their future characteristics (Hoem and Kreyenfeld, 2006), I do not expect a major bias to the extent the naturalisation process starts at least a year before the respondent officially becomes - and is registered as - a Dutch citizen. Yet, as a robustness check, I used an alternative specification where age at naturalisation is censored at age 10. This ensures temporal consistency but gives a conservative estimate for the age at naturalisation, as those who naturalise after 10 before the Cito test are included in the censored group. As expected, coefficients are smaller in magnitude, but the results do not substantively alter my interpretation.

\begin{tabular}{|c|c|c|c|c|c|c|c|}
\hline & \multicolumn{2}{|c|}{ Random-effects } & \multicolumn{2}{|c|}{ Within-effects } & \multicolumn{2}{|c|}{ Between-effects } & \multirow{2}{*}{$\begin{array}{c}\beta_{1}^{W B}=\beta_{3}^{W B} \\
p\end{array}$} \\
\hline & $\beta_{1}^{R E}$ & $p$ & $\beta_{1}^{W B}$ & $p$ & $\beta_{3}^{W B}$ & $p$ & \\
\hline \multicolumn{8}{|l|}{ Age at nat. } \\
\hline Age 0 & 0.093 & 0.000 & 0.066 & 0.241 & 0.093 & 0.000 & 0.639 \\
\hline Age 1-2 & 0.084 & 0.000 & 0.081 & 0.133 & 0.078 & 0.000 & 0.953 \\
\hline Age 3-5 & 0.098 & 0.000 & 0.106 & 0.042 & 0.085 & 0.000 & 0.699 \\
\hline Age 6-10 & 0.090 & 0.000 & 0.089 & 0.076 & 0.086 & 0.000 & 0.950 \\
\hline Age 11-13 & 0.056 & 0.001 & 0.063 & 0.124 & 0.053 & 0.007 & 0.822 \\
\hline Age $\geq 14$ & ref. & ref. & ref. & ref. & ref. & ref. & \\
\hline Observations & \multicolumn{2}{|c|}{94,727} & \multicolumn{4}{|c|}{94,727} & \\
\hline Family clusters & \multicolumn{2}{|c|}{69,894} & \multicolumn{4}{|c|}{69,894} & \\
\hline Covariates & \multicolumn{2}{|c|}{ All* } & \multicolumn{4}{|c|}{ All ${ }^{*}$} & \\
\hline
\end{tabular}

Regression coefficients, $p$-values in parentheses

Table C14: Random-effects and between-within models for the standardised test scores obtained at the end of primary school by children of immigrants born in the Netherlands, by age at naturalisation censored at age 10 .

*I include all the covariates described in Table C2. 
Different age groupings for age at naturalisation

$>$ Age dummies

\begin{tabular}{|c|c|c|c|c|c|c|c|}
\hline & \multicolumn{2}{|c|}{ Random-effects } & \multicolumn{2}{|c|}{ Within-effects } & \multicolumn{2}{|c|}{ Between-effects } & \multirow{2}{*}{$\begin{array}{c}\beta_{1}^{W B}=\beta_{3}^{W B} \\
p\end{array}$} \\
\hline & $\beta_{1}^{R E}$ & $p$ & $\beta_{1}^{W B}$ & $p$ & $\beta_{3}^{W B}$ & $p$ & \\
\hline \multicolumn{8}{|l|}{ Age at nat. } \\
\hline Age 0 & 0.096 & 0.000 & 0.093 & 0.187 & 0.094 & 0.000 & 0.991 \\
\hline Age 1 & 0.078 & 0.000 & 0.096 & 0.172 & 0.072 & 0.001 & 0.744 \\
\hline Age 2 & 0.095 & 0.000 & 0.122 & 0.079 & 0.085 & 0.000 & 0.609 \\
\hline Age 3 & 0.099 & 0.000 & 0.123 & 0.077 & 0.085 & 0.000 & 0.610 \\
\hline Age 4 & 0.102 & 0.000 & 0.147 & 0.032 & 0.085 & 0.001 & 0.395 \\
\hline Age 5 & 0.094 & 0.000 & 0.116 & 0.093 & 0.093 & 0.000 & 0.757 \\
\hline Age 6 & 0.090 & 0.000 & 0.129 & 0.059 & 0.078 & 0.008 & 0.493 \\
\hline Age 7 & 0.061 & 0.025 & 0.070 & 0.305 & 0.077 & 0.022 & 0.929 \\
\hline Age 8 & 0.073 & 0.012 & 0.096 & 0.164 & 0.078 & 0.029 & 0.814 \\
\hline Age 9 & 0.066 & 0.029 & 0.155 & 0.021 & 0.030 & 0.425 & 0.105 \\
\hline Age 10 & 0.030 & 0.344 & 0.080 & 0.232 & 0.016 & 0.688 & 0.408 \\
\hline Age 11 & 0.030 & 0.380 & 0.071 & 0.282 & 0.024 & 0.578 & 0.550 \\
\hline Age 12 & 0.019 & 0.588 & 0.049 & 0.468 & 0.041 & 0.343 & 0.263 \\
\hline Age 13 & 0.024 & 0.521 & 0.034 & 0.622 & 0.035 & 0.453 & 0.996 \\
\hline Age $\geq 14$ & ref. & ref. & ref. & ref. & ref. & ref. & \\
\hline Observations & \multicolumn{2}{|c|}{94,727} & \multicolumn{4}{|c|}{94,727} & \\
\hline Family clusters & \multicolumn{2}{|c|}{69,894} & \multicolumn{4}{|c|}{69,894} & \\
\hline Covariates & \multicolumn{2}{|c|}{ All* } & \multicolumn{4}{|c|}{ All* } & \\
\hline
\end{tabular}

Regression coefficients, $p$-values in parentheses

Table C15: Random-effects and between-within models for the standardised test scores obtained at the end of primary school by children of immigrants born in the Netherlands, by age at naturalisation (age dummies).

*I include all the covariates described in Table C2. 


\begin{tabular}{|c|c|c|c|c|c|c|c|}
\hline & \multicolumn{2}{|c|}{ Random-effects } & \multicolumn{2}{|c|}{ Within-effects } & \multicolumn{2}{|c|}{ Between-effects } & \multirow{2}{*}{$\begin{array}{c}\beta_{1}^{W B}=\beta_{3}^{W B} \\
p\end{array}$} \\
\hline & $\beta_{1}^{R E}$ & $p$ & $\beta_{1}^{W B}$ & $p$ & $\beta_{3}^{W B}$ & $p$ & \\
\hline \multicolumn{8}{|l|}{ Age at nat. } \\
\hline Age 0 & 0.095 & 0.000 & 0.091 & 0.171 & 0.094 & 0.000 & 0.968 \\
\hline Age 1-2 & 0.086 & 0.000 & 0.107 & 0.098 & 0.079 & 0.000 & 0.674 \\
\hline Age 3-5 & 0.098 & 0.000 & 0.128 & 0.039 & 0.088 & 0.000 & 0.533 \\
\hline Age 6-10 & 0.068 & 0.000 & 0.103 & 0.061 & 0.060 & 0.001 & 0.458 \\
\hline Age $11-13$ & 0.012 & 0.592 & 0.051 & 0.311 & 0.004 & 0.881 & 0.409 \\
\hline Age $\geq 14$ & ref. & ref. & ref. & ref. & ref. & ref. & \\
\hline Observations & \multicolumn{2}{|c|}{94,727} & \multicolumn{4}{|c|}{94,727} & \\
\hline Family clusters & \multicolumn{2}{|c|}{69,894} & \multicolumn{4}{|c|}{69,894} & \\
\hline Covariates & \multicolumn{2}{|c|}{ All* } & \multicolumn{4}{|c|}{ All* } & \\
\hline
\end{tabular}

Regression coefficients, $p$-values in parentheses

Table C16: Random-effects and between-within models for the standardised test scores obtained at the end of primary school by children of immigrants born in the Netherlands, by age at naturalisation (6 instead of 7 clusters).

*I include all the covariates described in Table C2. 


\section{Impact Paragraph}

This dissertation analyses the relationship between the citizenship status of the children of immigrants and their educational outcomes in the Netherlands. As in two out of three countries in the world, children of immigrants born in the Netherlands do not have automatic rights to the citizenship of their country of birth. They instead rely on their parents' ability and desire to naturalise if they are to acquire Dutch citizenship before the age of majority. Surprisingly, the potential effects of host country citizenship - or lack thereof - on the life trajectories of children of immigrants have received limited attention from either a research or policy perspective. This dissertation aims to enhance scholarly understanding of the relevance of host country citizenship for children of immigrants, specifically by examining how citizens and non-citizens find their way in a complex educational system such as the Dutch one. By doing so, it provides valuable evidence of the barriers and opportunities that children of immigrants face in relation to citizenship, which should inform current policy and public debates on immigrant integration. In this section, I will briefly highlight the scientific and social impact of my dissertation and consider its potential in the near future.

The main objective of this dissertation was to conceptualise and evaluate the potential effects of host country citizenship on education in a comprehensive perspective. While previous research has focused primarily on whether citizenship matters for children of immigrants, I combined different strands of literature to develop a nuanced understanding of why and how citizenship status affects educational outcomes. The empirical findings show that citizenship has positive and substantial effects on the school trajectories of children of immigrants: students who have acquired Dutch citizenship not only perform better on tests at the end of primary school, but are also better equipped to move upward through secondary education and avoid dropping out of school compared to their non-citizen counterparts. However, contrary to previous research, this dissertation shows that the effects of citizenship are not uniform. Dutch citizenship matters most when it is acquired early in the settlement process, when children have not yet entered primary school, and is most relevant for children whose parents are at a disadvantage in the labour market and housing market. The evidence of timing and heterogeneous effects adds new layers of complexity in the relationship between citizenship 
and education, which merit greater attention in future research on the citizenship of children of immigrants. Finally, this dissertation employs innovative identification strategies to determine whether citizenship affects educational outcomes independently, beyond parents' self-selection into naturalisation. I provide additional evidence of a causal relationship between citizenship and education, where, with a few exceptions, previous studies were likely to measure spurious associations. In this respect, this dissertation contributed to the dissemination of methods that had previously received little attention in research on the citizenship of children of immigrants.

These findings are not only relevant to academic research, but also to policy makers. Ensuring equal opportunities for the children of immigrants is an important social challenge in most European societies, including the Netherlands. There is consistent evidence that some children face significant obstacles in school and in their adult life, including lack of socioeconomic and host country-specific resources and discrimination. Yet, it is rarely considered that ensuring smooth and rapid access to host country citizenship for these disadvantaged groups can be an effective policy lever. In particular, two important aspects have so far been neglected in Dutch political and parliamentary debates. First, while requirements for becoming a Dutch citizen have been increasingly restricted over the past decades to increase the obligations of naturalisation applicants, the potential consequences of such reforms for the children of immigrants are generally not taken into consideration. However, I demonstrate that restrictive naturalisation reforms not only prevent or delay the acquisition of Dutch citizenship by immigrants, but also have spillover negative repercussions on the propensity of their children to become Dutch. This dissertation therefore shows that the trend towards stricter naturalisation requirements has wider and longer-term consequences then currently envisaged in policy debates.

A second aspect pertains to school inequalities. In the Netherlands, differences in student outcomes based on ethnicity are widely discussed in public reports. Students with a migration background tend to perform less well than their native counterparts, which has drawn a lot of attention to the factors that differentiate children of immigrants and those of natives. This emphasis has obscured significant heterogeneity within the group of immigrants' children, and in particular their unequal access to Dutch citizenship. This dissertation shows that students' citizenship status should be considered as a potential factor of school success, helping some children of immigrants to overcome initial disadvantages in education. In doing so, it directs attention to the factors that are specific to the migration and settlement experiences of immi- 
grant families, as well to the legal and institutional context that shapes these experiences. Policy makers should give more weight to these factors when addressing ethnic inequalities in educational achievement, in order to design policies tailored to the diverse needs of immigrant families. Besides, the empirical findings suggest that facilitating access to Dutch citizenship could be an effective policy lever to attenuate educational disparities, at limited cost: while direct educational interventions require significant funding, facilitating access to Dutch citizenship for children has a mainly administrative cost. ${ }^{1}$

My research findings are relevant to different groups. First, from a research perspective, it speaks to researchers who have contributed in relative isolation to two major areas of study: the literature on the second generation, which has paid little attention to the legal obstacles that children of immigrants may face in host societies; and citizenship studies, which have neglected the role and place of children in the process of immigrant naturalisation. In this dissertation, I argued that a better integration of these two bodies of work allows for a more detailed understanding of the life experiences of children of immigrants. Second, from a policy perspective, this research is relevant to various actors involved in law and policy making. While parliamentary debates on strengthening naturalisation requirements should take into account the intergenerational effects of these restrictive reforms, educational policies should address the legal barriers that non-citizen children of immigrants can face while growing up.

Last but not least, this research is aimed at the main stakeholders: the nativeborn children of immigrants themselves. Although, to my knowledge, there is no strong public campaign calling for better access to Dutch citizenship for the children of immigrants in the Netherlands, such campaigns exist in other ius sanguinis citizenship regimes such as Italy and Switzerland. This dissertation provides a detailed study of the patterns and effects of Dutch citizenship acquisition, which can support the formulation of evidence-based claims for the introduction of conditional ius soli. Although the empirical findings are not directly transferable to other countries, they can nevertheless provide a relevant benchmark, which may be particularly valuable in light of the current lack of data and research on the citizenship status of children of immigrants in Europe.

These target groups were - or will be - informed about the research in different ways. During my PhD, I shared insights from my research by publishing

\footnotetext{
${ }^{1}$ See the costs and benefits of introducing conditional ius soli in Germany, compared to direct educational interventions, estimated by Felfe et al. (2020, pp.173-174).
} 
several peer-reviewed articles and presenting at ten international conferences and workshops. I have been careful to present at both education-focused and citizenship-focused conferences, in order to reach out and connect areas of research that rarely intersect. In a similar vein, in 2020, I co-organised the workshop "Citizenship of children of immigrants. Legal status and life opportunities in host country societies" with the aim of bringing together researchers from various backgrounds (political science, sociology, law and economics) to discuss ongoing research on how legal status affects the life opportunities of children of immigrants in Western countries. This workshop was designed to gather isolated and fragmented knowledge about children's citizenship status and stimulate research on the topic. ${ }^{2}$

I used Twitter to communicate my research to a wider audience and to connect with relevant institutions and associations committed to improving access to legal status and citizenship for immigrants and their children. ${ }^{3}$ To reach out policy makers and the general public, I participated in November 2020 to the workshop "Societal Impact of your Research", co-sponsored by Springer Nature, the Association of Dutch Universities (VSNU) and Maastricht University. During this workshop, I designed an impact plan to organise how I will reach and interact with relevant stakeholders in the future. ${ }^{4}$ On the institutional level, the impact plan includes the submission of a paper to Statistische Trends, the online medium of Statistics Netherlands, to draw attention to the citizenship of native-born children of immigrants. This publication, written in Dutch, will share my results in a more condensed and accessible way and highlight the need to rethink some of the statistical categories used by Statistics Netherlands to identify and analyse the Dutch second generation. At the societal level, the impact plan includes the publication of an Op-Ed in a Dutch newspaper that will summarise the main findings of the dissertation in a policy perspective. This will serve to raise awareness about the citizenship status of children of immigrants born in the Netherlands, and may initiate policy or societal debates on whether and how to address unequal access to citizenship for children of immigrants.

\footnotetext{
${ }^{2}$ Unfortunately, this workshop scheduled for June 2020 has been cancelled due to covid-19.

${ }^{3}$ My Twitter account is available at the following link: https://twitter.com/ LabussiereMarie.

${ }^{4}$ For a short presentation of the impact plan, see the slide deck prepared while working on the Societal Impact Workshop at https://zenodo.org/record/ 4271473 [accessed July 16, 2021].
} 


\section{Nederlandse samenvatting}

De 'tweede generatie', kinderen die zijn geboren in het land waarnaar hun ouders migreerden, vertegenwoordigen een aanzienlijk en groeiend aandeel van de Europese bevolking. De onderwijsresultaten van deze kinderen zijn in de afgelopen decennia uitgebreid bestudeerd, voortvloeiend uit de brede constatering dat kinderen van immigranten vaak minder goed presteren dan hun leeftijdsgenoten waarvan de ouders zijn geboren in het land waarin zij worden grootgebracht. Aangezien onderwijs van cruciaal belang is voor hun kansen op allerlei levensterreinen, staat het verklaren van het verschil in onderwijsresultaten tussen deze groepen hoog op de onderzoeksagenda. Onderzoekers hebben verschillende factoren tegen het licht gehouden om te verklaren waarom kinderen van migranten dikwijls problemen ervaren op school. Hierbij is aandacht voor de migratieachtergrond van hun ouders en daaraan gerelateerde hindernissen voor de onderwijsprestaties van hun kinderen. Migrantenouders ondervinden bijvoorbeeld structurele obstakels op de arbeidsmarkt, waardoor zij hun kinderen minder goed kunnen ondersteunen. Daarnaast is het mogelijk dat migrantenouders meer dan andere ouders moeite hebben bij het begeleiden van hun kinderen en hun onderwijstrajecten, omdat zij in het algemeen minder bekend zijn met het onderwijssysteem en de bredere institutionele en sociale context waarbinnen hun kinderen opgroeien.

Terwijl de invloed van sociaaleconomische en culturele kenmerken van immigrantengezinnen op onderwijsprestaties van de tweede generatie uitgebreid is bestudeerd, blijven alternatieve verklaringen onderbelicht. Er is weinig onderzoek naar de rol van nationaliteit (staatsburgerschap) in de onderwijsprestaties van migrantenkinderen. Dit is opmerkelijk, aangezien kinderen in de meeste Europese landen standaard de nationaliteit van hun ouders verkrijgen, en niet die van hun eigen geboorteland. Dit houdt in dat kinderen van de tweede generatie voor het verkrijgen van deze nationaliteit grotendeels afhankelijk zijn van de naturalisatie van hun ouders. Over de rol van nationaliteit in de kansen van migrantenkinderen in het algemeen en onderwijsprestaties in het bijzonder, is nog weinig bekend. In dit proefschrift staat het theoretiseren en het analyseren van effecten van nationaliteit op onderwijsresultaten van de tweede generatie centraal. De centrale onderzoeksvraag (geïntroduceerd in Hoofdstuk 1) luidt als volgt: In hoeverre heeft de nationaliteit invloed op onderwijsresultaten van in Nederland geboren kinderen van immi- 
granten? Ik beantwoord deze vraag aan de hand van empirisch onderzoek in Nederland; een land waarvan de nationaliteitswetgeving in grote lijnen representatief is voor de Europese context. In Nederland geboren worden geeft niet automatisch toegang tot de Nederlandse nationaliteit. Minderjarige kinderen van migrantenouders zijn voor toegang tot het Nederlanderschap afhankelijk van de naturalisatie van hun ouders. Meerderjarige kinderen kunnen zelfstandig naturaliseren. Nederland vormt hiermee een geschikte casus om te analyseren in hoeverre kinderen van immigranten van elkaar verschillen in hun toegang tot het Nederlanderschap. Dit genereert inzicht in de vraag in hoeverre en op welke wijze toegang tot de Nederlandse nationaliteit samenhangt met specifieke trajecten binnen het onderwijssysteem.

Onderzoek naar de relatie tussen nationaliteit en onderwijs in andere landen dan Nederland toont aan dat het verkrijgen van de nationaliteit van het vestigingsland een positief effect heeft op onderwijsresultaten van kinderen van immigranten. Deze studies vragen echter om meer diepgang, zowel vanuit conceptueel als vanuit methodologisch oogpunt. Ten eerste zijn de onderliggende mechanismen van het effect van nationaliteit op onderwijsprestaties niet duidelijk geïdentificeerd in bestaande literatuur en zijn deze niet ingebed in een overkoepelend theoretisch kader. Dit maakt het lastig te doorgronden waarom en hoe naturalisatie ertoe doet. Ten tweede stel ik vast dat het identificeren van de effecten van nationaliteit belangrijke methodologische uitdagingen met zich meebrengt, aangezien de positieve samenhang tussen nationaliteit en onderwijs mogelijk (deels) een schijnverband is. Naturalisatie is immers een kostbaar proces dat niet alle migrantengezinnen kunnen of willen doorlopen. Ouders die naturaliseren zijn mogelijk in een betere positie om de onderwijsloopbaan van hun kinderen te ondersteunen, reeds voordat naturalisatie aan de orde komt. Een dergelijk mechanisme illustreert de noodzaak om te controleren voor selectie in naturalisatie.

Dit proefschrift adresseert de bestaande theoretische en empirische tekortkomingen op twee manieren. Hoofdstuk 2 behelst een uitgebreide bespreking van de bestaande literatuur en besteedt aandacht aan de verschillende theoretische kanalen die nationaliteit en onderwijsresultaten met elkaar verbinden. Vanuit een levensloopperspectief veranker ik deze kanalen in een overkoepelend theoretisch kader waarin de rol van gezins-, temporele en institutionele dynamieken worden geïntegreerd. Dit verrijkte theoretische model vormt het fundament voor de empirische hoofdstukken 3 tot en met 5, welke de patronen en effecten van naturalisatie analyseren aan de hand van bevolkingsregisters op micro-niveau van het CBS. Ik volg verschillende cohorten van migrantenkinderen die tussen 1995 en 2010 in Nederland zijn ge- 
boren, en traceer hun nationaliteitstransities en schoolresultaten tot 2016. Het volgen van een gehele groep van de tweede generatie kinderen in Nederland en het brede observatievenster bieden unieke methodologische mogelijkheden om de effecten van nationaliteit op de onderwijsresultaten te identificeren en te doorgronden.

De volgende hoofdstukken voorzien in een samenvatting van de theoretische bijdrage van dit proefschrift en de belangrijkste bevindingen uit de empirische hoofdstukken.

\section{Theoretische bijdragen}

In bestaand onderzoek komen zowel de nationaliteit als de onderwijsresultaten van kinderen van immigranten uitgebreid aan bod. Deze twee zaken worden echter hoofzakelijk afzonderlijk van elkaar geanalyseerd. Zo wordt in onderzoek naar staatsburgerschap van kinderen van immigranten zelden gekeken naar de mogelijke effecten hiervan op onderwijsprestaties, en laat literatuur over verschillen in onderwijsresultaten de nationaliteit van leerlingen meestal ongemoeid. De enkele studies die nationaliteit en onderwijs wel in relatie tot elkaar analyseren, bouwen niet expliciet op elkaar voort, waardoor deze resultaten moeilijk in een breder overzicht te plaatsen zijn.

Hoofdstuk 2 heeft als doel de relevante onderzoeken samen te brengen en de complementaire inzichten die hieruit voorvloeien uit te lichten. Dit doe ik aan de hand van de sociologische levensloop benadering om de effecten van nationaliteit op onderwijsprestaties verder inzichtelijk te maken, waarbij ik mij richt op de dynamiek en onderlinge afhankelijkheid van levenslopen. Ten eerste ben ik van mening dat onderzoek naar staatsburgerschap en onderwijs rekening dient te houden met intergenerationele samenhang: kinderen zijn wettelijk afhankelijk van hun ouders om de nationaliteit van het vestigingsland te verkrijgen en kunnen dus zowel direct als indirect profiteren van de naturalisatie van hun ouders. Dit vraagt om het inzichtelijk maken van naturalisatie op familieniveau, wat afwijkt van eerdere perspectieven waarbij de nadruk ligt op volwassenen.

Ten tweede laat ik zien dat de gevolgen van nationaliteit moeten worden geplaatst binnen de specifieke structuur van kansen en beperkingen waarmee scholieren van de tweede generatie worden geconfronteerd. Terwijl nationaliteitswetgeving een directe invloed heeft op de mogelijkheden voor vestiging en verblijf van migrantengezinnen, wordt de schoolervaring van kinderen in het vestigingsland bepaald door de kenmerken van het onderwijssysteem. 
Het is van groot belang om patronen en effecten van naturalisatie te bezien in het licht van deze macro factoren, aangezien de waarde van de nationaliteit van het vestigingsland kan variëren naar gelang de institutionele context waarmee immigrantengezinnen te maken hebben. Ik analyseer het verkrijgen van nationaliteit als een bron die de mate van zelfbeschikking van kinderen en hun ouders vergroot, en zo ook hun bekwaamheid zich een weg te banen in een complex institutioneel landschap als het onderwijssysteem. Dit perspectief bouwt voort op bestaande benaderingen, waarin de focus hoofdzakelijk ligt op toegenomen verwachtingen die ouders hebben wat betreft onderwijs, zonder dat hiermee inzicht wordt gegeven in de wijze waarop deze verwachtingen zich vertalen naar daadwerkelijke investeringen in het onderwijs van hun kinderen.

Tot slot stel ik dat naturalisatie moet worden geanalyseerd in de context van levenslopen. Naturalisatie is een proces dat geruime tijd voor de daadwerkelijke transitie in nationaliteit begint - namelijk wanneer aspirant-staatsburgers zich gaan verdiepen in de vereisten en zich voorbereiden op een aanvraag. Het proces duurt bovendien voort na het verkrijgen van de nationaliteit, getuige de voordelen van de nieuwe nationaliteit die immigranten op lange termijn ervaren. Desondanks wordt naturalisatie veelal gemodelleerd als een geïsoleerde, eenmalige transitie in het leven van een individu, waarmee belangrijke temporele dynamieken onbelicht blijven. In mijn onderzoek daarentegen, plaats ik patronen en effecten van naturalisatie binnen de bredere levensloop van kinderen, met een focus op wanneer nationaliteit wordt verkregen en de vraag of timing van naturalisatie van belang is voor onderwijsuitkomsten. Daarnaast laat ik zien dat de effecten van nationaliteit afhankelijk zijn van de hulpbronnen van kinderen en hun ouders: naturalisatie voltrekt zich niet in een vacuüm, maar hangt samen met andere individuele- en gezinskenmerken.

\section{Empirische bevindingen}

De levensloopbenadering vormt een sterk theoretisch uitgangspunt voor een empirische analyse van de nationaliteit van kinderen van migranten. De drie empirische hoofdstukken, gebaseerd op gepubliceerde of ingediende artikelen, richten zich op drie onderling samenhangende deelvragen omtrent naturalisatiepatronen van tweede generatie migranten in Nederland, en de effecten van deze patronen en trajecten op uitkomsten in het Nederlandse onderwijssysteem. 
Hoofdstuk 3 onderzoekt wie naturaliseert onder tweede generatie migranten in Nederland, en wanneer en onder welke condities dat het geval is. Een beschrijvende analyse laat zien dat het overgrote merendeel van de kinderen van migranten het Nederlanderschap verkrijgen via hun ouders, wat onderstreept dat intergenerationele afhankelijkheid binnen de familie in acht genomen dient te worden. Op basis van event history modellen analyseer ik vervolgens of toegang tot het Nederlanderschap onder kinderen van migranten beïnvloed is door de invoering van restrictieve eisen voor naturalisatie in de jaren negentig. Resultaten tonen aan dat kinderen van ouders die pas in aanmerking kwamen voor naturalisatie na de invoering van een strenger naturalisatiebeleid een lagere kans hadden om Nederlander te worden dan hun tegenhangers wiens ouders onder meer liberale condities konden naturaliseren. Belangrijk is bovendien dat kinderen die Nederlander werden onder het restrictieve beleid een veel hogere kans hadden om te naturaliseren met één ouder in plaats van met beide ouders, wat suggereert dat gezinnen strategisch omgaan met de kosten voor naturalisatie. Dynamic modelling van de kans op naturalisatie laat verder zien dat het negatieve effect van de beleidswijziging afhangt van de specifieke eisen: hoewel migrantenouders die afstand moeten doen van hun oorspronkelijke nationaliteit (vanaf 1997) afzien van naturalisatie op de lange termijn, zorgen inburgeringseisen (vanaf 2003) vooral voor uitstel. Meer algemeen laten de resultaten zien dat migrantengezinnen verschillende naturalisatietrajecten volgen afhankelijk van hun maatschappelijke omgeving, wat resulteert in verschillende naturalisatiepatronen onder kinderen van migranten. Dit benadrukt het belang van het gezin en contextuele factoren, en onderstreept de intergenerationele impact van wijzigingen in nationaliteitswetgeving: eisen voor naturalisatie voor migranten hebben een indirect effect op de toegang tot het Nederlanderschap van hun kinderen.

Hoofdstuk 4 en 5 toetsen vervolgens of uitstel - of afstel - van het verkrijgen van het Nederlanderschap een negatief effect heeft op de onderwijsprestaties van kinderen van migranten. Hoofdstuk 4 is verkennend en onderzoekt hoe kinderen van migranten het Nederlandse onderwijssysteem navigeren, en of de nationaliteit van het vestigingsland samenhangt met verschillende onderwijstrajecten. De focus op volledige onderwijstrajecten in plaats van geïsoleerde uitkomsten of overgangen van het ene opleidingstype naar een ander geeft waardevolle inzichten in hoe tweede generatie scholieren hun weg vinden in het complexe Nederlandse schoolsysteem. In Nederland wordt scholieren een specifiek onderwijstraject toegewezen vanaf twaalf jaar, wat hen voorbereidt op een specifieke kwalificatie. Hoewel het mogelijk is van traject te wisse- 
len vereist dit informatie en kennis die niet aanwezig is onder alle gezinnen. Op basis van de hypothese dat de nationaliteit van het vestigingsland het migrantengezinnen makkelijker maakt om keuzes te maken, analyseer ik of scholieren die het Nederlanderschap verkregen mobieler zijn binnen het onderwijslandschap dan hun tegenhangers zonder de Nederlandse nationaliteit. Met dat doel maak analyseer ik de opeenvolgende overgangen tussen schooltypes die scholieren maken in het voortgezet onderwijs. Beschrijvende resultaten laten zien dat een meerderheid van de tweede generatie scholieren een standaardroute volgt in het voortgezet onderwijs, maar dat meer dan een kwart niet in het traject blijft waarin zij oorspronkelijk waren begonnen. Ik laat een veelvoud aan trajecten zien, waarbij scholieren omhoog en omlaag bewegen tussen de verschillende onderwijstypen maar ook het Nederlandse onderwijssysteem verlaten en weer terugkomen. In de regressies analyseer ik of naturalisatie samenhangt met specifieke mobiliteitspatronen. Resultaten tonen aan dat studenten die Nederlander werden voor hun twaalfde een hogere kans hebben om in een opwaarts mobiliteitstraject te zitten, en minder kans hebben om zonder diploma van school te gaan. Dit suggereert dat naturalisatie scholieren en hun gezin helpt om te profiteren van de achterdeuren en vangnetten van het flexibele onderwijssysteem. Hoewel het exploratieve karakter van hoofdstuk 4 geen causale relaties impliceert, geeft het een eerste indicatie dat naturalisatie lange-termijn effecten heeft op de onderwijstrajecten van tweede generatie migranten.

Hoofdstuk 5 gaat specifieker in op het effect van naturalisatie door te onderzoeken in welke mate het effect van de nationaliteit van het vestigingsland gedreven wordt door selectie van ouders in naturalisatie, en of het effect afhangt van timing of persoonskenmerken. Ik ontwikkel een empirische strategie op basis van gezin fixed-effects om te achterhalen of (een deel van) de geconstateerde positieve relatie tussen naturalisatie en de schoolprestaties van kinderen een schijnverband is. Dit zou het geval zijn wanneer ongemeten kenmerken van ouders samenhangen met zowel de kans op naturalisatie als de schoolprestaties van hun kinderen. Om voor dergelijke ongemeten kenmerken op gezinsniveau te controleren vergelijk ik Cito scores van zussen en broers die het Nederlanderschap op verschillende leeftijden verkregen. Deze strategie is niet alleen meer robuust tegen vertekeningen door selectie, maar maakt bovendien mogelijk om te meten of de timing van naturalisatie ertoe doet. Dit bouwt voort op bestaand onderzoek dat zich louter richt op de vaag of kinderen genaturaliseerd zijn of niet op het moment van observatie. Een belangrijke bevinding in hoofdstuk 5 is dat de relatie tussen naturalisatie en onderwijs niet volledig gedreven wordt door selectie: scholieren die Nederlander werden 
vroeg in hun kindertijd hebben significant hogere Citoscores dan hun nietgenaturaliseerde tegenhangers, zelfs wanneer voor ongemeten gezinskenmerken gecontroleerd wordt via de vergelijking met zussen of broers. Dit komt overeen met de bevindingen van verschillende studies die een oorzaakgevolg relatie vaststellen tussen naturalisatie en onderwijsuitkomsten in andere landen. Bovendien vind ik bewijs dat de timing van naturalisatie ertoe doet. Hoe later scholieren Nederlander worden, des te zwakker is het positieve effect daarvan op hun Citoscore. Meer specifiek laten de resultaten zien dat kinderen vooral profijt hebben van het Nederlanderschap wanneer dit verkregen wordt voordat zij aan het basisonderwijs beginnen. Onderzoekers zouden daarom niet alleen oog moeten hebben voor de vraag of de nationaliteit van het vestigingsland door migrantengezinnen verkregen wordt maar ook wanneer. Hoofdstuk 5 geeft meer bewijs dat het effect van naturalisatie niet gelijk is voor alle scholieren: het doet er vooral toe voor kinderen wiens ouders een achterstand hebben op de arbeidsmarkt en woningmarkt. Dit suggereert dat naturalisatie vooral als een compenserend instrument functioneert dat de onderwijsprestaties bevordert van kinderen waarvan de ouders beperkte middelen hebben. Hoewel vergelijkbare compenserende mechanismen in de literatuur over naturalisatie van eerste generatie migranten zijn vastgesteld is er sprake van veel minder aandacht voor de tweede generatie. Hoofdstuk 5 roept daarom op tot meer onderzoek naar factoren die de relevantie van naturalisatie voor kinderen van migranten conditioneren.

\section{Conclusie}

Hoewel er zowel in onderzoek als in officiële stastieken ruim aandacht wordt besteed aan de tweede generatie, is nog steeds weinig bekend over de juridische drempels waarmee kinderen van immigranten te maken krijgen in landen waarin zij opgroeien, maar waarvan zij niet automatisch staatsburger zijn. Dit proefschrift laat zien dat het niet hebben van de nationaliteit van het land waar kinderen opgroeien een negatieve uitwerking heeft op onderwijskansen van de tweede generatie. Zo blijken kinderen met de Nederlandse nationaliteit aan het eind van de basisschool betere Cito-scores te behalen en beter in staat te zijn zich een weg te banen door het complexe systeem van voortgezet onderwijs dan kinderen zonder de Nederlandse nationaliteit. Met andere woorden: het verkrijgen van het Nederlanderschap heeft niet alleen invloed op de prestaties van scholieren, maar houdt ook verband met hun mobiliteit en het type onderwijs waartoe zij toegang hebben. Tegen deze achtergrond zullen recente restricties in de toegang tot het Nederlanderschap 
van immigrantenouders het verschil in onderwijsresultaten tussen kinderen met en zonder de Nederlandse nationaliteit verder doen toenemen en zo ook de verschillen tussen kinderen met en zonder migratieachtergrond. Een belangrijke kanttekening hierbij is dat de effecten van nationaliteit op onderwijsprestaties niet uniform zijn: ze moeten worden bezien in de context van de levensloop en sociale relaties van individuen. Staatsburgerschap doet er met name toe wanneer dit verkregen is tijdens de vroege jeugd en wanneer het families betreft die structurele hindernissen ervaren in het vestigingsland. Dit suggereert dat het faciliteren van vroege toegang tot het verkrijgen van staatsburgerschap voor kinderen van immigranten als hefboom kan fungeren, in het bijzonder voor de minst bevoordeelde gezinnen. Gezien aanhoudende hindernissen die kinderen van immigranten over het algemeen ervaren binnen en buiten het schoolsysteem, is voortzetting van onderzoek naar potentiële verzachtende factoren zoals toegang tot staatsburgerschap van cruciaal belang. 


\section{Acknowledgments}

Back when I was a Bachelor student, I had the rare opportunity to attend a lecture by the American sociologist Howard S. Becker in Bordeaux. While I cannot remember precisely the theme of the lecture, one of his remarks has stayed with me until today. As he was discussing art work, Howard Becker drew our attention to the gap between how we typically describe movies ("the last movie by director $X^{\prime \prime}$ ) and the never-ending list in the end credits of the individuals who contributed to the creation of the film. The focus on the haloed figure of the artist tends to obscure the collective dimension of art work and the many individuals who contribute to the process of creation. I would draw a parallel with research: behind each researcher, there is usually a whole crew of people involved to varying degrees in conducting the research. Acknowledgements in PhD dissertations are actually one of the few opportunities to bring them out of the shadows.

First of all, I am thankful to my supervisors. Maarten and Mark, I do not see how these four years spent under your guidance could have gone better. You have accompanied me throughout this journey and provided a subtle balance between support and autonomy, guiding my steps while encouraging me to develop my own ideas. You also formed a very complementary pair, trained in both discrete monitoring in calm weather and emergency response when the waves suddenly became too intimidating. I learned a lot from you - and probably much more that I am aware of. Maarten, I am always impressed by the generosity and relevance of your feedback, and you have passed on to me your passion for citizenship issues. Mark, the way you dissect the arguments and empirical strategies of academic papers - and identify their weaknesses - never ceased to fascinate me. I also want to take this opportunity to express my gratitude to the members of the assessment committee, whose research has inspired this thesis in many ways.

My PhD dissertation would not have been the same without the MiLifeStatus research team. Christophe, starting the $\mathrm{PhD}$ at the same time as you meant that I never felt alone. You were my compagnon de galère and I could always count on you to discuss ideas, brainstorm on methods and complain about data issues. Floris and Swantje, you have given me so much support since the beginning of the project that I do not know where to start. You prepared the initial data-set for my PhD research and were always available to help 
and to think things through with. Floris, I cannot remember how many times I knocked at your office door and yet you never gave me the impression that I was bothering you (even if I was). Thank you for acting as an intermediary with Statistics Netherlands and managing my multiple data requests with unfailing serenity. Swantje, you have this special power that makes things more clear and rational as soon as one discusses them with you. Fortunately, you are not stingy with it: you were never short of advice, support and sharp feedback, whether it was about my $\mathrm{PhD}$ project or my existential questions. My work has benefited greatly from the dedication of both of you; I do not have better examples to follow now that I am a postdoc myself. The MiLifeStatus seminars were also an important part of my $\mathrm{PhD}$ journey. They were enlivened by Prof. dr. Gerard-René de Groot - a well of legal knowledge and Prof. dr. Hans Schmeets, who also greatly facilitated my access to the data at CBS.

Beyond the MiLifeStatus team, I received tremendous support from the $\mathrm{PhD}$ community around me. Most importantly, the office 0.13 was a haven of peace in stormy weather. I want to thank all my successive office mates for contributing to the warm and welcoming atmosphere of this room - which cannot be explained by the sofa and banana trees alone. Anna-Lena, Marloes, Karlien, Maria, Laura, Manling, Cecilia (by order of arrival), I was always happy to walk through the office door because of your good mood, kindness and caring. Marloes, you gave me unwavering support from my very first day. We shared our successes as well as our struggles along the way, and there was no thought or question that I could not raise with you. Our countless exchanges, chats and philosophical discussions have been very enriching in all respects, for you are such a curious, open-minded and warm-hearted person. You have been the best mentor I could wish for, but also so much more than that! Karlien, Manling and Cecilia, you brightened my working days but also my evenings and week-ends. Thanks for the many walks, cycling tours, gezellig lunches and dinners, and climbing sessions that we shared together. I can only hope that we will continue to see each other despite the distance!

My thanks do not stop at office 0.13. Imogen, your arrival at the faculty marked the beginning of a new era in which I could share my passion for cooking and chatting (possibly about cooking) while walking. I really enjoyed our conversations and outings, and you were always there to provide me not only with freshly made zongzi but also with attentive listening and wise advice. Together with Zahar, you were my loyal lunch partner and I miss our daily conversations about anything and everything in the coffee room. I 
enjoy research much more after sharing a good meal, which was made possible by the periodic "PhD soups" and the gargantuan dinners of the confidential FASoS cooking club. Karlijn, you were always up for such initiatives, and I want to thank you for your availability and generosity. You always made room for me in your schedule and in your house, and you taught me a lot about research and academia.

More broadly, my research has benefited from a stimulating and supportive research environment at the Faculty of Arts and Social Sciences (FASoS). I really enjoyed participating in and chairing the Transnational Migration Group (TMG), which brings together researchers from various disciplines and perspectives. Bilisuma, Ester, Gladys, Joan, Konjit, Laura, Maha, Nikolas, Onallia, Pomme, Sarah, Valentina, thanks for the insightful exchanges and open discussions. The TMG is part of the Globalisation, Transnationalism and Development group, which I also need to commend for its seminars and famous research retreat. The PhDs of the Faculty formed a very nice community that I enjoyed meeting at the Wednesday workshops of the Graduate School. Alexandra Supper and Joeri Bruyninckx deserve special recognition for having organised these meetings so well. The Department of Political Science was full of inspiring and generous people, and I am very grateful for the support I received there as a novice researcher and teacher. Finally, I want to thank all the support and administrative staff, including Cecile Luijten, Sabine Kuipers, Vincent Cordewener and Yleen Simonis, for being so available and for making FASoS a very nice place to work in.

A few hundred meters from FASoS, I found precious support at the Research Centre for Education and the Labour Market (ROA). In particular, Alexander Dicks provided feedback on several of my drafts, which undeniably benefited from his sharp eye and critical comments. Lynn van Vugt, Per Bles and Timo Huijgen helped me to find my way through the maze of the educational registers without counting their time.

Completing a PhD during a pandemic is not an ideal scenario. I want to thank those who helped me to finalise my manuscript in the best conditions possible. Karlijn, Floris and Swantje, I could always count on you in times of doubt and exhaustion. My paranymphs, Imogen and Marloes, read many parts of the dissertation in the final stretch and have put together a top team to help me organise the defense in short time. Last but not least, Marloes and Floris translated the Dutch summary and deserve my infinite gratitude for making my convoluted French-inspired writing intelligible in another language. I finalised this book while starting as a postdoctoral researcher at the University 


\section{Acknowledgements}

of Amsterdam; I am grateful to Thijs Bol, Luisa Burchartz and Viktor Decker for making it a very smooth and enjoyable transition.

I come to the end of the credits, where the people mentioned are not film professionals but the family and friends who supported the director through their ups and downs. I leave Maastricht full of good memories, thanks to the great people I met and who made me feel at home. The various dinners and outings with Imogen and Li-Ming, as well as the long days cycling through Limburg with Esam, have a special place in those memories. So do the Wednesday rowing or erging sessions with the Rudermädels 8 and their irreplaceable coach Titus. Learning how to skiff towards the end of my $\mathrm{PhD}$ helped me greatly to stop thinking about my research. Vester, heel erg bedankt voor de vele en gezellige roeisessies op de Maas en de heerlijke stroopwafels \& koffie. Ik heb veel vooruitgang geboekt met jou, hoewel mijn inpik nog niet perfect is.

Il y a aussi ceux qui m'ont constamment soutenue ces dernières années depuis la France et ailleurs. Ceux qui m'ont souvent entourée de leur présence malgré la distance, ceux qui savent être présents sans être là, ceux que je vois peu mais qui n'en écrivent pas moins. Les compagnons de toujours, Manon et Hugo, mes premiers lecteurs qui seront sans doute heureux de tenir entre leurs mains un livre dont j'ai écrit la fin. Merci pour votre amitié toutes ces années; chacune de nos retrouvailles me revigore et me remplit de joie ! Je remercie aussi les nombreux camarades de classe et d'école qui m'ont nourrie de leur sagacité et curiosité. Je pense notamment à Guillaume et Quentin, qui ont partagé ma passion des sciences sociales à une époque où les équations avaient pris le dessus. Il y a aussi les amis que j'ai failli ne jamais connaître, tels Constance et Léni qui m’ont accueillie comme une reine lors de mes nombreuses escales à Paris. À tous les amis du 28 août 2020, en somme: mille fois merci.

Ma famille a toujours été là pour moi, d'une manière qu'il est vain de chercher à décrire. Je suis infiniment reconnaissante à mes parents de m'avoir encouragée et donné les moyens de suivre mon propre chemin, alors même que certaines directions devaient paraître hasardeuses. Maman, merci de renouveller chaque jour la promesse de l'aube. Ta confiance et ton irrésistible optimisme sont les meilleures remèdes à la mélancolie que je connaisse! Papa, j'ai beaucoup appris de ton esprit critique et il n'est pas étranger à mon goût pour la recherche. Merci de me pousser sans relâche à aiguiser mon sens de l'observation, qui a le malheur d'être très selectif... 
Toutes ces années, j'ai été portée par l'amour inconditionnel de mes grandsparents et choyée par ma famille de sang et de cœur. Merci pour votre affec-

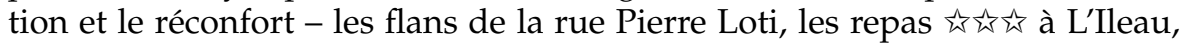
les brownies striés de sucre glacé, les croquants aux amandes et autres cornes de gazelle...

Infine devo dire un grande grazie ai miei suoceri e cognati basco-italiani, che ritrovo sempre con gioia e che mi hanno sostenuto molto nelle ultime settimane di lavoro per la tesi.

Je finis ces remerciements par là où tout a commencé. Par celui qui m'a poussée à candidater à cette thèse alors que je n'avais jamais envisagé de partir à l'étranger. Celui qui a quitté son travail pour m'accompagner et accepté que la thèse occupe une partie de mes pensées et de nos soirées. Celui qui m'a aidée à débugger mon code à des heures improbables, fait répéter des présentations qu'il connaissait par cœur, et préparé à manger les jours où je me serais uniquement nourrie de pistaches. Cette liste non exhaustive ne rend pas justice au soutien de celui qui croit en moi pour deux depuis le début de cette aventure, et s'est fait «le pyromane de mon cœur, canadair de mes frayeurs $\gg \downarrow$. Je sais que tu n'aimes pas être au centre de l'attention Matteo, mais les héros discrets du quotidien méritent eux-aussi de sortir de l'ombre.

Marie Labussière

Amsterdam

October 11, 2021 



\section{About the author}

Marie Labussière was born in Rochefort, France, on November 5th, 1992. She obtained a Bachelor's degree in 2013 after three years in the Classe préparatoire aux grandes écoles BL "Arts and Social Sciences" in Toulouse and Bordeaux (France). She was then admitted to the École Nationale de la Statistique et de l'Administration Économique (ENSAE) in Paris, where she completed an engineering program specialised in statistics, economics and data science from 2013 to 2016.

During her studies at the ENSAE, Marie worked as a research assistant in several research institutes: the Center of Socio-Political Data (CDSP) of SciencePo Paris in 2014, the Laboratory of Quantitative Sociology (LSQ) in 2015, and the Center Maurice Halbwachs (CMH) in 2016. Her research focused on social stratification, gender and labour market inequalities.

In 2017, Marie graduated Cum Laude from the Research Master program Interdisciplinarity in Social Sciences at the École Normale Supérieure (ENS) and École des Hautes Études en Sciences Sociales (EHESS) in Paris. During this program, she conducted ethnographic fieldwork on contemporary women's movements, exploring the links between feminism, conservatism and religion.

From 2017 to 2021, Marie completed her PhD at the Faculty of Arts and Social Sciences of Maastricht University under the supervision of Prof. Dr. Maarten Vink and Prof. Dr. Mark Levels. Her PhD study, which analyses the relation between citizenship and education among the children of immigrants in the Netherlands, was part of the ERC-project "Migrant Life Course and Legal Status Transitions" led by Prof. Dr. Maarten Vink. For this research, she was associated with the Maastricht Centre for Citizenship, Migration and Development (MACIMIDE) and the International Migration, Integration and Social Cohesion in Europe (IMISCOE) network.

As of September 2021, Marie Labussière works as a postdoctoral researcher at the Sociology department of the University of Amsterdam. 
